\title{
3 Rentenversicherungspolitische Weichenstellungen und die Verflechtung mit NS-Unrecht: Inklusions- und Exklusionsprozesse durch das Verwaltungshandeln
}

\subsection{Behördlicher Ausbau zwischen organisatorischer Effizienz und weiterer Selbstgleichschaltung}

Am 25./26. November 1935 kam der neu berufene Beirat der RfA zu seiner ersten Sitzung zusammen. ${ }^{1}$ Unter Leitung von Präsident Grießmeyer und im Beisein von Vertretern des RAM sowie des RVA standen nach einem allgemeinen Lagebericht vor allem zwei Themen auf der Tagesordnung: die Aktivitäten im Wohnungsbau und die Vermögenspolitik der RfA. ${ }^{2}$ Seit 1933 waren die Rücklagen von 2,1 Mrd. RM um 27,6 Prozent auf 2,68 Mrd. RM gestiegen, 1936 sollte die Drei-Mrd.-RM-Grenze übersprungen, 1939 mit 3,9 Mrd. fast die nächste Milliardenhürde erreicht werden. Um allerdings etwaigen Begehrlichkeiten einen Riegel vorzuschieben, betonte die RfALeitung gegenüber dem Beirat das alte Dogma der Anwartschaftsdeckung. Den rund 2,5 Mrd. RM Vermögen stünden daher nicht nur ca. 2,5 Mrd. laufende Rentenansprüche gegenüber, sondern weitere fünf Mrd. RM künftige Rentenansprüche. ${ }^{3}$ Tatsächlich aber nahm das Reich längst in erheblichem und wachsendem Umfang die Mittel der RfA für eigene Zwecke in Anspruch. Geradezu verzweifelt versuchte dabei die RfA die eigentlich gesetzlich vorgeschriebenen Grundsätze der Vermögensanlage zu verteidigen - lange Zeit durchaus erfolgreich. Demnach musste das Vermögen mündelsicher, d.h. mit möglichst hoher Sicherheit angelegt werden. Darunter fielen im Wesentlichen Aktien staatlicher Unternehmen, ferner Darlehen an die öffentliche Hand und erstrangige Hypotheken; auch Grundbesitz war zulässig. Die RfA hatte daher vor allem immer auf eine größtmögliche Mischung der vier verschiedenen Anlagearten Wert gelegt und dabei auch eine weitgehende Streuung nach wirtschaftlichen und territorialen Gesichtspunkten angestrebt, verbunden mit einem Fristenmanagement, d.h. unterschiedlichen Laufzeiten mit Tilgungsmöglichkeiten und damit der Chance zur flexiblen weiteren Optimierung des Anlagenportfolios. ${ }^{4}$ Die drei großen Vermögensgruppen Wertpapiere, Darlehen und Hypotheken machten mit je etwas über 30 Prozent gleichgroße Anteile aus, während der Grundbesitzanteil am

\footnotetext{
1 Vgl. Niederschrift über die erste Sitzung des Beirats der RfA am 25./26.11.1935, in: BArch R 89/3468. 2 Interessanterweise wurden dem Beirat auch die drei Vertreter der RfA-Belegschaft, Fachschaftsgruppenleiter Kliem, Hauptvertrauensmann Maletzek und Betriebszellenobmann Schirrmacher, vorgestellt.

3 Vgl. ebd., S. 3.

4 Vgl. Vortrag Regierungsrat Haenel als Leiter der Abt. III (Vermögensverwaltung) auf der Beiratssitzung, S. 6, in: ebd. Vgl. auch 25 Jahre Angestelltenversicherung, S. $148 \mathrm{ff}$.
} 
Gesamtvermögen nur zwischen 0,6 und 0,9 Prozent umfasste. Den größten Posten unter den Wertpapiern machten 1935 dabei mit knapp 300 Mio. RM Zertifikate zu siebenprozentigen Reichsbahn-Vorzugsaktien aus, gefolgt von Anleihen des Reichs und der Länder mit 247 Mio. RM. ${ }^{5}$ Der gesamte Hypothekenbestand gliederte sich auf annähernd 24.000 Hypotheken an städtischen Grundstücken, dazu kamen weitere 1000 landwirtschaftliche und rund 350 industrielle und gewerbliche Hypotheken. ${ }^{6}$ Mit Abstand größter Schuldner war hier seit jeher die Gagfah (Gemeinnützige Aktiengesellschaft für Angestellten-Heimstätten), die 1935 eine hypothekarische Verschuldung bei der RfA von knapp 180 Mio. RM aufwies, gefolgt vom Kommunalen Umschuldungsverband mit etwa 160 Mio. RM. Während die meisten Schulden mithin das Reich bzw. die öffentliche Hand betrafen, trugen praktisch die etwa 36.000 Mieter und Eigenheimbesitzer, die durch ihre Leistungen die Verzinsung und Tilgung der GagfahHypotheken sicherten, die Verschuldung der Gagfah.

Ziel all dessen war es, einen möglichst hohen Zinsertrag zu erwirtschaften, der 1935 etwa 138 Mio. RM ausmachte und bis 1938 auf über 180 Mio. RM stieg; das waren fast 30 Prozent der Beitragseinnahmen bzw. knapp 20 Prozent der Gesamteinnahmen der RfA. ${ }^{7}$ Doch es gab weitere außerordentliche Vermögenszuwächse. Einen deutlichen Schub bei den Rücklagen hatte es etwa 1935 durch das Hinzukommen des Vermögens der Saarversicherungsanstalt für Angestellte mit rund 15 Mio. RM sowie des Vermögens der Ersatzkassen mit etwa 110 Mio. RM gegeben. Allerdings barg die Übernahme der Ersatzkassen auch Risiken. Im November 1937 wandte sich der Reichsstatthalter von Hamburg an die RfA mit der dringenden Bitte, die in Not geratene Hamburgische Versorgungskasse für staatliche Angestellte zu übernehmen. Es ging um einen Versichertenbestand von 8358 Personen und einem Rentnerbestand von knapp 1500 Ruhegeldempfängern sowie Witwen und Waisen. Angeblich stand den laufenden Versorgungsleistungen von monatlich 80.353 RM ein Vermögen von 4,4 Mio. RM gegenüber. Die Versicherungsmathematiker der RfA hatten jedoch schnell einen tatsächlichen Fehlbetrag von 6 Mio. RM festgestellt und rieten dringend von einer Übernahme der Kasse ab. ${ }^{8}$ Seit jeher war aber auch ein weiterer Grundsatz der Anlagepolitik der RfA gewesen, den sozialen Wohnungsbau zu fördern, sprich Darlehen und Hypotheken für den Wohnungsbau, darunter auch Hypotheken zur Förderung des Eigenheimbaus, an Versicherte zu vergeben. Dafür verlangte die RfA Ende 1935 zwischen 4,5 und fünf Prozent Zinsen. Ein Spezifikum war auch, dass die RfA langfristig plante und auf dem Geldmarkt daher als Kreditnehmer nicht auftrat. Der

5 Vgl. Geschäftsbericht für 1935, S. 28, in: BArch R 89/3468. Zur Vermögensverwaltung und Anlagenpolitik vgl. auch Bericht des Direktoriums der RfA über das Geschäftsjahr 1933, S. 14 ff., in: BArch R $112 / 102$.

6 Vgl. Vortrag Haenel auf der Beiratssitzung, S. 10, in: BArch R 89/3468.

7 Vgl. Geschäftsbericht für das Jahr 1935, S. 26 und Geschäftsbericht für das Jahr 1938, S. 34, in: BArch R 89/3468.

8 Vgl. Schreiben des Reichsstatthalters vom 19.11.1937 sowie RfA-Vermerk vom 19.1.1938, in: RfA-Archiv Fach 111, Nr. 4. 
dauernde Zustrom größerer Einnahmen an Beiträgen und Zinsen und der stetige Rückfluss von Tilgungsbeiträgen machte eine weitere Liquidität des Vermögens entbehrlich. Allerdings erforderte die sofortige Daueranlegung große Erfahrung und ein sicheres Gefühl für den vermutlichen Ablauf der Auszahlung. All dies wurde durch einen Lombard-Kredit ermöglicht, der der RfA bei der Reichsbank zur Verfügung stand.

Bei der Verteilung der Vermögensstrukturen zeichnen sich auf den ersten Blick zumindest bis 1938 keine deutlichen Verschiebungen ab. Weiterhin machten Wertpapiere, Darlehen und Hypotheken zwischen 31 und 34 Prozent des Gesamtvermögens aus, der Anteil des Grundbesitzes war inzwischen auf 0,9 Prozent leicht gestiegen. ${ }^{9}$ Doch bei genauerem Hinsehen zeigen sich markante Verschiebungen, die signalisieren, dass sich der Handlungsspielraum der RfA in ihrer Vermögenspolitik immer weiter einschränkte. Schon 1933 hatte man sich in den Dienst des neuen Regimes gestellt und als Sondermaßnahme insgesamt über 100 Mio. RM unter anderem in Form von Darlehen an die Deutsche Gesellschaft für öffentliche Arbeiten sowie die Deutsche Siedlungsbank für die Arbeitsbeschaffungsmaßnahmen gegeben. ${ }^{10}$ Und auch 1936 notierte man im Geschäftsbericht, dass

in diesem letzten Jahre des ersten Vierjahresplans es die Reichsversicherungsanstalt - entsprechend ihrer ganzen bisherigen Betätigung - für ihre selbstverständliche Pflicht [hielt], zur erfolgreichen Durchführung der Maßnahmen der Reichsregierung mit allen Kräften beizutragen und deshalb ihre Mittel in erster Linie solchen Zwecken zuzuführen, die der Belebung der Wirtschaft und der Arbeitsbeschaffung dienten. ${ }^{11}$

Die Zinserträge, die so wichtig für die Vermögensentwicklung der RfA waren, sanken. Den deutlichsten Einschnitt hatte man hier schon zwischen 1931 und 1933 hinnehmen müssen, als die Zinseinnahmen bei einem Zinssatz von 6,8 bis 5,4 Prozent bei 130 Mio. RM stagnierten, obwohl im gleichen Zeitraum das Vermögen um mehr als 500 Mio. zugenommen hatte. ${ }^{12}$ Seither waren die Zinserträge infolge der Zinssenkungspolitik der NS-Regierung langsam, aber kontinuierlich um jährlich etwa 40 Mio. RM gesunken. Auch von der ursprünglich im Sanierungsgesetz von Dezember 1933 vorgesehenen Mittelübertragung der Reichsanstalt für Arbeitsvermittlung und Arbeitslosenversicherung war bei der RfA bis 1936 nichts angekommen. Ende 1936 gewährte die Arbeitslosenversicherung immerhin 20 Mio. RM als Ausgleich für den Zinsausfall infolge der wiederholten Verschiebung der Beitragsübertragung, von denen allerdings nur ganze 6 Mio. RM an die RfA überwiesen wurden. ${ }^{13}$ Anleihen des Reichs hatten inzwischen ein Volumen von fast 800 Mio. RM erreicht - 1934 waren es noch erst 171

9 Vgl. die Bilanz im Geschäftsbericht für 1938, S. 36, in: BArch R 89/3468.

10 Vgl. Bericht des Direktoriums der RfA über das Geschäftsjahr 1933, S. 17, in: BArch R 112/102.

11 Geschäftsbericht 1935, S. 14, in: RfA-Archiv Nr. 78.

12 Vgl. Vortrag Haenel auf der RfA-Beiratssitzung vom 26.11.1935, S. 11, in: BArch R 89/3468.

13 Vgl. Rundschreiben des RVA an die Rentenversicherungsträger vom 13.7.1936, in: BArch R 89/3427 sowie Bericht auf der Beiratssitzung vom 18.5.1936, S. 2, in: BArch R 89/3468. 
Mio. RM gewesen - und damit die Reichsbahnvorzugsaktien deutlich überflügelt. Die Diversifikation der Anlagen nahm deutlich ab und gleichzeitig stiegen die Portfoliorisiken. RfA-Direktor Haenel hatte schon in seinem Vortrag vor dem Beirat im November 1935 bei seinem historischen Rückblick deutlich auf die gewaltigen Verluste der RfA durch die Anrechnung nicht gezahlter Beiträge und die dadurch entstandenen ungedeckten Mehrbelastungen sowie die Anlage des größten Vermögensanteils in später wertlose Kriegsanleihen verwiesen. Ohne dass es explizit ausgesprochen wurde, war man sich in der RfA-Führung offenbar durchaus bewusst, dass der Versicherungsträger durch den NS-Staat erneut in eine ähnliche Zwangslage manövriert zu werden drohte.

Tatsächlich sollte das RVA im Oktober 1937 initiativ werden, gegen die Bedenken der RfA die strengen Kriterien der Vermögensverwaltung, hier vor allem der Hypothekenvergabe, aufzuweichen, indem man „neue“ Sicherheiten für die Beschaffung sogenannter dritter Hypotheken für die Förderung des Siedlungswesens konstruierte. ${ }^{14}$ Dazu kam, dass seit April 1938 sämtliche Versicherungsträger gezwungen wurden, Vermögen und Rücklagen mindestens zur Hälfte in verbriefte Forderungen gegen das Reich oder Reichsschuldverschreibungen anzulegen, oder, solange dieser Betrag nicht erreicht wurde, mindestens zwei Drittel des jährlichen Vermögenszuwachses entsprechend $\mathrm{zu}$ investieren. „Die Vermögensverwaltung ist in weitem Maße zwangsläufig geworden“, kommentierte Grießmeyer damals unverblümt diese Entwicklung gegenüber dem Beirat. ${ }^{15}$ Von den erwarteten rund 400 Mio. RM Überschuss des Haushaltsjahres 1938 mussten demnach 300 Mio. RM in „Reichswerten“ angelegt werden. Für die Beleihung von Bauten und den Kauf von Grundbesitz waren demgegenüber stark einschränkende Bestimmungen ergangen. Angesichts dieses Anlagezwangs hatten die Versicherungsträger, selbst wenn sie wollten, praktisch keinen Spielraum mehr für andere Anlageformen. Da der Plan zur politisch gewollten massiven Förderung des Siedlungswesens „immerhin gewisse Gefahren für die Sicherheit und den Ertrag der zur Verfügung gestellten Gelder der Rentenversicherung in sich birgt“, sollte das Reich mit der Übernahme von Ausfallbürgschaften die gesetzlichen Voraussetzungen für die Mittelvergabe durch die Versicherungsträger gleichsam neu begründen. ${ }^{16}$

Das Vermögen der RfA wurde zudem zur Sanierung der maroden Gagfah benutzt. Im Zuge einer verdeckten Transaktion, „um zu vermeiden, dass die mit der Gagfah arbeitenden Kreise die Aktionärseigenschaft der RfA erkennen“, hatte die RfA im Oktober 1935 mit Hilfe der Thüringischen Staatsbank, die quasi als Strohmann fungierte, aus eigenen Mitteln für rund 5,75 Mio. RM das bei der DAF liegende GagfahAktienpaket erworben und mit weiteren sechs Mio. RM eine Kapitalerhöhung bei der

14 Vgl. Bericht des RVA an das RAM über die ablehnende Stellungnahme der RfA vom 5.10.1937, in: BArch R 89/4393.

15 Niederschrift der Beiratssitzung vom 28.11.1938, S. 2, in: BArch R 89/3470.

16 Vgl. Bericht auf der Beiratssitzung vom 18.5.1936, S. 5, in: BArch R 89/3468. 
Wohnungsbaugesellschaft vorgenommen. ${ }^{17}$ Im Dezember 1937 erfolgte eine weitere Kapitalerhöhung auf 18 Mio. RM, an der die RfA mit 16,8 Mio. RM beteiligt war. Die Übernahme der 1918 als gemeinnützige Wohnungsbaugesellschaft gegründeten Gagfah durch die RfA wäre eine eigene Darstellung wert, denn der Transaktion gingen langwierige, vielfach intern und hinter verschlossenen Türen erfolgte Verhandlungen und Gespräche zwischen RVA, DAF, Thüringischer Staatsbank bzw. dem Thüringischen Ministerpräsidenten Willy Marschler, dem RAM und den Vermögensfachleuten der RfA voraus. ${ }^{18}$ Eigentlicher Drahtzieher und Initiator der ganzen Aktion war offenbar Marschler gewesen, der, seit 1934 Aufsichtsratsvorsitzender der Gagfah, die RfA nicht nur für die Sanierung der Gesellschaft, sondern auch für eine Verlegung des Hauptsitzes von Berlin nach Weimar gewinnen konnte. ${ }^{19}$ Das RAM hatte seine Zustimmung zu dem Kauf an die Bedingung geknüpft, dass die RfA der Aufsicht über die Geschäftsführung der Gagfah eine besondere Sorgfalt widmete. ${ }^{20}$ In der Folge trat daher nicht nur Grießmeyer als stellvertretender Vorsitzender in den Aufsichtsrat ein, sondern auch zwei weitere RfA-Beamte. Es war mithin weniger vermögenspolitisches Kalkül als vielmehr staatspolitische Vorgabe, dass die RfA inzwischen geradezu eine Monopolstellung im Bereich der Wohnungsneubauförderung erreichte. Mehr als die Hälfte aller vom Reich verbürgten Hypotheken auf Wohnungsneubauten kamen 1935 allein von der RfA, woraus aber gleichzeitig zu erkennen ist, wie stark die Wohnungsneubauförderung aus Mitteln des allgemeinen Kapitalmarktes inzwischen eingeengt worden war. Mit dem Gagfah-Engagement sollte die RfA nicht recht glücklich werden. In einem internen Vermerk vom März 1939 war von einer erneuten Unterkapitalisierung in Höhe von 6,7 Mio. RM die Rede und anhaltenden Mängeln in der Geschäftsüberwachung durch die RfA. Erst jetzt sollte auch die endgültige Übernahme sämtlicher Aktien der Gagfah erfolgen und mit ihr auch die alleinige Kontrolle über das Gebaren der Gagfah-Geschäftsführung. Bis Oktober 1938 war die hohe Summe von

17 Vgl. Entwurf des Treuhandvertrags vom 14.5.1935, in: BArch R 89/3466. Der tatsächliche Kapitalbedarf hatte mit neun Mio. sogar noch erheblich höher gelegen, denn neben der Kapitalerhöhung vergab die RfA noch ein Darlehen von drei Mio. RM. Vgl. dazu auch den Vortrag Haenels auf der Beiratssitzung vom November 1935, in: ebd. sowie auch Bonz, Manuskript, S. $344-349$ zur länger zurückreichenden Geschichte des Verhältnisses von Gagfah und RfA. Vgl. auch Gagfah 1918-1968. Eine Dokumentation, Berlin 1968. Eine Gesamtgeschichte der Gagfah harrt noch der wissenschaftlichen Untersuchung.

18 Vgl. etwa die Besprechungsniederschrift vom 5.9.1935 in den Geschäftsräumen von Ministerpräsident Marschler in Weimar, in: BArch R 89/3466.

19 Vgl. dazu auch Vermerk über eine Besprechung bei Grießmeyer am 6.12.1935, bei der Direktor Haenel auch über die finanzielle Lage der Gagfah berichtete. Demnach war die Gagfah infolge kurzfristiger Kredite illiquid geworden und benötigte dringend frisches Kapital, das die DAF damals aber nicht bereitstellen wollte. Vgl. den Vermerk in: BArch R 89/3447.

20 Vermerk Grießmeyers vom 3.10.1935, von dem sich Marschler im Übrigen in seiner Position als Aufsichtsratsvorsitzender angegriffen fühlte, weshalb er ein entsprechendes Schreiben an Grießmeyer richtete, in: ebd. 
259 Mio. RM an RfA-Mitteln in Gagfah-Bauten festgelegt worden, was den Fachleuten der Vermögensabteilung in der Ruhrstraße offenbar erhebliche Sorgen bereitete. ${ }^{21}$

Doch zurück zur Beiratssitzung vom November 1935. Beraten wurde dort im Zusammenhang mit der Vermögenspolitik auch der Voranschlag für das Haushaltsjahr 1936, der unbeanstandet beschlossen wurde. Einige der Beiratsmitglieder nutzten die Erläuterung der einzelnen Haushaltstitel ganz in der Tradition der Vertretung der Versicherteninteressen $\mathrm{zu}$ weitergehenden rentenversicherungspolitischen Bemerkungen und Forderungen. Die Ruhensbestimmungen, insbesondere soweit sie die freiwillig versicherten Ehefrauen beträfen, so vermerkte das Protokoll die Wortmeldung eines Beiratsmitglieds, bedürften einer Abänderung und seien mit dem Rechtsempfinden nicht in Einklang zu bringen.22 Grießmeyer versprach, entsprechend beim RAM vorstellig zu werden, und hielt, wie ein Schreiben vom 19. Dezember 1935 über das RVA an das RAM zeigt, auch Wort. $^{23}$

Die Vermögensverwaltung sowie die Ausgabenpolitik und die sich aus Sicht der RfA hier ergebenden wachsenden Zwänge und Vorgaben dominierten auch die nächsten Beiratssitzungen. Schon bei einer Besprechung von Grießmeyer und seinen beiden Stellvertretern Haenel und Schaefer im Reichsversicherungsamt Ende Februar 1936 war der RfA-Führung mitgeteilt worden, dass man die Bereitstellung erheblicher Mittel für die Reichsaufgaben in der Gesundheitsfürsorge erwartete. ${ }^{24}$ Die Bekämpfung der Tuberkulose und der Geschlechtskrankheiten stand aus ideologischen Gründen beim Kampf um die Förderung der Volksgesundheit ganz oben auf der Agenda der NS-Sozialpolitik, und die RfA mit ihren zehn eigenen Heilanstalten und 121 Vertragssanatorien, Heilstätten und Kurheimen war dafür eine zentrale Institution zur Instrumentalisierung im Sinne der NS-Politik. ${ }^{25}$ Schon 1934 hatte man 400.000 RM für den Reichs-Tuberkulose-Ausschuss bereitgestellt, eine Reihe von RfA-Beamten, allen voran der Leiter der Abteilung II (Gesundheitsfürsorge) Dr. Walther von Gimborn, arbeiteten in diversen Arbeitsgemeinschaften und vertraten die deutschen Interessen

21 Vgl. den Vermerk vom 10.3.1939, in: BArch R 89/3466.

22 Vgl. Protokoll der Beiratssitzung vom 26.11.1935, S. 5, in: ebd.

23 Schreiben Grießmeyers vom 19.12.1935, in: BArch R 89/3409.

24 Aktenvermerk über die Besprechung vom 25.2.1936, in: BArch R 89/3447.

25 Vgl. dazu auch die ebenso ausführlichen wie statistisch unterfütterten und überdurchschnittlich umfangreichen Darstellungen zur Heilfürsorge der RfA in: 25 Jahre Angestelltenversicherung, S. 105140. Mit den Vertragshäusern, in denen die RfA für ihre Patienten Kost und Logis zahlte, gab es häufig Ärger. Die Qualifikation als RfA-Vertragshaus war für die Vermieter bzw. Betreiber ein lukratives Geschäft und nach der Machtergreifung hatte das ganze System noch eine politische Dimension erhalten. So wurden jüdische Besitzer zunehmend ausgeschaltet, aber auch Häuser bei der Belegung nicht mehr berücksichtigt, deren Besitzer oder Pächter Doppelverdiener waren. Exemplarisch waren etwa die Auseinandersetzungen im April 1937 bei der Belegung bzw. Nicht-mehr-Berücksichtigung von zwei Kurhäusern im niederschlesischen Bad Altheide. Dort waren zeitweise bis zu 38 Häuser mit AV-Patienten belegt worden und unter den Betreibern waren auch ein bei der kommunalen Badeverwaltung tätiger Oberkellner sowie ein Kurhausportier, die sich beide (letztlich erfolglos) an die Kanzlei des Führers mit ihrer Beschwerde wegen der Belegungspolitik der RfA gewandt hatten. Vgl. dazu das Schreiben der RfA an das RVA vom 8.4.1937, in: BArch R 89/3390. 
auf internationalen Tagungen wie dem Tuberkulose-Kongress im Herbst 1936 in Lissabon. Jahr für Jahr gingen mit steigender Tendenz über 100.000 Anträge auf Heilverfahren in der Ruhrstraße ein, und für die bewilligten knapp 50.000 Anträge wurden über 20 Mio. RM pro Jahr aufgewendet. ${ }^{26}$ Mit der Nationalsozialistischen Volkswohlfahrt (NSV) wurden zudem Gespräche über die gegenseitige Zuständigkeitsabgrenzung für Heilverfahren geführt, die vor allem dazu führten, dass die RfA auf Zuschüsse Dritter verzichtete. Die NSV erzielte dadurch erhebliche Einsparungen, während auf die RfA jährliche Mehrkosten von 150.000 RM zukamen. ${ }^{27}$ Auch die DAF suchte sich auf Kosten der RfA schadlos zu halten. Vertreter des Amtes „Kraft durch Freude“ hatten angeregt, die Schiffe der KdF-Flotte, die im Winter nicht benötigt wurden, als eine Art schwimmender Sanatorien der Versicherungsträger zu verwenden, und die RfA sicherte zu, mit 400 Versicherten einen entsprechenden Pilotversuch zu starten. ${ }^{28}$

Die Heilfürsorge der RfA war auch Gegenstand der folgenden Sitzungen des Beirats. Dieser hatte inzwischen eine Aufwertung und erweiterte Kompetenzen erhalten. Um den Betriebsführern und Versicherten „einen maßgeblichen Einfluss auf die wesentlichsten, den Bestand und die wirtschaftlichen Grundlagen des Versicherungsträgers betreffenden Maßnahmen zu sichern“, war dem Beirat in wichtigen Fragen wie Erlass und Änderung der Satzung sowie Feststellung des Haushaltsplanes ein Recht auf Gehör gegeben worden. ${ }^{29}$ Zudem bedurfte der RfA-Leiter alljährlich für das abgelaufene Geschäftsjahr der formellen Entlastung durch den Beirat, was auf der zweiten Beiratssitzung am 18. Mai 1936 nach der Vorlage des neuen Haushaltsplanes durch Grießmeyer auch erstmals geschah. ${ }^{30}$ Im Falle einer Ablehung der Entlastung hätte das RVA als Aufsichtsbehörde über die strittigen Punkte entschieden. Faktisch waren damit eigentlich wieder Elemente der früheren Selbstverwaltung installiert worden. Und auch dass auf Initiative von Grießmeyer die damaligen Beirats-Ausschüsse - der Haushalts- und Rechnungsausschuss und der Heilverfahrensausschuss - wieder gebildet wurden, war eine Rückkehr zu den traditionellen Organisationsstrukturen. Das gestiegene Selbstbewusstsein des Beirats signalisierte unter anderem auch, dass wie selbstverständlich auch wieder sämtliche stellvertretende Beiratsmitglieder an der Sitzung teilnahmen, obwohl dies das RVA deutlich als unzulässig monierte. ${ }^{31}$ Tatsächlich war unübersehbar, dass der Beirat eine gewisse Eigendynamik entwickelte und vermehrt zu grundsätzlichen Fragen der Rentenversicherung Stellung nahm. Noch auf der Sitzung im Mai wurde rege und offen über eine ganze Reihe von Problemaspekten diskutiert: von der Verunsicherung bei den Überwachungsbeamten und in der Öffentlichkeit über die künftige Selbständigkeit der RfA

26 Vgl. Geschäftsbericht für das Jahr 1935, S. 12f., in: BArch R 89/3468.

27 Vgl. Bericht Direktor Schaefers auf der Besprechung im RVA vom 25.2.1936, in: BArch R 89/3447.

28 Vgl. Niederschrift der dritten Beiratssitzung vom 10.8.1936, S. 9, in: BArch R 89/3468.

29 Vgl. RGBl. I, S. 400, zitiert nach Bonz-MS, S. 481.

30 Vgl. Niederschrift über die zweite Sitzung des Beirats der RfA am 18.5.1936, S. 3, in: BArch R 89/ 3468.

31 Vgl. Vermerk vom 18.6.1936, in: ebd. 
und die Rolle der DAF bis zu einzelnen Bestimmungen wie der Beibehaltung der Berufsunfähigkeit mindestens ein Jahr arbeitsloser Versicherter und der Ausdehnung der Beitragsrückerstattungen beim Tod von weiblichen Versicherten auch auf ledige männliche Versicherte. ${ }^{32}$ Allerdings wurde auch nachgefragt, ob in den RfA-Sanatorien noch jüdische Ärzte als Vertrauensärzte oder behandelnde Ärzte tätig seien, was von Grießmeyer und von Gimborn unisono verneint wurde. ${ }^{33}$

Auch auf der dritten Beiratssitzung Mitte August 1936 änderte sich an der Rollenverteilung und dem durchaus konstruktiven Zusammenwirken von Präsident und Beirat nichts. Im Mittelpunkt standen diesmal unter anderem die Bemühungen der RfA-Vermögensverwaltung, ihr Anlageportfolio stärker zu diversifizieren und vor allem vermehrt in Grundstücke $\mathrm{zu}$ investieren. Das Vermögen sollte nicht nur in Papierforderungen, sondern auch in effektiven Werten angelegt werden, was vom Beirat einstimmig gebilligt wurde. ${ }^{34}$ Dies erschien umso dringender, als der größte Teil der Vermögensneuanlagen gezwungenermaßen in Reichsanleihen angelegt worden war. Die RfA hatte mit 40 Mio. RM allein acht Prozent der gesamten neuen Anleihen des Reichs übernommen. Das war aber nicht alles. Auf Geheiß des RVA hatte die RfA die Finanzierung einer ganzen Reihe weiterer, dem NS-Regime genehmen Prestigebauten übernommen wie das Haus des Deutschen Rechts (mit 2,2 Mio. RM zu fünf Prozent) oder den Bau der Deutschlandhalle (für 3 Mio. RM) im Rahmen der Mitfinanzierung der Olympischen Spiele. ${ }^{35}$ Seit 1934 waren der RfA auch regelmäßige Zahlungen von 5 Mio. RM an die DAF auferlegt, ebenso wie 20 Mio. RM, die man ,auf Anregung des Herrn Chefpräsidenten [der RVA]“ an die Invalidenversicherung als Zuschuss für den Arbeiterwohnungsbau überwies. ${ }^{36}$ Und nicht zuletzt sollte die RfA im November 1938 die Finanzierung des Neubaus des RVA-Dienstsitzes übernehmen. Das alte Dienstgebäude in der Berliner Innenstadt stand den Neugestaltungsplänen von Generalbauinspektor Speer im Wege, so dass der Umzug des Reichsversicherungsamtes in die Gegend der Nord-Südachse vorgesehen war. Um dem Reich die sofortige Aufwendung der Baukosten von rund 20 Mio. RM zu ersparen, war die RfA aufgefordert worden, den Bau zu finanzieren und ihn dann an das Reich zu vermieten. ${ }^{37}$

All dem gegenüber bemängelte das RVA jedoch im selben Atemzug, dass die Aufwendungen der RfA für freiwillige Leistungen in Höhe von 27 Mio. RM im Vergleich zu den anderen Versicherungsträgern zu hoch seien. Dabei war dies unter anderem den Forderungen der verschiedenen, unter dem Dach der DAF organisierten Berufs-

32 Vgl. Niederschrift über die zweite Sitzung des Beirats der RfA am 18.5.1936, S. 4, in: BArch R 89/ 3468.

33 Vgl. Niederschrift über die zweite Sitzung des Beirats der RfA am 18.5.1936, S. 6, in: ebd.

34 Vgl. dazu den Vortrag Haenels vor dem Beirat in: Niederschrift über die dritte Sitzung des Beirats der RfA vom 10.8.1936, S. 4, in: ebd.

35 Vgl. Vermerk über eine Besprechung Grießmeyers mit Schaefer und Haenel beim RVA vom 30.10. 1936, in: BArch R 89/3447.

36 Vermerk über eine Besprechung beim RVA vom 21.1.1937, in: ebd.

37 Vgl. Niederschrift über die Sitzung des Beirats der RfA vom 28.11.1938, S. 9, in: BArch R 89/3470. 
gruppen geschuldet, die immer neue Ausweitungen der Heilverfahrensregelungen der RfA verlangten, wie etwa die Reichsmusikkammer, die Zahnheilverfahren auch für die Blasmusiker forderte. ${ }^{38}$ Spätestens seit dem Aufbaugesetz von 1934 war die RfA zur Trägerin von Gemeinschaftsaufgaben verpflichtet, und dazu gehörte an erster Stelle der Betrieb von Heilanstalten und Erholungsheimen. ${ }^{39}$ Die RfA wurde zudem für den Kampf gegen die Tuberkulose immer stärker in Anspruch genommen und instrumentalisiert. ${ }^{40}$ Ferner beteiligte sich die RfA gemeinsam mit den Landesversicherungsanstalten an den auf Veranlassung der DAF reichsweit stattfindenden Betriebsuntersuchungen durch anteilige Übernahme der Untersuchungskosten sowie durch Heilmaßnahmen bei den für behandlungsbedürftig befundenen Belegschaftsmitgliedern. Vor allem aber gewährte die RfA immer wieder und in erheblichem Umfang kostenlose Gesundheitsfürsorgeleistungen an verdiente Nationalsozialisten. Bereits seit 1933 beteiligte sich die RfA auf Drängen der Obersten SA-Führung an der „Hitler-Spende“ durch Gewährung von 2500 kostenlosen Verpflegungstagen in den Sanatorien Wehrawald und Schwarzwaldheim für lungenkranke SA-, SS-, NSBO- und Stahlhelm-Männer, die keiner Versicherung angehörten. ${ }^{41}$ Weitere RfA-Sanatorien und Kurheime wurden in der Folgezeit dafür nutzbar gemacht. Seit 1935 kamen eine Reihe weiterer Führungsleute und politische Leiter ohne Versicherungszugehörigkeit in den Genuss kostenloser Heilverfahren. ${ }^{42}$ In vorauseilendem Gehorsam war die RfA zudem dazu übergegangen, bei Erholungsanträgen Fragebogen zurückzuschicken, in denen zu beantworten war, ob und seit wann der Betreffende Parteigenosse war. Diese Praxis veranlasste im November 1938 sogar den Stab des Stellvertreters des Führers zur Intervention, um den damit verbundenen Eindruck zu entkräften, dass in erster Linie nur Parteigenossen in den Genuss der RfA-Gesundheitsfürsorgemaßnahmen kämen. ${ }^{43}$ Das RVA hatte zudem dafür gesorgt, dass auf die RfA weitere Aufgaben im Bereich der Gesundheitsfürsorge zukamen, etwa durch die Erweiterung der nachgehenden Fürsorge und der Arbeitstherapie. All dies waren deutliche Indizien dafür, dass das RVA seine Aufsichtsfunktion durchaus eng interpretierte und die RfA an der kurzen Leine führte.

38 Vgl. Vermerk über die Besprechung beim RVA vom 30.10.1936, in: BArch R 89/3447.

39 Vgl. auch den von RfA-Regierungsrat Dr. Haueisen verfassten Artikel über „Die Reichsversicherungsanstalt für Angestellte als Trägerin von Gemeinschaftsaufgaben“, in: Deutsche Rentenversicherung Nr. 7 (1939), S. 124-130. Vgl. auch Bericht des Leiters der RfA betr. seine Aufsicht über die Ersatzkassen der Krankenversicherung für Angestellte im Jahre 1936, in: RfA-Geschäftsbericht 1936, S. $19-23$.

40 Vgl. dazu Curt Perlin (RfA-Beamter), Die Rentenversicherung im Kampf gegen die Tuberkulose, in: NS-Sozialpolitik 6 (1939), S. 456-459.

41 Vgl. Bericht des Direktoriums der RfA über das Geschäftsjahr 1933, S. 6, in: BArch R 112/102. Zum folgenden vgl. auch Bonz-MS, ohne genaue Seitenangabe.

42 Vgl. Geschäftsbericht 1936, S.12, Geschäftsbericht 1937, S. 13 und Geschäftsbericht 1938, S.13, in: BA Berlin R 89/3468.

43 Vgl. BArch R 89/3388, Bl. 187-189. Vgl. auch Bonz-MS, ohne Seitenangabe. 
Auf der Beiratssitzung im August 1936 hatte Grießmeyers Stellvertreter Schaefer auch die aktuellen Zahlen zu Beitragseinnahmen und Leistungsausgaben vorgetragen, und hier konnte er eine Zäsur verkünden. Denn bereits im Juli 1936 war die alte Höchstmarke bei den Beitragseinnahmen von 385 Mio. RM im Jahr 1930 erstmals übersprungen worden, wobei allerdings berücksichtigt werden muss, dass damals der Betrag von 3,5 Mio. Versicherten aufgebracht worden war, während es nun inzwischen 4,1 Mio. Versicherte waren. Trotz der Steigerung der Beitragseinnahmen wies die Struktur der Angestelltenversicherung nach wie vor Verwerfungen auf. Eine Analyse des Zustroms der Beitragszahler zeigte, dass immerhin 51.000 vormals arbeitslose Angestellte wieder Arbeitsstellen hatten; ca. 70.000 Angestellte waren durch die Übernahme der Ersatzkassen zur RfA hinzugekommen und etwa weitere 50.000 angestellte Versicherte waren im Rahmen des normalen Neuzugangs hinzugekommen. ${ }^{44}$ Trotz der guten Zahlen erschien der RfA-Leitung daher nach wie vor eine Erhöhung der Beiträge als unumgänglich, um die Leistungen der Angestelltenversicherung künftig sicherzustellen - eine Forderung, die das NS-Regime so höchst ungern öffentlich machen wollte.

Es spricht vieles dafür, dass die DAF von den ihr zugestandenen Mitsprache- bzw. Berufungsrechten bei der Zusammensetzung des Beirats nicht profitieren konnte. ${ }^{45}$ Dem RVA wie dem RAM war offenbar daran gelegen, die Beiräte zu einem echten Konsultativorgan zu machen, und auch Grießmeyer betrachtete die Beiratsmitglieder zweifellos nicht als verlängerten Arm der DAF, sondern als Vertreter der Versichertengemeinschaft, worauf er jeden Einzelnen auch auf der ersten Beiratssitzung per Handschlag verpflichtet hatte. Ende 1936 war im Übrigen die erste Amtsperiode des Beirats abgelaufen und eine Neubestellung, diesmal für die Zeit von Januar 1937 bis Dezember 1941, erfolgt. An der personellen Zusammensetzung hatte sich dabei nicht viel geändert, bemerkenswert waren nur zwei Neubesetzungen bei den Versichertenvertretern, wo Rudolf Lencer, Leiter der Reichsbetriebsgemeinschaft Banken und Versicherungen, sowie der Behördenangestellte Wilhelm Kemnitz die beiden ausscheidenden Beiräte ersetzten. ${ }^{46}$ Bei den Vertretern der Betriebsführer war alles beim Alten geblieben. Dort fungierten unter anderen immer noch Jakob Hasslacher, der Generaldirektor der Rheinischen Stahlwerke, Otto Neubaur, Vorstandsmitglied der Reichs-Kredit-Gesellschaft, Max Ebbecke, Direktor der Berliner BEWAG, sowie Fritz Reuters, Generaldirektor der Nordstern Lebensversicherungs AG, als RfA-Beiräte. Im Vorfeld hatte es allerdings hinter den Kulissen eine umfangreiche Korrespondenz zwischen RVA, RfA und dem Sozialamt der DAF gegeben. Zum einen hatte Grießmeyer massive Bedenken gegen eine Wiederberufung des stellvertretenden Beiratsmitglieds Hans Hermann Fassbender angemeldet, da dieser bis dahin noch an keiner Beirats-

44 Vgl. Niederschrift über die dritte Sitzung des Beirats der RfA vom 10.8.1936, S. 7, in: BArch R 89/ 3468.

45 So schon die These in Bonz-MS, S. 487. Vgl. auch Teppe, S. 238.

46 Vgl. Der Beirat der RfA in: Mitteilungen der RfA Nr. 2, 1937. 
sitzung teilgenommen hatte. ${ }^{47}$ Zum anderen waren Zweifel aufgetaucht, ob Generaldirektor Hasslacher „noch die Betriebsführereigenschaft“ besaß, da dieser schon längst aus dem Vorstand der Stahlwerke ausgeschieden war. Fassbender wurde tatsächlich nicht mehr berufen, Hasslacher nach einer Rückfrage bei der Reichsgruppe Industrie aber wohl. Schon am 14. Dezember gab das Sozialamt der DAF als letzte Instanz grünes Licht für die Neubesetzung.

Zwischen März 1937 und April 1939, der letzten Sitzung vor dem Krieg, trat der RfABeirat noch fünf Mal zusammen. Die Sitzungen standen dabei ganz im Zeichen der glänzenden Zahlen, die die finanzielle Konsolidierung der RfA signalisierten. Und Oberregierungsrat Haenel, einer der beiden Stellvertreter Grießmeyers und der Leiter der Abteilung III, der trotz aller wachsenden Zwänge Garant für eine solide Vermögensverwaltungspolitik der RfA war, schied im März 1937 altersbedingt aus. ${ }^{48}$ Ende November 1937 stand dann die bereits erwähnte zweite Kapitalerhöhung um sechs Mio. RM bei der Gagfah auf der Tagesordnung, und um die Zustimmung der Beiratsmitglieder zu sichern, waren dazu auch Ministerpräsident Marschler sowie GagfahGeneraldirektor Knoblauch angereist. ${ }^{49}$ Die Kapitalerhöhung wurde, nachdem Grießmeyer noch einmal die Zustimmung auch von RVA und RAM betont hatte, ebenso durchgewinkt wie der vorgelegte Finanzplan für das Haushaltsjahr 1938. Die übrigen Aktivitäten der RfA-Leitung standen jedoch ganz im Zeichen des Jubiläums der Behörde. Im September 1937 hatte Grießmeyer das RVA aus Anlass des 25. Jahrestages des Inkrafttretens des Angestelltenversicherungsgesetztes um die Genehmigung zur Abhaltung einer „schlichten Feierstunde“ gebeten. ${ }^{50}$ Doch bei der am 17. Januar 1938 stattfindenden Feier waren alle vertreten, die Rang und Namen in der Sozialversicherungspolitik hatten. Auffälligerweise standen aber, obschon mit Sicherheit gleichfalls eingeladen, keine DAF-Funktionäre auf der Rednerliste. ${ }^{51}$

Doch Grießmeyers Rede war selbst ein klares Bekenntnis zur Indienstnahme der RfA für die nationalsozialistischen Ziele, und damit - ohne Not und durchaus aus innerer Überzeugung - eine geradezu unterwürfige Geste gegenüber dem Nationalsozialismus und seinen anwesenden Vertretern, allen voran des stellvertretenden Gauleiters von Berlin, Artur Görlitzer. ${ }^{52}$ Die ganze bisherige Entwicklung der Angestelltenversicherung und erst recht die gegenwärtige und künftige Aufgabenstellung wurde in der Darstellung des RfA-Präsidenten geradezu auf die NS-Bewegung und ihre

47 Schreiben an das RVA vom 23.11.1936, in: BArch R 89/3469.

48 Vgl. dazu Niederschrift über die fünfte Sitzung des Beirats der RfA vom 15.3.1937, S. 5, in: BArch R $89 / 3468$.

49 Vgl. Niederschrift über die sechste Sitzung des Beirats der RfA vom 29.11.1937, in: ebd.

50 Schreiben Grießmeyers vom 1.9.1937, in: BArch R 89/3446.

51 Die DAF-Position vertrat vermutlich Rudolf Lencer, der aber in seiner Funktion als Beiratsmitglied sprach. Am Vorabend der Veranstaltung hatte schon ein aufwändig organisierter Gefolgschaftsabend stattgefunden, unter anderem mit zahlreichen Einlagen des Männerchors der RfA und weiterer RfABelegschaftsangehöriger sowie anschließendem Tanz.

52 Die Rede wurde abgedruckt als Beilage zum Geschäftsbericht der RfA für 1937, S. 41-47, in: RfAArchiv Nr. 78. 

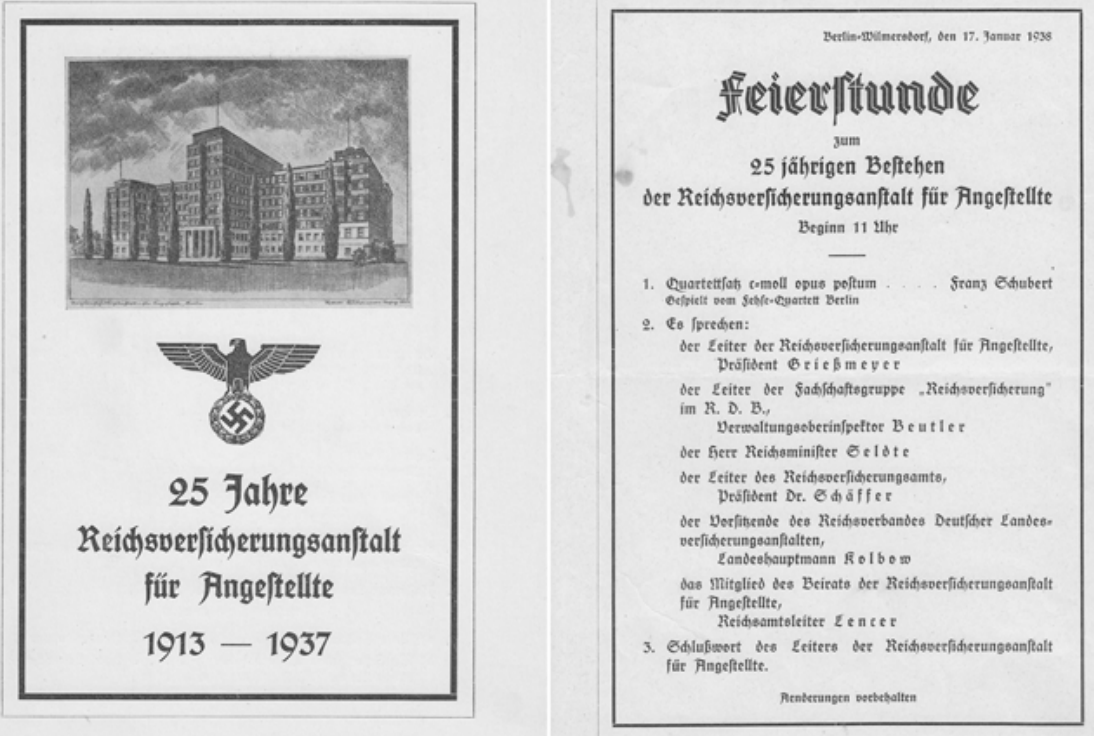

Abb. 12: Programm zur Feier des 25-jährigen Bestehens der RfA am 17. Januar 1938

ideologischen sozialpolitischen Ziele ausgerichtet, wie etwa die Mitwirkung an der Schaffung eines „kräftigen, gesunden und lebensfrohen Volkstums“, „.....] denn was hülfe es ihr, wenn sie noch so hohe Renten bezahlte und hätte doch ein schwächliches, krankes und schaffensmüdes Volk hinter sich“. ${ }^{53}$ Selbst der auch von Grießmeyer als sehr niedrig benannte Betrag von 58,30 RM als damals monatliche Durchschnittsrente wurde noch schön gerechnet und als guter Ausgangspunkt für einen Leistungsausbau nach nationalsozialistischen Grundsätzen dargestellt. Der RfA-Präsident ließ zudem ein aufwändiges, fast 200 Seiten starkes Jubiläumsbuch erstellen, das nicht nur nach außen die Leistungen der RfA dokumentierte, sondern auch allen Mitarbeitern, die darin sämtlich namentlich aufgeführt worden waren, in die Hand gedrückt wurde. ${ }^{54}$ Von der von nationalsozialistischem Gedankengut triefenden Rede Grießmeyers hob sich das Buch deutlich ab. Obschon im Duktus der NSZeit geschrieben, findet sich darin ein statistisch angereicherter Rückblick auf die gesetzliche wie behördliche Entwicklung der Angestelltenversicherung. Selbst der Völkische Beobachter druckte eine Sonderausgabe, in der Grießmeyer die Leistungen der Reichsversicherung für Angestellte pries. ${ }^{55}$ Man könnte diese Aktivitäten Grieß-

53 Ebd., S. 45.

5425 Jahre Angestelltenversicherung. 1913-1937, Berlin 1938.

55 Albert Grießmeyer, Spiegelbild eines Vierteljahrhunderts. Die Leistungen der Reichsversicherung für Angestellte, in: Völkischer Beobachter Nr. 7 vom 7.1.1938. 
meyers durchaus auch als strategische Instrumentalisierung des Jubiläums und als politischen Schachzug verstehen, durch den öffentliche Akzeptanz und Zusammenhalt unter den Mitarbeitern geschaffen und zugleich etwaigen anderslautenden sozialversicherungspolitischen Überlegungen bei der DAF der Wind aus den Segeln genommen werden sollte. Man kann sie aber auch als politische Unterwerfung und Anpassung an das NS-Regime sehen, hinter der die tatsächliche Bereitschaft zur Instrumentalisierung der RfA für die Ziele des Nationalsozialismus stand. Rudolf Lencer jedenfalls, seinerzeit Leiter der Reichsbetriebsgemeinschaft Banken und Versicherungen und RfA-Beiratsmitglied, schrieb in seiner, in den Monatsheften für NS-Sozialpolitik abgedruckten Würdigung der Angestelltenversicherung anlässlich des Jubiläums geradezu drohend, dass „Bewegung und Staat in Zukunft einen noch größeren Einfluss auf die Rentenversicherungsträger nehmen [werden]. Die Ausrichtung muss in jeder Beziehung nach nationalsozialistischen Grundsätzen vorgenommen“ und dem Ziel eines großzügigen Ausbaus der Altersversorgung untergeordnet werden. ${ }^{56}$ Und auch bei den Versicherten löste Grießmeyers Rede ein durchaus zwiespältiges Echo aus, wie der unten stehende Brief zeigt.

Im Jubiläumsjahr konnte Grießmeyer zudem neue Rekordzahlen verkünden. Die RfA verzeichnete mit knapp 457 Mio. RM die höchsten Beitragseinnahmen in ihrer nun 25-jährigen Geschichte. Schon während der Beiratssitzung im November 1936 hatte man im Übrigen auch den Abschluss der seit 1934 dauernden Neubaumaßnahmen gefeiert, die mit etwas über einer Mio. RM zu Buche schlugen. Nun hatte man endlich auch freie Hand in der Restbebauung des Fehrbelliner Platzes, denn die DAF hatte endgültig ihre Pläne fallen gelassen, die die RfA gezwungen hätte, die Spitze ihres dortigen Grundstücks als Freifläche auszuweisen. ${ }^{57}$

Grießmeyer war als RfA-Präsident inzwischen unangefochten und weithin respektiert; er war offensichtlich auch in die politischen Kreise hinein gut vernetzt, auch wenn seine Verbindungen im Einzelnen aus den Quellen nur undeutlich hervorgehen. Über einen repräsentativen Dienstwagen verfügend war Grießmeyer schon 1934 in den Aufsichtsrat der Deutschen Bau- und Bodenbank gewählt worden, dazu kam dann im Dezember 1935 das Aufsichtsratsmandat bei der Gagfah. ${ }^{58}$ Für beide Nebenbeschäftigungen erhielt er jährlich 2400 bzw. 1200 RM Vergütung, zusätzlich zu seinem Gehalt als RfA-Präsident von über 18.000 RM. Und es kamen weitere Aufsichtsratsmandate hinzu: Ende 1938 trat Grießmeyer auf entsprechende Anfrage der DAF in den Aufsichtsrat der „Neuland“ Gemeinnützige Wohnungs- und Siedlungsgesellschaft m.b.H. „,in der Stadt des KdF-Wagens“ ein, im März 1939 in den Aufsichtsrat der Deutschen Wohnstätten-Hypothekenbank AG. ${ }^{59}$ Der RfA-Präsident war auch häufiger Gastredner auf diversen DAF-Fachtagungen wie etwa der am 15. Oktober 1937 in Frankfurt statt-

56 Rudolf Lencer, Zum 25jährigen Jubiläum der Angestelltenversicherung, in: Monatshefte für NSSozialpolitik 5 (1938), S. $40-41$.

57 Protokoll der Beiratssitzung vom 30.11.1936, S. 4, in: BArch R 89/3468.

58 Vgl. Notiz vom 24.4.1934, in: BArch R 3901/103525, Bd. 1.

59 Vgl. Genehmigungsanfrage Grießmeyers an das RAM vom 5.11.1938 sowie vom 20.3.1939, in: ebd. 


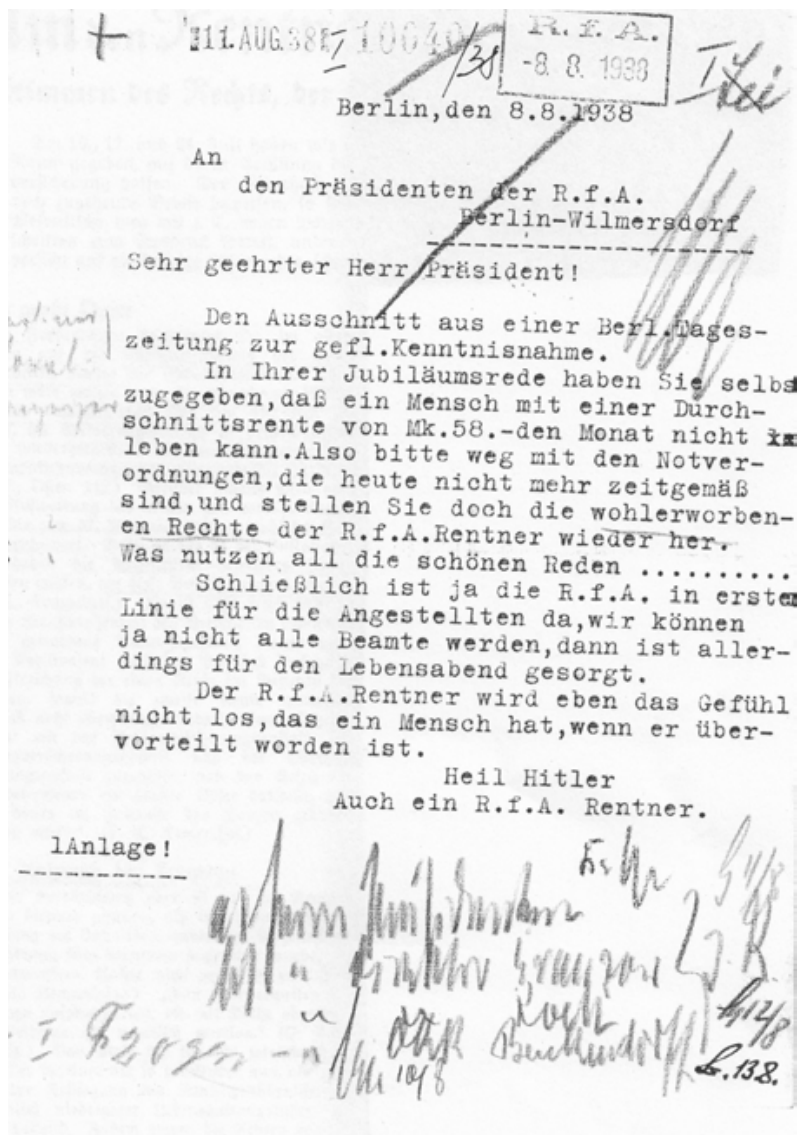

Abb. 13: Brief eines Versicherten an Präsident Grießmeyer vom 8. August 1938

findenden Sondertagung der neu gegründeten Reichsfachgruppe Sozialversicherung in der Reichsbetriebsgemeinschaft Banken und Versicherungen, wo Grießmeyer vor über 1000 Teilnehmern über die Sanierung der Rentenversicherungen sprach. ${ }^{60}$ In den wenig später gegründeten Beirat der Fachgruppe Sozialversicherung im Fachamt Banken und Versicherungen der DAF ließ sich Grießmeyer allerdings nicht berufen. Als Vertreter der RfA saß dort jedoch sein Personalleiter und enger Vertrauter Dr. Gaber. $^{61}$

Wie wichtig für Grießmeyer die Außendarstellung der RfA war, zeigen die Vorgänge um die Organisation und Beteiligung an einer DAF-Ausstellung im Dresdner

60 Vgl. dazu den Bericht zur Tagung und auch zu Grießmeyers Vortrag, in: Soziale Praxis 46 (1937), S. $1330-1334$ und in: Deutsche Invaliden-Versicherung 9 (1937), S. 225-227.

61 Vgl. dazu die Notiz zur Neuberufung des Beirats in: Deutsche Rentenversicherung Nr. 12 (1939), S. $208-209$. 
Hygiene-Museum über „Gesundes Leben, Frohes Schaffen“ im Dezember 1937. Auf einer Besprechung waren die zur Beteiligung aufgeforderten Versicherungsträger, aber auch Industrie- und Wirtschaftsvertreter, eigentlich mit vollendeten Tatsachen konfrontiert worden: Die Wehrmacht und die DAF beanspruchten fast die ganze Ausstellungsfläche, alle anderen sollten sich vor allem an den zu erwartenden hohen Kosten beteiligen - als Staatszuschuss waren vom Finanzministerium ganze 10.000 RM genehmigt worden. ${ }^{62}$ Für die Rentenversicherungsträger war eine kleine Abteilung mit Darstellungen zur Bekämpfung von Seuchen- und Volkskrankheiten, zu Kinderfürsorge und zum Wohnungs- und Siedlungswesen vorgesehen. Unter diesen Umständen lehnten RVA und RAM eigentlich eine Beteiligung ab, aber in der RfA war man offenbar entschlossen, keine Kosten zu scheuen und präsentierte im Juli 1938 ein aufwändiges Ausstellungskonzept, mit einem eigens angefertigten Modell des RfAeigenen Nordseekurheims Uterum/Föhr, Wandbildern sowie zahlreichen weiteren Fotos. ${ }^{63}$ Eine zumindest formelle Stärkung seiner Machtposition ergab sich für Grießmeyer schließlich auch durch die Gründung des Reichsverbandes Deutscher Rentenversicherungsträger im Oktober 1938, der als Dachverand der LVA, der RfA sowie der Knappschaftsversicherung fungieren sollte. Präsident wurde durch Berufung des RAM Dr. Martin Möbius, Leiter der LVA Sachsen in hohem SS-Rang und rentenversicherungspolitischer Hardliner, der die ideologische wie praktische Ausrichtung der Rentenversicherung auf die Ziele des NS-Regimes weit mehr als Grießmeyer vorantrieb. Sein Stellvertreter wurde Grießmeyer, der allerdings, obwohl er an den regelmäßigen Sitzungen des Reichsverbands teilnahm, keine größere Rolle spielte. $^{64}$

Grießmeyer entwickelte vor allem aber ein ausgeprägtes Faible für die Teilnahme an internationalen Tagungen. Den Anfang sollte eigentlich der Internationale Kongress der Sozialversicherungsfachleute machen, der im Mai 1935 in Budapest stattfand. Aber die damaligen Turbulenzen um sein Parteigerichtsverfahren verhinderten die Teilnahme, so dass sein Stellvertreter Schaefer zu dem Treffen fuhr und auch als Redner auftrat. ${ }^{65}$ Der Zweite Internationale Kongress fand im September 1936 in Dresden statt, und hier war Grießmeyer inzwischen präsent, auch wenn der Leiter des Referats 5 (Auslandssachen) in der Abteilung I Leistung, Dr. Gottfried Denicke, den Fachvortrag hielt. Er sprach über „Erfahrungen der Reichsversicherungsanstalt für

62 Vgl. Vermerk über die Besprechung des RVA vom 17.12.1937, in: BArch R 89/3448.

63 Darunter war etwa eine bildliche Darstellung der seit Bestehen der RfA gewährten 750.000 Heilverfahren, dargestellt in Form eines 50 km langen Marschblocks der Versicherten in Zwölferreihe. Vgl. Schreiben Grießmeyers an das RVA vom 23.7.1938, in: ebd.

$64 \mathrm{Zu}$ den Machtkämpfen innerhalb der LVA im Hintergrund und Vorfeld der Reichsverbandsgründung vgl. unter anderem Martin Dröge, Männlichkeit und ,Volksgemeinschaft‘. Der westfälische Landeshauptmann Karl Friedrich Kolbow (1899-1945). Biographie eines NS-Täters, Paderborn 2015, S. $273 \mathrm{ff}$.

65 Vgl. Die Rationalisierung der Sozialversicherung: Die Arbeiten des Ersten Internationalen Kongresses der Sozialversicherungsfachleute, Budapest 1935 sowie dazu auch der Bericht in: Deutsche Invaliden-Versicherung 7 (1935), S. 107-112. 
Angestellte im Verkehr mit ausländischen Versicherungsträgern“ und plädierte, in straffem NS-Duktus gehalten, für eine bessere zwischenstaatliche Zusammenarbeit durch möglichst weitgehende gegenseitige Rechtsangleichung. ${ }^{66}$ Ehe im Frühjahr 1938 in Wien der Dritte Internationale Kongress der Sozialversicherungsfachleute auf dem Reiseplan Grießmeyers stand, winkte noch die Tagung des Internationalen Verbandes für Wohnungswesen und Städtebau in London, die dort im Juli 1937 abgehalten wurde und deren Mitglied die RfA war. Hatte das RVA bislang sämtliche Auslandsreisen Grießmeyers problemlos abgesegnet, so gab es diesmal Probleme. Auch das RAM mochte nicht allein entscheiden und bat im Juni um die Entscheidung des Führers und Reichskanzlers. ${ }^{67}$ Nur wenig später beantragte Grießmeyer erneut eine Dienstreise ins Ausland. Diesmal ging es nach Lugano, wo der vorbereitende Ausschuss des Wiener Sozialversicherungskongresses tagte, dessen Mitglied der RfAPräsident inzwischen geworden war. ${ }^{68}$ Nahezu zeitgleich publizierte Grießmeyer mehrere Aufsätze, etwa über „Die Berechtigung und Bedeutung der Angestelltenversicherung in Deutschland“, in der angesehenen italienischen Fachzeitschrift Le Assicurazioni Sociali. ${ }^{69}$ Im April 1938 folgte schließlich die große internationale Tagung in Wien, und Grießmeyer nutzte die Teilnahme nicht nur zu einem Auftritt mit einem Quasi-Koreferat als erster Diskussionsredner zum Thema „Vermögensanlage der Sozialversicherungsträger“, sondern auch zu einem Abstecher nach Budapest auf Einladung der ungarischen Landessozialversicherungsanstalt. ${ }^{70}$ Noch im September desselben Jahres stand dann eine Dienstreise nach Venedig zur Sitzung des von Grießmeyer inzwischen geleiteten Vorbereitungsausschusses auf dem Programm, auf der die Details der nächsten Internationalen Tagung der Sozialversicherungsfachleute, diesmal im Frühjahr 1939 in Rom, diskutiert wurden. ${ }^{71}$ In dem Genehmigungsgesuch Grießmeyers an das RAM heißt es:

66 Vgl. den Vortrag in: Bericht über die Arbeiten des Zweiten Internationalen Kongresses der Sozialversicherungsfachleute in Dresden vom 4.-8.9.1936, hrsg. vom Reichsverband Deutscher Landesversicherungsanstalten, Stuttgart/Berlin 1938, S. 67-70.

67 Vgl. Anfrage Grießmeyers vom 4.3.1937, in: BArch R 89/3467. Wie die Entscheidung verlief, geht nicht aus den Akten hervor. Vermutlich wurde der Antrag jedoch abgelehnt.

68 Vgl. Schreiben Grießmeyers vom 11.3.1937 sowie der Bericht der dortigen Beratungen in: ebd.

69 Vgl. den Aufsatz in: Assicurazioni Sociali 12 (1936), S. 178-183 sowie Albert Grießmeyer, Wesen und Umfang der Deutschen Angestelltenversicherung, in: Le Assicurazioni Soziali 15 (1939), S. 492-498. 70 Vgl. Bericht über die Arbeiten des Dritten Internationalen Kongresses der Sozialversicherungsfachleute in Wien vom 18.-22.5.1938, hrsg. vom Reichsverband der Sozialversicherungsträger in Wien, Wien 1938, S. 202-207. Grießmeyers Beitrag fiel dabei weniger durch fachkundige Äußerungen zur Vermögensverwaltung der RfA auf als durch allgemeine Bemerkungen im NS-Duktus, etwa dass es in der Frage der Erhaltung des Vermögens der Sozialversicherung im Falle eines allgemeinen Vermögensverfalls keine absolute Krisenfestigkeit gebe, da die Sozialversicherung nach deutscher Auffassung auf Gedeih und Verderb mit der Volksgemeinschaft und damit auch mit dem Volksvermögen schicksalsmäßig verbunden sei. Vgl. auch den Bericht zur Tagung in: Deutsche Invalidenversicherung 10 (1938), S. 89-99.

71 Vgl. den Bericht Grießmeyers vom 3.10.1938 über die Vorbereitungstagung, auf der neben Deutschland, Italien und Ungarn auch Polen vertreten war, in: BArch R 89/3467. 
Ich gehöre wohl nicht zu den Persönlichkeiten des Staates, deren Auslandsreisen der besonderen Zustimmung des Auswärtigen Amts und der Genehmigung des Führers bedürfen, aber ich möchte nicht verfehlen, darauf aufmerksam zu machen, dass ich als Präsident des Vorbereitenden Ausschusses obigen Kongresses in die Lage komme, in Rom öffentlich aufzutreten oder zu sprechen. Es wird sich hierbei zwar immer nur um unpolitische Reden handeln, aber ich bitte zu entscheiden, welche Mitteilungen hierwegen an Auswärtiges Amt oder Präsidialkanzlei zu geben sind. ${ }^{72}$

Im Bewusstsein und Selbstverständnis seiner Bedeutung ließ sich Grießmeyer daher auch gleich eine Beamtenuniform schneidern, um im „uniformreichen Italien“ vor allem bei der für Kongressbeginn vorgesehenen Kranzniederlegung angemessen auftreten zu können. ${ }^{73}$ Doch dies war voreilig erfolgt, und als Grießmeyer nachträglich im November 1939 beim RAM eine Genehmigung dafür einholen wollte, kam wenig später zur Empörung des RfA-Präsidenten ein Absageschreiben zurück. ${ }^{74}$ Erst nach einigem Hin und Her erteilte das RAM die Genehmigung, allerdings nur für eine feldgraue Uniform; Grießmeyer hatte sich aber eine weit eindrucksvollere blaue Uniform machen lassen. Der Krieg ließ diese Posse dann in den Hintergrund treten, zumal deshalb auch die vorgesehene Tagung in Rom nicht stattfand.

Mehr noch als sein Bedachtsein auf die eigene Außenwirkung und die präsidiale Repräsentanz der RfA in der Öffentlichkeit hatte Grießmeyer in den nun seit der Machtergreifung amtierenden fünf Jahren maßgeblich daran mitgewirkt, die RfA kontinuierlich zu einer willfährigen Behörde im NS-Verwaltungsstaat zu transformieren. Die Durchsicht seiner Präsidialverfügungen gibt einen deutlichen Eindruck von der Art und Intensität dieses Prozesses. Vor allem Betriebsappelle und Abordnungen zu Aufmärschen gehörten nun geradezu zum Behördenalltag. Aus Anlass der dritten Wiederkehr des „Tages der nationalen Erhebung“ wurde die Belegschaft am 30. Januar 1936 gegen Mittag zum gemeinschaftlichen Rundfunkempfang des SAAppells mit der Rede Hitlers zur Versammlung im großen Speise- bzw. Sitzungssaal aufgerufen und im Anschluss an die Führerrede kündigte Grießmeyer noch eigene Gedanken „über die besondere Bedeutung des Tages“ an. ${ }^{75}$ Zuvor schon waren die RfA-Beamten per Verfügung zum Bezug der nationalsozialistischen Presse aufgefordert worden. Darunter wurde, in einer ergänzenden Präsidialverfügung besonders die Halbmonatsschrift „Die Wehrmacht“ zur „Vertiefung des Wehrgedankens im deutschen Volk“ empfohlen, und in einer Verfügung vom 1. Februar 1936 hatte Grießmeyer alle auf Lebenszeit angestellten Beamten des höheren und mittleren Dienstes aufgefordert, sich an einer KdF-Sammlung für bedürftige Gefolgschaftsmitglieder zu beteiligen. Zur Erleichterung des Verfahrens und in Annahme des Einverständnisses der Betroffenen erfolgte im Jahr darauf durch die Hauptkasse als „Kameradschaftsbeitrag“ gleich ein direkter Abzug von den April-Bezügen in Höhe der Hälfte einer Mo-

72 Schreiben Grießmeyers vom 14.8.1939, in: ebd.

73 Notiz Grießmeyers vom 30.11.1939, in: BArch R 3901/103525, Bd. 1.

74 Vgl. Antrag vom 9.11.1939 und Schreiben vom 15.11.1939, in: ebd.

75 Präsidialverfügung vom 29.1.1936, in: RfA-Archiv Nr. 2. 


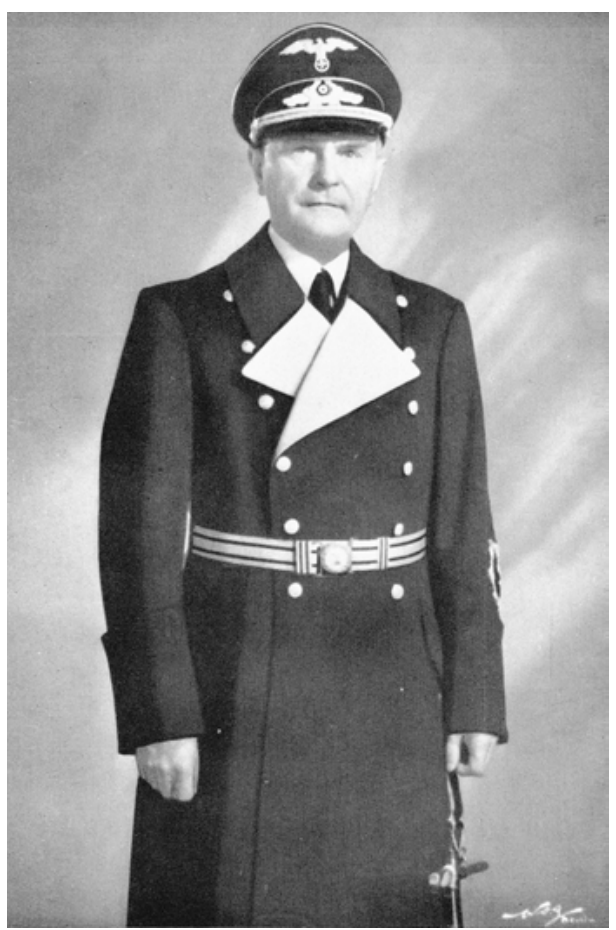

Abb. 14: RfA-Präsident Albert Grießmeyer in Uniform (1939)

natsspende für das Winterhilfswerk. Wer nicht damit einverstanden war, konnte sich melden. ${ }^{76}$ Ähnlich pragmatisch ging die RfA-Leitung per Präsidialverfügung bei der Einrichtung eines „Olympia-Fonds“ vor. Es ging dabei um die angemessene Vertretung Deutschlands auf den Zuschauerrängen der im Jahr 1940 in Tokio geplanten Olympischen Spiele. Grießmeyers Idee war, auch sechs bis acht RfA-Gefolgschaftsmitglieder nach Japan zu schicken; dafür sollten alle Beschäftigten ab 1. Januar 1937 Monat für Monat 0,10 RM in einen Fonds einzahlen. Bis zum Sommer 1940 würden sich damit rund 6000 RM ergeben, mit denen die Reise der per Losentscheid ausgewählten Teilnehmer dann finanziert werden könnte. Für zusätzlich vier RM konnte jeder RfABeschäftigte eine „Glücksanwartschaft“ erwerben. ${ }^{77}$

Regelmäßig fanden nun auch Vorträge zur „allgemeinen beruflichen Weiterbildung“ statt, wobei die Teilnahme nahezu der gesamten Belegschaft per Präsidialverfügung angeordnet wurde. Da ging es einmal um „Grundsätzliches aus der neueren Rechtsprechung zur Sozialversicherung“, über die ein RVA-Direktor Ende Februar 1936 sprach, aber auch um „Marksteine in der Entwicklung des Nationalsozialismus“ oder

76 Vgl. Präsidialverfügung vom 1.2.1936 sowie Präsidialverfügung vom 6.3.1937, in: ebd. 77 Vgl. die Präsidialverfügung vom 12.9.1936 und vom 15.12.1936, in: ebd. 
um „Die Lage und Bedeutung des Auslandsdeutschtums“, um „Aufgaben und Ziele der NS-Gemeinschaft ,Kraft durch Freude““ oder wie im Januar 1939 um „Die Aufgaben und Organe der Staatssicherung“ (Vortragender: SS-Obersturmführer Werner Best). ${ }^{78}$ Es gab so gut wie keine öffentliche Führerrede, sei es auf dem Reichsparteitag in Nürnberg, vor den Arbeitern des Essener Krupp-Konzerns oder auf DAF-Tagungen, die nicht in den Räumen der RfA per Gemeinschaftsempfang übertragen wurden. ${ }^{79}$ Und es gab in Berlin keine öffentlichen Kundgebungen wie 1.-Mai-Feier, Hitler-An- und Abfahrten oder Staatsempfänge ausländischer Gäste wie der Besuch Mussolinis im September 1937, zu dem nicht die RfA-Belegschaft in meist dreihundertköpfigen Abordnungen oder gar vollzählig aufzumarschieren hatte. ${ }^{80}$ Grießmeyer beteiligte sich auch eifrig an der Ausbreitung des Hitler- und Führerkultes. Im Lichthof der Behörde wurde am 20. April 1936 eine Hitler-Büste aufgestellt und feierlich enthüllt; regelmäßig wurden am Geburtstag Hitlers Betriebsappelle abgehalten und Ehrenlisten zur Eintragung für das „Dankopfer der Nation an den Führer“ ausgelegt. ${ }^{81}$ Keineswegs alle dieser Präsidialverfügungen waren nur den entsprechenden Erlassen des RAM oder anderer Reichsministerien zur Bekanntgabe an die Gefolgschaft geschuldet, wie etwa der Aufruf zur Beteiligung an und entsprechenden Abstimmung bei der Scheinwahl des Reichstags, verbunden mit der (nachträglichen) Volksabstimmung zur Eingliederung von Österreich am 10. April 1938, sondern sie entsprangen durchaus der Eigeninitiative Grießmeyers. Diesen Ideologisierungs- und Konformisierungsmaßnahmen konnte sich praktisch kein RfA-Beschäftigter entziehen. Zwei Aspekte der behördeninternen Entwicklung, die maßgeblich von Grießmeyer geprägt und von ihm verantwortet wurden, seien kurz näher beleuchtet: zum einen die Personalpolitik, zum anderen der weitere Ausbau zu einer modernen Leistungsverwaltung.

\section{Rekrutierung, Beförderungen und zweite Säuberungswelle: Aspekte der Personalpolitik}

Die Hoheit über die Personalpolitik der RfA hatte neben Grießmeyer, der sich insbesondere die letzte Entscheidungsbefugnis in allen Personalsachen der Beamten und Angestellten des höheren Dienstes ausbedungen hatte, Dr. Erwin Gaber inne, der Leiter des Personalreferats, enger Vertrauter Grießmeyers und später selbst erster Präsident der RfA-Nachfolgebehörde BfA. Gaber war erst 1932 zur RfA gekommen und damals gerade 29 Jahre alt gewesen. Allerdings besaß in allen Personalangelegenheiten auch das RVA als Aufsichtsbehörde ein Mitspracherecht und vor allem mussten

78 Vgl. dazu u.a. die Präsidialverfügungen vom 3.5.1938 und 21.1.1939, in: RfA-Archiv Nr. 3. 79 Vgl. die entsprechenden Präsidialverfügungen vom 26.9., 24.3. und 24.9.1936, in: ebd.

80 Vgl. dazu die Präsidialverfügungen vom 27.4. und 29.4.1936 (darin war unter anderem detailliert geregelt, welche Abteilungen wieviele Gefolgschaftsmitglieder für die insgesamt 391 RfA-Mitarbeiter umfassende Ehrenabordnung zu stellen hatten) sowie vom 23.3.1936 und 25.9.1937, in: ebd.

81 Vgl. die Präsidialverfügungen vom 24.4.1937, 12.4.1937 und 19.4.1938, in: ebd. 
sämtliche Neueinstellungen und nicht zuletzt auch die Beförderungen durch das Personalamt der Berliner NSDAP-Gauleitung abgesegnet werden. Erst nach deren Zustimmung konnten die jeweiligen personalpolitischen Maßnahmen vorgenommen werden. ${ }^{82}$ Dass die Gauleitung auch vor direkten personalpolitischen Interventionen nicht zurückschreckte, hatte die RfA-Leitung schon unmittelbar nach der Machtergreifung zu spüren bekommen. Damals waren zur Bewältigung von vorübergehenden Mehrarbeiten 25 Hilfskräfte eingestellt worden, die zum überwiegenden Teil alte Kämpfer der NSDAP waren. Eigentlich sollte diesen vertragsgemäß zum April 1934 gekündigt werden, was aber auf Drängen der Gauleitung seitens des RfA-Direktoriums rückgängig gemacht wurde. Auch ein erneuter Kündigungsversuch zum Monatsende Juni wurde durch Intervention der Parteistelle verhindert. ${ }^{83}$ Die für die RfA geltende Prüfungsordnung für die Angestellten des gehobenen wie des einfachen mittleren Dienstes war nach der Machtergreifung schnell an die neuen politischen Verhältnisse angepasst worden. Bei der mündlichen Prüfung musste der jeweilige Bewerber hinreichende Kenntnisse der nationalsozialistischen Weltanschauung, der Rassenkunde, Rassen- und Erbgesundheitspflege und des Aufbaus der NSDAP nachweisen. ${ }^{84}$ Die NSParteizugehörigkeit war noch nicht Voraussetzung, sollte jedoch im Juli 1941 mit dem Erlass einer neuen Ausbildungs- und Prüfungsordnung verpflichtend werden. ${ }^{85} \mathrm{Ob}$ ligatorisch war jedoch seit Juli 1937 der Besuch eines NS-Lagers für Verwaltungsbeamte im oberbayerischen Tutzing, in dem die Anwärter für den höheren Staatsdienst in dreiwöchigen Lehrgängen einer besonderen weltanschaulichen Schulung unterzogen wurden. ${ }^{86}$

Auch die Beamten des Reichsfinanzministeriums hatten ein gewichtiges Wort mitzureden. Mit ihnen hatte Grießmeyer alle Mühe, bei der Aufstellung des Personalhaushalts nicht nur die dringend benötigten zusätzlichen Stellen durchzusetzen, sondern auch Angestellte und Beamte mit den geforderten höheren Qualifikationen rekrutieren zu können. Im November 1936 klagte denn auch Grießmeyer auf der Beiratssitzung ungeschminkt über die zunehmend prekäre Personallage der RfA. Noch immer galt die alte Dienstordnung, nach der im mittleren Dienst Anstellungen auf Lebenszeit sowie mit Ruhegehalt und Hinterbliebenenrente nicht vorgenommen werden konnten. Ausgebildete Dienstanfänger waren daraufhin scharenweise ausgeschieden, wenn ihnen andernorts planmäßige Anstellungen auf Lebenszeit angeboten wurden. Die Angestellten des mittleren Dienstes waren mit fast 1000 Personen gleichsam das personelle Rückgrat der RfA, wobei die Personalstärke inzwischen je-

82 Vgl. einige Bespiele dazu in den Resten der RfA-Personalakten, Bestand Bonz.

83 Vgl. Schreiben der Gauleitung an das RAM vom 6.7.1934 sowie die Stellungnahme der RfA dazu vom 3. 8.1934, in: BArch R 3901/5705, Bl. $153 \mathrm{f}$.

84 Vgl. die jeweiligen Prüfungsordnungen vom 25.1.1936, in: RfA-Archiv Nr. 2 sowie auch Schreiben der RfA an das RVA vom 22.3.1938, in: BArch R 89/3485, Bl. $39 \mathrm{ff}$.

85 Vgl. Bonz-MS, S. $51 \mathrm{f}$.

86 Vgl. dazu das Scheiben von Vizepräsident Schaefer an das RAM zusammen mit einer Liste der zum Lehrgang einzuberufenden Assessoren der RfA vom 8.7.1937, in: BArch R 89/3481. 
doch auf 875 gesunken war; von den als Ersatz vorgesehenen jungen Nachwuchskräften waren im Laufe der zurückliegenden Jahre 116 bereits wieder ausgeschieden. ${ }^{87}$ Durch einen dann auch verabschiedeten Nachtrag in der Dienstordnung der RfA, die die Aussicht auf planmäßige Anstellung eröffnete, hoffte Grießmeyer, dieser Entwicklung endlich einen Riegel vorschieben zu können. Die Personalprobleme blieben jedoch bestehen. Aufgrund eines Erlasses des RAM durften bei der RfA nur 231 der im gehobenen mittleren Dienst Beschäftigten die Amtsbezeichnung „Verwaltungsoberinspektor“ führen. Das hatte zu einem regelrechten Beförderungsstau geführt, denn der ungünstige Altersaufbau in der davon betroffenen RfA-Beamtenschaft gab nur einem ganz verschwindend kleinen Teil die Aussicht, während ihrer Dienstlaufbahn noch je die Amtsbezeichnung Verwaltungsoberinspektor erhalten zu können. ${ }^{88}$ Von den ca. 300 davon betroffenen altgedienten RfA-Beamten war der Großteil zudem bereits $1920 \mathrm{zu}$ Verwaltungsinspektoren ernannt worden und damit seit 17 Jahren in der gleichen Dienststellung. Dass dies demotivierend wirkte, lag auf der Hand. Um all diese drängenden Probleme zu lösen, hatte sich Grießmeyer über sein Personalreferat schon 1935 bei der Vorlage des neuen Besoldungs- und Haushaltsplans für das laufende Geschäftsjahr mit dem Reichsfinanzministerium angelegt und den offenen Konflikt nicht gescheut, denn die geplanten personellen Aufstockungen waren vom Ministerium gerügt und deren Finanzierung verweigert worden. In einem fünfseitigen Schreiben an das RVA kritisierte Grießmeyer das Verhalten des Finanzministeriums, dem er auch unverblümt die Zuständigkeit hinsichtlich der Organisation der Träger der Sozialversicherung absprach. ${ }^{89}$

Es ist nicht meine Aufgabe, dem Herrn Reichsminister der Finanzen gegenüber die Grenzen der Zuständigkeit aufzuzeigen; ich möchte nur darauf hinweisen, dass, sowie die RfA in Frage kommt, jedenfalls kein Vertreter des Reichsfinanzministeriums sich an Ort und Stelle über organisatorische Notwendigkeiten und Möglichkeiten unterrichtet hat. Daher kommt es auch, dass der Vorschlag des Reichsministers der Finanzen sachlich unbrauchbar ist. ${ }^{90}$

Doch er konnte sich nicht durchsetzen.

Zwei Jahre später startete Grießmeyer einen neuen Versuch. Im August 1937 legte er dem RAM über das RVA einen umfangreichen Stellenplan vor, durch den er für insgesamt 1040 Bedienstete, darunter vor allem 610 Verwaltungsoberinspektoren, 79 Verwaltungsinspektoren und 246 Verwaltungssekretäre, Beamtenstellen einzurichten plante. ${ }^{91}$ Da Stellen für Beamte nur eingerichtet werden durften, sofern sie der Wahrnehmung obrigkeitlicher Aufgaben dienten bzw. aus Gründen der staatlichen Sicherheit nicht von Angestellten oder Arbeitern versehen werden durften, erläuterte und begründete er ebenso ausführlich wie detailliert die „obrigkeitliche Natur“ der

87 Vgl. Protokoll der Beiratssitzung vom 30.11.1936, S. 3, in: BArch R 89/3469.

88 Vgl. Schreiben RfA an das RAM vom 3.11.1937, in: BArch R 89/3486.

89 Schreiben vom 23.4.1935, in: BArch R 89/3478, Bl. $24 \mathrm{ff}$.

90 Ebd. Vgl. dazu auch Bonz-MS, S. 78ff.

91 Vgl. das Schreiben vom 25.8.1937, in: BArch R 89/3482. 
jeweiligen Amtsträger und Verwaltungsleute. Gleichsam im Windschatten des 25jährigen Jubiläums plante er gleichzeitig, eine Reihe der altbewährten Beamten endlich zu befördern. Ob dies gelang, ist unklar, das RVA meldete jedenfalls Bedenken an, zumal Grießmeyer schon im April 1937 anlässlich des Führergeburtstags eine Welle von Beförderungen vorgenommen hatte. ${ }^{92}$ Die Engpässe in den einzelnen Diensträngen nahmen jedoch weiter zu. Als Verwaltungsamtmänner waren etwa gerade einmal 25 im Stellenplan vorgesehen; dabei wäre dringend eine Verdoppelung nötig, wie der Personalleiter im August 1938 dem RVA gegenüber klagte. ${ }^{93}$ Insbesondere bei der Rekrutierung ärztlicher Kräfte als Referenten in der Heilverfahrensabteilung gab es erhebliche Schwierigkeiten, da diese nur nach der Tarifordnung des öffentlichen Dienstes bezahlt werden durften, was gegenüber andernorts oder freiberuflich tätigen Ärzten erhebliche Einkommenseinbußen bedeutete. ${ }^{94}$ Auch die Möglichkeiten zur Einstellung und Beförderung von Regierungsräten war, wie Grießmeyer in einer weiteren Sitzung Ende November 1938 dem Beirat gegenüber beklagte, begrenzt. ${ }^{95}$

Das ganze Problem der Personalentwicklung bei der RfA wurde noch dadurch kompliziert, dass der „RfA-Beamte“ einen eigenen und gegenüber den Reichsbeamten unklar abgegrenzten Status hatte. Das Problem bestand schon seit den 1920er Jahren, als das RVA in einer Grundsatzentscheidung bestimmt hatte, dass

\begin{abstract}
die Büro- und Kanzleibeamten der RfA weder Reichsbeamte sind noch die Rechte und Pflichten der Reichsbeamten haben. Sie sind vielmehr als freie Angestellte von dem Direktorium der Anstalt zu berufen. Durch ihre Anstellung erlangen sie auch nicht mittelbar die Rechtsstellung von Beamten. ${ }^{96}$
\end{abstract}

Eigentlich war im Aufbaugesetz von 1934 vorgesehen gewesen, dass die im Dienst der RfA beschäftigten Beamten des höheren Dienstes Reichsbeamte sind, doch aufgrund der Abstimmungsprobleme mit den entsprechenden Beamten der LVA kam eine entsprechende Durchführungsverordnung nicht zustande. Für Grießmeyer und die betroffenen RfA-Beamten war dies eine massive Ungerechtigkeit, die man auch als $\mathrm{Zu}$ rücksetzung der Behörde insgesamt auffasste, verwehrte man der RfA doch damit sozusagen den Status als Reichsbehörde. Auch der Reichsrechnungshof hatte im Mai 1935 bei seinen Prüfungen moniert, dass die Dienstbezüge der mittleren und der Unterbeamten der RfA an die der Reichsbeamten noch nicht angeglichen worden waren. ${ }^{97}$ Die ganze Angelegenheit hatte sich dann $\mathrm{zu}$ einer regelrechten Groteske entwickelt, als es um die Abnahme des Treueeids auf den Führer ging, was eigentlich

92 Vgl. die entsprechende Präsidialverfügung vom 20.4.1937, in: RfA-Archiv Nr. 2.

93 Vgl. dazu auch den Personalhaushaltsplan für das Geschäftsjahr 1938, in: ebd.

94 Schreiben der RfA an das RAM vom 24.10.1938, in: BArch R 89/3485.

95 Vgl. Protokoll der Beiratssitzung vom 28.11.1938, S. 7, in: BArch R 89/3468.

96 Zitiert nach Bonz-MS, S. 390 f.

97 Vgl. das Schreiben des Rechnungshofes vom 15.5.1935 sowie das Antwortschreiben der RfA an das RVA vom 23.8.1935, in: BArch R 89/3486. 
nur „echten“ Reichsbeamten des höheren Dienstes zustand. Grießmeyer forderte, dass durch ihn nicht nur die höheren RfA-Beamten, sondern auch die im kündbaren Angestelltenverhältnis Beschäftigten des mittleren und unteren Dienstes per Handschlag den Treueeid ableisten sollten. Eine rechtsbegründende Wirkung sei damit nicht verbunden, dafür aber eine starke statusbezogene Aufwertung der Betroffenen. ${ }^{98}$ Das RAM verweigerte jedoch den RfA-Mitarbeitern und Grießmeyer die Vereidigung auf den Führer, was, so jedenfalls versuchte es Letzterer der Aufsichtsbehörde gegenüber zu vermitteln, zu massiver Empörung in der Gefolgschaft geführt habe. Tatsächlich hatte sich eine Reihe von Betroffenen geweigert, nicht das statusmäßig minderwertigere Gelöbnis auf Hitler abzulegen, und die Leistung eines Treueeids gefordert, wenn ihnen schon auch die anderen beamtenrechtlichen Zugeständnisse wie Dienstzeitanrechung und Versorgungszulagen nicht gewährt würden. ${ }^{99}$ Im September 1939 kochte die ganze Angelegenheit im Rahmen einer Arbeitsgerichtsklage eines Dienststellenleiters sowie eines Bürovorstehers gegen die RfA erneut hoch, wobei klar war, dass die Behördenleitung eigentlich auf Seiten der Kläger stand und sich in ihren Besoldungsmaßnahmen und der Frage der unerreichten „Beamtenwerdung der Angestellten“ nur als Ausführende sah, die an die Weisungen des Reichsfinanz- und des Reichsarbeitsministeriums gebunden war. ${ }^{100}$ „Es fand sich bisher niemand“, so hieß es in der Berufungsbegründung der Kläger rückblickend, „der die Verwirrung in den Verhältnissen der ,Bediensteten` der Sozialversicherungsträger beseitigt hätte. Auf diese Weise ist die Unzufriedenheit und Unsicherheit bei den Bediensteten bestehen geblieben." ${ }^{101}$

Tatsächlich war der beamten- und besoldungsrechtliche Status der Bediensteten der RfA ziemlich heterogen: Neben den planmäßigen Beamten des höheren Dienstes mit Rechten und Pflichten von Reichsbeamten gab es die übrigen Beamten der RfA, die aufgrund der Dienstordnung Dauerangestellte auf Lebenszeit waren, die Angestellten mit gesetzlicher oder vereinbarter Kündigung ihrer Beschäftigungsverhältnisse sowie schließlich die als Arbeiter tätigen RfA-Angehörigen. Trotz mehrerer Anläufe war auch $\mathrm{zu}$ Kriegsbeginn die Frage der Beamteneigenschaft der RfABeschäftigten des höheren Dienstes nach wie vor ungeklärt. Grießmeyer hatte noch im Oktober 1939 einen Erlass des RAM über die „Änderung der Amtsbezeichnung der im Geschäftsbereich der Sozialverwaltung tätigen Beamten des gehobenen Dienstes“ zum Anlass genommen, auch für die RfA entsprechende Änderungen anzuordnen. Demnach führten die Verwaltungsamtmänner, -inspektoren und -oberinspektoren nun die Fachbezeichnung „Regierungsamtmann“. ${ }^{102}$ Doch schnell stellte sich heraus,

98 Vgl. Schreiben Grießmeyers an das RAM vom 16.1.1936, in: BArch R 89/3479. Vgl. dazu auch BonzMS, S. $40 \mathrm{ff}$.

99 Vgl. dazu auch Bonz-MS, S. $54 \mathrm{ff}$.

100 Vgl. Schreiben des Reichsfinanzministeriums vom 25.9.1939, in: BArch R 89/3508.

101 Schreiben vom 28.12.1939, S. 4, in: ebd. Das Verfahren vor dem Arbeitsgericht wurde endgültig im November 1940 ohne Ergebnis und durch Rücknahme der Klage beendet.

102 Vgl. die Präsidialverfügung vom 20.10.1939, in: RfA-Archiv Nr. 3. 
dass Grießmeyer auf eigene Faust gehandelt hatte. Trotz Drängen des RAM weigerte er sich beharrlich, diesen Erlass rückgängig zu machen. ${ }^{103}$ Und er beschloss, „um den Arbeitsfrieden zu erhalten und aus sozialen Rücksichten“, allen im Arbeiterverhältnis stehenden RfA-Beschäftigten einen widerruflichen Lohnzuschlag zu gewähren. Aber auch hier verweigerte das RAM seine Zustimmung. ${ }^{104}$

Die bloßen Zahlen zur Entwicklung der Beschäftigten in der RfA verdecken daher vielfach die dahinterstehenden Probleme einer auf Wachstum und steigende Qualifikationsbedürfnisse ausgerichteten Behörde. Seit der Stagnation im Jahr 1932 mit 1361 beschäftigten Beamten, Angestellten und Arbeitern war die Zahl der Gefolgschaftsmitglieder bis Ende 1939 langsam aber kontinuierlich auf 1872, d.h. um 37 Prozent gestiegen. ${ }^{105}$ Die Qualifikationsstruktur der Beschäftigten hatte sich dabei allerdings nicht verändert. Nach wie vor stellten die knapp 70 Beamten sowie 21 Angestellte des höheren Dienstes die Minderheit unter der Belegschaft, während 1560 RfA-Mitarbeiter Beamte des mittleren und unteren Dienstes waren, davon 465 Frauen. Dazu gab es 63 männliche Arbeiter und 102 Reinigungsfrauen. ${ }^{106}$ Dass Frauen schon lange vor der Machtergreifung der Nationalsozialisten „nur in sachlich bedingtem Umfang“ beschäftigt worden, und kaum in gehobeneren Bedienstetenpositionen mit Aufstiegschancen vertreten waren, war weder behörden- noch RfA-spezifisch. ${ }^{107}$ Bei der RfA hielt man sich zugute, dass man im Vergleich zu anderen Versicherungsträgern den mit etwa 40 Prozent überdurchschnittlich hohen Anteil von Frauen unter den Versicherten auch angemessen bei der Zusammensetzung der RfA-Beschäftigten berücksichtigte. Im Jubiläumsjahr 1937 waren immerhin 540 weibliche Beschäftigte unter der RfA-Gefolgschaft, das waren knapp 30 Prozent. Die große Mehrheit von ihnen arbeitete aber als Verwaltungssekretärinnen und einfache Büroangestellte; es gab nur drei Verwaltungsinspektorinnen, davon zwei in der Dienstelle 1 der Kontenverwaltung und eine in der Dienststelle 2 der Abteilung I Versicherung. ${ }^{108}$ Umso bewerkenswerter war es, dass sich im Oktober 1937 eine einfache Büroangestellte der Leistungsabteilung in einem elfseitigen Schreiben an den Reichsarbeitsminister wandte und über die fortgesetzte Benachteiligung der Frauen bei der RfA klagte. ${ }^{109}$ Seit März 1933 bei der RfA, war die Betroffene - wie auch ihre fünf Kolleginnen - mehrmals bei der Auswahl zur Zulassung zum Lehrgang für die Verwaltungsprüfung des gehobenen mittleren Dienstes unter den Dienstanfängern übergangen worden. Alle Versuche in Bezug auf

103 Vgl. das Schreiben Grießmeyers an das RAM und RVA vom 19.2.1940, in: BArch R 89/3489, Bl. $164 \mathrm{f}$.

104 Schreiben Grießmeyers an den Reichstreuhänder für den öffentlichen Dienst vom 24. 8.1939, in: BArch R 89/3487.

105 Vgl. die Zusammenstellung des Personalstands der RfA bei Bonz-MS, S. 87.

106 So die Angaben mit Stand 1.10.1938 im Prüfbericht des RVA, S. 3, in: BArch R 89/3450.

107 So später auch die Auskunft der RfA an die Gauleitung Berlin vom 3.8.1934, in: BArch R 5705/5, vgl. auch Bonz-MS, S. 63.

108 Das ergab die Auswertung der namentlichen und mit Dienstbezeichnung versehenen Liste sämtlicher Gefolgschaftsmitglieder, die als Beilage in der 25-Jahre-Festschrift gedruckt wurde.

109 Vgl. das Schreiben vom 27.10.1937, in: BArch R 89/3459. 
Gespräche mit Grießmeyer und der Personalleitung und diverse schriftliche Gesuche waren abgeblockt und verworfen worden. In dem Schreiben an den Minister heißt es:

Es ist mir bekannt, dass der nationalsozialistische Staat der Anstellung weiblicher Beamter nicht günstig gesinnt ist, weil er den eigentlichen Wert der Frau erst in ihrem natürlichen Beruf als Frau und Mutter erfüllt sieht [...]. Doch hat auch der nationalsozialistische Staat die Anstellung weiblicher Beamter für die Zukunft durch gesetzliche Bestimmungen nicht unmöglich gemacht, nicht einmal die Einberufung weiblicher Kräfte für die Beamtenlaufbahn verhindert. ${ }^{110}$

Sie forderte daher nun das RAM dazu auf, sie zu der in den Anstellungsgrundsätzen für Angestellte des einfachen und mittleren Dienstes vorgesehenen und ihr damit auch zustehenden Verwaltungsprüfung für den gehobenen mittleren Dienst zuzulassen, und ihr eine Anstellung in einer planmäßigen Lebenszeitstelle zu gewähren sowie die Amtsbezeichnung und die Bezüge eines nichtplanmäßigen Beamten zu verleihen. Grießmeyer, zur Stellungnahme aufgefordert, gab dabei offen zu, dass er im Gefolge der nationalsozialistischen Erhebung und den damit veränderten Verhältnissen bewusst dazu übergegangen war, bei der lebenslänglichen Anstellung von Nachwuchskräften als Beamte der RfA nur männliche Bedienstete zu berücksichtigen und die weiblichen Angestellten auszuschließen. ${ }^{111}$ RAM, RVA und RfA waren sich in dieser Frage völlig einig und im Januar 1938 wurde daher das Gesuch der Angestellten abgelehnt.

Weit mehr Diskriminierungen sahen sich jedoch ungeachtet des Geschlechts diejenigen RfA-Beschäftigten ausgesetzt, die den rassischen und politischen Vorgaben des Regimes nicht entsprachen. Im Frühjahr 1936 hatte eine zweite große Säuberungswelle innerhalb der RfA-Belegschaft eingesetzt. Begonnen hatte es unter anderem mit einer Präsidialverfügung Grießmeyers - auf Anordnung des RAM - vom 19. Februar 1936, in der von den bei der RfA tätigen Dauerangestellten „mit Rücksicht auf ihre beamtenähnliche Tätigkeit“ eine Erklärung über die Zugehörigkeit zu Freimaurerlogen gefordert wurde, die dem Personalbüro vorzulegen war. ${ }^{112}$ Die Angelegenheit war durchaus pikant, denn zum einen war Grießmeyer selbst Logenmitglied gewesen, zum anderen gab es mit dem Unterabteilungsleiter der Heilfürsorgeabteilung, Dr. med. Walther von Gimborn, einen prominenten RfA-Beamten, der von der Erfassung betroffen war. Im November 1936 hatte Grießmeyer zunächst noch an das RVA „Fehlanzeige“ gemeldet, im Juni 1937 jedoch einen Rückzieher machen müssen und von insgesamt vier RfA-Beamten mit ehemaliger Logenzugehörigkeit berichtet. ${ }^{113}$ Für die Betroffenen galt, dass sie nur mit Zustimmung des Stellvertreters des Führers (weiter-)beschäftigt werden durften; das hatte Grießmeyer allerdings zugunsten von Gimborn, den er als medizinischen Experten der Heilverfahrensverwaltung auf keinen Fall verlieren wollte, zunächst eng ausgelegt, sah sich dann aber doch zu einer

110 Ebd., S. 9.

111 Schreiben Grießmeyers an das RAM vom 20.11.1937, in: ebd.

112 Verfügung vom 19.2.1936, in: RfA-Archiv Nr. 2.

113 Vgl. Schreiben Grießmeyer an das RVA vom 5.6.1937, in: BArch R 89/3481. 
Kehrtwendung gezwungen. In einem Schreiben würdigte er nun ausführlich die Verdienste seines Beamten, betonte, trotz der fehlenden Parteizugehörigkeit, dessen nationale und politische Zuverlässigkeit und bat um eine offizielle Zustimmung zur Weiterbeschäftigung, die auch kurz darauf folgte. Bei anderen ehemaligen Logenangehörigen war Grießmeyer dagegen weniger großzügig und einsatzfreudig. Einem Verwaltungsoberinspektor und Dienststellenleiter in der Leistungsabteilung war zum 1. Januar 1937 eine Beförderungsstelle zum Amtmann genehmigt worden, die ihm jedoch auf Einspruch der DAF-Fachschaft des Reichsbundes der Deutschen Beamten mit der Begründung der ehemaligen Logenmitgliedschaft und eines angeblich falsch angegebenen Austrittsdatums wieder aberkannt wurde. ${ }^{114}$ Der Betroffene hatte sich schon wegen einer Denunziation 1933 vor dem politischen Ausschuss der RfA verantworten müssen, worauf Grießmeyer mit einer fünfjährigen Beförderungssperre reagierte. Nach erfolgreichem Widerspruch war im Mai 1936 eine Rehabilitation und Aufhebung der Beförderungssperre erfolgt; nun machte aber das DAF-Personalamt erneut Front gegen den unliebsamen Beamten und Grießmeyer knickte gegenüber den NS-Beamtenfunktionären ein. Wegen Widersprüchen über die Zeitangaben des Logenaustritts wurde die Beförderung weiter solange zurückgestellt, bis der Betroffene die entsprechenden Nachweise erbringen würde. ${ }^{115}$ Als dies dem Verwaltungsoberinspektor im Frühjahr 1939 endlich gelang, hatten Grießmeyer und Gaber jedoch die Stelle bereits anderweitig besetzt. ${ }^{116}$

Nicht minder übel erging es auch denjenigen RfA-Beschäftigten, die aufgrund einer im September 1936 vom RAM gestarteten Aktion ihre Rasseeigenschaft nachweisen mussten. Sämtliche verheiratete Beamten und Dauerangestellte wurden in einer neuen Fragebogenaktion zu Angaben darüber aufgefordert, inwieweit sie selbst Juden, ,jüdische Mischlinge“ oder ,jüdisch versippt“ waren, d. h. jüdische Ehepartner besaßen. Über das entsprechende Ergebnis hatte Grießmeyer umgehend zu berichten und sich gleichzeitig dazu zu äußern, ob die betreffenden Bediensteten im Dienst belassen werden konnten oder eine Versetzung in den Ruhestand angezeigt erschien. Der Rücklauf der ganzen Aktion war allerdings schleppend. Ende Oktober hatten von den ca. 900 in Frage kommenden RfA-Bediensteten erst 700 die Fragebogen - und zwar vielfach unvollständig - beantwortet. Wie schon 1933 agierten Grießmeyer und sein Personalleiter Gaber bei den Ermittlungen über die Abstammung der Betroffenen äußerst eifrig - nunmehr auf der Grundlage der Nürnberger Rassengesetze von 1935. Am 20. Januar 1937 informierte Grießmeyer in einem als geheim deklarierten Schreiben das RVA darüber, dass bei der RfA insgesamt neben vier jüdischen Beamten neun jüdisch versippte Bedienstete vorhanden seien. Hinsichtlich des weiteren Beschäftigungsverhältnisses äußerte er sich noch nicht, da erst noch die gleichzeitig erfor-

114 Vgl. das umfangreiche Schreiben des Betroffenen an das Reichsinnenministerium vom 25.3.1938, in: BArch R 89/3504.

115 Bescheid des RVA vom 23.5.1938, in: ebd.

116 Vgl. das Beschwerdeschreiben des Betroffenen an das Reichsinnenministerium vom 20.4.1939 sowie auch die Stellungnahme Grießmeyers vom 9.5.1939, in: BArch R 89/3505. 
derliche Stellungnahme der Gauleitung eingeholt werden musste. ${ }^{117}$ Ende Mai meldete der RfA-Präsident dann Vollzug und korrigierte zunächst die Zahl der ,jüdisch versippten“ Beamten auf fünf. ${ }^{118}$ Vier der Betroffenen waren im mittleren Dienst beschäftigt, einer im höheren Dienst. Die vier ersteren wurden zum Ende Juni in den Ruhestand versetzt, für den Beamten des höheren Dienstes jedoch, Regierungsrat Dr. med. Oskar Gummig, Frontkämpfer und seit 1929 bei der RfA als einer der inzwischen dienstältesten Sachbearbeiter der Abteilung für Gesundheitsfürsorge, erbat Grießmeyer eine Ausnahmeregelung und die Belassung im Dienst. Alles hing vom politischen Zeugnis der Parteistellen ab, das schließlich sogar in Form eines Schreibens des Stellvertreters des Führers aus München im Mai auf dem Schreibtisch Grießmeyers landete. Darin wurde Gummig eine überaus korrekte Haltung bescheinigt, zugleich aber keine bejahende Einstellung zum nationalsozialistischen Staat attestiert. ${ }^{119}$ Letztlich konnte Grießmeyer aber seinen Beamten behalten. Mindestens ebenso altgedient und für das reibungslose Arbeiten der RfA als Behörde mitverantwortlich war die Verwaltungssekretärin Käthe W. Seit 1924 in der Behörde tätig war die nun 44Jährige für die Archivierung und Durchprüfung der laufenden Versichertenakten verantwortlich, und im Verhinderungsfall hatte sie auch den Aufsicht führenden Beamten der Dienstelle vertreten. Doch für ihren Verbleib setzten sich Grießmeyer und Gaber im April 1937 nicht ein. Wegen ihrer jüdischen Großeltern väterlicherseits wurde sie zwangsweise in den Ruhestand versetzt und ihre Personalakte mit dem Verweis „Wiederverwendung unerwünscht“ versehen. ${ }^{120}$

Womit weder die Parteistellen noch Grießmeyer gerechnet hatten, war, dass sich die Entlassenen massiv wehrten und um ihre Rehabilitierung kämpften. Ursprünglich hatte Gaber den Betroffenen nahegelegt, sich entsprechend der RfA-Dienstordnung mit vollem Ruhegehalt pensionieren zu lassen, um einer drohenden Dienstentlassung zu entgehen. Das taten diese auch, was aber kurz darauf den Unmut des RVA erregte, denn anstelle einer Sanktion bekamen die Angestellten, ,im besten Mannesalter stehend und voll dienstfähig“, nun ihre ganze Pension. ${ }^{121}$ Im RVA wie in der RfA zerbrach man sich daher den Kopf darüber, wie der zwar rechtswidrig ergangene, aber formell rechtswirksame Pensionierungsbescheid zurückgenommen werden könnte. Zudem kam zu Tage, dass die RfA bei ihren Ermittlungen über das Ziel hinausgeschossen war und bei einem Verwaltungsoberinspektor völlig zu Unrecht ,jüdische Versippung“ angenommen hatte. In der Personalabteilung der RfA lag daher bereits dessen Wiedereinstellungsbegehren auf dem Schreibtisch. Die Äußerungen, die der RfA-Personaldirektor bei dem darauffolgenden Gespräch im RVA Ende September machte, sprechen Bände über

117 Vgl. Schreiben Grießmeyers an das RVA vom 20.1.1937, in: BArch R 89/3481.

118 Da sich herausgestellt habe, dass die übrigen vier, wenn auch ihre Ehefrauen ,jüdischen Bluteinschlag“ hätten, nicht jüdisch versippt im Sinne des RAM-Erlasses seien. Schreiben vom 31.5.1937, in: ebd.

119 Brief vom 24.5.1937, in: ebd.

120 Vgl. die Personalakte Käthe W., in: Bestand Bonz.

121 Vermerk vom 17.9.1937, in: BArch R 89/3482. 
die in der Behörde herrschende personalpolitische Ausrichtung. Er gab freimütig zu, den Begriff der ,jüdischen Versippung“ bewusst weit gefasst zu haben, da man gleichsam in Vorwegnahme einer weiteren Verschärfung der antijüdischen Gesetzgebung im Falle einer anstehenden Verbeamtung davon ausgegangen war, dass die Weiterbeschäftigung des Betroffenen über kurz oder lang sowieso nicht möglich gewesen wäre. „Eine Wiedereinstellung des Z. würde die RfA nicht freiwillig vornehmen, da sie sich damit Missdeutungen politischer Art aussetzen könnte. “122 Auch Grießmeyer argumentierte gegenüber dem RVA, dass das Gesuch des Z. um Pensionierung ,sein freier Entschluss war" und die Neueinstellung von Personen, deren Ehefrauen nicht arischer Abstammung waren, ausgeschlossen sei. „Im Übrigen halte ich eine Wiederverwendung auch im Hinblick auf die bevorstehende Beamtenwerdung nicht für angebracht. “123 Die Eingabe des zu Unrecht entlassenen RfA-Beamten verdeutlicht, dass und wie Gaber von der Personalabteilung ihn massiv unter Druck gesetzt hatte. ${ }^{124}$ Der Fall zog sich allerdings zum Missfallen der RfA-Personalstelle weiter hin, denn das RVA sah durchaus eine Berechtigung zur Wiedereinstellung, was Gaber dazu veranlasste, im Mai 1938 über die Reichsstelle für Sippenforschung weitere Erkundigungen über die Abstammung des Verwaltungsoberinspektors und seiner Frau einzuholen. ${ }^{125}$ Im Februar 1939 meldete dann Gaber geradezu triumphierend an das RVA, dass die Ehefrau jüdischer Mischling mit zwei der Rasse nach volljüdischen Großelternteilen sei und daher keine Veranlassung bestehe, die Versetzung in den Ruhestand rückgängig zu machen. ${ }^{126}$

Und es gab weitere Fälle: Der eine betraf einen RfA-Verwaltungsoberinspektor, der in Stuttgart als Überwachungsbeamter tätig war und wegen seiner jüdischen Ehefrau von Personalreferent Gaber vorgeladen wurde. Dieser eröffnete ihm, dass er als ,jüdisch versippter“ Beamter keinesfalls in Stellungen, die mit Publikumsverkehr verbunden waren, verwendet werden konnte. Seine weitere Beschäftigung bei der RfA sei daher höchst zweifelhaft und allenfalls könne über das Gesuch einer Versetzung in den Innendienst eine Regelung gefunden werden. ${ }^{127}$ Der Betroffene weigerte sich allerdings, sowohl ein entsprechendes Gesuch als auch einen Antrag auf Versetzung in den Ruhestand zu stellen, worauf aufgrund der vielfach ungeklärten gesetzlichen Lage der RfA-Personalstelle nichts anderes übrig blieb, als ihn im Dienst zu belassen. Die übereifrige Säuberungspolitik und das von vorauseilendem Gehorsam bei der politischen wie rassischen Überprüfung der Belegschaft geprägte Verhalten von RfA-

122 Vermerk des Besprechungsergebnisses vom 23.9.1937, in: ebd.

123 Schreiben vom 31.7.1937, in: BArch R 89/3505.

124 Vgl. dazu die Eingabe von W.Z. vom 12.7.1937 an den Reichsarbeitsminister, in: BArch R 89/3505. Vgl. dazu auch die erhaltene, umfangreiche Personalakte von W.Z. mit dem gesamten Schriftwechsel, in: Bestand Bonz.

125 Schreiben des Leiters der Reichsstelle an Gaber vom 30.5.1938, in: ebd.

126 Schreiben vom 21.2.1939, in: ebd.

127 Vgl. der Bericht des betroffenen Verwaltungsoberinspektors vom 20.2.1937 an den Reichsarbeitsminister in: BArch R 3901/5705. 
Personalreferent Gaber entwickelte sich letztlich aus der Perspektive der Behörde kontraproduktiv. Alle Betroffenen wandten sich letztendlich mit Gesuchen zur Wiedereinstellung und Verweisen auf die von der RfA ausgeübten Zwänge, denen keine gesetzliche Bestimmung zugrunde lag, direkt an das RAM. Dabei hatte Gaber, wohlwissend um die sich ergebenden dienstrechtlichen Probleme, den Betroffenen deutlich vermittelt, dass es „sehr gefährlich sei“, das RAM zur Entscheidung anzurufen, da Grießmeyer als RfA-Präsident die Pensionierungen „selbständig aus Wohlwollen zu den betroffenen Beamten wegen ihrer langjährigen treuen Dienste behandele“. ${ }^{128} \mathrm{Im}$ Schreiben eines der Betroffenen an das RAM heißt es:

Diese erschütternde Mitteilung über die Vernichtung meiner Existenz traf mich gänzlich unerwartet und brachte mich seelisch völlig aus dem Gleichgewicht. Bei der Kürze der mir gestellten Frist für den bedingungslosen Pensionierungsantrag blieb mir zunächst keine andere Entscheidung [...]. Meine Bitte, Herr Reichsminister, geht nun dahin, meine Wiedereinstellung in den Dienst der RfA zu den früheren Bedingungen verfügen zu wollen, da bisher keine gesetzliche Bestimmung ergangen ist, wonach der Abbau aller nichtarisch verheirateter Beamten gefordert würde. ${ }^{129}$

Letztlich gelang jedoch keinem der ,jüdisch belasteten“ früheren RfA-Beamten die Wiedereinstellung. Die rassische Säuberung der RfA-Belegschaft wurde jedoch gleichzeitig zum auch in den Folgejahren praktizierten Prinzip des Personalmanagements. Bei jeder Neueinstellung und vor allem auch jeder Heirat eines RfA-Beamten wurde der Nachweis der deutschblütigen Abstammung und beharrlich die Beibringung der entsprechenden Nachweise eingefordert. ${ }^{130}$ Wie erhalten gebliebene Personalakten zeigen, sollte der RfA-Personalreferent auch während des Krieges sein ideologisch-rigides Verhalten beibehalten und mit Dienststrafverfahren gegen Beamte vorgehen, die von Kollegen wegen Zweifeln am Endsieg denunziert worden waren.

Dass Gaber aber auch bei der politischen Säuberung keineswegs effizient gewesen war, zeigt der Fall einer Verwaltungsangestellten, auf die das Personalreferat allen Fragebogenaktionen und Überprüfungen der politischen Vergangenheit zum Trotz erst im Mai 1937 infolge der Verhaftung durch die Gestapo aufmerksam geworden war. Angeklagt wegen Hochverrats wurde die seit 1934 bei der RfA zunächst aushilfsweise, seit Mai 1935 dann auf Dauer angestellte Sachbearbeiterin, die zugleich aktiv im kommunistischen Jugendverband und in den Widerstandsplanungen der KPD gewesen war. Sie wurde zu sechs Jahren Zuchthaus verurteilt und im Zuge dessen auch aus der RfA entlassen. ${ }^{131}$ Überhaupt nahm es die RfA-Personalabteilung auch in anderen Fällen, in denen es ihr opportun schien, mit den NS-Rassevorstellungen dann doch

128 So die Wiedergabe von Gabers Äußerung im Schreiben der VOI K.B. an das RAM vom 6.7.1937, in: BArch R 89/3483.

129 Ebd., S. 2.

130 Vgl. dazu etwa Vermerk vom 7.12.1941 in einer der wenigen überlieferten Personalakten, hier des Überwachungsbeamten Gustav N., in: Bestand Bonz.

131 Vgl. die Personalakte von Hildegard B. in: ebd. 
nicht so genau. Im Juli 1939 etwa beantragte der Personalreferent die Verleihung des Treudienst-Ehrenzeichens an den Hausmaler des Sanatoriums Schwarzwaldheim. Das Problem war, dass dieser mit zwei volljüdischen Großeltern als Mischling ersten Grades galt. Nach den Kriterien des Erlasses zum Reichsbürgergesetz, so lautete das Argument, gelte er damit aber nicht als Jude im Sinne dieser Bestimmungen und daher stehe einer Verleihung nichts im Wege. ${ }^{132}$

Insgesamt waren jedoch nicht viele RfA-Beschäftigte von den Diskriminierungsmaßnahmen direkt betroffen; von einer massenhaften Entlassungswelle kann keine Rede sein. ${ }^{133}$ Doch auch die wenigen bekannt gewordenen Fälle sorgten für ein Klima der Angst und Anpassung, und vermutlich gab es auch eine in ihrem Umfang nicht näher zu bestimmende Dunkelziffer bei den politisch motivierten Beförderungsablehnungen. Tatsächlich geben die wenigen überlieferten Personalakten deutliche Hinweise darauf, dass bei den RfA-Beschäftigten in mehr als nur den offiziell als „jüdisch versippt“ gemeldeten Fällen schon bei geringsten rassischen „Bedenken“ die „freiwillige“ Beantragung der Versetzung in den Ruhestand durch das Personalreferat betrieben wurde. Einer Verwaltungssekretärin etwa wurde, obwohl seit 1911 von ihrem damaligen jüdischen Ehemann geschieden, die vorzeitige Pensionierung nahegelegt, da dieser Ehe eine Tochter entstammte und andernfalls die zwangsweise Pensionierung mit stark gekürzter Pension durchgesetzt würde. ${ }^{134}$ Letztendlich ließen sich die personalpolitischen Maßnahmen Grießmeyers und Gabers zwischen 1935 und 1938 unter der Formel zusammenfassen, die auch schon der RfA-Fachschaftsleiter Beutler im Februar 1937 gegenüber einem der ,jüdisch versippten“ Beamten geäußert hatte: Es handele sich „um zwei Gruppen von Beamten; bei der einen habe die RfA kein Interesse daran, sie zu entlassen, bei der anderen Gruppe habe die RfA kein Interesse daran, sie zu behalten“. ${ }^{135}$ Das Rasseargument war mithin nur vorgeschoben.

Um Wiedereinstellung und Rehabilitierung bemühten sich tatsächlich auch eine Reihe von RfA-Bediensteten, die 1933 aus politischen Gründen entlassen worden waren. Aber trotz des inzwischen spürbaren Mangels an qualifizierten Sachbearbeitern lehnte das RAM dies mit Verweis auf einen Erlass des Stellvertreters des Führers ab, denn der Zeitpunkt für eine Wiederverwendung dieser Entlassenen sei noch nicht gekommen. ${ }^{136}$ Erstaunlicherweise war die RfA-Personalstelle aber auch bei der Wiedereinstellung „Alter Kämpfer“ und angeblich während der Weimarer Republik wegen

132 Vgl. Schreiben zur Verleihung vom 12.7.1939, in: BArch R 89/3489.

133 So die Darstellung ohne weitere Nachweise bei Glootz, S. 74.

134 Viele dieser Fälle kamen erst im Zuge der Wiedergutmachung nach 1945 zum Vorschein. Vgl. Personalakten-Bestand Bonz. Vgl. hier die Akte von Frieda G. und deren Schreiben an die BfA vom 30.1. 1956, in: ebd.

135 Vermerk W.Z. über die Besprechung im Personalreferat vom 10.2.1937, in: Personalakte H.M., Bestand Bonz.

136 Erst im Laufe des Jahres 1939 und des Krieges wurden entsprechende Gesuche positiv beschieden und die Betroffenen, allerdings auch nur bei Nachweis der politischen Läuterung u.a. durch Parteieintritt und politisches Engagement, eingestellt. Vgl. einige Fälle in den Personalakten, Bestand Bonz. 
ihrer nationalsozialistischen Überzeugung entlassenen RfA-Bedienstete relativ unbestechlich geblieben. Das bereits im Juni 1933 erlassene „Gesetz über die Aufhebung der im Kampf für die nationale Erhebung erlittenen Dienststrafverfahren und sonstigen Maßregelungen“ hatten eine ganze Reihe Personen, die im Zuge der zwischen 1924 und 1933 erfolgten Entlassungswellen bei der RfA aus der Behörde ausgeschieden waren, zu nutzen versucht, um ihre Wiedereinstellung zu betreiben. Bei genauerem Hinsehen zeigt sich allerdings meist, dass die Entlassungen nicht aus politischen Gründen, sondern wegen unterdurchschnittlicher Arbeitsleistungen oder gar dienstrechtlicher Verfehlungen erfolgt waren. ${ }^{137}$ Einige RfA-Beschäftigte suchten zudem auf andere Weise von dem Erlass zu profitieren und verlangten - wie im Fall eines 1924 entlassenen, 1929 jedoch wieder in der RfA eingestellten Verwaltungsinspektors und inzwischen SA-Sturmmanns - eine Neufestsetzung der Besoldung entsprechend dem Dienstalter, das sich ohne Unterbrechung der Laufbahn ergeben hätte. ${ }^{138}$ Hier, wie auch in einer ganzen Reihe anderer Fälle jedoch widerstand die RfA den Begehrlichkeiten und hielt trotz zum Teil massiver politischer Interventionen etwa durch Empfehlungs- und Antragsschreiben einer Gauleitung an ihren damaligen Entlassungs- und Besoldungsbeschlüssen fest. ${ }^{139}$ Auch die diversen Anordnungen Hitlers über Stellenvorbehalte für Versorgungsanwärter und Nationalsozialisten sowie Sonderaktionen zur Unterbringung von Amtsleitern der NSDAP und von SA-Führern blieben, anders als man etwa erwarten könnte, in der RfA-Personalpolitik ohne größere Wirkung. Zwar hatte das Direktorium der RfA schon im Mai 1934 beschlossen, den bei der Behörde tätigen Dienstanfängern aus dem Stand der Zivilanwärter, die sich vor dem 30. Januar 1933 nachweislich in den nationalen Verbänden wie NSDAP, SA, SS und HJ betätigt hatten, eine auf 170 RM erhöhte Monatsvergütung zu gewähren. ${ }^{140}$ Aber Anfang 1937 zeigte sich, dass von den im Laufe des Jahres 1936 ursprünglich 74 offenen Stellen des einfachen mittleren Bürodienstes sämtliche wiederbesetzt worden waren, jedoch mangels Nachfrage nur eine der eigentlich 30 reservierten Stellen mit einem dieser „politischen“ Versorgungsanwärter, einem ehemaligen Berufssoldaten. Im weit höhere Qualifikationen erforderlichen Bürodienst der Expedienten waren eigentlich elf Stellen freigeworden, die aber sämtlich aufgrund der vom RAM angeordneten Änderung der Dienstordnung weggefallen waren. Alles in allem waren am Schluss des Kalenderjahres 1936 bei der RfA 38 Versorgungsanwärter

137 Vgl. dazu eine Reihe von Fällen in: BArch R 89/3478, darunter vor allem der Fall des schon am 1.1. 1924 zwangsweise in den Ruhestand versetzten RfA-Verwaltungsinspektors Julius S. Dessen Fall zog sich, unter anderem auch weil S. auf die ablehnenden Bescheide der RfA mit Eingaben und Gesuchen an das RAM und Hitlers Stellvertreter Rudolf Hess antwortete, das ganze Jahr 1935 über hin.

138 Vgl. den Fall Karl B., in: BArch R 89/3479.

139 Vgl. Schreiben der RfA, Präsidentenabteilung - auffälligerweise nicht von Grießmeyer, sondern von Haenel unterzeichnet -, an das RVA vom 6.9.1935, in: ebd.

140 Vgl. dazu die entsprechenden Vergütungsregelungen und diversen Nachweise in einigen Personalakten, in: Bestand Bonz. Diese Vergünstigung entfiel zum 1.10.1938. Vgl. dazu auch Bonz-MS, S. 72 sowie auch BArch R 89/3478, RfA-Erlass zu den Anstellungsgrundsätzen vom Februar 1933 mit den Ergänzungsparagraphen. 
auf Privatdienstvertrag beschäftigt, 30 ehemalige Berufssoldaten und acht ehemalige Angehörige der Schutzpolizei. ${ }^{141}$ Die Fälle, in denen arbeitslose Angestellte ihre Einstellungsgesuche bei der RfA mit Nachweisen der politischen Tätigkeit sowie Bescheinigungen verschiedener Parteistellen ergänzten, um ihre Chancen als Dienstanfänger $\mathrm{zu}$ verbessern, nahmen allerdings deutlich $\mathrm{zu} .{ }^{142}$

Tatsächlich gab es vor allem bei Beförderungen eine nachweisbare Bevorzugung politisch aktiver Nationalsozialisten auf Kosten anderer Bediensteter mit gleicher, wenn nicht sogar besserer Qualifikation und Erfahrung sowie mit gleicher oder gar größerer Anzahl geleisteter Dienstjahre. Bei einigen, erst wenige Jahre zuvor bei der RfA eingetretenen Regierungsassessoren ist ein auffallender zeitlicher Zusammenhang zwischen Parteieintritt und raschem Aufstieg durch Beförderung festzustellen. ${ }^{143}$ Eine schnelle Karriere vom einfachen Betriebsassistenten zum Beamten machte auch der DAF-Betriebsobmann bei der RfA. ${ }^{144}$ Von einer Beförderung vom Verwaltungsamtmann zum Regierungsrat und der Höherstufung des Besoldungsdienstalters profitierte auch der als DAF-Verbindungsmann zur RfA eingesetzte RfA-Beamte Robert Reinecke. Er war ebenso ein NSDAP- wie RfA-Urgestein, denn seit 1913 Expedient und Kalkulator war er schon im September 1922 Parteimitglied geworden und hatte in Würzburg auch die dortige Ortsgruppe gegründet. ${ }^{145}$ In Würdigung dieser Verdienste erschien es Grießmeyer denn auch angebracht, die Beförderung anlässlich des Führergeburtstags vornehmen zu können. Überhaupt standen auffallend viele „alte Kämpfer“ bei den Ernennungen zu höheren Dienstgraden obenan, wie etwa der seit August 1934 als juristischer Hilfsarbeiter bei der RfA tätige Dr. Otto Dageförde, der im Juli 1937 zum Regierungsrat ernannt wurde. Dageförde war seit November 1932 NSDAP-Mitglied und hatte sich, wie in seiner Personalakte explizit vermerkt worden war, schon seit Mitte des Jahres 1930 ,zielbewusst für den Sieg der nationalsozialistischen Revolution eingesetzt“.${ }^{146}$ Auch außerhalb der RfA hatte er Karriere gemacht und es zum SS-Unterscharführer in der Reichsführung des SD-Hauptamtes gebracht. Bei vielen Parteimitgliedern gab es offensichtlich geradezu die feste Erwartung einer gegenüber anderen Bediensteten bevorzugten Beförderung. Im September 1936 etwa hatte sich der als Überwachungsbeamter tätige Verwaltungsoberinspektor Karl S. mit Hinweis auf seine seit Januar 1931 bestehende Parteimitgliedschaft beim Stellvertreter des Führers über seine ausstehende Beförderung auf eine Amtmannstelle beschwert.

141 Schreiben der RfA an das RAM bzw. RVA vom 26.1.1937, in: BArch R 89/3387.

142 Vgl. dazu eine Reihe von Beispielen in den erhaltenen Personalakten, etwa die von Erwin R. sowie Günther M., in: Bestand Bonz.

143 Vgl. dazu das Schreiben zur Ernennung vom 8.6.1939, in: BArch R 89/3505, Bl. $173 \mathrm{ff}$.

144 Vgl. dazu die Präsidialverfügung vom 18.5.1937, in: RfA-Archiv Nr. 2.

145 Vgl. Schreiben zur Beantragung der Ernennung vom 1.4.1936, in: BArch R 89/3479.

146 Vgl. dazu den Vorgang mit einem Schreiben Grießmeyers an das RAM vom 13.7.1937, in: BArch R 89/3482. Als weiteres Beispiel für die bevorzugte Beförderung eines „alten Kämpfers“ war die Ernennung des Regierungsassessors Albrecht von Altrock im März 1939 zum Regierungsrat. Altrock war seit August 1932 Parteimitglied gewesen. Vgl. dazu Schreiben vom 22.3.1939, in: BArch R 89/3505. 
Zwar hatte Grießmeyer, wie er auf die darauffolgende Anfrage aus dem RVA hin mitteilte, alle drei in Zukunft freiwerdenden Amtmannstellen bei den Überwachungsbeamten für die drei parteiältesten Bewerber vorgemerkt. Das Pech des S. aber war, dass darunter ein Verwaltungsinspektor war, der wesentlich früher in die NSDAP eingetreten war und daher bei der Beförderung zuerst zum Zug kam. ${ }^{147}$ Zudem zeigte sich bei der genaueren Nachprüfung, dass S. sein Überwachungsamt wegen zahlreicher parteiamtlicher Dienstgeschäfte kaum ausübte. Und dann tauchte noch ein Schreiben der NSDAP-Ortsgruppe Bad Oynhausen, der Heimatgemeinde des Beamten, vom Januar 1934 auf, in dem ein vernichtendes Urteil über die Charaktereigenschaften von S. gefällt wurde und das mit dem Satz endete: „Für die Stadtgemeinde sowohl als auch für die Bewegung würde es ein Segen sein, wenn S. möglichst weit von hier weg versetzt würde." ${ }^{148}$

Ein besonders markantes Beispiel für parteipolitische Patronage bei den Beförderungen war Otto Braß, seit 1917 bei der RfA und im März 1930 NSDAP-Mitglied geworden, seit 1934 auch Oberführer der SS und NSDAP-Reichstagsmitglied. Obschon im April 1933 noch einfacher Verwaltungsoberinspektor, der zwischen 1934 und 1936 eine politische Karriere als Stabsführer der SS in Königsberg sowie in Berlin begann, wurde Braß seine Stelle quasi reserviert. Am 1. Januar 1937 trat er wieder als Referent in der Gesundheitsfürsorgeabteilung ein und wurde nur wenig später, im März 1938 zum Regierungsrat in den höheren Dienst befördert. ${ }^{149}$ Nicht zuletzt machte auch Grießmeyers Personalreferent Dr. Erwin Gaber selbst eine schnelle Karriere bei der RfA. Parteimitglied seit April 1933 und seit Juli 1932 als juristischer Hilfsarbeiter (Assessor) bei der RfA, wurde Grießmeyers Vertrauter im Dezember 1939 zum Oberregierungsrat ernannt. ${ }^{150}$ Es gab aber durchaus auch Beispiele, bei denen die fachlichen Qualitäten und Kompetenzen letztlich doch gegenüber poltischen Bewertungen den Ausschlag gaben. Dr. Hans-Wolf Dockhorn, medizinischer Referent in der Gesundheitsfürsorgeabteilung der RfA, wurde von Grießmeyer im Januar 1938 zur Beförderung als Regierungsrat vorgeschlagen, obwohl er Nicht-Pg war und von den Parteistellen über seine Teilnahme am Tutzinger „Reichslager für Beamte“ ein verheerendes politisches Zeugnis ausgestellt bekommen hatte. ${ }^{151}$ Opfer der Benachteiligungen bei der Beför-

147 Vgl. das Schreiben Grießmeyers an das RVA vom 10.8.1936 sowie den weiteren Schriftwechsel dazu in: BArch R 89/3480.

148 Abschrift des Briefes vom 25.1.1934, in: ebd.

149 Braß’ Beförderungsweg bei der RfA lief auch im Krieg weiter. Obschon zwischenzeitlich als Landrat im Sudetengau tätig und seit September 1939 als Kompanieführer einer Einheit der Waffen-SS eingezogen, wurde für ihn im Oktober 1941 die Einweisung in eine Planstelle der Besoldungsgruppe A 2 a vorgenommen. Vgl. dazu das Schreiben vom 4.10.1941, in: BArch R 89/3505. Vgl. auch den WikipediaEintrag zu Braß, https://de.wikipedia.org/wiki/Otto_Bra\%C3\%9F, zuletzt aufgerufen am 24.10.2017. 150 Vgl. dazu das Schreiben und den Ernennungsvorschlag vom 1.12.1939, in: Barch R 89/3506.

151 Vgl. Schreiben vom 25.1.1938, in: Barch R 89/3504. „Der ärztliche Referent Dr. med. Hans-Wolf Dockhorn, welchen Sie zur Ernennung zum Regierungsrat auf Lebenszeit vorschlagen, hat an dem Lehrgang Nr. 26 des Reichslagers für Beamte teilgenommen“, heißt es in dem Zeugnis. „Dockhorn nahm an der Lagergemeinschaft keinen inneren Anteil, da ihm jedes Gemeinschaftsempfinden fehlt. 
derung wegen Nichtzugehörigkeit zur NSDAP gab es dennoch zuhauf. Doch deren Fälle wurden wenn überhaupt erst nach 1945 bekannt. Ein im Oktober 1916 bei der RfA eingetretener Verwaltungsinspektor beklagte sich nach Kriegsende:

\begin{abstract}
Wie mir zur Kenntnis gelangte, bin ich auch wiederholt zur Beförderung vorgeschlagen worden, jedoch scheiterte diese unter anderem daran, dass ich nicht Mitglied der NSDAP war und keine Mitarbeit in einer Gliederung der Partei nachweisen konnte. Eine Zurücksetzung erblicke ich auch darin, dass andere Beamte, die zur gleichen Zeit oder später bei der RfA eingetreten sind, ohne besondere dienstliche Veranlassung lediglich aufgrund ihrer Parteizugehörigkeit zu Oberinspektoren befördert worden sind, obwohl sie dem Dienstalter nach noch nicht hätten befördert werden können. ${ }^{152}$
\end{abstract}

Gleichwohl war die RfA kein Sammelbecken von überzeugten Nationalsozialisten. Nach einer Erhebung vom Februar 1939 waren 460 der damals 1687 Bediensteten Parteimitglieder, das waren 24 Prozent. ${ }^{153}$ Ihr Anteil variierte jedoch zwischen den einzelnen Gruppierungen und Dienstgraden erheblich. Den „Nazifizierungsgrad“ mit 65 Prozent wiesen die Angestellten des höheren Dienstes auf, gefolgt von den Beamten des höheren Dienstes, unter denen fast jeder Zweite NSDAP-Mitglied war. Bei den Unterbeamten betrug der Parteizugehörigkeitsanteil 32 Prozent, bei den Beamten des mittleren Dienstes 27 Prozent, und am Ende rangierten mit 17 bzw. 16 Prozent die Arbeiter und einfachen Büroangestellten. Im Vergleich zu den anderen Versicherungsträgern stand die RfA damit aus damaliger Sicht des RVA bei weitem am schlechtesten da, denn in der Unfall- und der Invalidenversicherung etwa lagen die Zahlen der Parteimitglieder unter den Bediensteten bei Beamten wie Angestellten um bis zu zehn Prozent höher. ${ }^{154}$ Bis Juli 1940 sank der Grad der Parteizugehörigkeit unter den RfA-Beschäftigten sogar leicht auf 22,2 Prozent. ${ }^{155}$ Mit Ausnahme der Präsidialabteilung, in der Vizepräsident Schaefer einziger Nicht-Pg war, waren alle wichtigen Abteilungsleitungspositionen sowohl in der Vermögensverwaltung als auch in der Leistungs- und Versichertenabteilung mit Nicht-Parteimitgliedern besetzt und keinen politisch motivierten Personalwechseln unterworfen. Viele der jüngeren RfA-Beamten unter den Parteimitgliedern sollten aber, wie Gaber oder Dr. Rudolf Schmidt - seit 1934

Er ist ein typischer Einzelgänger. Außerdem hat er kein soldatisches Empfinden und zeigte eine mangelhafte Dienstauffassung. In den Arbeitsgemeinschaften des Lagers war er ungenügend. Aus seiner im Lehrgang gezeigten Gesamthaltung kann nur gefolgert werden, dass ihm die nationalsozialistische Weltanschauung noch ein völlig fremder Begriff ist. Die Pflichten eines Beamten im nationalsozialistischen Staat hat er noch nicht erkannt. Ihm wurde von der Lagerleitung das Prädikat ,nicht genügend‘ gegeben. Seine Teilnahme an einem Wiederholungslehrgang ist vor der planmäßigen Anstellung notwendig." Schreiben vom 6.5.1938, in: ebd.

152 Schreiben vom 6.7.1945, in: Wiedergutmachungsfall A.G., Personalakten, Bestand Bonz.

153 Vgl. Schreiben an das RVA vom 10.2.1939, in: BArch R 89/3485, Bl. 160.

154 Vgl. die vergleichende Aufstellung vom 17.2.1939, in: ebd.

155 Vgl. das umfangreiche Verzeichnis der NSDAP-Mitglieder bei der RfA nach dem Stande vom 1.7. 1940, in: BArch R 89/3493. 
bei der RfA -, bis 1938 zum Regierungsrat in der Leistungsabteilung aufsteigen und nach 1945 Karriere machen. ${ }^{156}$

Ungeachtet dessen wurde unter Grießmeyer der Ausbau der RfA zu einer modernen Leistungsverwaltung vorangetrieben. Seit dem Ende der Wirtschaftskrise war die Behörde im Zuge der einsetzenden konjunkturellen Erholung, des Zustroms an Versicherten und der zusätzlichen Aufgaben erheblich expandiert. Aus den 1228 Beamten und Angestellten, die 1931 in der Behörde arbeiteten, waren inzwischen 1768 RfA-Beschäftigte geworden. Außer den Veränderungen in der Leitungsstruktur, dem Wegfall von zwei der drei stellvertretenden Direktoren Grießmeyers und der Schaffung eines „Vizepräsidenten der RfA“, der Aufsichtsbehörde und der Vertretungsorgane hatte sich an der Behördenstruktur auf der Ebene des operativen Verwaltungshandelns selbst nicht viel geändert. Nach wie vor gab es vier Abteilungen mit ihren Unterabteilungen, Dienststellen und Referaten, die allerdings an Zahl deutlich zugenommen hatten. Bei der Abteilung I Versicherung gab es etwa vier Referate und sechs Dienststellen mehr, in der Leistungsabteilung waren zusätzlich drei Referate und zwei Dienststellen eingerichtet worden. Im Detail selbst hatte es allerdings im Sinne einer gleichsam permanenten Optimierung der Verwaltungsabläufe laufend Veränderungen in der Geschäftsverteilung der Referate gegeben. ${ }^{157}$ Um die Einheitlichkeit des Geschäftsganges für die Leistungsabteilung bei der Bearbeitung der Rentensachen und für die Versicherungsabteilung in Fragen der Berufsfähigkeit auch hinsichtlich der ärztlichen Begutachtung sicherzustellen, war etwa im Oktober 1934 die Bearbeitung der allgemeinen ärztlichen Angelegenheiten in der Hand eines ärztlichen Referenten zusammengefasst worden. ${ }^{158}$

Was wie eine einfache Verbesserung der Verwaltungsorganisation aussah, war in der Praxis ein kompliziertes Austarieren von Abteilungskompetenzen mit weitreichenden Rückwirkungen auf den jeweiligen Geschäftsgang und die verwaltungsmäßigen Entscheidungsprozesse. ${ }^{159}$ Im August 1935 wurde zudem unter der Bezeichnung Abteilung I Leistung 14 eine neue zentrale Auslandsstelle geschaffen, und im November 1936, um die Präsidialabteilung nach der Übernahme der Aufsicht über die Ersatzkassen von Aufgaben zu entlasten, wurden die Angelegenheiten des Überwachungsdienstes wie schon zu früheren Zeiten in die Abteilung I Leistung zurückverlagert. Die rasante Vermehrung nicht nur der Versicherten-, sondern auch der Rentnerzahl machten im Oktober 1936 Neueinstellungen in der Renten- wie Zinsenbuchhalterei notwendig. Auch bei den Aufbewahrungsfristen für Akten und im

156 Vgl. das Schreiben Grießmeyers zur Ernennung von Schmidt in: BArch R 89/3484, Bl. $163 \mathrm{ff}$. Schmidt wurde in den 1950er Jahren zweiter Präsident der RfA-Nachfolgebehörde BfA.

157 Vgl. dazu etwa die Geschäftsverteilungspläne der Leistungsabteilung vom 1.6.1935 und vergleichend dazu vom 1.3.1938, in: RfA-Archiv Nr. 73.

158 Vgl. Präsidialverfügung vom 4.10.1934, in: RfA-Archiv Nr. 72 a.

159 Vgl. dazu das siebenseitige Schreiben Kochs vom 17.6.1935 über die vielfach nach wie vor unklaren Verfahrensregelungen zwischen Leistungs- und Heilverfahrensabteilung, insbesondere im Fall des Zusammentreffens von Heilverfahren mit einem Ruhegeldverfahren in: RfA-Archiv Nr. 20. 


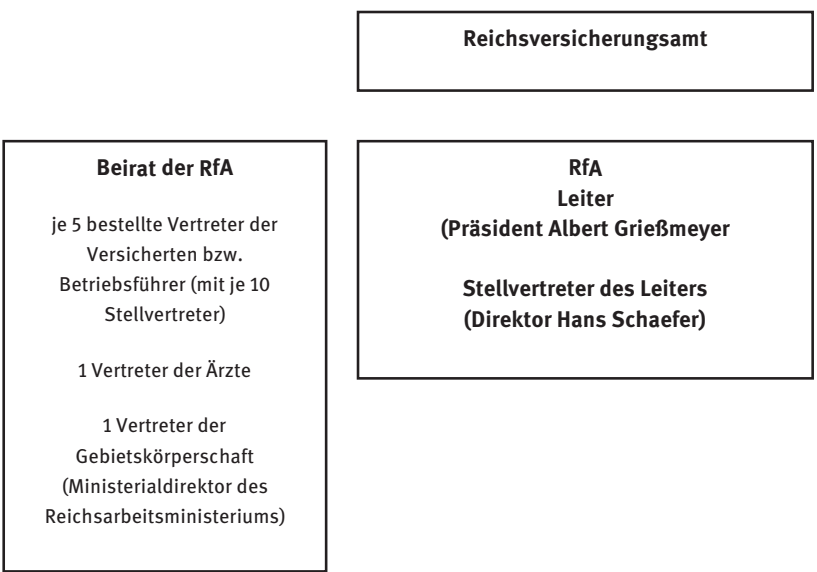

\begin{tabular}{|c|}
\hline Präsidialabteilung \\
(Beirat, Personal, \\
Haushalt, Allgem. \\
Dienst- und \\
Geschäftsbetrieb, \\
Aufsicht über die \\
Ersatzkassen) \\
Unterabteilungsleiter \\
2 Referenten, 1 \\
Bürodirektor \\
(4 Dienststellen mit 371 \\
Arbeitskräften) \\
Hauptkasse \\
(1 Hauptkassendirektor; \\
2 Dienststellen mit 62 \\
Arbeitskräften) \\
\hline
\end{tabular}

\begin{tabular}{|c|}
\hline Abteilung I \\
Versicherung Leistungen \\
Abteilungsleiter (Direktor) \\
je 1 Unterabteilungsleiter \\
13 Referenten, 1 Bürovorsteher \\
14 Dienststellen mit 393 Arbeitskräften \\
(Rechtsfragen, Schriftwechsel mit \\
Versicherten und Arbeitgeber etc.) \\
Kontenverwaltung \\
1 Bürovorsteher \\
4 Dienststellen mit 142 Arbeitskräften \\
13 Referenten und 1 Bürovorsteher \\
15 Dienststellen mit 412 Arbeitskräften \\
Bearbeitung der Renten und \\
Erstattungsanträge, \\
Rentenfestsetzungen etc.
\end{tabular}

\begin{tabular}{|c|c|}
\hline Abteilung II & Abteilung III \\
\hline $\begin{array}{l}\text { Gesundheits- } \\
\text { fürsorge }\end{array}$ & $\begin{array}{l}\text { Vermögens- } \\
\text { verwaltung }\end{array}$ \\
\hline $\begin{array}{l}\text { Abteilungsleiter } \\
\text { (Direktor) }\end{array}$ & $\begin{array}{l}\text { Abteilungsleiter } \\
\text { (Direktor) } \\
2 \text { Unterabteilungs- }\end{array}$ \\
\hline $\begin{array}{c}2 \text { Unterabteilungs- } \\
\text { leiter }\end{array}$ & leiter \\
\hline 19 Referenten 1 & 14 Referenten 1 \\
\hline Bürovorsteher & Bürovorsteher \\
\hline $\begin{array}{l}8 \text { Dienststellen } \\
\text { mit } 200\end{array}$ & $\begin{array}{l}9 \text { Dienststellen } \\
\text { mit } 120\end{array}$ \\
\hline Arbeitskräften & Arbeitskräften \\
\hline
\end{tabular}

Schaubild 2: Organisation der Reichsversicherungsanstalt für Angestellte (RfA) 1937 Quelle: 25 Jahre Angestelltenversicherung, S. 191.

Schriftverkehr gab es nennenswerte Änderungen. Im Frühjahr 1935 wurde etwa auf Veranlassung des RVA „mit Rücksicht auf die Durchführung des Gesetzes zur Verhütung erbkranken Nachwuchses“ die Aufbewahrungsfrist von Akten erheblich verlängert, um das in den Versicherungsakten enthaltene Material für die Erb- und Rassenpflege nutzbar zu machen. ${ }^{160}$ Ende April 1937 erließ Grießmeyer zudem eine

160 Rundschreiben des RVA an die Sozialversicherungsträger vom 28.2.1935, in: BArch R 89/3457 sowie die Verfügung zur Aussonderung von Akten der Leistungsabteilung vom 5.4.1935, in: ebd. 
Präsidialverfügung zum Schriftverkehr, in dem genau geregelt wurde, wer wann mit welcher Formel die jeweiligen Schriftstücke unterzeichnen durfte. ${ }^{161}$ Formal unterzeichnet, ob in Originaltinte oder als Unterschriftenstempel, waren sämtliche Schreiben und Bescheide, die die Ruhrstraße verließen, von Grießmeyer. Aber nur diejenigen, die im Briefkopf auch „Der Präsident“ trugen, waren ihm selbst zuzuschreiben, alle anderen Briefe, in denen etwa „Der Leiter“ (in dem von Beamten und Angestellten des höheren Dienstes geführten Schriftwechsel) oder „In Vertretung“ bzw. „Im Auftrag“ stand, stammten von den Unterabteilungsleitern und Referenten. ${ }^{162}$

Die Verwaltungsarbeit der RfA stand ganz im Zeichen einer Rationalisierung und Automatisierung bzw. Mechanisierung der Geschäftsabläufe. Der Einsatz von Lochkartenmaschinen, Addier- und Rechenmaschinen, Schreibmaschinen und Adressiermaschinen, Sortiermaschinen, Prägemaschinen und Tabellendruckern, der schon zuvor bei der RfA Einzug gehalten hatte, wurde angesichts von 436.000 Rentenempfängern und jährlich rund 27.000 neu hinzukommenden Rentnern im Herbst 1937 massiv ausgebaut. ${ }^{163}$ Man setzte dabei nach wie vor auf die Beratungskompetenz der erfahrenen Firma Powers, aber auch von Siemens. Es waren kleine, aber sich umso massiver nachteilig auf die Arbeitsabläufe auswirkende Engpässe, die es zu beheben galt. Die noch Ende der 1920er Jahre angeschafften sechsstelligen Rechenmaschinen etwa reichten infolge der immer mehr anwachsenden Höhe und Zahl der Beiträge längst nicht mehr aus und mussten durch zehnstellige Rechenmaschinen ersetzt werden. In einem Vermerk an den Bürovorsteher der Leistungsabteilung vom Oktober 1937 heißt es:

Ferner sind an den Berechnungen, die durch die Maschinen vorgenommen werden müssen, sowohl die Rechendamen als auch die Prüfer beteiligt, insgesamt 17 Personen, die bei dem derzeitigen Stand einen dauernden Austausch der Maschinen erforderlich machen. Für die glatte Abwicklung des Dienstbetriebes ist dieser Zustand natürlich sehr störend. ${ }^{164}$

Vor allem die Kontenverwaltung litt unter den rasant steigenden Arbeitsanforderungen. Zur Beseitigung der sich drohend abzeichnenden Engpässe allein im Raumbedarf für Kartenschränke hatte man kurzzeitig überlegt, sogenannte Sammelkonten einzurichten. Aber nachdem interne Berechnungen ergeben hatten, dass die dafür notwendige Übertragung der damals vorhandenen rund 14 Mio. Versicherungskarten mindestens zwei Jahre dauern und Kosten von fast zwei Mio. RM verursachen würde,

161 Vgl. Präsidialverfügung vom 29.4.1937, in. RfA-Archiv Nr. 2.

162 Ohne Kenntnis dieser Verwaltungspraxis besteht die Gefahr zu Fehlurteilen, wie sie etwa Mierzejewski unterlaufen, der praktisch sämtliche RfA-Schreiben inhaltlich und damit auch verantwortungsmäßig Grießmeyer direkt zuordnet. Der RfA-Präsident und die RfA werden dadurch als Einheit begriffen, was der Realität der Behörde völlig widerspricht.

163 Vgl. dazu etwa das Schreiben der Büroleitung der Abt. I über den Bedarf an Büromaschinen vom 13.10.1937, in: RfA-Archiv Nr. 13.

164 Der Vermerk vom 7.10.1937, in: ebd. 
ließ man das Projekt wieder fallen. ${ }^{165}$ Die Arbeitsabläufe und die Organisation des Dienstbetriebs in der RfA erschienen allerdings vielen anderen Versicherungsträgern durchaus vorbildlich. Auf dem Internationalen Kongress der Sozialversicherungsfachleute in Budapest, der unter dem Oberthema „Die Rationalisierung der Sozialversicherung“ stand, referierte RfA-Vizepräsident Schaefer über „Die Rentenzahlung in der Deutschen Angestelltenversicherung unter Verwendung des Lochkartenverfahrens“ ${ }^{166}$ Er schilderte detailliert den Stand der bei der RfA inzwischen erreichten Mechanisierung des Verwaltungsbetriebes. Im Mittelpunkt standen dabei die verschiedenen Maßnahmen, die man eingeführt hatte, um auch bei den rasant steigenden Versicherten- und Rentenempfängerzahlen die rechtzeitige und richtige Zahlung der Renten zu gewährleisten. Das waren zum einen die Bereitstellung der monatlichen Zahlungsunterlagen für die Post, über die die Auszahlung der Renten an die Empfänger erfolgte, zum anderen die besondere Buchführung über die gezahlten Beträge. Die Grundlagen für diese Mechanisierung des Rentenauszahlungs- und Buchungsverfahrens mit Hilfe von Lochkartenmaschinen waren wie erwähnt schon 1930 gelegt worden, seitdem war das Verfahren laufend weiterentwickelt und modernisiert worden, und deutlichster Ausdruck für den Erfolg der Maßnahme waren die niedrigen Verwaltungskosten. Ein Ende Dezember 1938 vorgenommener Vergleich des Rentenund Personalbestands infolge Umstellung der Rentenbuchhaltung auf das Lochkartensystem gegenüber dem Jahr 1928 zeigte einen gleichgebliebenen Personalbestand von 61 bei allerdings einer Vervierfachung des Rentenbestandes und damit potenziellen Arbeitsaufwandes. Die einst über 30 Buchhalter waren dabei zunehmend von Prägerinnen und Locherinnen sowie Zuarbeiterinnen verdrängt worden, unter dem Strich konstatierte man jährliche Kosteneinsparungen von 730.620 RM. ${ }^{167}$

Auch die gleichfalls ausgebauten regelmäßigen Kontrollen der in der Präsidialabteilung angesiedelten Prüfstelle zeigten, dass die Qualität des Verwaltungshandels hoch und die Mängelquote der Bescheide und Bewilligungen der Leistungsabteilung niedrig war. ${ }^{168}$ Mit Hilfe der Lochkarten hatte man in der RfA auch ein ausgeklügeltes Verfahren zur ebenso schnellen wie exakten Durchführung statistischer Erhebungen entwickelt. Das Ergebnis waren seit 1935 rasch aufeinanderfolgende Statistische Sonderhefte, in denen das umfangreiche Material an laufenden Renten versicherungstechnisch ausgewertet wurde. Das betraf etwa die statistische Auswertung der

165 Vgl. Notiz der Kontenverwaltung vom 10.8.1934, in: RfA-Archiv Fach 115, Nr. 3.

166 Vgl. den Vortrag in: Die Rationalisierung der Sozialversicherung: Die Arbeiten des ersten Internationalen Kongresses der Sozialversicherungsfachleute, Budapest 1935, S. 86-94. Vgl. auch das Antwortschreiben der RfA auf eine entsprechende Anfrage zum Einsatz des Lochkartensystems durch die Ungarische Landes-Sozialversicherungsanstalt vom 14.12.1935, in: RfA-Archiv Nr. 202.

167 Vgl. die Gegenüberstellung im Bd. 3 der Anlagen zum Revisionsgutachten der RVA, S. 18, in: BArch R 89/3453.

168 Vgl. dazu etwa die Prüfberichte für die Zeit vom 2.6. bis 14.7.1937, in der 220 Rentenakten auf sachliche und rechnerische Richtigkeit überprüft worden waren. Bei 21 Akten ergaben sich meist kleinere Beanstandungen. Bei der Prüfung von gleichfalls 220 Akten im Juli 1938 ergeben sich nur 10 Beanstandungen. Vgl. dies und weitere Prüfberichte in: RfA-Archiv Nr. 22 und Nr. 23. 
laufenden Witwenrenten des Kalenderjahrgangs 1934 und dann auch 1935 sowie die aktuellen, höchst dynamischen Rentenbewegungen, d.h. Bestand und Aufbaugliederung der aktiven Versicherten der RfA, deren Neuzugänge, Berufsunfähigkeit und Aktivensterblichkeit. ${ }^{169}$ In der mathematisch-statistischen Durchdringung ihres Versichertenbestandes war die RfA damit anderen Versicherungsträgern weit voraus. Das war auch das Ergebnis einer umfassenden Betriebsprüfung, die das RVA zwischen Oktober 1938 und April 1939 bei der RfA durchführte. Akribisch wurden innerhalb dieser über ein halbes Jahr dauernden Prüfung sämtliche Arbeitsabläufe in den einzelnen Abteilungen und Dienststellen und die vielfältigen Organisationsstrukturen der RfA durchleuchtet. Dazu kamen Besichtigungen und Kontrollen bei zahlreichen Überwachungsstellen sowie einer Reihe von Heilstätten der RfA. Die Ergebnisse fanden sich dann in einem 104-seitigen Abschlussbericht, ergänzt durch sechs umfangreiche Anlagenbände, insgesamt 522 Seiten. ${ }^{170}$

Einen konkreten Anlass für diesen Aufwand gab es nicht. Es mag sein, dass die RVA damit nur ihre Machtposition als Aufsichtsbehörde demonstrieren wollte. Die Prüfergebnisse vermittelten dabei von der RfA das Bild einer modernen Leistungsverwaltung, das auch die Kontrolleure aus dem RVA merklich beeindruckte. Auch wenn einige der Abläufe aus heutiger Sicht umständlich erscheinen, wie etwa die Organisation der Zentralkanzlei, so waren sie für damalige Verhältnisse und im Verglich zu anderen Behörden durchaus modern und effizient. In der Kanzlei arbeiteten 42 Stenotypistinnen, und die Kanzleiarbeit wurde vom Kanzleileiter so auf die einzelnen Maschinenschreiberinnen verteilt, dass diese möglichst immer für das selbe Arbeitsgebiet der einzelnen Abteilungen schrieben. „Hierdurch lernen sie die Handschrift der Sachbearbeiter kennen und werden mit den fachtechnischen Ausdrücken vertraut, wodurch Rückfragen vermieden werden. “171 Jede Stenotypistin hatte täglich etwa 50 bis 60 Schreiben zu verfassen, die dann von Lesegruppen zu je zwei Leserinnen gegengelesen und beglaubigt wurden. Für größere Abschriften etwa ärztlicher

169 Vgl. Statistisches Sonderheft der RfA Nr. 1 und 2 (1935) und Sonderheft Nr. 3 (1936), in: RfA-Archiv, Handakte Granzow. Bis 1939 erschienen insgesamt acht Statistische Sonderhefte der RfA. Trotz des Maschineneinsatzes war der Aufwand für die Erstellung der Statistiken enorm. Im März 1937 erstellte die Leistungsabteilung eine exemplarische Auswertung des Jahrgangs R 1871. Hierbei kamen 15.000 Rentenempfänger in Frage, mit deren Auswertung zwei Locherinnen 80 Stunden ununterbrochen beschäftigt waren. Die umfangreicheren Statistiken erstreckten sich allerdings auf bis zu 150.000 Rentenempfänger, wofür zur Auswertung rechnerisch 80 Tage und eine zusätzliche Sortiermaschine mit zwei Mann Bedienung sowie zwei weitere Locherinnen notwendig waren. Vgl. Vermerk des Büroleiters Minow an Koch vom 24.3.1937, in: RfA-Archiv Nr. 78.

170 Vgl. Aktenvermerk zur Vorbesprechung über das Prüfprogramm vom 22.11.1938 sowie „Bericht über die Geschäftsprüfung bei der Reichsversicherungsanstalt für Angestellte 1938/39“, in: BArch R 89/ 3450. Die Anlagenbände befassten sich mit folgenden Bereichen: Bd. 1: Präsidialabteilung, Bd. 2: Prüfung von Überwachungsstellen, Bd. 3: Sammlung von Dienstanweisungen und Beschreibung des Lochkartenverfahrens, Bd. 4: Diverses zu den Heilanstalten, Bd. 5: Bericht über die Besichtigung des RfA-eigenen Gutes Elslaake sowie Diverses zur Gagfah und Bd. 6: Sammlung von Vordrucken der Leistungsabteilung.

171 Bericht, S. 15, in: ebd. 
Gutachten gab es bereits eine Lichtbildstelle mit Fotokopierer. In dem Prüfbericht hervorgehoben wurde auch die Bedeutung der Prüfstelle, die quasi als interne Revision fungierte, wobei den Begutachtern die Zahl der Prüfer angesichts des großen Umfangs der zu prüfenden Unterlagen nicht ausreichend erschien. ${ }^{172}$

Auch die Organisation der komplizierten und umfangreichen Zahlungsflüsse der RfA, die Verwaltung der Kassengelder, der Lombardentnahmen bei der Reichsbank, der Geldzuflüsse und Auszahlungen sowie der diversen Maßnahmen im Zusammenhang mit der Vermögensverwaltung wie das Fristenmanagement von Darlehen und Hypotheken, war nicht nur ohne Beanstandung, sondern offensichtlich auch modern und effizient. ${ }^{173}$ Das galt auch für das Herzstück der RfA, die Kontenverwaltung, deren Aufgabe ja nicht nur das karteimäßige Sammeln und Ablegen der in jedem Jahr eingehenden rund zwei Mio.Versichertenkarten war, sondern die auch deren regelmäßige Prüfung nach den verschiedensten Gesichtspunkten wie Beruf, Alter, Befreiung, Beitragszeiten etc. übernahm, so dass im Leistungsfalle keinerlei Klärungen mehr zu erfolgen brauchten. Das zweite Herzstück der RfA war der Ablauf der Rentenfestsetzung, der mit der Briefannahme der eingehenden Rentenanträge begann. Von dort gingen diese an die Kontenverwaltung weiter, um dann, zusammen mit eventuellen Anlagen, dem zuständigen Dienststellenleiter vorgelegt $\mathrm{zu}$ werden. Die weiteren Stationen waren die Registratur und die Rentenexpedition, wo die genaue Prüfung der Anträge auf Anwartschaft, Wartezeit und Vollständigkeit der erforderlichen Unterlagen erfolgte. Im Zweifelsfall gingen die Anträge auf Ruhegeld nun an den beratenden Arzt zur Stellungnahme, dann wieder zurück zu den Rentenexpedienten, die eine Rentenverfügung erstellten, die vom jeweiligen Dienststellenleiter gegengezeichnet wurde, ehe die Unterlagen dann zur Bescheidstelle liefen, wo die Reinschriften der Bescheide erfolgten sowie mit Hilfe der Rechenmaschine die Rentenberechnung vorgenommen wurde. Alles wurde schließlich von einem Prüfer noch einmal kontrolliert und dann dem Referenten, einem Beamten des höheren Dienstes, zur endgültigen Festsetzung und Zeichnung vorgelegt. ${ }^{174}$ Es folgte die Eintragung in Rentenlisten und eine abermalige Prüfung durch die Rentenkontroll-Abteilung, die auch die zu zahlenden Renten in der Rentenbuchhalterei verbuchten. Erst dann ging der Bescheid an die Absendestelle und von dort an den künftigen Rentenbezieher.

Auch die Organisation der Heilverfahren, die keine Pflichtleistungen der RfA waren, erschien den RVA-Prüfern zweckmäßig und trotz ständiger Zunahme der Anträge (1937: 160.190) und der hier besonders häufig erforderlichen Zusammenarbeit mit anderen Versicherungsträgern effizient geregelt. Der RfA wurde bescheinigt, dass sie in der Bewilligung von Heilverfahren durchaus nicht kleinlich verfuhr. Die Prüfbeamten nahmen auch keinen Anstoß an den erwähnten kostenlosen Heilverfahren für NS-Parteifunktionäre und andere verdiente Nationalsozialisten. ${ }^{175}$ Dieses Räder-

172 Vgl. ebd., S. 17.

173 Vgl. ebd., S. $24 \mathrm{ff}$.

174 Vgl. ebd., S. $55 \mathrm{ff}$.

175 Vgl. ebd., S. 79. 
werk des Dienstbetriebs in der Ruhrstraße lief offensichtlich gut geölt und ohne größere Reibungsverluste. ${ }^{176}$ Doch die atemlose und komplizierter werdende Gesetzgebung, das weitere Anwachsen der Zahl der Versicherten wie Rentnern und die Zunahme der Dynamik der Rentenbewegungen, die räumliche Expansion der Angestelltenversicherung über die bisherigen Reichsgrenzen hinaus und nicht zuletzt der Krieg mit all seinen Folgen sollten die Verwaltungsarbeit der RfA bald an ihre Grenzen und darüber hinaus bringen. Im Frühjahr 1939 jedoch attestierten die Betriebsprüfer des RVA alles in allem, dass sich keinerlei Mängel und Beanstandungen ergeben hatten. „In allen Abteilungen [wird] von allen Beamten und Angestellten mit großem Fleiß und großer Sachkenntnis gearbeitet, so dass die Versicherten und ihre Arbeitgeber das Bewusstsein haben können, dass die Verwaltung der Angestelltenversicherung gut geführt wird“, so teilte man Grießmeyer und praktisch allen Abteilungsleitern und übrigen höheren Beamten auf der großen Abschlussbesprechung am 14. April mit. ${ }^{177}$ Das Urteil stärkte die Position und das Ansehen der RfA als Behörde wie auch die seines Präsidenten Grießmeyer, der wenige Monate später auch seinen 60. Geburtstag feierte, gleichzeitig mit seinem 40 -jährigen Dienstjubiläum. ${ }^{178} \mathrm{Zu}$ diesem Zeitpunkt war schon ein Teil der weiteren Gesetzgebung und deren Umsetzung abgeschlossen. Die eigentlichen Belastungsproben und Krisen der Angestelltenversicherung standen aber noch bevor.

\section{Das Ausbaugesetz 1937 und seine Folgen}

Im Vorfeld des Gesetzes zum Ausbau der Rentenversicherung vom 21. Dezember 1937 hatte eine rege versicherungsrechtliche Debatte fachintern wie in der breiten Öffentlichkeit das Bild bestimmt. Eines der Hauptthemen war die Herabsetzung der Altersgrenze von 60 Jahren bei Erhalt der Arbeitslosenrente auf 50 Jahre oder noch weniger. Dazu heißt es in einem internen Vermerk der Leistungsabteilung von Ende April 1936:

Es steht zweifellos fest, dass eine Not der älteren Angestellten, schon vom Lebensalter 40 an beginnend, vorhanden ist [...]. Nicht nur weibliche, sondern in größerem Maße auch männliche Angestellte sind von dieser "Altersnot“ des Angestelltenstandes betroffen. Dies gab schon seit Jahrzehnten Anlass zu Klagen seitens der Vertreter der Angestellten. ${ }^{179}$

176 Im Allgemeinen erfolgte die Erledigung eines Rentenantrags innerhalb von drei bis vier Monaten, in zahlreichen Fällen erging der Bescheid aber bereits innerhalb von vier bis sechs Wochen.

177 Ebd., S. 104.

178 Vgl. dazu die kurze Würdigung und Laudatio durch Möbius in: Deutsche Rentenversicherung 11 (1939), Nr. 12, S. 1.

179 Vermerk vom 24.4.1936, in: RfA-Archiv Handakte Granzow. 
Den nun aber allenthalben auftauchenden Forderungen nach einer entsprechenden Gesetzesänderung erteilte man RfA-intern eine klare Absage. Auf die damit verbundenen Mehrausgaben sei die RfA nicht eingerichtet, wie überhaupt die im Aufbaugesetz von 1933 in Aussicht gestellte, aber nach wie vor nicht umgesetzte Beitragserhöhung dringend gefordert werden müsse. ${ }^{180}$ Das andere Thema, um das die Diskussion kreiste, war die Härte der komplizierten Anwartschaftsbestimmungen. Immer wieder erschienen in der Tagespresse kritische Artikel über die „Anwartschaftskatastrophe“ infolge nicht geklebter Marken in der Invaliden- wie Angestelltenversicherung. Alfred Anders, Mitglied der Akademie für Deutsches Recht und Vorsitzender des dortigen Ausschusses für Sozialversicherung, erstellte im Dezember 1936 in der Zeitschrift „Der Sozialversicherungsbeamte“ eine umfangreiche Liste zur Reform des Anwartschaftsrechts. ${ }^{181}$ Der Großteil der Forderungen richtete sich dabei auf Gesetzesänderungen in der Invalidenversicherung im Sinne einer Angleichung an bereits bestehende Bestimmungen des Angestelltenversicherungsrechts, wie etwa die Abschaffung der sogenannten Dreivierteldeckung zugunsten einer Bestimmung, nach der bereits die Belegung der Hälfte des ganzen Versicherungszeitraums vom Eintritt in die Versicherung bis zum Versicherungsfall selbst zum Erhalt der Anwartschaft und der Berechtigung der Leistungszahlung (die sogenannte Halbdeckung) genügte.

Diese Tendenz zur weiteren Entschärfung, aber nicht völligen Abschaffung der Notverordnungen sowie zur Vereinheitlichung der Bestimmungen in der Rentenversicherung, die damit nicht die Angestelltenversicherung, sondern die Invalidenversicherung in den Mittelpunkt von Gesetzesmaßnahmen rückte, zeigte sich auch in den ersten Referentenentwürfen, die im März 1937 aus dem RAM kommend auch auf dem Schreibtisch der RfA-Abteilungsleiter zur Kommentierung landeten. ${ }^{182}$ Der Entwurf eines damals noch als Gesetz über die weitere Vereinfachung, Vereinheitlichung und finanzielle Neuordnung in der Reichsversicherung firmierenden Maßnahmenpakets verstand sich dabei in seiner vorangestellten Begründung explizit als „Überleitung zu einem neuen einheitlichen Volksversicherungsgesetz“. ${ }^{183} \mathrm{Im}$ Zentrum standen drei Dinge: die Neuregelung des Anwartschaftsrechts, der Ausbau der Beitragsrückerstattung bzw. die Erleichterung der Rückerstattungsbedingungen sowie, nach wie vor ganz im Zeichen der Sanierungsbemühungen, die Neuordnung des finanziellen Verhältnisses der Sozialversicherung zum Reich. Schon einen Monat später übereichte die RfA dem RAM ihren von Abteilungsdirektor Granzow verfassten Kommentar zu dem Gesetzesentwurf. Er begrüßte die Reformabsichten, übte aber im Detail massive und unverhohlene Kritik an einer ganzen Reihe von Bestimmungen. ${ }^{184}$ Anders als die Landesversicherungsanstalten, die als Träger der Invalidenversicherung einhellig das

180 Vgl. ebd.

181 Vgl. den Artikel in: DSB 26 (1936), S. 649-650 sowie auch der Beitrag dazu in Soziale Praxis 45 (1936), S. 1499-1503 und weitere einschlägige Zeitungsausschnitte in: RfA-Archiv Fach 3, Nr. 2.

182 Vgl. den 50 Seiten dicken ersten Entwurf vom 9.3.1937, in: BArch R 89/3165.

183 Vgl. ebd., Bl. 95.

184 Die RfA-Stellungnahme vom 9.4.1937, in: BArch R 89/3165, Bl. $138 \mathrm{ff}$. 
beabsichtigte neue Gesetz begrüßten, war man in der RfA über einzelne, den Kern der Angestelltenversicherung berührende Bestimmungen geradezu entsetzt. Schon gegen die kommentarlose Beseitigung des Abschnitts des Angestelltenversicherungsgesetzes über „Geschäftsgang und Verfahren“ und dessen Ersetzung durch einen im einzelnen nicht näher bestimmten Bezug auf für die Invalidenversicherung geltende Vorschriften meldete man erhebliche Bedenken an. Nicht nur die Verständlichkeit des Gesetzes im Vergleich zu den bestehenden Regelungen würde dadurch erheblich erschwert, sondern auch die Rechtsanwendung selbst. „Es dürfte“, so hieß es daher in der RfA-Stellungnahme, ,nicht gerechtfertigt sein, für eine verhältnismäßig kurze Übergangszeit in der Angestelltenversicherung ein Gesetz einzuführen, mit dem, wenn auch nur äußerlich, neues Recht geschaffen werde, „das demnächst [aber] wieder beseitigt werden soll. “185 Wie auch schon 1933 und 1934 waren viele Bestimmungen nicht im Gesetz selbst geregelt, sondern sollten erst in späteren Durchführungsverordnungen näher bestimmt werden. Auch das kritisierte Granzow deutlich. Vor allem was die komplizierte Regelung der nun möglichen Nachentrichtung von Beiträgen zur Aufrechterhaltung bzw. Wiederbelebung der Anwartschaft anging, sah man massive Probleme auf die AV und ihren Träger RfA zukommen. Durch die Nachversicherung mit Hilfe einfacher Beitragszahlungen würde dem Versicherungsträger „namhafter Schaden“ entstehen, umso mehr, als die nachgezahlten Beiträge auch als Pflichtbeiträge gelten sollten. Damit wurde aber auch die Wartezeit weitgehend abgekürzt. All dies widersprach fundamental dem eigentlich geltenden Grundsatz des Anwartschaftsdeckungsverfahrens.

Dazu kamen die Folgen der beabsichtigten Öffnung der Sozialversicherung für die Selbständigen durch freiwilligen Beitritt.

Die Freiwilligkeit führt zu einer Selbstauslese der Versicherten mit dem Ergebnis, dass die ungünstigen Risiken: die Verheirateten, Kinderreichen und Personen von schwacher Gesundheit dem Versicherungsträger zur Last fallen, während die zum Ausgleich erforderlichen günstigen Risiken, Junggesellen u. a. der Versicherung fern bleiben,

monierten die RfA-Beamten. Zudem waren in diesem Fall auch geringere Beitragsmonate (sechs statt wie in der AV durchschnittlich 9,5) vorgesehen. „Dies ist versicherungstechnisch zu wenig und zerstört auch den Sinn der Anwartschaftsdeckung [...]. Jedenfalls darf der Zustand nicht eintreten, dass die Selbständigen die halbe Beitragsleistung, die Unselbständigen die ganze Beitragsleistung haben. “" ${ }^{186}$ In einer ganzen Reihe von Einzelbestimmungen entdeckten die RfA-Beamten zudem neu geschaffene Härten und Ungerechtigkeiten. Den zentralen Punkt, der von der RfA immer wieder als Reformverlangen vorgetragen worden war, die Milderung oder Abschaffung der Ruhensbestimmungen, suchten die RfA-Beamten in dem Gesetzentwurf vergeblich - dies beschäftigte auch das RVA, denn in Erwartung neuer Bestimmungen hatten

185 Ebd., S. 2.

186 Ebd., S. $6 \mathrm{f}$. 
die Revisionssenate die zahlreichen anstehenden Streitverfahren schon längere Zeit vorübergehend ausgesetzt. Der inzwischen entstandene Rückstau ungeklärter Revisionsverfahren war erheblich und damit auch die Gefahr, dass bei den Versicherten durch die Verfahrensaussetzungen Hoffnungen geweckt worden wären, „die vielelleicht nicht erfüllt werden können und sich dann nur in umso größere Enttäuschung verwandelt“. ${ }^{187}$ Dafür entdeckten die RfA-Beamten in dem Referentenentwurf, dass einige aus ihrer Sicht wesentliche Bestimmungen zur Vermögensverwaltung weggefallen und durch neue Regelungen ersetzt worden waren. Diese öffneten dem RVA als Aufsichtsbehörde in Form von Genehmigungsvorbehalten Tür und Tor für weitere massive Eingriffe in die Entscheidungen zur Anlage des Vermögens. ${ }^{188}$ Der von der RfA seit jeher bewusst gepflegte Grundsatz einer vielfältigen Mischung der Vermögensanlagen wurde damit weitestgehend unmöglich gemacht. Der ganze Aufbau des Vermögens „erfährt eine grundlegende Wandlung“, unter anderem auch mit der Folge eines deutlichen Absinkens des durchschnittlichen Zinsertrags. ${ }^{189}$

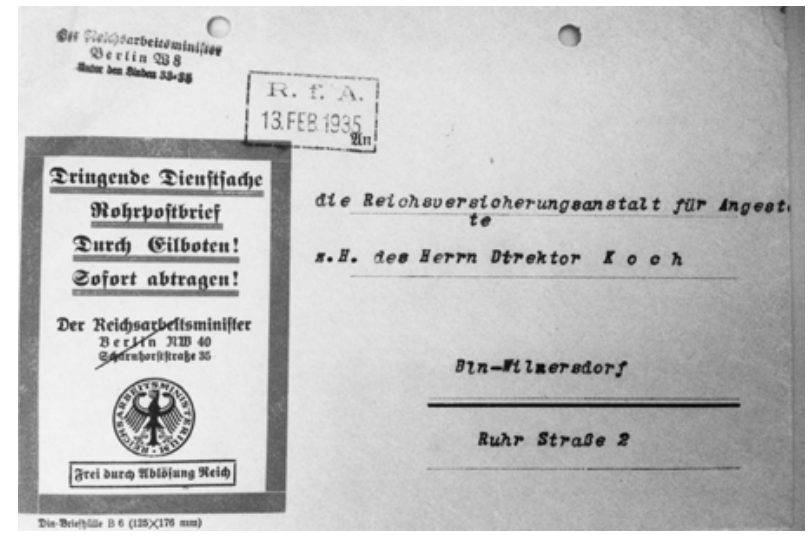

Abb. 15: Dienstschriftverkehr zwischen dem RAM und der RfA (1935)

Unter dem Strich gab es drei Entwürfe sowie einen Vorentwurf des Ausbaugesetzes, zu dem die Versicherungsträger ausgiebig gehört worden waren. Den Bedenken der RfA war dabei allerdings kaum Gehör geschenkt worden. ${ }^{190}$ Am zweiten Entwurf, der im Juli vorgelegt worden war, hatten die RfA-Beamten nach wie vor kritisiert, dass „die in Aussicht genommene Regelung die für die Handhabung des

187 Schreiben des RVA an das RAM vom 17.6.1937, in: BArch R 89/3165.

188 Das betraf vor allem die Genehmigungspflicht beim Ankauf inländischer Grundstücke. Vgl. RfAStellungnahme vom 9.4.1937, S. 18, in: BArch R 89/3165.

189 Vgl. RfA-Stellungnahme vom 9.4.1937, in: BArch R 89/3165, Bl. $138 \mathrm{ff}$.

190 Vgl. dazu auch einen entsprechenden frustrierten handschriftlichen Vermerk an Vizepräsident Schaefer vom 10.9.1937, in: RfA-Archiv Nr. 23. 
Gesetzes wichtigsten Bestimmungen in der Schwebe [lässt]“. ${ }^{191}$ Grießmeyers Rede Mitte Oktober 1937 auf der Reichsarbeitstagung der Reichsbetriebsgemeinschaft Banken und Versicherungen in Frankfurt, die die Sanierung der Rentenversicherungen zum Thema hatte, kann man durchaus als einen letzten und vergeblichen Versuch deuten, die Gesetzesmacher im RAM vor teuren Experimenten und der Zerstörung des Anwartschaftsdeckungsverfahrens zu warnen. ${ }^{192}$ Als das Gesetz Ende Dezember 1937 erschien und zum 1. Januar 1938 in Kraft trat, war die Reaktion gespalten. ${ }^{193}$ Die NSPresse, allen voran Das Schwarze Korps, bejubelte die grundsätzliche Neuordnung der Regelungen von Wartezeit und Anwartschaft sowie die große Zahl einzelner Verbesserungen für die Versicherten im Ausbaugesetz. Jedem Deutschen, auch wenn er nicht versicherungspflichtig war, biete sich nun die Möglichkeit, durch freiwillige Beitragsleistungen, die vor dem 40. Lebensjahr einsetzen oder durch freiwillige Wiederaufnahme früherer Pflichtbeiträge in den Genuss der Altersversorgung zu gelangen. ${ }^{194}$ In der Sozialen Praxis legte auch Gerhard Zschimmer, der zuständige Ministerialdirigent im RAM seine Deutung des Ausbaugesetzes dar. ${ }^{195}$ Darin pries er zuallererst die finanztechnische Seite des Gesetzes, mit der die eigentlich vorgesehene offene Beitragserhöhung durch eine verdeckte infolge der Übertragung von Beiträgen der Arbeitslosenversicherung auf die IV und die AV vorgenommen werde. Als Beitragssatz würden im Durchschnitt 4,8 Prozent des Arbeitseinkommens festgesetzt, in Wirklichkeit betrug der von den Versicherten aufzubringende Beitragssatz aber sechs Prozent, da 1,2 Prozent des Arbeitseinkommens aus der Arbeitslosenversicherung auf die RfA übertragen wurden. Der RfA flossen dadurch künftig jährlich etwa 110 Mio. RM $\mathrm{zu}$, der Invalidenversicherung ein doppelt so hoher Betrag. Dazu übernahm seinerseits das Reich erstmals für weitere Versicherungsleistungen die Zusage finanzieller Mittel als Zuschuss. Die faktischen Leistungsverbesserungen waren eher marginal, sie bewegten sich „,in Richtung einer weiteren Auflockerung der früheren Notverordnungen“, wie Zschimmer kryptisch schrieb, und sie betrafen vor allem die Invalidenversicherten. Sie machten alles in allem, so jedenfalls die Berechnungen des RAM, 130 Mio. RM aus, die weiteren Erleichterungen der Versicherung etwa 20 Mio. RM, Beitragssenkungen für die Bergleute 70 Mio. RM und die Verstärkung des Sondervermögens für die Kinderbeihilfen 277 Mio. RM. Die Kosten für das Ausbaugesetz schlugen insgesamt mit einem Betrag von rund einer halben Mrd. RM zu Buche. Aus dieser Perspektive wurden denn auch die eigentlichen Ziele hinter dem Ausbaugesetz viel deutlicher sichtbar: Erstens wurde unter dem Signum der „endgültigen Sanie-

191 Stellungnahme vom 14.8.1937, in: RfA-Archiv Handakte Granzow.

192 Vgl. den Bericht der Tagung und die Rede Grießmeyers in: Deutsche Invalidenversicherung 9 (1937), S. 225-226.

193 Vgl. das Gesetz über den Ausbau der Rentenversicherung in: Mitteilungen der RfA Nr. 13, 1937, S. 45-52. Vgl. auch Glootz, S. 79.

194 Vgl. „Das Ziel: Volksversicherung!“, in: Das Schwarze Korps vom 27.1.1938, S. 6-7.

195 Gerhard Zschimmer, Gesundung und Ausbau der deutschen Rentenversicherung, in: Soziale Praxis 47 (1938), S. $66-70$. 
rung“ bei Erhaltung der Sozialversicherungsleistungen die offene Beitragserhöhung, die dem Image des Regimes wohl erheblich geschadet hätte, vermieden. Zweitens wurde mit der faktischen Rechtsangleichung weiter Teile der Bestimmungen zwischen Invaliden- und Angestelltenversicherung tatsächlich eine erste Etappe zur nationalsozialistischen Volksversicherung sowie zum Ausbau der Versicherungsleistungen nach nationalsozialistischen Grundsätzen eingeschlagen. Drittens ging es um Beitragserleichterungen für die Bergleute, d.h. um die Loyalitätssicherung bei einer zentralen Gruppe in der Arbeiterschaft, und viertens verfolgte man mit den Kinderbeihilfen eine klare nationalsozialistische Familien- und Bevölkerungspolitik. ${ }^{196}$ Für die Angestellten brachte das neue Gesetz jedoch so gut wie nichts. Im Gegenteil: Nimmt man das Ausbaugesetz und dessen Umsetzung über die tägliche Verwaltungsarbeit der RfA näher unter die Lupe, so zeigten sich viele Probleme und Nachteile für diese Versichertengruppe.

Der zentrale Punkt in der Neuregelung des Anwartschaftsrechts war die Einführung der sogenannten Halbdeckung. Künftig galt die Anwartschaft in der AV wie der IV auch dann als erhalten, wenn beim Eintritt des Versicherungsfalls durch Berufsunfähigkeit, durch Tod oder durch Vollendung des 65. Lebensjahres die Zeit seit dem ersten Eintritt in die Versicherung nur zur Hälfte mit Beiträgen belegt waren. Auch die neu geschaffenen Möglichkeiten zur Verteilung der Wochenbeiträge sowie zu Beitragsnachzahlungen beseitigten empfindliche Härten des geltenden Rechts. Die tatsächliche Anwendung der Halbdeckungs-Regelung war jedoch reichlich unklar. Erst eine Anfrage der Sozialabteilung des IG-Farben-Konzerns Anfang Februar 1938 über die Anrechnung der an sich rentensteigernd wirkenden Kriegs-, Arbeits- und Militärdienstzeiten brachte zu Tage, dass in der Angestelltenversicherung diese Anrechnung nicht mehr erfolgte und vom Gesetzgeber bewusst ausgeschlossen worden war. Dies, so beeilte sich der zuständige RfA-Referent in seinem Antwortschreiben zu betonen, bedeute für die Angestellten keine Verschlechterung der bisherigen Lage. ${ }^{197}$ In einem internen Vermerk für RfA-Vizepräsident Schaefer vom Oktober 1938 steht:

Zahlreiche Versicherte haben, zum Teil bestärkt durch Auskünfte der Behörde oder einer anderen zuständigen Stelle, im Vertrauen auf die Dreivierteldeckung die Beitragsleistungen wieder aufgenommen. Sie müssen aber jetzt bei Eintritt des Versicherungsfalles erfahren, dass die Dreivierteldeckung seit 1938 nicht mehr gilt, und Halbdeckung nicht vorhanden ist. ${ }^{198}$

Auch das Wiederaufleben der Anwartschaft trotz erloschener Beitragsmarken durch Nachentrichtung war beseitigt worden. Das neue Recht kannte das Wiederaufleben

196 Vgl. dazu auch die ziemlich unverblümte Darstellung von Inhalt und Bedeutung des Ausbaugesetzes von Oberregierungsrat Dobbernack, einem anderen hauptverantwortlichen Referenten bzw. Staatssekretär im RAM in der Deutschen Invalidenzeitung 10 (1938), S. 3-7.

197 Vgl. das Schreiben der IG Farben vom 11.2.1938 sowie das Antwortschreiben vom 3.3.1938, in: RfA-Archiv Fach 3, Nr. 2.

198 Vermerk vom 9.10.1938, in: RfA-Archiv Fach 113, Nr. 6. 
der Anwartschaft nicht mehr, allerdings gab es eine Übergangsregelung mit Stichtag 31. Dezember 1937, d.h. die Zulassung der Nachentrichtung von Beiträgen für zurückliegende Zeiten (1931 bis 1937) und eine Härtefallklausel. Viele Versicherte, die aufgrund der neuen Regelungen nun eine Rentenleistung erwarteten, wurden enttäuscht. Denn an dem Prinzip, dass Rentenleistungen der AV voraussetzten, dass die Wartezeit erfüllt und außerdem die Anwartschaft erhalten sein musste, hatte das Ausbaugesetz nichts geändert. Ob die Anwartschaft durch die Halbdeckung erhalten war, konnte nur im Versicherungsfall beurteilt werden. War sie zu diesem Zeitpunkt nicht erreicht, so blieben auch die zur Erreichung der Halbdeckung geleisteten freiwilligen Beiträge für die Anwartschaft unwirksam. War die Halbdeckung erreicht, so konnte gleichwohl eine Rente nur gewährt werden, wenn die Wartezeit erfüllt war. Die neuen Regelungen für die Verkürzung der Wartezeit durch freiwillige Beiträge zur Halbdeckung galten zudem erst ab dem 1. Januar 1938 und nicht rückwirkend. ${ }^{199}$ In einem bald als Standardtext formulierten Bescheid an einen Versicherten vom Februar 1938 steht:

Ihre Anwartschaft aus den für 1914/1918 zur Angestelltenversicherung entrichteten Beiträgen ist nach wie vor erloschen. Ein Versicherter, dessen Anwartschaft erloschen ist, kann sich freiwillig weiterversichern, um die Halbdeckung in der AV zu erreichen [...]. Die Versicherung zur Erreichung der Halbdeckung geschieht aber auf eigene Gefahr des Versicherten; denn die Beiträge werden erst wirksam, wenn im Versicherungsfall die Halbdeckung vorhanden ist. Wenn dieses Ziel nicht erreicht wird, so bleiben die Beiträge unwirksam und werden nicht zurückgezahlt. ${ }^{200}$

Nicht rückwirkend angerechnet werden konnte die Halbdeckung auch auf die Beitragsrückerstattung der verheirateten Frauen, auch wenn sich in der Öffentlichkeit hier vielfach andersartige Auffassungen und Informationen verbreitetet hatten. Ein RfA-Beamter blickt in einem Aufsatz zurück:

In Übereinstimmung mit der Verwaltungsübung der RfA mangels Rechtsgrundlage kann dem nicht gefolgt werden. Es ist bedauerlich, dass durch diese den entscheidenden Punkt übersehende Auslegung bei den betroffenen Ehefrauen Hoffnungen erregt worden sind - wie sich aus zahlreichen Zuschriften an die RfA ergeben hat -, die nicht in Erfüllung gehen können. ${ }^{201}$

Bald häuften sich daher bei den DAF-Rechtsberatungsstellen wie der RfA selbst die Anträge auf Anwendung der Härtefallregelung und auf Kulanz bei der Gewährung und Berechnung von Renten. Dabei hatte die RfA schon im Herbst 1937 im Vorgriff auf die zu erwartende Regelung vielfach Kulanz in ihrer Verwaltungspraxis geübt und Anträge auf Gewährung von Renten, die wegen Erlöschens der Anwartschaft eigentlich

199 Vgl. das entsprechende Erläuterungsschreiben aus der Versichertenabteilung auf eine Anfrage nach Klärung durch den Frankfurter Überwachungsbeamten vom 12.3.1938 hin, in: ebd.

200 Bescheid vom 11.2.1938, in: RfA-Archiv Fach 94, Nr. 2.

201 ORR Otto Hartmann, Zur neuen Beitragserstattung in der Rentenversicherung der Arbeiter und Angestellten, in: Deutsche Rentenversicherung 11 (1939), S. 23-26, hier S. 24. 
abzulehnen waren, in Rücksprache mit dem RVA dann gewährt, „wenn eine formalrichtige Ablehnung eine dem Rechtsempfinden nicht entsprechende Härte bedeuten würde““. ${ }^{202}$ Bei den seit 1938 nun eingehenden zahlreichen Anträgen auf Anwendung der Härtefallregelung, die auf den Schreibtischen der RfA-Beamten landeten, zeigte man sich jedoch in Anwendung der Gesetzeslage unnachgiebig. Ungeachtet dessen, dass die DAF-Rechtsberatungsstellen für eine flexible Handhabung der Bestimmungen zugunsten ihrer jeweiligen Mandanten plädierten, lehnte die RfA die Anträge fast durchweg ab. ${ }^{203}$ Der Tenor der Bescheide lautet:

\footnotetext{
Eine Ermächtigung, in Fällen besonderer Härte die Anrechnung von Invalidenbeiträgen auf die Halbdeckung neben gleichzeitig entrichteten Angestelltenversicherungsbeiträgen zuzulassen, oder die bis zum Inkrafttreten des Ausbaugesetzes erreichte Dreivierteldeckung über den 31. Dezember 1937 fortdauern zu lassen, sieht das Gesetz nicht vor. ${ }^{204}$
}

Nach wie vor wich trotz der Angleichungstendenzen das Anwartschaftsrecht in der Angestelltenversicherung grundlegend von dem der Invalidenversicherung ab und entsprechend waren Schwierigkeiten beim Übergang von einer zur anderen Versicherung zu erwarten, d.h. bei den sogenannten Wanderversicherten. Von einer Vereinfachung des komplizierten Anwartschaftsrechts und von „klaren, einfachen Vorschriften, die auch dem einfachen Manne verständlich sein müssten“, wie RAMStaatsekretär Zschimmer überheblich in der Sozialen Praxis geschrieben hatte, konnte keine Rede sein. ${ }^{205}$

Das galt auch für die mit dem Ausbaugesetz vorgenommene Erweiterung der freiwilligen Selbstversicherungsmöglichkeiten sowie die Entrichtung von Zusatzbeiträgen. Seit dem 1. Januar 1938 waren alle deutschen Staatsangehörigen, die nicht versicherungspflichtig waren, bis zum vollendeten 40. Lebensjahr zum freiwilligen Eintritt in die Angestelltenversicherung berechtigt, und zwar ohne Rücksicht auf die Höhe des Einkommens und die Zugehörigkeit zu einer bestimmten Berufsgruppe. Damit war die alte Regelung, nach der die freiwillige Selbstversicherung erst nach aufwändiger Einzelfallprüfung entschieden wurde, aufgehoben. ${ }^{206}$ Dies bedeutete eine weite Öffnung der Rentenversicherung „für jedermann“, die bis zur Rentenreform von 1957 gelten sollte und durch das Rentenreformgesetz vom Oktober 1972 erneut und ergänzt durch Nachversicherungsregelungen wieder eingeführt wurde. Damals gab es jedoch auf Seiten der RfA erhebliche Bedenken gegen die Neuregelung der Selbstversicherung, insbesondere gegen eine laxe Handhabung der Nachversicherungs-

202 Präsidialverfügung vom 1.12.1937, in: RfA-Archiv Nr. 22.

203 Vgl. dazu eine Sammlung von Härtefällen in: BArch R 89/3534.

204 Bescheid vom 21.6.1938, in: RfA-Archiv Fach 3, Nr. 2. Vgl. dazu auch die Abteilungsverfügung zur Härtefallklausel vom 17.2.1938, in: RfA-Archiv Nr. 23.

205 Vgl. Zschimmer, Gesundung und Ausbau der deutschen Rentenversicherung, in: Soziale Praxis 47 (1938), S. 69. Vgl. auch das umfangreiche eigens dafür erstellte Merkblatt Nr. 4a zur Halbdeckung in der Angestelltenversicherung, in: RfA-Archiv Fach 3, Nr. 2.

206 Vgl. dazu den diversen Schriftwechsel in: RfA-Archiv Fach 64, Nr. 3. 
möglichkeiten. Laut Gesetz war es auch den später eintretenden freiwilligen Selbstversicherern nur bis 1. Januar 1938 erlaubt, Beiträge nachzuentrichten. Auf dieser Haltung beharrte auch die RfA in ihrer Verwaltungspraxis, denn faktisch bedeuteten alle anderen Auslegungen eine für die RfA teure, für die Versicherten allerdings ziemlich günstige Verkürzung der Wartezeiten um die Hälfte. Konflikte zwischen den Pflichtversicherten und den freiwillig Versicherten waren damit geradezu vorprogrammiert. Das RVA jedoch unterlief mit seiner Rechtsprechung diese Handhabung und eröffnete den Selbstversicherten die Möglichkeit, auch für die Zeit von 1932 bis 1937 freiwillige Beiträge nachzuentrichten. ${ }^{207}$ Die RfA sah sich daher im Oktober 1939 gezwungen, auf die Position des RVA einzuschwenken. ${ }^{208}$ Vehement wehrte sich die RfA auch gegen die von den Landesversicherungsanstalten praktizierte Verwaltungshandhabung des Ausbaugesetzes, auch den nach Vollendung des 40. Lebensjahres gestellten Anträgen auf Selbstversicherung $\mathrm{zu}$ entsprechen, wenn durch Nachverwendung von Beiträgen der Eintritt in die Selbstversicherung gleichsam vor das 40. Lebensjahr zurückverlegt wurde. ${ }^{209}$

Mindestens den Versicherungsmathematikern unter den RfA-Beamten waren all diese Regelungen ein Graus, hegten sie doch eine grundsätzliche Abneigung gegen die freiwillige Versicherung bei einer an sich auf Versicherungspflicht beruhenden Einrichtung. Die freiwillig Versicherten stellten für sie eine „Selbstauslese besonders gefährdeter Personen“ mit versicherungstechnisch höheren Risiken dar.

Die freiwillige Übernahme einer Vergrößerung der ungünstigen Risiken durch Entgegennahme von Zusatzbeiträgen schließt Gefahrenmomente für die Anstalt ein, die sich allen versicherungsmathematischen Berechnungen entziehen, weil eine ihre Grundlagen - das Wahrscheinlichkeitsmoment - zum Teil dadurch ausgeschaltet ist, dass dem Willen der Versicherten, möglichst günstig abzuschneiden, freier Lauf gelassen wird,

so hieß es in einem internen Vermerk. ${ }^{210}$ Daher erschien es der RfA aus grundsätzlichen Erwägungen und im eigenen Interesse notwendig, die freiwillige Versicherung wenn nicht auszuschließen, so doch möglichst - etwa durch Verbot der Versicherung in den „unrentablen“ Gehaltsklassen A und B - zu beschränken zu suchen. ${ }^{211}$

207 Vgl. Abteilungsverfügung Abt. I Versicherung vom 25.6.1938, in: RfA-Archiv Nr. 23 sowie dazu u. a. das Schreiben des Versicherungsamts Stuttgart an das RfA vom 27.4.1940, in: ebd.

208 Vgl. Abteilungsverfügung vom 19.10.1939, in: RfA-Archiv Fach 1, Nr. 1 sowie Vermerk vom 29.4. 1940, in: RfA-Archiv Fach 11, Nr. 7.

209 Vgl. Schreiben des Reichsverbandes Deutscher Versicherungsanstalten an die RfA vom 14.6.1938 sowie das Antwortschreiben vom 27.6.1938, in dem die RfA ihren andersartigen Standpunkt bekräftigte, in: RfA-Archiv Fach 111, Nr. 7.Vgl. dazu auch die umfangreichen Vorschläge von Direktor Koch vom 15.2.1938 für eine Durchführungsverordnung zum Ausbaugesetz sowei das entsprechende Schreiben der RfA an das RVA vom 18.2.1938, in: RfA-Archiv, Handakte Granzow.

210 Vermerk vom 15.7.1938, in: RfA-Archiv Handakte Granzow.

211 Vgl. den Vermerk bereits vom 13.11.1935 sowie das darauf aufbauende Schreiben an das RVA vom 14.11.1935, in: RfA-Archiv Nr. 20. 
Das Ausbaugesetz eröffnete zudem auch die Möglichkeit zur Überversicherung, d.h. die Versicherung konnte in einer höheren als der gesetzlich vorgeschriebenen Beitragsklasse erfolgen, allerdings war vorher eine einvernehmliche Vereinbarung zwischen Arbeitgeber und Versichertem notwendig. Auch hier meldete das RfA gegenüber dem entsprechenden Referentenentwurf im Juni 1938 massive Bedenken an, vor allem gegen die geplante Gleichstellung von Zusatzbeiträgen und freiwilligen Beiträgen, was ebenfalls ein Einfallstor für die Versicherten schuf, eine schnellere Erfüllung der Wartezeit, die Verhütung von Anwartschaftsverlusten und die Erlangung höherer Versicherungsleistungen zu erreichen.

Von der neuen Möglichkeit, noch durch Zusatzbeiträge Leistungen zu erzielen, würden voraussichtlich nur Versicherte Gebrauch machen, die sich entweder jahrelang um ihre Versicherung nicht gekümmert haben oder die mit einem alsbaldigen Leistungsanspruch zu rechnen haben; das würde aber zu einer nicht erwünschten Risikoauslese führen,

notierten die RfA-Beamten dazu. ${ }^{212}$ Das Ziel war eine allgemeine Erhöhung der anerkanntermaßen zu niedrigen Renten, allerdings durch freiwillige Initiative und Beiträge der Versicherten. ${ }^{213}$ Das Zusatzbeitrags-System sah eine gewisse Mindestbeitragshöhe vor, ein Widerspruch, wie die RfA-Beamten monierten. Denn da die Zusatzversicherung auf der freien Entscheidung des Versicherten beruhte, „sollte man auch die Höhe der Zusatzbeitragsleistung dem freien Willen des Versicherten und vor allem seiner finanziellen Leistungsfähigkeit überlassen“. ${ }^{214}$ Zudem hatten die RfASachbearbeiter berechnet, dass die entsprechenden Bestimmungen aus dem RAM tatsächlich nur geringe Höherleistungen der Rente mit sich bringen würden, die weit unter den Erwartungen der Versicherten lagen. In einem internen Vermerk der Büroleitung der Abteilung I Leistung von Mitte Juli 1938 heißt es dazu gleichsam zusammenfassend:

Der Wille, eine Erhöhung der Renten zu ermöglichen, ist zu begrüßen. Der Weg scheint mir allerdings ein reichlich umständlicher zu sein, abgesehen davon, dass ich die Beamten bedauere, die später Beitragsübersichten aufstellen und Renten berechnen müssen, haben sie doch auseinander zu halten: Pflicht-, freiwillige, Höherversicherungs-, Zusatzversicherungs- und Zusatzbeiträge mit ihrer verschiedenartigen Verwertung. Ganz außer allem Zweifel wird sich beim Versicherungsfall ein umfangreicher und unbefriedigender Schriftwechsel ergeben und das Verfahren wesentlich verzögern. ${ }^{215}$

212 Vermerk vom 15.7.1938, in: RfA-Archiv Fach 114, Nr. 20.

213 Vgl. dazu die elfseitige Stellungnahme der RfA vom 8.7.1938 zu dem Referentenentwurf, in: RfAArchiv Fach 114, Nr. 20.

214 Ebd., S. 4.

215 Stellungnahme vom 13.7.1938, in: RfA-Archiv Fach 114, Nr. 20. Vgl. dazu auch das 22-seitige Schreiben Grießmeyers an das RVA dazu vom 26.7.1938 mit der deutlich ablehnenden Stellungnahme, in: RfA-Archiv Fach 114, Nr. 20. Im April 1939 schickte das RAM an die RfA und das RVA einen neuen Entwurf für eine Verordnung über Zusatzbeiträge in der Rentenversicherung. Vgl. dazu auch die eher zurückhaltende Stellungnahme des RVA vom 9.5.1939, in: BArch R 89/3169. 
Auffälligerweise sah man sich hier einer Meinung mit dem Sozialamt der DAF. ${ }^{216}$

Ein weitgehend unbeachtetes Beispiel für die Rückwirkungen der Rechtsangleichung auf die Verwaltungspraxis der RfA war die Gewährung des Kinderzuschusses und der Waisenrente. Den Anspruch auf diese Leistungen hatte die RfA wie erwähnt als satzungsgemäße Mehrleistung bei Schul- oder Berufsausbildung auch auf die Jahre zwischen dem 15. und 18. Lebensjahr ausgedehnt hatte. Das Ausbaugesetz führte dies nun allgemein, d.h. auch in der Invalidenversicherung ein und schuf damit einen gesetzlichen Anspruch, wobei allerdings die Begriffe der Schul- und Berufsausbildung nicht näher bestimmt worden waren. Für die RfA bedeutete dies, dass sie ihre Satzung ändern musste: „Die entgegenkommendere Auslegung, die in der Verwaltungsübung der RfA für Mehrleistungen maßgebend war, [ist] für die Entscheidung über die gesetzlichen Ansprüche nicht mehr anzuwenden“, hieß es in einem Vermerk. ${ }^{217}$ Andere Maßnahmen und Verwaltungspraktiken im Geschäftsverkehr zwischen den verschiedenen Versicherungsträgern, die höchst arbeitsintensiv waren und erheblichen bürokratischen Aufwand erforderten, wie etwa die erforderliche Anhörung im Rentenfeststellungsverfahren von Wanderversicherten oder bei der Zuständigkeit für die Feststellung und Zahlung der Leistungen von Wanderversicherten, ließ das Gesetz dagegen bestehen und unterwarf es keiner Vereinheitlichung bzw. Vereinfachung. ${ }^{218}$ Der Hauptprofiteur des Ausbaugesetzes war zweifellos die Invalidenversicherung; erst jetzt wurden hier auch die Beitragsrückerstattungen an weibliche Versicherte bei der Heirat möglich ebenso wie die Anrechnung der Dienstzeiten in der Wehrmacht und im Reichsarbeitsdienst als Ersatzzeit für die Anwartschaftserhaltung sowie die Gewährung von Steigerungsbeträgen für die Kriegsdienstzeiten. Demgegenüber ergaben sich für die AV und damit die RfA eher erhöhte Risiken, vermehrte Arbeitsbelastung und zusätzliche Ausgaben. Letztendlich waren, wie schon in den Gesetzen zuvor, zahlreiche Regelungen unklar und in der Auslegung strittig geblieben. Bereits im September 1938 war daher eine „Verordnung zur Durchführung und Ergänzung des Gesetzes über den Ausbau der Rentenversicherung“ erlassen worden und im Reichsversicherungsamt gab es bereits eine lange Liste mit weiteren „Zweifelsfragen“ aus dem Ausbaugesetz, die ihrer endgültigen Regelung durch spätere Durchführungsverordnungen harrten. ${ }^{219}$

Für alle Versicherungsträger gleichermaßen galt, dass das Ausbaugesetz massive Mehrarbeit mit sich gebracht hatte. Die RfA wurde schon kurz nach Erlass des Ge-

216 Vgl. die umfangreiche Stellungnahme der DAF vom 10.8.1938 zu dem Referentenentwurf, in: ebd. 217 Vermerk der Abteilung I Leistung vom 10.3.1938, in: RfA-Archiv Nr. 23 sowie dort auch die ausführliche neue „Anweisung für die Gewährung von Waisenrenten und Kinderzuschuss für Kinder vom 15. bis 18. Lebensjahr“ vom 29.1.1938.

218 Vgl. dazu etwa den Vermerk der Abt. I Leistung vom 15.9.1938 sowie auch die Niederschrift über die Besprechung vom 25.10.1938 zwischen RfA, Reichsknappschaft und dem Reichsverband deutscher Landesversicherungsanstalten, in: RfA-Archiv Nr. 58a.

219 Die Verordnung vom 1.9.1938, in: Mitteilungen der RfA Nr. 9, 1938, S. 1-2 sowie das Rundschreiben des RVA an die Versicherungsträger vom 3.10.1938, in: RfA-Archiv Nr. 23. 
setzes mit Anträgen von Rentenberechtigten auf Erhöhung der Rente regelrecht überschüttet. ${ }^{220}$ Der Arbeitsaufwand nahm nach dem Erlass der ersten Durchführungs- und Ergänzungsverordnung noch deutlich $\mathrm{zu}$, in der nun endlich die lange versprochenen Steigerungsbeträge für Soldaten, Arbeitsmänner und Kriegsteilnehmer festgelegt wurden. Das machte die Umrechnung laufender Rentenbescheide notwendig. ${ }^{221}$ Allein 1938 wurden von der Leistungsabteilung rund 20.000 Fälle hinsichtlich der Frage geprüft, ob ein Anspruch auf den Steigerungsbetrag aus der Invalidenversicherung für eine geleistete Kriegsdienstzeit bestand, und in über 10.000 Fällen war auch eine entsprechende Bewilligung erfolgt. ${ }^{222}$ Große Kreise unter den „RfA-Rentnern“ hatten sich infolge des allgemeinen Rentenverbesserungsgerüchte in der Öffentlichkeit, und ohne sich um die Details der tatsächlichen Bestimmungen des Ausbaugesetzes zu kümmern, Hoffnungen auf eine Ruhegelderhöhung gemacht. Doch in den meisten Fällen wurden entsprechende Anfragen von der RfA mit dem lapidaren Hinweis abgelehnt, dass Steigerungsbeträge aus der Invalidenversicherung nicht gewährt würden, wenn in der laufenden Rente für die Zeit der Teilnahme am Weltkrieg schon Steigerungsbeträge aus der Angestelltenversicherung enthalten waren. ${ }^{223}$ Für die große Masse der RfA-Rentner änderte ich daher mit dem Ausbaugesetz nichts.

Ungeachtet dieser Probleme und Ungereimtheiten, die sich aus Sicht der RfA durch das Ausbaugesetz ergaben, stimmte Präsident Grießmeyer dennoch auf der Beiratssitzung Anfang April 1938 zunächst in den Chor der NS-Presse, die das Gesetz als „soziale Großtat“ feierte, mit ein. Das Ausbaugesetz verbürge die künftige finanzielle Sicherung aller Leistungen der Angestelltenversicherung, bahne einen Ausbau der Leistungen nach nationalsozialistischen Grundsätzen an und öffne die Tür für eine Rentenversicherung des ganzen Volkes. ${ }^{224}$ Auf der gemeinsamen Tagung aller Versicherungsträger mit dem RVA am 3. März 1939, in dem es unter anderem auch um die „vermutlichen Auswirkungen des Ausbaugesetzes in finanzieller Hinsicht“ ging, meldete sich Grießmeyer jedoch nicht zu Wort. ${ }^{225}$ So beherrschte dort die Perspektive der Landesversicherungsanstalten und der Invalidenversicherung das Bild. Angeblich fielen demnach die finanziellen Belastungen durch das Gesetz mit etwa 46 Mio. RM weit geringer aus, im Vergleich mit der ursprünglich veranschlagten doppelt so hohen Summe. Allerdings waren diese Berechnungen ohne großen Wert, da „ohne Zweifel noch erhebliche Belastungen ausstehen, über die erst die Zukunft das richtige Bild

220 Vgl. Notiz der Büroleitung der Abt. I Leistung vom 3.1.1938, in: RfA-Archiv Nr. 23. Die RfA hatte demnach eine Reihe von Hilfskräften eingestellt und vorübergehend eine eigene Dienststelle eingerichtet.

221 Vgl. RVA-Rundschreiben vom 6.10.1938, in: RfA-Archiv Nr. 23.

222 Schreiben der Abt. I Leistung vom 3.2.1939, in: RfA-Archiv Nr. 92.

223 Vgl. etwa das Schreiben vom 10.9.1938, in: RfA-Archiv Nr. 91.

224 Protokoll der Beitratssitzung vom 4.4.1938, S. 2, in: BArch R 89/3468. Vgl. auch die regimekonforme Würdigung in der RfA-Festschrift 25 Jahre Angestelltenversicherung, S. 46.

225 Vgl. die Niederschrift der Tagung beim RVA am 3.3.1939, in: BArch R 89/3165. 
geben wird“. ${ }^{226}$ Jedoch ergaben erste interne Berechnungen, dass sich auch bei der RfA die durch das Ausbaugesetz entstehenden Mehrausgaben in Grenzen hielten: Bis Ende 1938 waren es nur 700.000 RM bei den Ruhegeldern und 1,1 Mio. RM bei den Hinterbliebenenrenten. ${ }^{227}$ Die Verbesserungen fielen mithin sehr bescheiden aus und blieben ohne sichtbare Rückwirkung auf das Niveau der durchschnittlichen Rente. ${ }^{228}$ Unter dem Strich bedeutete das Ausbaugesetz daher für die Angestelltenversicherten keine nennenswerten Verbesserungen. „Alle Dankschreiben über Rentenerhöhungen nach dem Gesetz vom 21.12.1937 sind mir vorzulegen“, hieß es in einer Anordnung der Büroleitung der Abteilung I Leistung vom 29. Januar 1938. ${ }^{229}$ Doch in den Akten fanden sich keine, stattdessen aber viele Briefe mit unverhohlener Kritik. ${ }^{230}$

Und die Gerüchteküche über die künftigen Leistungen der Angestelltenrentenversicherung brodelte mehr denn je. Ende November 1938 berichtet ein ehemaliger Vertrauensmann aus Leipzig an die Direktion der RfA:

Es wird behauptet, dass von jetzt an die Witwen-Renten nur an über 65 Jahre alte Frauen gezahlt würden und früher genehmigte Renten an jüngere Witwen sollten nicht weiter gezahlt werden. Weiter wird behauptet, dass Renten nur noch in der Höhe bis zu 100 RM pro Monat gezahlt würden, ohne Rücksicht auf die hohen Einzahlungen der Versicherten. ${ }^{231}$

Dafür waren nicht zuletzt zahlreiche DAF-Vertreter und andere NS-Funktionäre auf Kreis- und Gauebene mitverantwortlich, die in ihren Versammlungen entsprechende Informationen in die Welt setzten. Die Behauptungen eines thüringischen DAFKreisobmanns Anfang April 1938 waren exemplarisch. Dieser hatte in einem Schulungskurs behauptet, dass

wenn nicht in diesem, dann im nächsten Jahr die Invaliden-, Knappschafts- und Angestelltenversicherung zusammengelegt würden und dass dann sowohl Arbeiter wie Angestellte, selbst der Generaldirektor der IG Farben, ein monatliches Ruhegeld von 140 RM erhalten würden. Manche Arbeiter hätten in ihrem Leben monatlich nicht verdient, was sie später als Ruhegeld erhalten würden,

so berichtet jedenfalls der örtliche RfA-Überwachungsbeamte über die Veranstaltung nach Berlin. ${ }^{232}$ In der Ruhrstraße war man darüber so verärgert, dass man sich darüber beim Stellvertreter des Führers beschwerte, wo man den Vorfall abzuwiegeln versuchte. ${ }^{233}$ Die alltägliche Arbeit der RfA-Beamten machte das nicht leichter.

226 Ebd., S. 12.

227 Vermerk vom 8.11.1938, in: RfA-Archiv Nr. 78.

228 Zur kritischen Bewertung des Gesetzes vgl. auch Schlegel-Voß, S. 69.

229 Schreiben vom 29.1.1938, in: RfA-Archiv Nr. 23.

230 Quelle: RfA-Archiv Fach 116, Nr. 8.

231 Schreiben vom 27.11.1938, in: RfA-Archiv Fach 57, Nr. 1.

232 Bericht vom 14.5.1938, in: RfA-Archiv Fach 19, Nr. 3.

233 Vgl. Schreiben vom 26.8.1938, in: ebd. Vgl. weitere ähnliche Vorfälle, etwa die Rede des Wormser Kreisleiters auf einer Versammlung Anfang Januar 1939, in: ebd. 


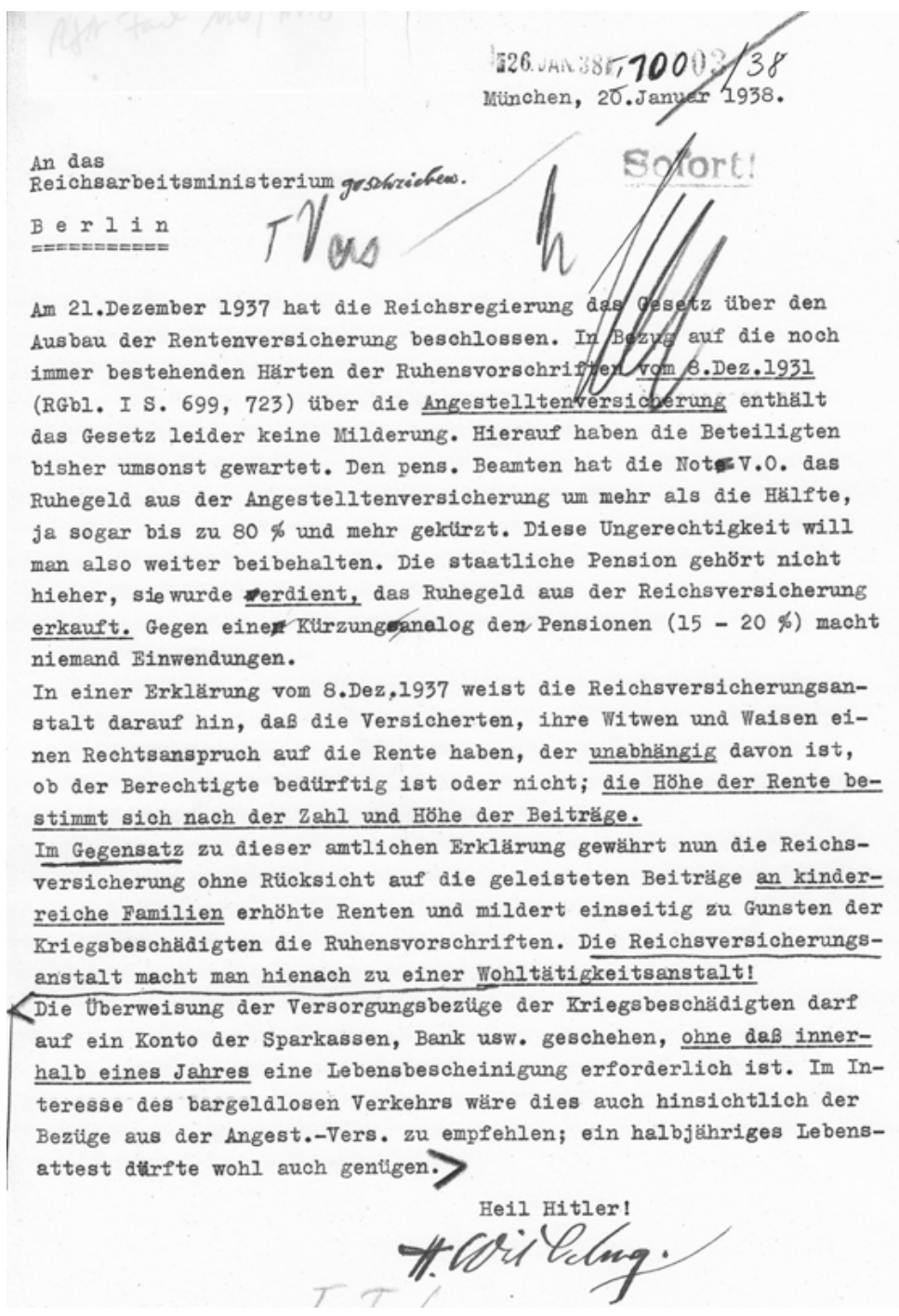

Abb. 16: Brief eines Versicherten an das RAM vom 20. Januar 1938 mit Kritik am Ausbaugesetz

\subsection{Verwaltungshandeln im nationalsozialistischen Behördenalltag}

\section{Neue Beschäftigungsverhältnisse und andere operative Probleme}

Obwohl drei Jahre seit dem letzten Rentenversicherungsgesetz vergangen waren, mussten sich die zuständigen Stellen immer noch mit der Umsetzung der ungebrochenen Flut von Durchführungsverordnungen des vagen Aufbaugesetzes befassen. 
Sieht man sich die wichtigsten Probleme und Aspekte im praktischen Verwaltungshandeln der RfA-Beamten genauer an, so lässt sich darin ein Spiegelbild der NS-Gesellschaft erkennen. Ein erstes Themenfeld war die versicherungsrechtliche Einordnung neuer Berufe, und hier gab es nicht nur die alten Konflikte zwischen RfA und LVA als zuständige Versicherungsträger der AV bzw. der Invalidenversicherung. Darüber hinaus war auch erkennbar, dass entgegen der proklamierten „Volksversicherungsideologie“ und den dahinterstehenden versicherungsrechtlichen Nivellierungsabsichten nach wie vor ein ungebrochener Trend bei den betroffenen Berufsgruppen bestand, im Zweifelsfall zu versuchen, in die Angestelltenversicherung mit höheren Renten und auch Prestige zu gelangen. Sowohl der langfristige Trend zu neuen Angestelltenberufen als auch die Dynamiken der nationalsozialistischen „Wirtschaftswunder-Gesellschaft“ hatten dazu geführt, dass das Berufsgruppenzugehörigkeitsverzeichnis von 1924 keine zehn Jahre später vielfach veraltet und überholt war. Neue Berufe bzw. sich auch in vielen alten Berufen ergebende Tätigkeitsveränderungen in vielen alten Berufen wie Hollerith-Tabellierer, Fleischbeschauer, Werkschutzleute, Badeaufseher, Molkerei-Leistungsprüfer oder Telefon-Revisoren erforderten eine rentenversicherungsrechtliche Zuordnung. ${ }^{234}$ Dutzende Aktenordner füllten etwa auch die Schriftwechsel zur versicherungsrechtlichen Stellung der Hebammen. Laufend fragten die jeweiligen Reichstreuhänder der Arbeit bei der Aufstellung der Tarifordnung in der Ruhrstraße an, ob und inwieweit angestellte Gefolgschaftsmitglieder, z. B. Büroboten, Kassenboten, Portiers u.a. tatsächlich als Angestellte im Sinne des Gesetzes zu gelten hatten. ${ }^{235}$

Die Regel war eigentlich einfach, denn die Zugehörigkeit zu einem der beiden Versicherungszweige richtete sich allein nach der Art der ausgeübten Tätigkeit. Dabei war es unerheblich, ob das betreffende Gefolgschaftsmitglied als Angestellter bezeichnet wurde und wöchentlich, monatlich oder nach anderer Art entlohnt wurde. Dennoch kam es immer wieder zu Streitverfahren, nicht nur mit den Landesversicherungsanstalten, sondern vor allem auch mit den betroffenen Versicherten selbst. Im Juli 1938 hatte etwa das Versicherungsamt Berlin die Stromgeldeinheber und Zählerableser bei der Berliner Kraft- und Licht-AG als invalidenversicherungspflichtig eingestuft, wogegen die Betroffenen, vertreten durch die Gaurechtsberatungsstelle der DAF, Beschwerde eingelegt hatten, um eine Zugehörigkeit zur Angestelltenversicherung zu erreichen. Mit Beschluss vom 30. November 1939 wurde ihnen tatsächlich Recht gegeben. ${ }^{236}$ Ein langes Hin und Her zwischen der Reichsgruppe Industrie, RfA und LVA ergab sich auch im Fall der Einordnung der Betriebsbeamten, Werkmeister und Werkgehilfinnen, für die die RfA letztlich keine pauschale Regelung traf, sondern

234 Vgl. dazu die entsprechenden Unterlagen und Schriftwechsel zu einzelnen Berufsgruppen in: RfAArchiv Fach 76, Nr. 1-11.

235 Vgl. dazu etwa Schreiben des Reichstreuhänders für das Wirtschaftsgebiet Brandenburg vom 13.9. 1937, in: RfA-Archiv Fach 16, Nr. 8.

236 Die Entscheidung mit Urteilsbegründung vom 30.11.1939, in: RfA-Archiv Fach 101, Nr. 5. Zahlreiche weitere Fälle zur Versicherungspflicht in: RfA-Archiv Fach 78, Nr. 1-3 und Fach 79, Nr. 1-4. 
gleichfalls erst nach Prüfung der genauen Tätigkeitsmerkmale entschied. ${ }^{237}$ Schon im Dezember 1934 hatte sich das RfA mit der Zuordnung der reichsweit ca. 150 Filialleiter des Bata-Schuhkonzerns befassen müssen. Hier ging es um die Frage der prinzipiellen Versicherungspflicht, die das Versicherungsamt Berlin mit Verweis auf die mit Umsatzprovision ausgestatteten „Handlungsagentenverträge“ verneinte. Im März 1935 wurde dann die Angestelltenversicherungspflicht festgestellt bzw. anerkannt und die bis dahin rückständigen Beiträge wurden bei den Betroffenen wie der Firma eingezogen. $^{238}$ Dagegen waren die Großtankstellenpächter (anders als die normalen Tankwarte) der aufstrebenden Mineralölfirmen wie Olex, Deutsche Gasolin AG und Reichskraftsprit GmbH nicht angestelltenversicherungspflichtig. ${ }^{239}$

Im Prinzip wurden die jeweiligen Entscheidungen über Versicherungspflichtigkeit oder versicherungsrechtliche Zuordnung relativ schnell gefällt. Wenn jedoch RfA und LVA unterschiedlicher Auffassung waren und um die Zugehörigkeit einer Berufsgruppe stritten, dann konnte es allerdings mit entsprechender negativer Rückwirkung für die Betroffenen länger dauern. Sechs Jahre lang verhandelten etwa das Versicherungsamt Nürnberg, die LVA Ober- und Mittelfranken und die RfA um die Versicherungszugehörigkeit der bei der Mechanischen Baumwollspinnerei in Bayreuth beschäftigten Web- und Spinnmeister. „Wir mussten häufig die Beobachtung machen“, so heißt es in einem Schreiben der LVA an die RfA, „dass Sie unter Zugrundelegung der Angaben der Beteiligten die Versicherten mit Hilfe des § 193 des AVG auf die Seite der Angestelltenversicherung zu ziehen versuchen.“240 Seit 1932 stritten sich RfA und die LVA Sachsen-Anhalt auch über die Angestelltenversicherungspflicht der Kassenschaffner bei der Magdeburger Straßenbahn AG. Die RfA hielt die Kassenschaffner für angestelltenversicherungspflichtig, die LVA hielt sie für invalidenversicherungspflichtig. Die Betroffenen selbst beantragten, aktiv unterstützt von der Rechtsberatungsstelle der DAF, ihre Zugehörigkeit zur RfA, die dann im Oktober 1940 in einem Grundsatzurteil auch bestätigt werden sollte. ${ }^{241}$ Schon fast legendär war der seit 1929 zwischen RfA und den Landesversicherungsanstalten schwelende Streit über die Versicherungszugehörigkeit der über das ganze Reich verteilten Warenverteiler der schleswig-holsteinischen Firma Friedrich Bölck AG. Die Betroffenen selbst wollten mit der Begründung, dass ihre Tätigkeit ein überwiegend kaufmännisches Gepräge trage und weit über die Tätigkeit eines Handarbeiters hinausgehe, in die RfA. Dennoch waren sie zunächst als invalidenversicherungspflichtig eingestuft worden, und der Reichsverband der Landesversicherungsanstalten legte im Herbst 1937 alles daran, die Abwanderung der ca. 3000 Warenverteiler mit ihrem damaligen Beitragsaufkommen von 300.000 RM zur RfA zu verhindern, „um der sich immer stärker bemerkbar ma-

237 Vgl. dazu die drei Aktenmappen für die Zeit 1935 bis 1944, in: RfA-Archiv, ohne Signatur (Regalreihe 5).

238 Vgl. RfA-Archiv Fach 78, Nr. 1.

239 Vgl. dazu die Abteilungsverfügung vom 12.7.1939, in: RfA-Archiv Fach 1, Nr. 1.

240 Schreiben vom 24.4.1937, in: RfA-Archiv Fach 57, Nr. 5.

241 Der Vorgang in: BArch R 89/22705. Weitere Vorgänge mit 16 Akteneinheiten in: BArch R 89/22702. 
chenden Aushöhlung des Versichertenbestandes der Invalidenversicherung entgegenzutreten“, wie die LVA Schleswig-Holstein dazu schrieb. ${ }^{242}$

Bei einigen Berufsgruppen spielten auch politisch-ideologische Motive in ihren Bemühungen um Anerkennung als Angestellte und Zugehörigkeit zur RfA mit hinein. Im Zuge der politischen Aufwertung versuchten etwa der Reichsbauernführer sowie der Reichsjägermeister, Jagdaufseher bzw. Revierjäger und Forstwarte mit dem Argument des im NS-Staat angeblich wesentlich erweiterten Aufgabenkreises aus ihrer früheren Invalidenversicherungspflicht in die Angestelltenversicherung zu bringen. ${ }^{243}$ Im Windschatten der politischen Verhältnisse versuchten auch die Schriftleiter versicherungsrechtliche Privilegien zu erlangen und von der Angestelltenversicherung insgesamt befreit zu werden. Schon im Dezember 1933 hatte sich deshalb die RfA mit der Versorgungsanstalt der Reichsarbeitsgemeinschaft der Deutschen Presse angelegt und die Nachentrichtung der AV-Beiträge für die ca. 1500 Mitglieder unterhalb einer bestimmten Einkommensgrenze (600 RM pro Monat) gefordert. ${ }^{244}$ Das Goebbels-Ministerium hatte sich dabei offenbar auf die Seite der Schriftleiter geschlagen, und so beschäftigte die Angelegenheit die Behörde bis 1935. Letztlich ging es dabei um die Frage, ob die Reichsregierung einem Berufsstand gestatten durfte, ,sich von der Versichertengemeinschaft, deren Träger die RfA ist, abzusondern, um daraus für sich Vorteile zu erzielen“. ${ }^{245}$ RfA und RAM konnten sich tatsächlich nicht durchsetzen. Erst im Zuge des Aufbaugesetzes wurde der 1. Januar 1937 als Stichtag der Versicherungspflicht festgesetzt. Für diejenigen Schriftleiter, die infolge der Erhöhung der Versicherungspflichtgrenze vorher erneut angestelltenversicherungspflichtig geworden waren, galt allerdings für die Zeit vom 1. September 1928 bis 31. Dezember 1935 nach wie vor Versicherungsfreiheit, wie das RVA in einer Grundsatzentscheidung im Juni 1937 bestimmte. ${ }^{246}$ Auch anderweitig fiel das RVA der RfA in den Rücken. Ende Juni 1938 wurde in einem Rundschreiben zur Nachprüfung der Versicherungszugehörigkeit bestimmt, dass in langjährigen Versicherungsverhältnissen, in denen sich Arbeitgeber und Gefolgschaftsmitglieder über die Versicherungszugehörigkeit einig waren, trotz etwaiger andersartiger Zuordnung infolge einer Nachprüfung durch den Versicherungsträger „künftig grundsätzlich nicht mehr ohne besonders zwingenden Anlass von Amt wegen“ eingegriffen werden sollte und „grundsätzlich von einer Be-

242 Vgl. Schreiben der RfA an das RVA vom 24.9.1937 sowie Brief der LVA an das RVA vom 8.11.1937, in: BArch R 89/3446.

243 Vgl. dazu der sich von Mai 1938 bis Februar 1939 hinziehende Konflikt zwischen dem Badischen Oberversicherungsamt, der RfA und der DAF-Rechtsberatung um die Einstufung des Jagdaufsehers Hubert P. bzw. des Revierjägers Franz M., in: BArch R 89/22704. Vgl. auch das Schreiben des Reichsbauernführers an das RAM vom 15.6.1937 und vom 21.12.1940, in: RfA-Archiv Fach 109, Nr. 8.

244 Vgl. Aktennotiz vom 15.12.1933, in: RfA-Archiv Fach 116, Nr. 15/16.

245 Schreiben des RAM an das Reichsministerium für Volksaufklärung und Propaganda vom 16.3. 1935, in: ebd.

246 Das Grundsatzurteil zum Streifall der Pflichtbeiträge eines Schriftleiters aus Chemnitz vom 16.6. 1937, in: ebd. 
anstandung der Beiträge und Überführung in einen anderen Versicherungsträger abzusehen" war. ${ }^{247}$

Weit stärker politisch aufgeladen war demgegenüber die Klärung der Versicherungsfragen bei den vielen nun entstandenen NS-spezifischen Beschäftigungsverhältnissen. Wie sollten HJ-Landdienst und NS-Frauenhilfsdienst versicherungsrechtlich behandelt werden? Und wie die Dienstzeiten in der SA und den verschiedenen SSOrganisationen? Die RfA sah sich dabei mitten in einem politischen Aushandlungsprozess zwischen RAM, RVA und den verschiedenen NS-Stellen, auf den sie wenig Einfluss hatte. Unter dem Strich erfolgten hier eindeutige Privilegierungen und Ausnahmeregelungen, die von den gesetzlichen Bestimmungen deutlich abwichen. Dennoch versuchte die RfA in Einzelfällen durchaus, den Gesetzesabweichungen nicht Tür und Tor zu öffnen. Schon im Juni 1934 hatte sich die Abteilung I Versicherung mit der Frage der Versicherungspflicht der SA-Angehörigen zu befassen. Danach legte man im Einvernehmen mit der Rechtsabteilung der Obersten SA-Führung fest, dass die Aufwandsentschädigungen an in Verwaltungsstellen der SA Beschäftigte nicht als Entgelt im Sinne des Angestelltenversicherungsgesetzes anzusehen waren und daher Versicherungsfreiheit bestand. ${ }^{248}$ Im Mai 1936 war dann per Erlass des Reichsfinanzministeriums bzw. des RVA bestimmt worden, dass bei „Alten Kämpfern“ die Dienstzeiten in der SS, SA, als Amtswalter oder Redner der NSDAP sowohl beim Besoldungsdienstalter wie auch bei den Versicherungsanwartschaften ,ausnahmsweise“ angerechnet wurden. ${ }^{249}$ Ebenfalls angerechnet als Ersatzzeit zur Aufrechterhaltung der Anwartschaft wurden etwa auch die Zeiten in den SA-Hilfswerkslagern, die als berufliche Bildungsmaßnahme für SA-Angehörige angesehen wurden. ${ }^{250} \mathrm{Im}$ Mai 1939 wurde dies durch eine Sonderreglung hinsichtlich der Anrechnung der Dienstzeit in der SA-Standarte „Feldherrnhalle“ ergänzt. ${ }^{251}$ Eine weitergehende Sonderreglung für die „alten Kämpfer“ in Form einer nachträglichen Befreiung von der AV-Versicherungspflicht für diejenigen alten Nationalsozialisten, die im Rahmen des Stellenvorbehalts in das Beamtenverhältnis überführt worden waren, ließ sich jedoch nicht verwirklichen. ${ }^{252}$ Schon zuvor hatten einzelne höhergestellte SA-Angehörige mit Unterstützung ihrer zuständigen NSDAP-Kreisleitungen versucht, Ausnahmereglungen bei ihren Versicherungsverläufen zu erreichen, insbesondere bei der Anrechnung von Erwerbslosenzeiten vor 1933 bei der Rentenversicherung. ${ }^{253}$ Doch was als versicherungsrechtliches Unrecht der sogenannten Systemzeit dargestellt wurde, ent-

247 Rundschreiben des RVA vom 27.6.1938, in: ebd.

248 Vgl. Abteilungsverfügung vom 19.6.1934, in: RfA-Archiv ohne Signatur, Regal 5.

249 Vgl. Rundschreiben des RVA vom 26.5.1936 sowie dazu auch Rundschreiben vom 26. 2.1937, in: BArch R 89/3427 bzw. 3481.

250 Vgl. Abteilungsverfügung vom 14.1.1937, in: RfA-Archiv Nr. 1.

251 Vgl. Rundschreiben vom 8.5.1939, in: BArch R 89/3485.

252 Vgl. Schreiben des Reichsinnenministeriums vom 7.7.1940, in: RfA-Archiv Fach 12, Nr. 8.

253 Vgl. Schreiben der Kreisleitung Dortmund betr. SA-Obersturmbannführer Karl K. vom 29.1.1937, in: RfA-Archiv Fach 3, Nr. 2. 
puppte sich bei der Nachprüfung schnell als die einfache Tatsache erloschener Anwartschaften. „Dem Antrag des Versicherten K., ihm die Zeit seiner Arbeitslosigkeit als Ersatzzeit in der AV anzurechnen, kann nicht stattgegeben werden“, hieß es etwa lapidar in einem entsprechenden Bescheid der RfA an das RVA Mitte Juni 1937.254

Besonderheiten gab es auch in Bezug auf die Versicherungspflicht von SS-Angehörigen. Über die Frage, ob und in welcher Weise aufgrund der SS-Zugehörigkeit überhaupt Versicherungspflicht bestand, gab es seit 1933/34 lange Diskussionen, die sich in zahlreichen Einzelfall-Streitigkeiten zwischen SS-Angehörigen und der RfA niedergeschlagen hatten. Streit hatte es etwa im Herbst 1936 mit zwei Berliner bzw. Hamburger SS-Brigadeführern gegeben, die mit Verweis auf ihre beträchtlichen Nebeneinkünfte als Staatsräte und Reichstagsabgeordnete zusätzlich zu ihren Vergütungen als SS-Führer aufgrund des Überschreitens der Verdiensthöchstgrenzen für sich Versicherungsfreiheit reklamierten. RfA-Direktor Granzow stand jedoch auf einem anderen Standpunkt und machte klar, dass die keinem Dienstverhältnis entspringenden Nebeneinkünfte irrelevant waren und auch ein Führer der SS mit monatlich 500 RM Gehalt eine angestelltenversicherungspflichtige Tätigkeit ausübte. ${ }^{255}$ Bereits im Februar 1935 war es auch zu einem Disput zwischen der RfA und der Kommandantur des KZ Esterwegen (Emsland) gekommen. Der Lagerkommandant forderte dabei unter Verweis auf einen angeblichen geheimen Erlass des Preußischen Ministerpräsidenten vom Dezember 1933 zur Versicherungsbefreiung des dortigen Verwaltungsführers die vom Juli 1934 bis Januar 1935 gezahlten AV-Beiträge zurück. ${ }^{256}$ Doch die RfA-Beamten sahen keinen Grund für eine Befreiung von der Versicherungspflicht und verweigerten hartnäckig die Rückzahlung. Auch bei einer Reihe weiterer SS-Angehörige der KZ-Kommandantur war die Versicherungspflicht unklar und strittig, so dass sich die dortigen Lagerleiter bald mit Aufforderungen zu Nachtragszahlungen durch die RfA konfrontiert sahen. ${ }^{257}$ Eine endgültige Klärung des Falls blieb aus, denn Ende Mai 1937 musste das RVA in einem Rundschreiben eingestehen, dass die gesamten Rechtsverhältnisse der SS-Angehörigen nach wie vor im Fluss und damit ungeklärt waren. Mit einer Regelung sei allerdings in Kürze zu rechnen und daher sollten sämtliche anhängigen Streitfälle zurückgestellt werden. ${ }^{258}$ Anders als bei den anderen NS-Organisationen stand der gesamte Schriftwechsel in dieser Frage auch innerdienstlich bei der RfA unter dem Siegel hoher Vertraulichkeit und strenger Geheimhaltung.

Im August 1938 erfolgte dann eine vorübergehende Regelung der Sozialversicherungspflicht der Angehörigen der SS-Verfügungstruppe und der SS-Totenkopf-

254 Bescheid vom 15.6.1937, in: ebd.

255 Vgl. Bescheid Granzow vom 24.9.1936 sowie Schreiben Granzow vom 10.12.1936, in: RfA-Archiv ohne Signatur, Regal 5.

256 Schreiben an die RfA vom 8.2.1935, in: RfA-Archiv, ohne Signatur, Regalreihe 5.

257 Vgl. Schreiben der RfA an das RAM vom 18.5.1936, in: ebd.

258 Vgl. Abteilungsverfügung auf der Basis dieses Rundschreibens vom 29.5.1937, in: RfA-Archiv Nr. 22. 
verbände. Darin wurde eine maßgebliche Unterscheidung vorgenommen. Der vierjährige Pflichtdienst in einer SS-Verfügungstruppe wurde der Wehrdienstpflicht gleichgestellt, war damit nicht sozialversicherungspflichtig, aber als Ersatzzeit anrechenbar. Die Männer der SS-Totenkopfverbänden jedoch, die ihre ebenfalls vierjährige Dienstzeit im wesentlichen als Wachpersonal in den Konzentrationslagern ableisteten, waren nicht der Wehrpflicht gleichgestellt. Obwohl sie in dieser Zeit ebenfalls nicht versicherungspflichtig waren, erfolgte keine Ersatzzeitanrechnung. ${ }^{259}$ Im Oktober 1939 wurde dieser Erlass noch einmal bestätigt, verbunden mit dem Hinweis, dass „mit einer allgemeinen gesetzlichen Regelung der Rechtsverhältnisse der SS-Angehörigen offenbar zunächst nicht mehr zu rechnen [ist] “. ${ }^{260}$ Erst im Krieg sollte es der SS gelingen, auch diese versicherungsrechtliche Unterscheidung aufzuheben und die Totenkopfverbände einheitlich unter den Begriff der „Waffen-SS“ zu fassen. ${ }^{261}$ Eine andere Regelung erfuhren jedoch demgegenüber die „SS-Wachmänner“, die nach Angaben des SS-Hauptamtes reichsweit für staatswichtige Betriebe eingesetzt wurden. Bislang waren für sie einheitlich Beiträge in der Invalidenversicherung gezahlt worden, im März 1939 beantragte jedoch die zuständige SS-Stelle aufgrund der geänderten bzw. erweiterten Tätigkeit eine Überführung in die Angestelltenversicherung. ${ }^{262}$ Nach entsprechenden Verhandlungen, in die auch die LVA Berlin eingeschaltet war, wurde festgelegt, dass die SS-Wachmänner invalidenversicherungspflichtig blieben, die SS-Wachführer und ihre Stellvertreter dagegen in die AV zur RfA kamen. Statt der viel propagierten versicherungsrechtlichen Vereinheitlichung fand tatsächlich eine Ausdifferenzierung der versicherungsrechtlichen Verhältnisse und Zuordnungen statt.

Auch anderweitig suchten NS-Behörden und NS-Organisationen hinter den Kulissen versicherungsrechtliche Privilegien für sich und ihre Klientel zu erreichen. Im September 1938 wandte sich etwa der Geschäftsführer des Lebensborn e.V., SSObersturmbannführer Pflaum, direkt an Grießmeyer und bat um die Befreiung werdender lediger Mütter von der Beitragspflicht zur Angestelltenversicherung unter Aufrechterhaltung der Anwartschaft vom fünften Monat der Schwangerschaft bis zur Wiederaufnahme der Arbeit. ${ }^{263}$ In den Genuss dieser Regelung sollten allerdings nur jene Mütter kommen, die sich in eines der Lebensborn-Heime begeben hatten. Es kam sogar zu einer persönlichen Unterredung zwischen Pflaum und Grießmeyer, dessen Ergebnis allerdings, gestützt auf eine RfA-interne Stellungnahme des ärztlichen Re-

259 Vgl. Abteilungsverfügung vom 26.8.1938, in: RfA-Archiv Nr. 24.

260 Abteilungsverfügung vom 28.10.1939, in: ebd.

261 Vgl. die geheime Abteilungsverfügung vom 22.6.1940, in: ebd. sowie den Schriftwechsel mit dem OKW und den Brief des Reichsführers SS an die RfA vom 8.6.1940, in: RfA-Archiv Fach 97, Nr. 1.

262 Vgl. Schreiben des SS-Hauptamts an die RfA vom 28.3.1939, in: RfA-Archiv, ohne Signatur, Regal 5, Bd. 6.

263 Das Schreiben vom 7.9.1938, in: RfA-Archiv Fach 114, Nr. 13. 
ferenten, eine Ablehnung des Ansinnens war. ${ }^{264}$ Im September 1937 schon hatten sich die RfA-Beamten unter anderem auch mit der Versicherungszugehörigkeit der Kriminalangestellten bei der Gestapo beschäftigt. Dort gab es eine Reihe von angestellten Kraftfahrern, die neben der Führung und Wartung der Dienstfahrzeuge auch polizeiliche Dienstgeschäfte zu erledigen hatten. Die Gestapo selbst betrieb eine versicherungsrechtliche Aufwertung dieser Beschäftigten und nach eingehenden Besprechungen mit den Versicherungsträgern wurde für diese quasi einer Höherstufung in der Angestelltenversicherung beschlossen. ${ }^{265}$ Klärungsbedürftig waren auch die versicherungsrechtlichen Zuordnungen der (haupt- wie ehrenamtlich) in den Dienststellen des Reichsluftschutzbundes Tätigen. Zugeständnisse machte die RfA auch in der Frage der Anerkennung des HJ-Landdienstes als Berufsausbildung mit entsprechenden Rückwirkungen auf die Gewährung von Kinderzuschüssen bei Alters- oder Witwenrenten. ${ }^{266}$

In der Frage der Versicherungspflicht bzw. -freiheit der im Frauenhilfsdienst tätigen Mädchen, die für zwei Jahre im Gesundheitsdienst zur Unterstützung der Schwestern oder in der Wohlfahrtspflege zur Unterstützung der Volkspflegerinnen und Kindergärtnerinnen arbeiteten, kam es dagegen lange zu keiner Regelung im Sinne der NS-Stellen. Seit längerem schwebten hierzu Verhandlungen zwischen dem RVA, der Reichsfrauenführerin und dem Hauptamt für Volkswohlfahrt der NSDAP. Prinzipiell wurde die Versicherungsfreiheit angestrebt, aber das Problem war, dass Mädchen, die vor Eintritt in den Frauenhilfsdienst bereits eine angestellten- oder invalidenversicherungspflichtige Tätigkeit ausgeübt und demgemäß Versicherungsbeiträge entrichtet hatten, ihre Ansprüche infolge von Anwartschaftsverlusten durch Nichtkleben von Marken während der Hilfsdienstzeit verlieren konnten. Auch hier mussten daher Sonderregelungen (Verpflichtung zur Selbstversicherung und Tragen der Kosten durch die Gauamtsleitungen) entwickelt werden. ${ }^{267}$ Welche bürokratischen Kuriosa dabei geschaffen wurden, zeigt die Regelung der in den NSV-Kindergärten beschäftigten Kindergärtnerinnen, Kinderpflegerinnen und Hortnerinnen. Das RVA, das Hauptamt für Volkswohlfahrt und der Reichsverband der Deutschen Rentenversicherungsträger einigten sich im August 1939 darauf, dass sämtliche NSV-Beschäftigten in den Kindergärten, Horten und Krippen prinzipiell versicherungspflichtig waren. Für die Einordnung in die AV oder IV galt jedoch, dass in Erstere diejenigen Personen kamen, die eine staatliche Prüfung abgelegt hatten, in die IV fielen dagegen die nichtgeprüften Kindergärtnerinnen, denen nicht mehr als eine Helferin unter-

264 Man könne nicht anerkennen, dass allgemein schon vom fünften Monat der Schwangerschaft an zeitweise Arbeitsunfähigkeit vorliege, hieß es in der Begründung. Vgl. Schreiben an Lebensborn vom 5.10.1938, in: ebd.

265 Vgl. dazu die Abteilungsverfügung vom 10.9.1937, in: RfA-Archiv Nr. 22.

266 Vgl. Schriftwechsel des RVA mit der RfA vom Februar 1939, in: RfA-Archiv Nr. 24.

267 Vgl. dazu den Briefwechsel vom Dezember 1938 und vor allem das Schreiben des RVA an die RfA vom 15.3.1939, in: RfA-Archiv Fach 1, Nr. 1 und die entsprechende Abteilungsverfügung vom 4.1.1939, in: ebd. 
stand; andernfalls waren sie angestelltenversicherungspflichtig. ${ }^{268}$ Reichlich kompliziert war auch die versicherungsrechtliche Regelung der infolge der Notdienstverordnung vom 15. Oktober 1938 entstandenen Tätigkeiten und Dienst- bzw. Beschäftigungsverhältnisse. Kurzfristiger Notdienst begründete keine Beitragspflicht zur Angestelltenversicherung, langfristige Notdienstpflicht dagegen schon, allerdings mit weiteren Differenzierungen. Während einigen Notdienstpflichtigen, die etwa in Aufgaben von besonderer staatspolitischer Bedeutung eingesetzt wurden, die entsprechende Zeit für die Erhaltung der Anwartschaft, die Erfüllung der Wartezeit und rentensteigernd angerechnet werden konnten, galt das bei anderen, die etwa im Polizeihilfsdienst, Luftschutzwarndienst oder Luftschutzsicherheitsdienst eingesetzt wurden, nicht. ${ }^{269}$

Aufwändige Klärungen und immer neue Änderungen gab es auch hinsichtlich der Versicherungspflicht der diversen Beschäftigten in dem zum 1. Oktober 1935 eingeführten Reichsarbeitsdienst. Im Prinzip galt hier für das Stammpersonal, die einberufenen Arbeitsdienstpflichtigen sowie die Arbeitsdienstfreiwilligen Versicherungsfreiheit. RAM, Reichsfinanzministerium sowie Reichsinnenministerium hatten daher im März 1936 einvernehmlich beschlossen, „dass aus finanziellen Gründen die Zeit des Arbeitsdienstes als Ersatzzeit auf die Erhaltung der Anwartschaft beschränkt werden müsste“. ${ }^{270}$ Für hauptamtliches Führungspersonal wie die Reichsarbeitsdienstführerinnen galt jedoch Angestelltenversicherungspflicht und nach entsprechender Ernennung wurde eine Nachversicherung erforderlich. Schließlich ergaben sich auch mit der Einführung der Wehrpflicht im März 1935 umfangreiche sozialversicherungsrechtliche Änderungen. Kurzfristige Übungszeiten in der Wehrmacht galten als Ersatzzeiten für die Erhaltung der Anwartschaft in der AV, allerdings nur in dem Fall, dass kein Gehalt weitergezahlt wurde. Prinzipiell bestand aber noch im August 1936 eine Gesetzeslage, nach der sich ein Versicherter seine aktive Dienstpflicht in der Wehrmacht nicht als Ersatzzeit für die Anwartschaftserhaltung in der AV anrechnen lassen konnte. Eine entsprechende Änderung sollte erst 1939 kommen. Pech hatten auch diejenigen, die sich als „Junker der NSDAP“ zu einem der vierjährigen Lehrgänge auf den NS-Ordensburgen verpflichteten. Diese Lehrgänge waren als berufliche Fortbildung nicht anerkannt und daher war eine versicherungsrechtliche Berücksichtigung durch Anrechnung als Ersatzzeiten nicht möglich. ${ }^{271}$

Doch Berufsgruppenzugehörigkeit und neue NS-Beschäftigungsverhältnisse waren nur ein kleiner Ausschnitt aus den Verwaltungsproblemen, mit denen die RfAAngestellten täglich konfrontiert waren. Es gab drei weitere Problemfelder, die damals Versicherte wie Behördenmitarbeiter bewegten: die versicherungsrechtliche Behandlung von Weihnachtsgratifikationen als Entgelt, das Dauerproblem der Wan-

268 Vgl. Schreiben des RVA an die Versicherungsträger vom 26.8.1939, in: RfA-Archiv Fach 109, Nr. 8.

269 Vgl. Vermerk vom 18.10.1939 und die entsprechende Abteilungsverfügung, in: ebd.

270 Schreiben vom März 1936, in: BArch R 89/3427, Bl. 96.

$271 \mathrm{Vgl}$. dazu die entsprechende Anfrage eines Betroffenen an die RfA vom 5.10.1938 sowie das Antwortschreiben, in: RfA-Archiv Fach 12, Nr. 8. 
derversicherten und die sich daraus ergebenden Konflikte beim Zusammenwirken zwischen RfA und den LVA sowie schließlich das seit 1938 im Zuge des Arbeitskräftemangels immer drängendere Problem der Wiederbeschäftigung von Rentnern und Frauen. Prinzipiell bestand Versicherungspflicht, wenn Beschäftigte gegen Entgelt in einem Dienstverhältnis standen. Was und ab welcher Höhe als Entgelt in diesem Sinne galt, war aber strittig. Der RfA schlug wenig Sympathie dafür entgegen, dass sie Weihnachtszuwendungen generell bei der Berechnung der Versicherungsbeiträge mit berücksichtigte, vor allem wenn sie schriftlich in einer Tarif- oder Betriebsordnung fixiert waren und etwa einen Monatslohn überstiegen. ${ }^{272}$ Die DAF selbst gewährte ihren Mitarbeitern aufgrund einer Dienstordnung als Sonderleistungen Heiratsbeihilfen, Geburtsbeihilfen und Beihilfen aus Anlass der Einberufung zum Heeresdienst. Sämtliche Beihilfen jedoch stellten in den Augen der RfA Entgelte dar und waren daher im Monat der Zahlung mit ihrem vollen Betrag bei der Beitragsberechnung in Ansatz zu bringen. ${ }^{273}$ Auch die in den Großbetrieben als freiwillige Fürsorgeleistungen an die Belegschaft gezahlten Beträge fielen unter die Entgeltregelung, und die Überwachungsbeamten der RfA mussten sich bei ihren Besuchen vor Ort von den Personalund Sozialabteilungen ständig Klagen darüber anhören. ${ }^{274}$

Bald häuften sich die Beschwerden und versicherungsrechtlichen Streitverfahren, zumal die NS-Stellen bzw. die DAF in der strengen Auslegung der Entgeltregelung zunehmend kontraproduktive Effekte feststellten. ${ }^{275}$ Von den Maßnahmen waren etwa auch die 1935 von der Ilseder Hütte an die Belegschaft ausgeschütteten Dividenden in Höhe von 35 RM betroffen, die diese ,in Übereinstimmung mit der sozialen Einstellung unseres nationalsozialistischen Staates“ als Ertragsbeteiligung des guten Geschäftsjahres bar an die Gefolgschaft ausgezahlt hatte. ${ }^{276}$ Dass einzelne LVA und auch die RfA daraufhin von dem Unternehmen rückwirkend die entsprechenden Beitragsanteile forderten, sorgte bei Vorstand wie Belegschaft für wenig Begeisterung. Bei der RfA beharrte man jedoch unbeirrt auf einer strikten Auslegung der Entgeltregelung. Eine Stellungnahme zum Fall der Ilseder Hütte gegenüber dem RVA von Mitte Dezember 1938 verlautet:

272 Vgl. dazu Mitteilungen der RfA Nr. 11, 1936.

273 Vgl. dazu die Abteilungsverfügung vom 17.11.1936, in: RfA-Archiv Fach 1, Nr. 1.

274 Vgl. dazu etwa der Besuchsbericht vom Februar 1939 als Teil des Revisionsberichts des RVA in: BArch R 89/3452, Bl. 209 sowie Niederschrift über die Dienstbesprechung mit den in Schlesien tätigen Überwachungsbeamten vom 29.5.1936, in: RfA-Archiv Fach 68, Nr. 1.

275 Vgl. dazu etwa die im Juli 1939 entbrannte Streitsache des Oberversicherungsamtes Hamburg bzw. der RfA mit der Hamburger Firma Conrad Scholtz AG (die ihre Interessen von der Gaurechtsberatungsstelle der DAF wegen der Feststellung vertreten ließ, ob Versicherungsprämien als Entgelt im Sinne des $\S 160$ der RVO anzusehen waren, in: BArch R 89/22705. Im November 1940 wurde dann dazu das Urteil gefällt. Demnach gehörten die Versicherungsbeiträge, die ein Unternehmer für eine zugunsten seiner Gefolgschaft abgeschlossene Lebensversicherung aufbrachte, nicht zum Entgelt.

276 Schreiben des Aufsichtsrats der Iseder Hütte an das RAM vom 28.11.1938, in: RfA-Archiv Fach 109, Nr. 10. 
Mit Rücksicht darauf, dass die Höhe der Leistungen der AV sich im wesentlichen nach den eingezahlten Beiträgen richtet, deren Höhe wiederum vom Entgelt abhängt, müssen wir darauf bedacht sein, dass auch tatsächlich die volle Gegenleistung für die versicherungspflichtige Beschäftigung der Beitragsberechnung zugrunde gelegt wird. Andernfalls würde die RfA später nur Renten gewähren können, die nicht einmal dem als Beitrag zur AV berechneten ohnehin schon geringeren Anteil am Entgelt entsprächen. ${ }^{277}$

Dabei konnte man sich auf die Rechtsprechung berufen, denn nur kurz zuvor hatte die RfA in einem ähnlich gelagerten Streitfall mit der Berliner Schultheiss-PatzenhoferBrauerei AG in allen Punkten obsiegt. Ob die Deutsche Bau- und Bodenbank AG, die Klöckner Eisenhandels GmbH oder das Angestelltenbüro der Reichsbank, alle Betriebe bekamen weiterhin nach entsprechenden Überprüfungen durch die Überwachungsbeamten Mahnschreiben zur nachträglichen Beitragsanrechnung von gewährten Zuschüssen und Zulagen. Unter den Versicherungsträgern wurde die Entgeltfrage jedoch keineswegs einheitlich gehandhabt. Anfang April 1939 erschien der Leiter der Sozialabteilung der Siemens-Werke zusammen mit dem Leiter der Hauptpersonalverwaltung des Osram-Konzerns im RVA. Beide machten geradezu verzweifelt darauf aufmerksam, dass der jetzige Zustand der Gesetzesauslegung „unerträglich sei. Insbesondere bestehe hier in Berlin zwischen RfA und LVA eine völlig entgegengesetzte Auffassung. “278

Differenzen und daraus resultierenden erheblichen Abstimmungs- und Koordinierungsbedarf gab es auch bei den Wanderversicherten. Die Materie war reichlich kompliziert. Über zentrale Begriffe wie Arbeits- und Berufsfähigkeit, Berufsausbildung und Erwerbsfähigkeit gab es keinen Konsens. Die Rentenversicherungsträger und die Arbeitsämter wiesen unterschiedliche Handhabungen bei der Beurteilung der Invalidität auf, und LVA und RfA wiederum unterschieden zwischen Invalidität bzw. Arbeitsunfähigkeit und Berufsunfähigkeit. Die RfA stand zudem auf dem Standpunkt, dass die Entscheidung der Frage, ob eine Berufsunfähigkeit dauernd oder vorübergehend sei, von den besonderen Umständen des Einzelfalles abhänge, während die LVA das Unterscheidungsmerkmal dafür rein äußerlich ausschließlich auf einen von vornherein fest bestimmten Zeitabschnitt abstellten. ${ }^{279}$ Der Gesetzgeber hatte bisher, so argumentierte man auf Seiten der RfA, absichtlich davon abgesehen, hier eine einheitliche gesetzliche Regelung zu schaffen und dafür die Entscheidung den Versicherungsträgern überlassen. Neben den rein ärztlichen Beurteilungen der jeweiligen Vertrauensärzte gab es dabei auch noch andere, nichtmedizinische Aspekte, wie etwa die zumutbare Leistungsfähigkeit in der zuständigen Berufsgruppe vor einer entsprechenden Entscheidungsfindung und der Bescheiderteilung. In die Angelegenheit

277 Schreiben der RfA an das RVA vom 13.12.1938, in: ebd.

278 Vermerk über die Besprechung vom 4.4.1939, in: BArch R 89/3396.

279 Vgl. Schreiben der RfA an das RVA vom 1.12.1937, in: RfA-Archiv Nr. 22 sowie Ergebnis der Aussprache vom 26.1.1938 zwischen den Vertretern der RfA und dem Reichsverband deutscher Landesversicherungsträger über das Verfahren bei Feststellung der Renten von Wanderversicherten, in: RfAArchiv Nr. 59. 
mischte sich im November 1937 sogar der Stellvertreter des Führers ein, nachdem bei ihm mehrere Eingaben und Berichte von Gauleitungen über die unterschiedliche Beurteilung der Arbeitsfähigkeit durch die Behörden eingegangen waren. Auf dessen Veranlassung hin hatten das Sozialamt der DAF und das Hauptamt für Volksgesundheit eine umfassende Überprüfung der Verhältnisse vorgenommen, die die höchst unterschiedliche Handhabung denn auch bestätigten. ${ }^{280}$ Auch in der AV war es demnach, wie die RfA gegenüber dem RVA im Dezember 1937 einräumte, wiederholt vorgekommen, dass Versicherte, deren Berufsunfähigkeit aufgrund der ärztlichen Feststellungen im Verfahren der AV nicht anerkannt werden konnte und deren Anspruch auf Ruhegeld deshalb abgelehnt worden war, von dem zuständigen Arbeitsamt als arbeitsunfähig angesehen und aus der Arbeitslosenunterstützung herausgenommen worden waren. ${ }^{281}$

Unter den Betroffenen hatte das für erhebliche Empörung und Kritik gesorgt. Im Laufe des Jahres 1938 fanden deshalb zahlreiche Besprechungen über die Zusammenarbeit der Träger der Arbeitslosen- und der Rentenversicherung bei Feststellung der Arbeitsfähigkeit bzw. Invalidität statt. ${ }^{282}$ Dabei verteidigte die RfA vehement ihre Verwaltungspraxis und hielt „mit Rücksicht auf die besonderen Verhältnisse in der Angestelltenversicherung eine abweichende Regelung [...] für geboten“.283 Der Kriegsausbruch brachte dann aber erst einmal alle weiteren Abstimmungsbemühungen ins Stocken. ${ }^{284}$ Aber auch bei der Anrechnung der Ersatzzeiten, der Handhabung der Ruhensvorschriften und der Berechnung der Leistungen bzw. Anrechnung der Beiträge gab es unterschiedliche Auffassungen und Verwaltungspraktiken der Versicherungsträger. ${ }^{285}$ Lange Zeit war unklar, wie bei Wanderversicherten die jeweiligen Beiträge anzurechnen waren und welches Recht bei der Gewährung von Leistungen aus den einzelnen Versicherungszweigen für die Anwartschaft und Wartezeit maßgebend war. ${ }^{286}$ Prinzipiell galt, dass bei Wanderversicherten Invalidenversicherungsbeiträge nur dann auf die Wartezeit in der Angestelltenversicherung an-

280 Schreiben des Stellvertreters des Führers an das RAM vom 23.9.1937 sowie Antwortschreiben des RAM vom 6.11.1937, in: RfA-Archiv Nr. 22.

281 Schreiben der RfA an das RVA vom 27.11.1937, in: ebd.

282 Vgl. dazu etwa den Vermerk über die Besprechung vom 30.5.1938, in: RfA-Archiv Nr. 34.

283 Vermerk des Direktors Koch vom 7.6.1938, in: ebd.

284 Vgl. Vermerk Kochs vom 12.10.1939, in: ebd. In einem Runderlass hatte das RAM bzw. RVA die abweichende Verwaltungspraxis in einem Zusatz anerkannt. Vgl. Schreiben der RfA an das Landesarbeitsamt Bayern vom 28.11.1939 sowie Vermerk Kochs vom 7.10.1940, in: ebd.

285 Vgl. etwa auch Landesrat Fix (LVA Westfalen), Eine Lücke im Gefüge der Bestimmungen über das Zusammentreffen verschiedener Leistungen aus der Sozialversicherung, in: Deutsche Invaliden-Versicherung Nr. 5 (1937), S. 105-106. Vgl. auch das neu gefasste Abkommen der Rentenversicherungsträger über das Verfahren bei Feststellung der Renten von Wanderversicherten oder ihrer Hinterbliebenen vom 27. Oktober 1939, in: RfA-Archiv Nr. 68a. Siehe auch Regierungsrat von Altrock (RfA), Die Überführung von der AV zur IV und umgekehrt, eine Kritik, in: Deutsche Rentenversicherung Nr. 10 (1940), S. 131-132.

286 Vgl. Schreiben der RfA an das RVA vom 31.7.1936, in: RfA-Archiv Fach 112, Nr. 3. 
gerechnet werden konnten, wenn die Anwartschaft aus ihnen erhalten war. Dies und die Tatsache, dass eine einfache Überschreibung der zur IV geleisteten Beiträge auf die RfA beim Übergang in eine angestelltenversicherungspflichtige Beschäftigung nicht stattfand, übersahen viele betroffene Versicherte und strengten daraufhin, vielfach mit Unterstützung der Rechtsberatungsstellen der DAF, oftmals Beschwerdeverfahren zum Einklagen ihres vermeintlichen Rechtsanspruchs an. ${ }^{287}$

Und die Lage wurde noch komplizierter, denn seit dem 1. Januar 1938 wirkte im Zuge des Ausbaugesetzes der Bezug des Ruhegeldes und der Witwenrente aus der Angestelltenversicherung nicht mehr anwartschaftserhaltend in der Invalidenversicherung. Die Ruhegeldempfänger, denen die Leistungen aus der Invalidenversicherung bisher nicht bewilligt werden konnten, weil Invalidität noch nicht vorlag, mussten daher die Anwartschaft durch Beitragsentrichtungen aufrechterhalten. ${ }^{288}$ Das ganze Problem der Wanderversicherten gewann auch deshalb an Bedeutung, da im Zuge des NS-Wirtschaftsbooms „viele Volksgenossen, die früher eine angestelltenversicherungspflichtige Beschäftigung ausgeübt hatten, durch Wiedereingliederung in den Arbeitsprozess nun in eine invalidenversicherungspflichtige Beschäftigung kamen“ und „nun in Sorge um ihre Rechte aus der Angestelltenversicherung sind und die ehemaligen Vertrauensmänner um Rat und Auskunft [bitten], da die Rechtsberatungsstellen der DAF meist nicht in der Lage sind, eine klare Auskunft zu erteilen“, wie ein Versicherter schon im Dezember 1935 an die RfA schrieb. ${ }^{289}$ Weitere neue Wanderversicherungsfälle entstanden dann im Zuge der Verordnung zur Sicherstellung des Kräftebedarfs für Aufgaben von besonderer staatspolitischer Bedeutung vom 13. Februar 1939, als zahlreichen an sich Angestelltenversicherungspflichtigen auf Anordnung des Arbeitsamtes für unbegrenzte Zeit invalidenversicherungspflichtige Beschäftigungen zugewiesen wurden. ${ }^{290}$

Im Frühjahr und Sommer 1936 hatten sich die RfA und die LVA Sachsen einen ausführlichen Schriftwechsel über die unterschiedliche Auslegung der Ruhensbestimmungen beim Zusammentreffen von Renten aus der IV und der AV geführt, insbesondere um die Frage des Zeitpunkts des Ruhensbeginns und dabei auftretender Ausgleichszahlungen zwischen den Versicherungsträgern. Beide attestierten sich gegenseitig falsche Rechtsauffassungen und die RfA wandte sich schließlich an den Reichsverband der Landesversicherungsanstalten mit der Feststellung, dass man

beim besten Willen keine rechtliche Handhabe [sehe], die uns zu den von der LVA Sachsen gewünschten Zahlungen berechtigen sollte. Wir glauben aber, dass sich der Reichsverband und

287 Vgl dazu auch die Fälle und Schriftwechsel in der Akte „Wanderversicherte“, RfA-Archiv Fach 92, Nr. 4.

288 Vgl. Schreiben der LVA Hannover an die RfA vom 3.2.1939 sowie Vermerk Kochs dazu vom 3.11. 1939, in: RfA-Archiv Nr. 60a.

289 Brief vom 18.12.1935, in: ebd. Vgl. dazu auch die Niederschrift über die am 10.12.1935 bei der Reichsknappschaft abgehaltene Besprechung mit Vertretern des Reichsverbandes Deutscher Landesversicherungsanstalten und der RfA, in: ebd.

290 Vgl. Schreiben des RfA an das RVA vom 27.4.1939, in: BArch R 89/3181. 
auch die LVA Sachsen unseren Darlegungen nicht verschließen werden und hoffen, dass wir dadurch zu der wünschenswerten einhelligen Rechtsauffassung gelangen. ${ }^{291}$

Nicht zuletzt bemühte sich die RfA auch intensiv darum, das prinzipielle und von den LVA auch gut geheißene Anhörungsrecht in Leistungsfeststellungsverfahren von Wanderversicherten abzuschaffen oder zumindest einzuschränken. Nach einer Auszählung aller zwischen 24. April und 8. Mai eingegangenen Antragsverfahren, so rechnete man dem RVA im Mai 1937 vor, habe sich in 189 Rentenfällen durch Anhörung der Landesversicherungsanstalten eine Verzögerung von insgesamt 5224 Tagen ergeben, das entsprach jeweils für den einzelnen Fall 27,6 Tage. ${ }^{292}$

Ein ebenfalls rasch zunehmendes Problem war die Frage der rentenversicherungsrechtlichen Behandlung von Ruhegeldempfängern und von mit Beitragsrückerstattungen ausgeschiedenen Ehefrauen, die nun nach und nach wieder in den von wachsendem Arbeitskräftemangel geprägten Arbeitsmarkt zeitweise oder auch für länger zurückkehrten. Spätestens seit Sommer 1937 wurden die RfA-Beamten geradezu von einer Flut von Anfragen einzelner Rentner, NSDAP-Stellen und Unternehmen, aber auch von Rechtsberatungsstellen der DAF überrollt, in denen nach den Folgen einer etwaigen Tätigkeitsaufnahme gefragt wurde. Im Mittelpunkt stand die Frage, welchen Betrag man im Monat hinzuverdienen konnte, ohne den Anspruch auf Berufsunfähigkeitsrente oder Altersruhegeld zu verlieren. ${ }^{293}$ Die Anfrage des Sozialbüros der IG Farbenindustrie AG vom Juli 1939 war nachgerade exemplarisch.

Prinzipiell galt, dass ein wegen Arbeitslosigkeit ausgezahltes Ruhegeld nur bei gelegentlicher Beschäftigung, die nicht länger als vier Monate dauerte, weiter gewährt wurde. $\mathrm{Zu}$ ihrer Wiedererlangung musste dann erst erneut ein Jahr Arbeitslosigkeit abgewartet werden. Dasselbe galt für verheiratete Frauen, die ihre berufliche Tätigkeit zunächst aufgegeben hatten. Waren sie nur geringfügig beschäftigt, so waren sie versicherungsfrei, wurden sie aber länger als vier Monate als vollbeschäftigte Aushilfen eingestellt, so begründete dies wieder ein neues angestelltenversicherungspflichtiges Beschäftigungsverhältnis. ${ }^{294}$ Anders war es im Fall einer Berufsunfähigkeitsrente. Ein Standardantwortbrief der RfA lautet:

Einem Empfänger von Ruhegeld wegen Berufsunfähigkeit steht es frei, den ihm noch verbliebenen Rest seiner Arbeitsfähigkeit nutzbringend zu verwerten. Der Verdienst wird nicht auf das Ruhegeld angerechnet. Das Ruhegeld muss jedoch entzogen werden, wenn nach Art und Umfang der Tätigkeit anzunehmen ist, dass der Ruhegeldempfänger nicht mehr berufsunfähig ist. Ob dies

291 Schreiben vom 1.7.1936, in: LfA-Archiv Nr. 60.

292 Vgl. Vermerk vom 11.5.1937 sowie Schreiben an das RVA vom 26.5.1937, in: RfA-Archiv Nr. 22. 293 Vgl. dazu etwa die Anfrage der NSDAP aus Ilmenau vom 15.11.1937 sowie der NS-Kriegsopferfürsorge Magdeburg vom 18.10.1937 sowie weitere Anfragen in: RfA-Archiv Nr. 91.

294 Vgl. dazu die Abteilungsverfügung vom 24. 8.1938, in: RfA-Archiv Fach 1 Nr. 1. Im Juni 1938 hatte es dazu eine intensive RfA-interne Diskussion gegeben, in der es - am Beispiel von Warenhausverkäuferinnen - um die Definition einer vorübergehenden oder gelegentlichen Dienstleistung ging. Vgl. dazu RfA-Archiv Fach 1, Nr. 1 und die daraus entstandene Abteilungsverfügung vom 24.8.1938. 


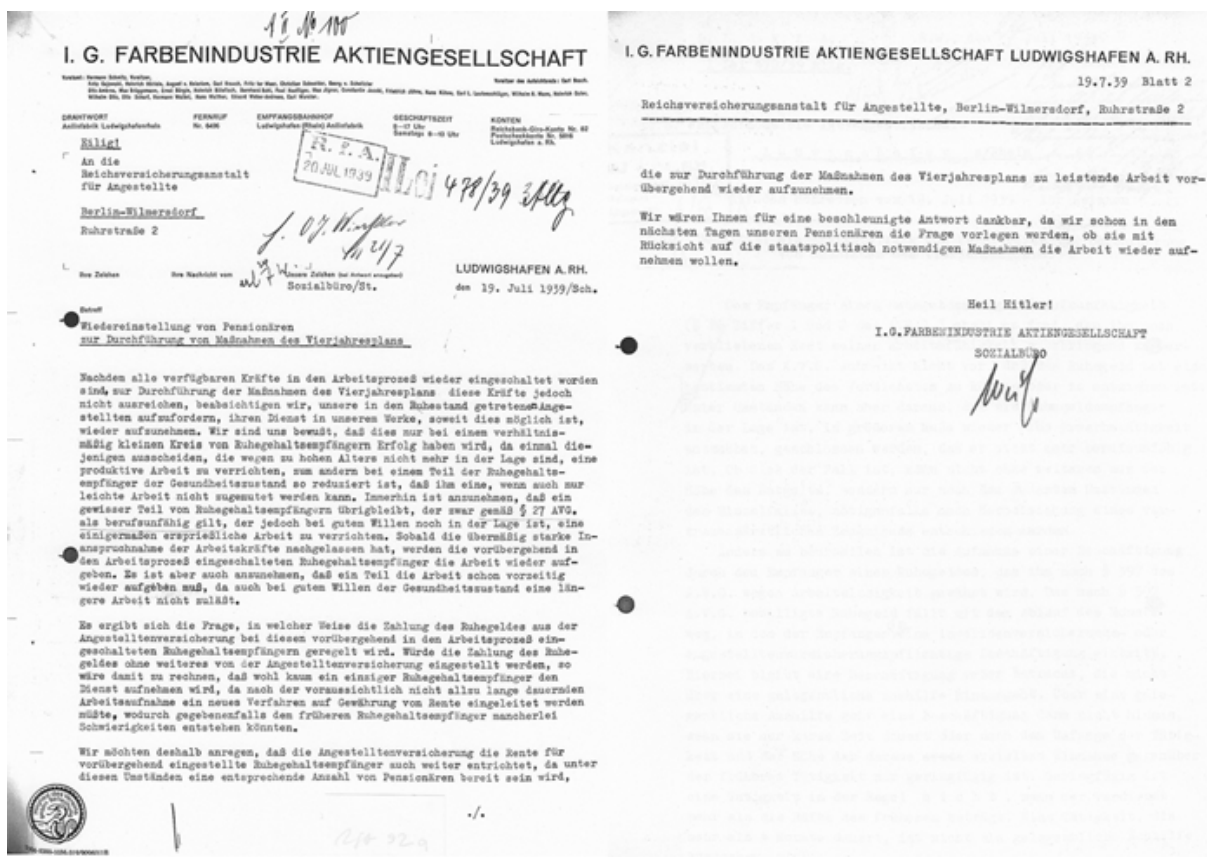

Abb. 17: Die Anfrage des Sozialbüros der IG Farbenindustrie AG vom Juli 1939

der Fall ist, kann nicht ohne weiteres aus der Höhe des Entgelts, sondern nur nach den gesamten Umständen des Einzelfalls, nötigenfalls nach Heranziehung eines vertrauensärztlichen Zeugnisses entschieden werden. ${ }^{295}$

Im Fall eines über 65 Jahre alten Altersruhegeldempfängers galten keinerlei Beschränkungen. Ein früherer Oberingenieur, der 67 Jahre alt war, seit 1931 Angestelltenrente bezog und nun im Juli 1937 einen Posten als Fabrikaufseher annehmen wollte, begründete allerdings bei längerer Tätigkeit ein neues Anwartschaftsverhältnis mit Beitragspflicht in der AV. All diese Regelungen waren aus Sicht der Landesarbeitsämter und der Arbeitsmarktexperten des NS-Regimes für eine Behebung des Arbeitskräftemangels eher hinderlich und stellten alles andere als Anreize für die Betroffenen dar, wieder Beschäftigungsverhältnisse einzugehen, bei denen es für viele allerdings auch darum ging, einen Zusatzverdienst zu der meist kärglichen Rente zu erlangen. „Mehr oder weniger sind die Ruhegeldempfänger doch gezwungen, etwas hinzu zu verdienen", hieß etwa in einem Schreiben eines DAF-Ortswalters an die Auskunftsstelle der RfA Ende Juli 1939, „da in den meisten Fällen die Rente zum Leben

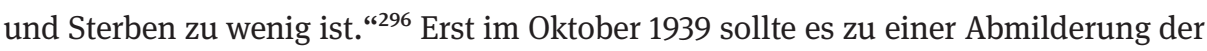
Bestimmungen dahingehend kommen, dass das Ruhegeld wegen Arbeitslosigkeit

295 RfA-Antwortschreiben vom 10.11.1937, in: RfA-Archiv Nr. 91.

296 Vgl. die Anfrage des Ortswalters der DAF Zwönitz vom 25.7.1939, in: RfA-Archiv Nr. 92a. 
schon im Folgemonat der Beendigung des Beschäftigungsverhältnisses wieder einsetzte und damit die einjährige Wartezeit praktisch entfiel. ${ }^{297}$

Gegen diese von der DAF initiierte Regelung hatte die RfA allerdings schon im Januar 1938 vergeblich erhebliche Bedenken erhoben, da damit unterschiedliche Regelungen unter den Rentnern geschaffen wurden, was dem Gebot gleichmäßiger Behandlung aller Versicherten eindeutig widersprach. ${ }^{298}$ Schon zuvor hatte das RVA jedoch die RfA und die anderen Versicherungsträger zu einer von der gesetzlichen Regelung abweichenden Handhabung verpflichtet. Die Beschäftigung eines Rentenempfängers bei den Erntearbeiten dürfe nicht zum Anlass für die Einleitung eines Rentenentziehungsverfahrens genommen werden, so hieß es in einem Rundschreiben im August 1938, und gleiches galt auch für die beim Westwallbau eingesetzten Rentner. ${ }^{299}$ Im September 1939 wurde aus der Ausnahmeregelung eine generelle Bestimmung. Arbeitsämter und DAF bemühten sich im Hinblick auf den großen Arbeitskräftemangel darum, Rentenempfänger wieder in Arbeit zu bringen, hieß es in einem Rundschreiben. „Diese Bestrebungen dürfen nicht dadurch gehemmt werden, dass die Rentenversicherungsträger versuchen, solchen Rentenempfängern [...] die Rente zu entziehen. “ ${ }^{\text {300 }}$ Eine ganze Reihe von Landesversicherungsanstalten hatten sich dabei von der Propaganda zur Mobilisierung der Rentner instrumentalisieren lassen. Die LVA Sachsen-Anhalt erließ etwa einen großen Aufruf an alle ihre zugehörigen Rentenempfänger, ihren Beitrag zum Erfolg der „Arbeitsschlacht“ zu leisten. Die RfA jedoch, obschon von einigen Seiten ebenfalls dazu gedrängt, entzog sich entsprechenden Aktivitäten. ${ }^{301}$

Die inzwischen erreichte Fülle von Gesetzen und Maßnahmen zur Rentenversicherung stieß auch bei den Versicherten auf wachsende Resonanz, allerdings nicht so, wie es das NS-Regime wohl erwartet hatte. Je mehr der Nationalsozialismus Niederschlag in der Rentengesetzgebung fand, desto häufiger kam auch Kritik aus der Bevölkerung. Nach jedem Gesetz erreichte eine Flut von Briefen die Ruhrstraße 2 in Berlin, in denen von wiederholt enttäuschten Erwartungen die Rede war, verbunden mit Forderungen nach Reformmaßnahmen und Verbesserungen. ${ }^{302}$ In den Jahren 1936/37 war ein deutliches zahlenmäßiges Anschwellen der zum Teil massive Kritik äußernden Briefe von Versicherten festzustellen. Das hastig erlassene Ausbaugesetz vom Dezember 1937 hatte durchaus den Zweck gehabt, diesen wachsenden Rentenunmut in der Bevölkerung aufzufangen. Das NS-Regime wurde dabei zum Opfer der eigenen Rentenpropaganda - aber auch die RfA erhielt nach jeder neuen Erfolgs-

297 Vgl. Schreiben der RfA an das RVA vom 12.9.1939, in: RfA-Archiv Nr. 113.

298 Vgl. Schreiben Grießmeyers an das RVA vom 6.1.1938, in: RfA-Archiv Fach 112, Nr. 5.

299 Rundschreiben vom 10.8.1938 und vertrauliches Rundschreiben vom 24.1.1939, in: RfA-Archiv Nr. 24.

300 Rundschreiben vom 6.9.1939, in: RfA-Archiv Nr. 86.

301 Vgl. dazu den Aufruf in: RfA-Archiv Nr. 90.

302 Vgl. dazu etwa Schreiben vom 18.3.1937 an die RfA, in: RfA-Archiv Fach 112, Nr. 6 sowie zahlreiche weitere Briefe in: RfA-Archiv Nr. 9. 
meldung über Einnahmen- und Rücklagensteigerungen zahlreiche Schreiben mit Forderungen nach Beitragssenkungen und Leistungsausweitungen: Kaum anderswo wurden von den Briefeschreibern so explizit Argumentationsmuster der „Volksgemeinschaft“ verwendet und Bezug auf die unter diesem Begriff propagierte neue NSGesellschaft genommen. Das kollektive Schreiben von sieben Rentnern vom Dezember 1938 ist exemplarisch dafür. ${ }^{303}$

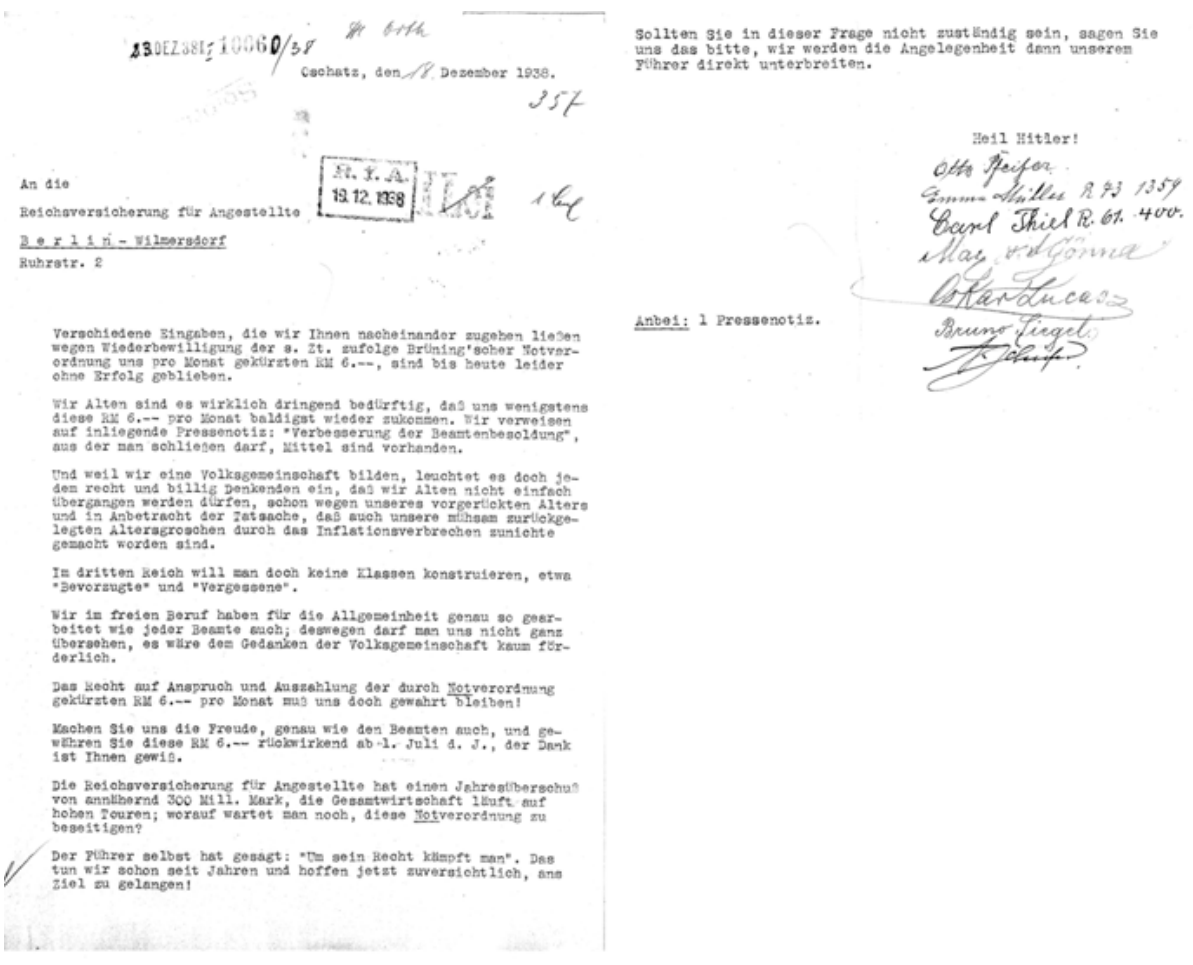

Abb. 18: Brief von Versicherten an die RfA vom 18. Dezember 1938

„Seit Jahr und Tag hören und lesen wir von wahrer Volksgemeinschaft, die wir so verstehen, dass es innerhalb des Volkes überhaupt nichts geben darf, was nicht im Sinne der Volksgemeinschaft liegt“, heißt es etwa auch in einem Schreiben an die RfA. Die Sanierung der Invalidenversicherung allein auf Kosten der AV, ohne Einbeziehung der Beamten-Pensionskassen, widerspreche dem „Volksgemeinschaftsempfinden“, und daher müssten die bestehenden Kürzungen rückgängig gemacht werden. „Unser Standpunkt entspricht wahrer Volksgemeinschaft, folglich ist uns Ihre Zustimmung sicher“, heißt es dann noch am Ende des Schreibens an die RfA. ${ }^{304}$ Auch Begriffe und

303 Das Schreiben in: RfA-Archiv Fach 111, Nr. 10.

304 Schreiben vom 3.2.1939, in: RfA-Archiv Fach 111, Nr. 9. 
Argumente des nationalsozialistischen Rechtsdenkens, insbesondere der Verweis auf die erforderliche Rücksichtnahme auf das „Volksempfinden“ bei Gesetzgebung wie Verwaltungspraxis, fand zunehmend Eingang in die Schreiben der Versicherten. Ein erheblicher Teil der von den Versicherten direkt bei der RfA vorgebrachten Beschwerden bezog sich auf abgelehnte Heilverfahrensanträge. Ungeachtet der Tatsache, dass es sich dabei seitens der RfA nicht um gesetzliche Pflicht-, sondern um Kann-Leistungen handelte, sahen es die Betroffenen als ihr gutes Recht an, Heilstättenaufenthalte gewährt zu bekommen. Die Anzahl der Anträge war dabei insgesamt kontinuierlich auf 180.000 im Jahr 1938 gestiegen und die Ablehnungsquoten mit durchschnittlich 40 Prozent relativ hoch. ${ }^{305}$ Die Chancen für eine Bewilligung wurden allerdings offenbar erheblich höher, wenn sich die Antragsteller nach einer Ablehnung an Parteistellen wandten oder ihre Beschwerde an die Schriftleitung des Schwarzen Korps schickten. In einem Bescheid vom Februar $1938 \mathrm{zu}$ einer entsprechenden Eingabe, die dann beim RAM gelandet war, ist etwa zu lesen:

Wenn auch die Aussichten auf Wiederherstellung der Berufsfähigkeit sehr fraglich sind und bereits größere Heilverfahrensaufwendungen für die Versicherten geleistet wurden, sind wir nach nochmaliger Prüfung der Vorgänge ausnahmsweise bereit, ein neues Heilverfahren in Davos zu gewähren. $^{306}$

Täglich gingen Briefe von Versicherten mit Vorschlägen zu Reformmaßnahmen und Gesetzesänderungen bei der RfA ein. Dabei ging es etwa im Februar 1936 um die Herabsetzung der für den Rentenbezug maßgebenden Altersgrenze, sowohl bei den Männern wie bei den Frauen. „Die Staats- und Gemeindebeamten erhalten das Zweiund Mehrfache an Pension - mit welchem Recht, wo wir doch eine Volksgemeinschaft haben, sollte da kein so krasser Unterschied mehr sein, wo auch noch die Allgemeinheit deren Lasten trägt. “307 Der Reichsbund der Kinderreichen forderte im Februar 1937 eine Senkung der Beiträge zur AV für Kinderreiche - was von den RfABeamten mit dem nüchternen Hinweis auf die gewährten Kinderzuschüsse und Waisenrenten sowie die rentenleistungsmindernden Folgen von Beitragssenkungen, „die durchaus nicht im Interesse von Kinderreichen liegen dürften“, abgelehnt wurden. ${ }^{308}$ Ferner gab es Forderungen zur Verkürzung der Wartezeit für das Beziehen von Ruhegeld wegen Berufsunfähigkeit - um damit den Frauen früher die Beitragsrückerstattung bei Heirat zu ermöglichen -, und zur Einführung von Abfindungen freiwillig geleisteter Versicherungsbeiträge bei Einstellung der Zahlungen. ${ }^{309}$ Beides

305 Vgl. RfA-Geschäftsbericht für 1938, S. 12ff., in: BArch R 89/3468.

306 Schreiben vom 24.2.1938, in: BArch R 89/3446.

307 Schreiben vom 9.1.1936 sowie auch Schreiben vom 20.2.1936, in: RfA-Archiv Fach 112, Nr. 5.

308 Schreiben vom 3.2.1937 sowie Brief der RfA vom 16.2.1937, in: RfA-Archiv Fach 114, Nr. 15.

309 „Die freiwillige Versicherung konnte sich der kleine Mann leisten, solange jährlich nur 4 Marken in jeder beliebigen Klasse notwendig waren. Im Laufe der Zeit aber stellte die AV ihre Forderungen hinsichtlich der freiwilligen Weiterversicherung derart in die Höhe, dass es einem in bescheidenen Familienverhältnissen lebenden Familienvater auch mit dem besten Willen nicht mehr möglich ist, 
lehnte die RfA in ihren Antwortschreiben ab unter anderem mit Verweis auf die erheblichen Kosten sowie andernfalls sich ergebenden Nachteile für die Pflichtversicherten. Aber auch hier galt: Je höher die NS-Stelle, an die die Eingabe oder Beschwerde gerichtet wurde, desto größer war die Wahrscheinlichkeit, dass sich die RfA zu dem jeweiligen Sachverhalt äußern und oft auch rechtfertigen musste. Im Dezember 1937 war etwa ein Schreiben des Stabs des Stellvertreters des Führers aus dem Braunen Haus in München auf dem Schreibtisch Grießmeyers gelandet. Darin wurde moniert, dass sich

in letzter Zeit die Eingaben von Invaliden [häufen], die sich auf Grund des Untersuchungsbefundes der RfA einer Operation unterziehen müssen. Eine Weigerung hätte in den meisten Fällen den Entzug der Invalidenrente zur Folge. Man könne sich des Eindrucks nicht erwehren, dass die Reichsversicherungsanstalt, deren Untersuchungsmethoden im übrigen seit langem Grund zur Beschwerde sind, diese Ansinnen in vielen Fällen stellt, um eine Handhabe zum Entzug der Rente zu bekommen. ${ }^{310}$

Wirkliche Einzelfälle, die die Vorwürfe hätten bestätigen können, ließen sich bei der RfA jedoch nicht ermittlen. Daneben zog sich wie ein roter Faden die scharfe Kritik an den noch immer nicht zurückgenommenen Rentenkürzungen der Notverordnungszeit durch die Schreiben der Versicherten an die RfA.

Doch all diese Forderungen wurden auch noch 1937 von der RfA mit derselben Formel aus dem Bescheid des RAM vom Februar 1934 beantwortet - also mit dem Hinweis auf die notwendigen Opfer durch alle Beteiligten und die Unmöglichkeit von Rentenerhöhungen bzw. der Rücknahme oder Milderung der früheren Kürzungen. ${ }^{311}$ Tatsächlich war das Rentenniveau trotz aller Sanierungs- und Leistungserweiterungspropaganda und als Ergebnis der bisher erfolgten Flut von Gesetzesmaßnahmen niedrig geblieben. Der Blick auf die Entwicklung der durchschnittlichen Rentenhöhe zeigt dies deutlich ${ }^{312}$ : Betrugen 1931 die monatlich ausgezahlten Ruhegelder noch 62,73 RM (bei Wanderversicherten waren es 82,25 RM), so waren sie bis 1934 auf 56,54 RM bzw. 70,28 RM abgesackt. Bis 1937 war es nur zu einem moderatem Wiederanstieg von 59,31 RM bzw. 72,51 RM gekommen und auch Ende 1938 war mit 60,39 RM bzw. 73,16 RM das Niveau der Weltwirtschaftskrisenjahre bei weitem noch nicht erreicht. Erst 1939 sollte ein Ruhegeldempfänger im Monat durchschnittlich 63,75 RM erhalten (als Wanderversicherter 76,49 RM) und damit erstmals wieder leicht über das Ausgangsniveau von 1931 hinauskommen. Nach sieben Jahren NS-Herrschaft stand bezüglich der AV unterm Strich eine Rentenerhöhung bzw. Reduzierung der früheren

hier weiter mitzumachen.“ Vgl. Schreiben vom 3.5.1937, in: RfA-Archiv Fach 113, Nr. 11 und Schreiben vom 23.4.1937, in: RfA-Archiv Fach 111, Nr. 6.

310 Schreiben des Stellvertreters des Führers an Grießmeyer vom 20.12.1937, in: RfA-Archiv Nr. 91. 311 Vgl. etwa das Antwortschreiben vom 23.6.1937, in: RfA-Archiv Fach 108, Nr. 11.

312 Die folgenden Zahlen aus: 25 Jahre Rentenversicherung, S. 91, RfA-Jahresbericht 1938, S. 10 und auch Protokoll der Beiratssitzung vom 25./26.11.1935, S. 9, in: BArch R 89/3468. Zu den Zahlen für 1939 vgl. RfA-Jahresbericht 1940, S. 3, in: BArch R 89/3513, Bl. 53 f. 


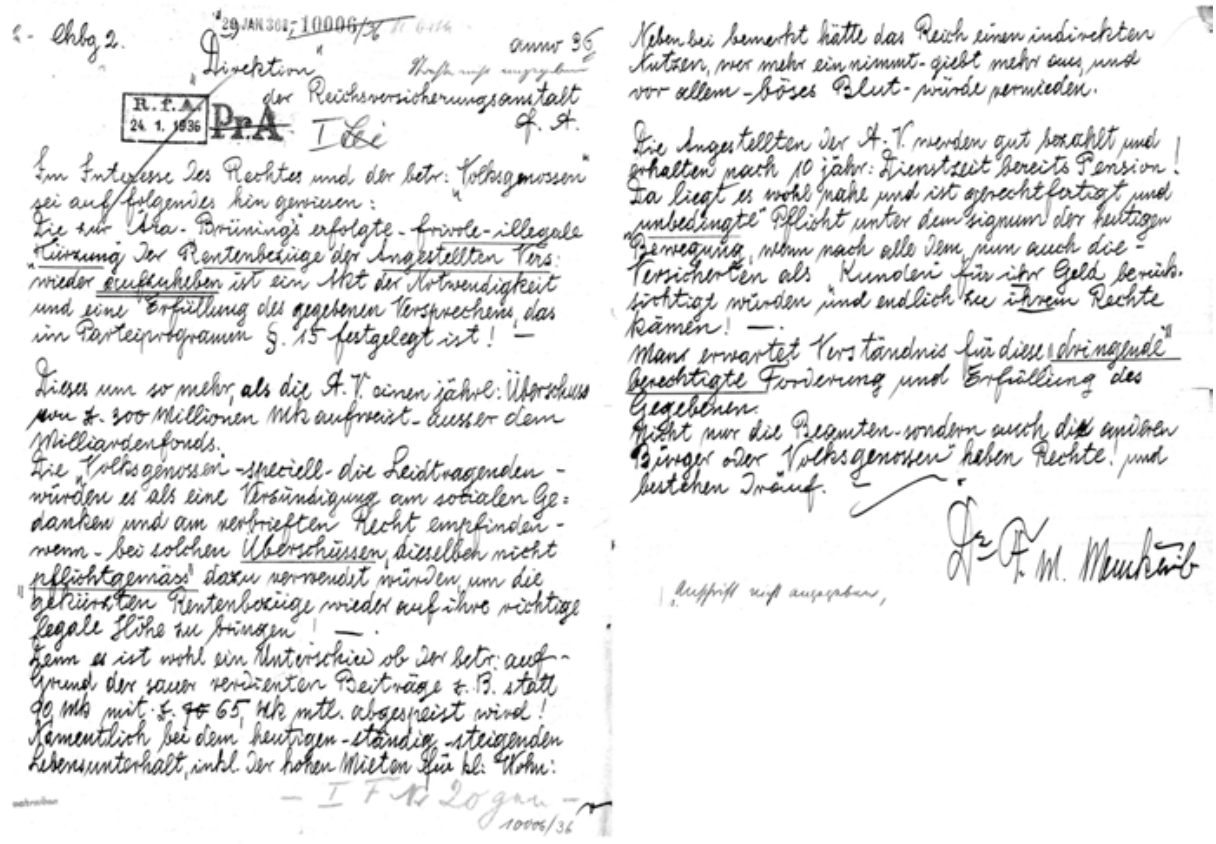

Abb. 19: Brief eines Versicherten an die Direktion der RfA vom 20. Januar 1936

Kürzungen von gerade einmal 12,7 Prozent (bzw. 8,8 Prozent), wobei das Durchschnittsniveau die breite Streuung in und unter den einzelnen Beitragsklassen verdeckt. Bereits im Mai 1936 hatte sich denn auch ein Versicherter an die „Leitung der RfA“ mit dem Hinweis auf jüngste Pressemeldungen über die durchschnittliche Angestelltenrente von 57 RM monatlich gewandt:

Es würde mich nun interessieren, wie ein arbeitsunfähiges Ehepaar mit diesen 57 RM leben kann. Angenommen sei gleichfalls, dass diese beiden Leute weder Kinder haben, die sie unterstützen können, noch Vermögen oder irgendeinen sonstigen Zuschuss zu dem genannten Betrag. Weiters wollen Sie bitte berücksichtigen, dass diese Leute nicht z. B. in irgendeinem Dorf in der Eifel, sondern in einer Großstadt wohnen, wo der betagte Ehemann viele Jahrzehnte als Angestellter tätig war. Für eine erschöpfende Beantwortung meiner Frage wäre ich Ihnen sehr zu Dank verbunden. ${ }^{313}$

Im Januar 1938, kurz nach der Veröffentlichung des Ausbaugesetzes, war auch Präsident Grießmeyer selbst in die Schusslinie der Kritik geraten. Der Stuttgarter NSKurier hatte in seiner Wochenendausgabe über ein Interview mit dem RfA-Präsidenten

313 Schreiben vom 26.5.1936, in: RfA-Archiv Fach 53, Nr. 4. Die RfA beantwortete dieses Schreiben tatsächlich auf drei Seiten mit eingehenden Erörterungen zur Rentenentwicklung und Rentenberechnung und verwies den Schreiber dann letztendlich auf einen evtl. Zuschuss von Seiten der öffentlichen Fürsorge. 
berichtet, in dem dieser auf den Hinweis, dass die Rente beim Durchschnitt der Versicherten zweifellos nicht den Lebensbedürfnissen entspreche, geantwortet habe,

dass die soziale Rentenversicherung nur ein fester Zuschuss für den Lebensbedarf im Alter sein soll und die gezahlten Beiträge schon größer sind, als nach dem ursprünglichen Angestelltenversicherungsgesetz vorgesehen war. Der Grundstock dieser Rente soll durch Vorsorge des Versicherten selbst ergänzt werden. Hierzu treten vielfach die Werkspensionskasssen und neuerdings die Gefolgschaftsversicherungen. Außerdem kann eine freiwillige Höherversicherungen selbst eingegangen werden. ${ }^{314}$

Für die langjährigen Angestellten, die wiederholt arbeitslos geworden waren und in kleinen Firmen ohne Werkspensionskasse oder Gefolgschaftsversicherung tätig waren, klangen diese Ausführungen wie Hohn. ${ }^{315}$ Noch im Dezember 1939 wandte sich unter anderem eine Kieler NSDAP-Ortgruppe mit einem Brandbrief über die soziale Notlage der Kleinrentner an den zuständigen Kreisleiter. Die Behörden wie LVA und Reichsversicherungsamt konzedierten nicht nur, dass die niedrigen Renten bei weitem nicht ausreichten, um auch den notdürftigsten Lebensunterhalt zu fristen, sondern auch, dass es nach wie vor entgegen aller Volksversicherungsideologie massive Ungleichheiten zwischen AV und IV gab. Die Witwe eines Angestellten erhielt etwa Witwenrente aus der AV ohne Rücksicht auf ihre Arbeitsfähigkeit, wogegen die Witwe eines in der IV Versicherten die Witwenrente nur dann erhielt, wenn sie selbst invalide oder über 65 Jahre alt war. ${ }^{316}$

Die Schreiben der Versicherten an „ihre“ RfA lassen oft auch Rückschlüsse über das damalige „Rentenwissen“ in der Angestellten-Bevölkerung zu. In der Regel wurden Anfragen von der RfA mit der Zusendung eines der vielen Merkblätter, verbunden mit einem Standardschreiben, beantwortet. Vielfach bemühten sich die zuständigen RfA-Sachbearbeiter jedoch auch darum, auf die einzelnen Belange einzugehen. „Die Anfrage vom 28.2.1938 zeigt“, so heißt es etwa in einem internen Vermerk, „dass der Fragesteller die Begriffe ,Anwartschaft' und ,Wartezeit' trotz der ihm zugesandten Merkblätter bisher nicht verstanden hat; es ist deshalb zweckmäßig, ihm eine individuelle Auskunft zu geben." ${ }^{317}$ Und bei einer ganzen Reihe von Versicherten ließen sich die RfA-Beamten erstaunlicherweise auch auf längere, zum Teil über Wochen sich hinziehende Schriftwechsel ein, in denen ebenso geduldig wie detailliert zu Einzelfragen des Rentenrechts und der Auslegung und Begründung von gesetzlichen Be-

314 Zitiert nach dem Schreiben an Grießmeyer vom 18.1.1938, in: RfA-Archiv Fach 111, Nr. 9.

315 Zum Thema Gefolgschaftsversicherung äußerte sich Grießmeyer noch einmal explizit Anfang Januar 1939 in einem Aufsatz in: Die Deutsche Volkswirtschaft. Vgl. Albert Grießmeyer, Gefolgschaftsversorgung bei der sozialen Rentenversicherung, in: Die Deutsche Volkswirtschaft, Januar 1939, S. $40-42$.

316 Vgl. Schreiben vom 12.12.1939 sowie die Stellungnahme der LVA Schleswig-Holstein vom 6.2. 1940, in: BArch R 89/3169.

317 Vermerk vom 1.3.1938, in: RfA-Archiv Fach 3, Nr. 2. 
stimmungen Stellung genommen wurde. ${ }^{318}$ In der Regel stammte das „Rentenwissen“ der Versicherten jedoch aus der Tagespresse. Monat für Monat erhielt die RfA dutzende von Briefen mit Verweis auf entsprechende Zeitungsartikel und die darin enthaltenen meist unklaren, oft falschen und damit verunsichernden oder beunruhigenden Informationen über geltende oder beabsichtigte Rentenversicherungsbestimmungen. ${ }^{319}$ Als im Juni 1938 der Berliner Lokal-Anzeiger unter der Rubrik „Was die Rentner hoffen“ eine Leseraktion startete, wurde die Redaktion von Zuschriften geradezu überschüttet. ${ }^{320}$

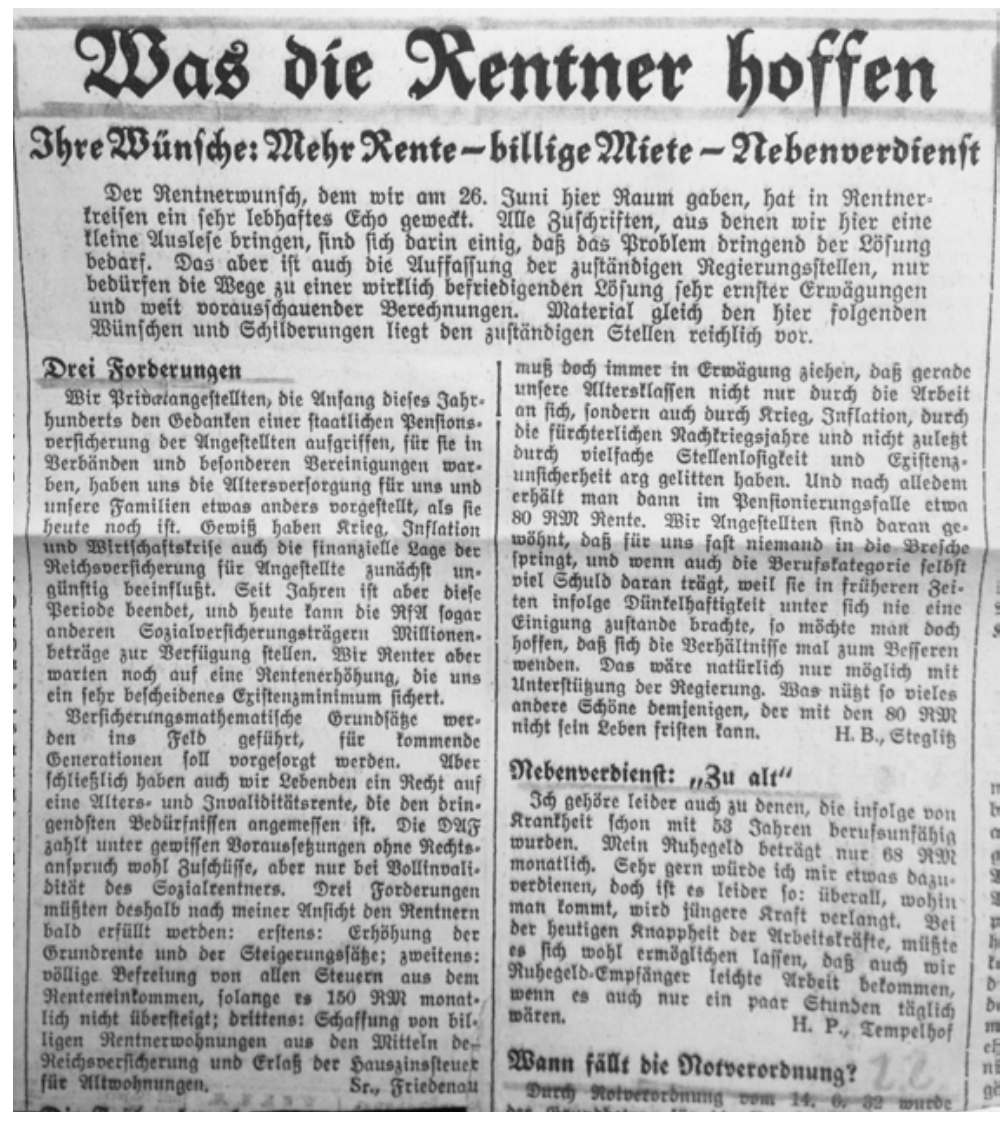

Abb. 20: Rentendebatte im Berliner Lokal-Anzeiger vom Juni 1938

318 Vgl. etwa den sich zwischen August und November 1937 hinziehenden Briefwechsel mit einem technischen Angestellten der Reichsautobahngesellschaft, in: RfA-Archiv Fach 94, Nr. 2.

319 Vgl. dazu etwa die Schreiben vom 30.11.1936 und vom 26.11.1936, in: RfA-Archiv Fach 53, Nr. 4. 320 Vgl. dazu Berliner Lokal-Anzeiger vom 10.7.1938 sowie vom 7.8.1938, als Kopie in: RfA-Archiv Fach 111, Nr. 9. 
Bis Anfang August war das Renten-Thema und die dabei auch oft erwähnte Rolle der RfA auf der Leserbriefseite dominant. Einige Versicherte nahmen dies zum Anlass, sich direkt an Präsident Grießmeyer zu wenden. Oft waren es aber falsche oder verkürzt wiedergegebene Informationen, die in der Presse erschienen, und die RfA-Beamten hatten alle Mühe, die schiefen oder falschen Darstellungen zu korrigieren. Heikel wurde die Sache vor allem dann, wenn es um entsprechende (und oft mit deutlicher Kritik an der RfA durchsetzte) Artikel einschlägiger NS-Organe wie dem Schwarzes Korps der SS oder dem Angriff der DAF ging. Im Februar 1937 wurde etwa in der SS-Zeitschrift unter der Überschrift „Soldaten müssen für Anwartschaft zahlen“ die Verwaltungspraxis hinsichtlich Beitragsbefreiungen durch die RfA angegriffen. ${ }^{321}$ In einem internen Vermerk heißt es dazu:

Die Veröffentlichung erfordert meines Erachtens eine Klarstellung. Sie sind, wenn sie unwidersprochen bleiben, geeignet, die in Versichertenkreisen verbreitete günstige Auffassung über die sozialen und volksverbundenen Geist atmende Geschäftsführung der RfA zu gefährden. ${ }^{322}$

Eine erhebliche Rolle spielten auch die Gespräche mit Kollegen am Arbeitsplatz und die dabei entstehenden Gerüchte, zu deren Klarstellung dann die RfA angeschrieben wurde, wie etwa in einem gleichfalls im Februar 1937 verfassten Schreiben an die RfA:

Hier wird verbreitet, dass den Firmen, welche arbeitslose ältere Angestellte neu einstellen, von der Angestelltenversicherung ein Zuschuss gewährt wird. Darf ich um gefällige Mitteilung bitten, ob dieses zutrifft oder ob in nächster Zeit eine solche Maßnahme beabsichtigt ist. ${ }^{323}$

Auch hier war es für die RfA-Beamten oft sehr mühsam, den Gerüchten entgegenzutreten, insbesondere dann, wenn es um Grundsatzprobleme wie die im Februar 1939 angeblich unmittelbar bevorstehende Verschmelzung der AV mit der IV ging und weder RAM, RVA oder die Parteistellen dazu offiziell Stellung nahmen. Die RfA-Beamten mussten jedoch den beunruhigten Versicherten antworten, ohne damit aber in eine rentenpolitische Zwickmühle zu geraten.

Eine maßgebliche Rolle spielte in diesem Zusammenhang die umfangreiche Beratungsliteratur. Was für die interessierten Versicherten eine wichtige Informationsquelle war, war für die RfA-Beamten jedoch ein häufiger Quell des Ärgernisses. Oft populär formuliert wurden diese Schriften von selbständigen Versicherungsvermittlungs- und Rentenberatungsbüros, aber in mindestens ebenso großem Umfang von diversen DAF-Stellen verfasst und herausgegeben. Für erheblichen Wirbel sorgte etwa im August 1938 das in hoher Auflage erschienene, weitverbreitete und ebenso knapp wie übersichtlich gehaltene „Sozialpolitische Lexikon“. Herausgegeben von Hans Wolkersdörfer, Reichsamtsleiter der DAF und Sozialreferent der Reichstagsfraktion

321 Vgl. den Artikel im Schwarzen Korps vom 12.2.1937, Kopie und Vorgang in: RfA-Archiv Fach 113, Nr. 6.

322 Vermerk vom 13.2.1937, in: ebd.

323 Schreiben vom 15.2.1937, in: RfA-Archiv Fach 19, Nr. 2. 
der NSDAP, wurden dort die oben bereits erwähnten Bestimmungen zur Gewährung von Witwenrente erläutert, allerdings unter fälschlicher Angabe der in der IV geltenden Voraussetzungen auch für die $\mathrm{AV}^{324}$ Bei vielen Angestellten war damit erhebliche Unruhe ausgelöst worden und die RfA drängte bei der DAF auf umgehende Richtigstellung. ${ }^{325}$ Nicht selten mussten sich die RfA-Beamten in anderen Fällen dann aber noch nach entsprechenden Bitten und Aufforderungen zur Berichtigung mit den Redakteuren um Auslegungsfragen streiten. Im Dezember 1938 hatte etwa der zuständige RfA-Beamte beim „Verlag der DAF“ „unzutreffende Ausführungen“ in einem Beitrag der DAF-Fachzeitschrift Arbeit und Staat moniert. Wenig später erhielt er jedoch von dem dortigen Hauptschriftleiter die knappe Mitteilung, dass man sich „Ihrer Rechtsauffassung“ nicht anschließen könne. Es handele sich um eine „strittige Rechtsfrage“, die verschieden beantwortet werden könne. Man würde es der RfA nicht verübeln, wenn sie eine Position in ihrem Interesse als Versicherungsträger einnehme, die DAF und der Verfasser des Artikels jedoch „vertreten eine Auffassung, die zu Gunsten der Versicherten neigt [...]. Solange die Gerichte keinen gegenteiligen Standpunkt einnehmen, glauben wir, dass Ihre Auffassung eine einseitige autoritative Entscheidung der Anstalt darstellt.“326

Und dann machten noch die Werbefeldzüge der Privatversicherungsunternehmen mit ihren eigenen Broschüren und „Aufklärungsschriften“ den RfA-Beamten das Leben schwer. Spätestens 1936 hatten die Lebensversicherungsgesellschaften eine regelrechte Werbe- und Informationskampagne gestartet, in der sie sich explizit als Konkurrenz zur RfA verstanden. Die Broschüre einer Berliner Lebensversicherungsgesellschaft etwa verlautet:

Wissen Sie schon, dass sich die Sozialversicherung bewusst auf die Sicherung des Existenzminimums beschränkt? Dass ein Angestellter bestenfalls etwa 20 Prozent, ein Arbeiter bestenfalls etwa 30 Prozent seines Endgehalts als Altersrente bekommt? Und bekanntlich beträgt die Sozialhinterbliebenenrente bei frühzeitigem Tode weniger als die Hälfte der Sozialaltersrente. ${ }^{327}$

Broschüren ähnlichen oder gleichen Inhalts verbreiteten auch andere Versicherungskonzerne wie die Nordstern Lebensversicherungsgesellschaft, dessen Generaldirektor pikanterweise als Vertreter der Betriebsführer im RfA-Beirat saß. ${ }^{328}$ Bei den Versicherten blieben diese und ähnliche Propagandaaussagen nicht ohne Rückwirkung, verstärkten sie doch den Eindruck, „dass die AV von ihrer ursprünglichen Be-

324 Vgl. Hans Wolkersdörfer, unter Mitarbeit von K. Roloff, Sozialpolitisches Lexikon. Praktischer Ratgeber für alle Fragen des sozialen Lebens, Berlin 1938, hier S. 114.

325 Vgl. Schreiben vom 15.8. und 19.8.1938, in: RfA-Archiv Nr. 91 b.

326 Schreiben vom 15.12.1938 sowie Brief der DAF vom 6.1.1939, in: RfA-Archiv Fach 98, Nr. 1.

327 Vgl. RfA-Archiv Fach 198, Nr. 4.

328 Vgl. dazu den Prospekt sowie weiteren Schriftwechsel zu den Aktivitäten der Berlinischen Lebensversicherungsgesellschaft, vor allem im Raum Chemnitz, in: RfA-Archiv Fach 98, Nr. 3. Vgl. dort auch eine im Januar 1937 erfolgte Zusammenstellung von Werbeveröffentlichungen für Gefolgschaftsversicherungen der vergangenen Monate. 
stimmung [...] ganz wesentlich abgewichen ist und in der heutigen Form nichts weiter als eine zusätzliche Besteuerung der Arbeitnehmerschaft darstellt, mit welcher gleichzeitig ein Altersalmosen verbunden ist. “" ${ }^{329}$ Zudem sah sich die RfA vermehrten Vorwürfen ausgesetzt, ihre Versicherten wenig oder überhaupt nicht über die jeweils neuesten Bestimmungen der Rentenversicherung aufzuklären. Wie bei den privaten Versicherungen sollte doch jeder, so ein Vorschlag, bei Abschluss der Versicherung über seine Rechte und Pflichten informiert werden und ihm etwa bei Ausstellung der ersten Versicherungskarte die Versicherungsbedingungen in übersichtlicher und allgemeinverständlicher Form übergeben werden. „So wie es jetzt ist, könnte leicht der Eindruck entstehen, dass die RfA aus der Unwissenheit ihrer Mitglieder Kapital zu schlagen versucht. “330 Die praktizierte Informationspolitik der RfA, so wurde weiter moniert,

scheint uns sehr wenig der heutigen Forderung der Volksverbundenheit zu entsprechen. Es dürfte ohne weiteres klar sein, dass nicht jeder Angestellte sich das Reichsgesetzblatt halten kann, weil evtl. dort Bestimmungen, die seine Angestelltenversicherung betreffen, veröffentlicht wurden. Ebenso wenig kann er sich Ihre Merkblätter anfordern, wenn er nichts darüber erfährt, dass Änderungen getroffen wurden [...]. Die jetzt auf der Rückseite der Versicherungskarte aufgedruckten Hinweise auf die Strafbestimmungen dürften vielleicht ein paar Dutzend Spitzbuben interessieren, nicht aber die Allgemeinheit, der vielmehr damit gedient wäre, wenn die normalen Versicherungsbedingungen auf der Karte stünden. Schließlich befinden wir uns ja nicht in einem Polizeistaate, sondern im nationalsozialistischen Dritten Reich, und wir finden, dass die Grundhaltung der Reichsversicherungsanstalt nicht mehr in unsere Zeit passt. ${ }^{331}$

Die RfA suchte sich diesem Wettbewerb mit den privaten Versicherern mit dem lapidaren Hinweis zu entziehen, dass „ein Vergleich der AV mit einer privaten Lebensversicherung grundsätzlich abwegig [ist], weil es sich um völlig wesensverschiedene Einrichtungen handelt““. ${ }^{332}$ Allerdings nahmen die Aktivitäten der Lebensversicherungsgesellschaften bald solche Dimensionen an, dass man sich in der Ruhrstraße zu einer Reaktion auf die zudem meist noch sachlich falschen bzw. „unrichtigen und irreführenden“ Werbeaussagen sowie die damit verbundene Diskreditierung der RfA gezwungen sah. ${ }^{33}$ Aus Sicht der Behörde war es etwa geradezu unverantwortlich, wenn die Versicherungsgesellschaften vor allem die freiwillig in der Angestelltenversicherung Versicherten zum Abschluss einer Lebensversicherung $\mathrm{zu}$ bewegen versuchten, verbunden mit einer Aufgabe der Weiterversicherung in der AV, „da diese

329 Schreiben an die RfA vom 18.4.1936, in: RfA-Archiv Fach 108, Nr. 4.

330 Schreiben an die RfA vom 1.9.1936, in: ebd.

331 Schreiben vom 16.9.1936, in: ebd.

332 Vermerk vom 5.6.1936 und Entwurf für ein Antwortschreiben in: RfA-Archiv Fach 108, Nr. 4.

333 Ebd. Sowie vgl. auch der sich von April bis September 1936 hinziehende ausführliche Schriftwechsel der RfA mit der Sozialabteilung der Margarinewerk Saar Gebr. Fauser GmbH in Sulzbach/Saar, in: ebd. 
ja nicht mehr verfallen könnte““.334 Dazu kam, dass im Laufe des Jahres 1937 ein regelrechter Markt für zusätzliche Alters- und Hinterbliebenenversorgung entstanden war, in den immer mehr Versicherungsunternehmen wie die Victoria Versicherungs AG, die Gothaer Lebensversicherungsgesellschaft oder die Berlinische Lebensversicherungsgesellschaft drängten. Zahlreiche Firmen, die bislang noch keine Rücklagen für Versorgungsmaßnahmen ihrer Gefolgschaft vorgenommen hatten, aber auch Betriebe, die bereits Rücklagen für soziale Zwecke in Form von Fonds oder Pensionsbzw. Unterstützungskassen gebildet hatten, beschäftigten sich in dieser Zeit intensiv mit der Frage von Zusatzversicherungen. So schrieb Grießmeyer im März 1937 an das RAM:

Wir stellen mit Besorgnis fest, dass die privaten Lebensversicherungsgesellschaften in äußerst rühriger Weise für eine Kapitalversicherung der Gefolgschaftsmitglieder (Gefolgschaftsversicherung) sowie für eine Zusatzversorgung durch den einzelnen Angestellten durch den Abschluss einer Lebensversicherung werben und die Werbung in der Hauptsache auf Vergleiche mit unzulänglichen Leistungen der Angestellten- und Invalidenversicherung stützen [...]. Aus $\mathrm{Zu}$ schriften unserer Versicherten ersehen wir, dass eine Beunruhigung, deren Ausmaß sich noch nicht übersehen lässt, bereits eingetreten ist und die Belange der Angestelltenversicherung ernstlich gefährdet werden. Wir halten es unbedingt für erforderlich, schleunigst geeignete Maßnahmen zur Unterbindung von Werbemethoden der privaten Lebensversicherungsgesellschaften zu treffen, die geeignet sind, das Vertrauen zur reichsgesetzlichen Rentenversicherung zu erschüttern und dem Gemeinschaftsgedanken entgegen zu wirken. ${ }^{335}$

Doch zunächst geschah nichts, das RAM leitete die Berichte und Beschwerden der RfA an das Reichsaufsichtsamt für Privatversicherung weiter und erst im Dezember 1937 kam es zu einem Rundschreiben der Fachgruppe Lebensversicherung an ihre Mitgliedsfirmen mit der Aufforderung, sich in ihrer Werbung aller das Ansehen der Sozialversicherung irgendwie herabsetzenden Hinweise zu enthalten. ${ }^{336}$ Aus Sicht der RfA-Führung war dabei besonders prekär, dass sich eine Reihe von NS-Zeitschriften, allen voran die DAF-Zeitung Der Angriff, mit zahlreichen Werbeinseraten und auch einschlägigen Aufsätzen geradezu zu einer Plattform für die Agitation der Privatversicherungskonzerne entwickelt hatten. ${ }^{337}$ Das Rundschreiben der Fachgruppe blieb ohne große Wirkung. Auch weiterhin erschienen, wie die Überwachungsbeamten nach Berlin meldeten, Werbeschriften und Abhandlungen, die mit unrichtigen Behauptungen für private Lebensversicherungen warben. ${ }^{338}$

$334 \mathrm{Vgl}$. das entsprechende (verunsicherte) Schreiben eines Versicherten an die RfA vom 31.3.1937, in: RfA-Archiv Fach 98, Nr. 3.

335 Schreiben vom 11.3.1937, in: RfA-Archiv Fach 98, Nr. 3.

336 Vgl. dazu auch die Abteilungsverfügung vom 3.1.1938 mit der Wiedergabe des Rundschreibens in: RfA-Archiv Regal 5.

337 So auch die Hinweise in dem RfA-Schreiben an das RAM, S. 4, in: RfA-Archiv Fach 98, Nr. 3. 338 Vgl. dazu etwa den Bericht des Kölner Überwachungsbeamten vom 8.1.1938, in: RfA-Archiv Fach 53, Nr. 4 sowie die Werbeschrift der Provinzial-Lebensversicherungsanstalt Brandenburg vom Oktober 1938, gegen deren Inhalt die RfA nun direkt bei der Fachgruppe Versicherungsvertreter und Versi- 


\section{Die Überwachungsbeamten und der Kampf gegen versicherungsrechtliche Verstöße}

In der RfA wusste man ziemlich gut und genau über die jeweilige Stimmungslage bei den Versicherten wie den Rentnern Bescheid. Da täglich dutzende Briefe in der Ruhrstraße ankamen, war der Behörde die Rentenwirklichkeit vor Ort durchaus bekannt. Ein zentrales Instrument, um über die Verhältnisse vor Ort informiert zu sein, waren die Überwachungsbeamten, die regelmäßig Berichte nach Berlin schickten. Zentrale Aufgabe der Überwachungsbeamten war die Beitragskontrolle, d.h. die Sicherstellung des möglichst vollständigen Eingangs der Mittel, die die RfA zur Durchführung ihrer Aufgaben benötigte. Sie wirkten daher auf eine vorschriftsmäßige Beitragsentrichtung für alle Angestelltenversicherungspflichtigen wie Arbeitgeber hin, veranlassten insbesondere die Beseitigung von Beitragsrückständen und verhinderten damit, dass die Leistungsansprüche der Angestellten durch Verstöße gegen die Beitragspflicht in Frage gestellt oder beeinträchtigt würden. ${ }^{339}$ Ende 1934 waren 107 Überwachungsbeamte in 63 Städten tätig (davon allein 17 in Berlin), deren Aufgabenfeld sich mit dem Ende der Vertrauensmänner vor allem hinsichtlich der Information, Beratung und Auskunftserteilung noch erweitert hatte. ${ }^{340}$ Dennoch sollte sich die Zahl der Überwachungsbeamten im Laufe der Jahre nur unwesentlich erhöhen. ${ }^{341}$ Auf einen Überwachungsbezirk kamen im Durchschnitt 2000 Arbeitgeber und Kleinbetriebe, die der Beamte regelmäßig (im Durchschnitt alle zwei Jahre) Haus für Haus und Straße für Straße zur Vornahme der Beitragsprüfung aufsuchte. Die Überwachungsbeamten rekrutierten sich aus dem Kreis der gehobenen mittleren Beamten des Innendienstes der RfA, d.h. sie waren meisten Verwaltungsoberinspektoren, die für den Außendienst besonders ausgebildet und geschult worden waren. Mit Beitragsrückständen musste aufgrund des herrschenden Markenbeitragsverfahrens immer gerechnet werden; ihr Umfang hing wesentlich von den jeweiligen konjunkturellen Schwankungen ab. Allerdings herrschte gerade auch auf dem Lande fast generell eine große Unkenntnis hinsichtlich der Versicherungspflicht und Beitragsentrichtung und etwa bei der Feststellung des Einkommens freiwillig versicherter Landwirte waren durchaus komplizierte Regeln zu beachten. ${ }^{342}$

cherungsmakler in der Wirtschaftsgruppe Vermittlergewerbe Protest erhob und eine Berichtigung verlangte, in: RfA-Archiv Fach 98, Nr. 3.

339 Vgl. dazu „Der Überwachungsdienst der Reichsversicherungsanstalt für Angestellte“ (drei Seiten), Manuskript vom November 1934, in: Bibliothek der DRV-Bund, Sign. II A 13 a 8925. Vgl. allgemein auch „Der Überwachungsdienst und seine Ergebnisse“, MS, zehn Seiten, vom 24.1.1925, in: RfA-Archiv Fach 13, Nr. 5.

340 Vgl. dazu auch das Überwachungsstellenverzeichnis mit Stand 8.1.1937, in: RfA-Archiv Nr. 74.

341 Erst im Laufe des Krieges wurden die Überwachungsbeamten, zahlenmäßig deutlich auf 146 (April 1941) aufgestockt.

342 Vgl. dazu das Rundschreiben Nr. 40 an die Überwachungsbeamten vom 2.3.1937, in: RfA-Archiv Nr. 22. Vgl. auch die Ausführungen zu den Überwachungsbeamten im Prüfbericht des RVA von 1938, S. 44 ff., in: BArch R 89/3450. 
Die Steuerung der Überwachungsbeamten erfolgte durch die RfA-Zentrale vor allem über Rundschreiben, aber auch, wenn nötig, durch individuellen Schriftverkehr zwischen Außen- und Innendienstbeamten. Dazu kamen die unter Grießmeyer eingeführten und bereits erwähnten regelmäßigen Dienstbesprechungen auf Regionalkonferenzen und nicht zuletzt intensive Weiterbildungsmaßnahmen durch Vorträge. Auf der Dienstbesprechung der in Mitteldeutschland tätigen Überwachungsbeamten etwa, die am 27. September 1935 in Bad Kösen stattfand, ging es neben der Erörterung versicherungsrechtlicher Detailfragen und der Weiterbildung unter anderem auch um Themen wie die Selbstversicherung von Erbhofbauern und Prüfbesuche bei Ärzten. ${ }^{343}$ Thema war 1936 und 1937 auch immer wieder die Zusammenarbeit mit den Rechtsberatungsstellen der DAF, die, wie erwähnt, keineswegs reibungslos verlief. So heißt es in einem Vermerk vom März 1937:

Nachdem durch den Wegfall der Vertrauensmänner der AV die Fühlung mit den Versicherten und
ihren Betriebsführern teilweise verloren gegangen war, bemühte sich die RfA, sie auf andere
Weise wiederherzustellen und erteilte zu diesem Zweck den Überwachungsbeamten wiederholt
ausführliche Weisungen, in denen gleichzeitig die Zweckmäßigkeit einer freundschaftlichen
Zusammenarbeit mit den beteiligten Stellen der DAF dargelegt wurde..$^{344}$

Die Berliner Überwachungsbeamten wurden angewiesen, unmittelbar mit den Leitungen und Betriebszellenobmännern größerer Betriebe Vorträge bei Betriebsappellen und ähnlichen Gelegenheiten zu vereinbaren und zu halten. Der RfA-Geschäftsbericht vermerkt denn auch ca. 500 Vorträge vor über 25.000 Zuhörern sowie 9800 Sprechstunden, in denen 61.000 Besucher beraten worden waren. ${ }^{345}$

Wie erfolgreich unter dem Strich die Arbeit der RfA-Überwachungsbeamten war, zeigt sich an der Entwicklung der ermittelten und dann erfolgreich eingetriebenen Beitragsrückstände. 1932 waren bei der Überprüfung von 240.000 Arbeitgebern mit 1,8 Mio. Angestellten Rückstände für über 500.000 Angestellte in Höhe von insgesamt 12,5 Mio. RM festgestellt und eingeholt worden. ${ }^{346}$ Seitdem nahm das Ausmaß der Beitragsrückstände kontinuierlich ab, von 10,5 Mio. RM (1933) auf 8,6 Mio. RM (1935), dann 6,6 Mio. RM (1937) bzw. 6,75 Mio. RM (1938). ${ }^{347}$ Das hing weniger mit einer veränderten Überwachungspraxis zusammen als vielmehr mit der konjunkturellen Erholung. Schon Ende 1934 allerdings war in der Zeitschrift „Deutsche Invalidenversi-

343 Vgl. Niederschrift der Dienstbesprechung vom 27.9.1935, in: RfA-Archiv Fach 68, Nr. 1. Dort auch weitere Protokolle von anderen Regionalkonferenzen. Eine Sammlung der Rundschreiben an die Überwachungsbeamten von Nr. 46 (16.3.1939) bis Nr. 100 (14.2.1945) in: RfA-Archiv Fach 68, Nr. 2. 344 Vermerk vom 20.3.1937, in: RfA-Archiv Fach 68, Nr. 1.

345 Vgl. den Geschäftsbericht der RfA für 1936, S. 6 und auch schon den Bericht des Direktoriums der RfA für das Geschäftsjahr 1933, S. 5, in: BArch R 112/102.

346 Vgl. Bericht des Direktoriums der RfA für das Geschäftsjahr 1933, S. 5, in: BArch R 112/102. Bei den LVA betrug zur gleichen Zeit der Rückstand 25,5 Mio. RM.

347 Vgl. zu den Zahlen die Angaben in den Geschäftsberichten der RfA für 1935 (S. 5), 1936 (S. 6), 1937 (S. 7), 1938 (S. 7), in: BArch R 89/3468 bzw. RfA-Archiv Nr. 78. Danach allerdings sollte kriegsbedingt mit 9,04 Mio. RM schon 1939 ein scharfer Anstieg der Beitragsrückstände einsetzen. 
cherung“ zumindest für die Landesversicherungsanstalten eine Verschärfung der Überwachungstätigkeit und eine Bekämpfung des „eingerissenen Gewohnheitsrechts der verspäteten Beitragszahlung mit allen Mitteln“ gefordert worden. ${ }^{348}$ Eine Rolle für die sinkenden Beitragsrückstände spielten allerdings auch Sanktionsmaßnahmen für säumige Beitragszahler, die seit 1936 verstärkt angewendet worden waren. Die Überwachungsbeamten waren verpflichtet, den örtlichen Versicherungsämtern und Kommunalbehörden alle jene Arbeitgeber zu melden, die für die Vergabe von öffentlichen Aufträgen in Frage kamen und mit ihren Beitragszahlungen länger als sechs Monate im Rückstand waren. Auch das Heereswaffenamt forderte vor Auftragsvergabe von seinen Zulieferern eine Bescheinigung darüber, dass alle Beiträge zur RfA ordnungsgemäß abgeführt worden waren. ${ }^{349}$ Dass die diversen Reichsstellen es dann dabei letztlich doch nicht so genau nahmen, zeigte sich im Herbst 1937, als Nachprüfungen bei denjenigen Firmen, die beim Bau der Reichsautobahn beteiligt waren, ergaben, dass eine ganze Reihe von ihnen mit erheblichen Beträgen an die Versicherungsträger im Rückstand waren, „ohne dass es aber möglich war, die Rückstände hereinzubringen“. ${ }^{350}$ Erst auf Intervention des RVA beim Generalinspekteur für das Deutsche Straßenwesen bekamen die Versicherungsträger die Erlaubnis, wegen Sanktionen sich direkt an die obersten Bauleitungen $\mathrm{zu}$ wenden. Prinzipiell hatte aber auch die RfA selbst ein berechtigtes Interesse daran, dass die pünktliche Entrichtung der AV-Beiträge zur Voraussetzung der Erlangung öffentlicher Aufträge gemacht wurde. Allerdings gab es innerhalb der Behörde doch erhebliche Bedenken, den Kreis der diesbezüglich auskunftsuchenden Behördenzu erweitern, denn nach dem Gesetz waren die Beamten der RfA zur Geheimhaltung der geschäftlichen und betrieblichen Angelegenheiten verpflichtet, die sie in ihrer amtlichen Tätigkeit erfuhren. Insofern wurde die Verwaltungspraxis bald dahingehend geändert, dass entsprechende Auskünfte nur noch auf Ersuchen der jeweiligen Unternehmen erfolgten. „Auf diese Weise geht die RfA allen Beschwerden und etwaigen Schadensersatzansprüchen der Unternehmer aus dem Wege und verhindert zugleich persönliche Differenzen zwischen den Überwachungsbeamten und den Arbeitgebern. “351

Es war letztlich dem einzelnen Überwachungsbeamten überlassen, im täglichen Dienst einen Mittelweg zwischen Kulanz und scharfer Strafverfolgung und Sanktionierung von Verstößen zu finden. In eine schwierige Situation kamen etwa die Überwachungsbeamten bei der Kontrolle der freiwillig Versicherten. Durch Zeitungsinserate waren diese im September 1937 im Gau Mecklenburg aufgefordert worden, sich zur Kontrolle der Beitragsentrichtungen in das Büro des Überwachungsbeamten zu be-

348 Vgl. „Überwachungsdienst“, in: Deutsche Invalidenversicherung 6 (1934), S. 175-178.

349 Vgl. Schreiben an den Nürnberger Überwachungsbeamten vom 18.3.1936 sowie die Anfrage des Reichsverbands des deutschen Mineralölhandels an die RfA vom 19.6.1936, in: RfA-Archiv Fach 554, Nr. 2 bzw. Fach 23, Nr. 2.

350 Rundschreiben des RVA vom 10.11.1937, das dann in eine Abteilungsverfügung der Abt. Versicherung mündete, in: RfA-Archiv Regal 5.

351 Interner Vermerk Dr. Wilhelm an Granzows vom 6.5.1936, in: RfA-Archiv Fach 54, Nr. 2. 
geben und dabei Einkommenssteuerbescheide der letzten zehn Jahre vorzulegen. In ca. 200 Fällen waren daraufhin zu niedrige Beitragsmarken festgestellt worden und die Betroffenen wurden mit Nachforderungen konfrontiert, die in die Hunderte gingen und von den meisten nicht geleistet werden konnten, wie das Sozialamt der DAF in einem persönlichen Brief an Grießmeyer bemängelte. ${ }^{352}$ Mit Hinweis auf die dadurch ausgelöste erhebliche Unruhe in der Bevölkerung und den offensichtlichen Ungleichheiten bei der Behandlung bat man daher um eine mildere Handhabung der geltenden Bestimmungen. Viel Spielraum dafür besaßen die RfA-Beamten jedoch nicht, da nach der Gesetzeslage freiwillige Beiträge in einer zu niedrigen Gehaltsklasse unwirksam waren und keinen Anspruch auf Leistung begründeten. ${ }^{353}$ Viele Überwachungsbeamte erwiesen sich bei ihrer Kontrolltätigkeit aber auch als unerschrockene und unbestechliche Prüfer, die weder auf Parteibuch noch auf NS-Rang Rücksicht nahmen. Es begann schon Anfang 1934, als etwa der zuständige Überwachungsbeamte in Berlin-Lichterfelde mit häufigen Klagen von Arbeitgebern wie Arbeitnehmern seines Bezirks konfrontiert wurde, dass zuständige Polizeireviere die Ausstellung und den Umtausch von Versichertenkarten ablehnten, obwohl sie dazu von Rechts wegen verpflichtet waren. ${ }^{354}$ Erst auf entsprechende Intervention des Überwachungsbeamten hin änderte sich das Verhalten. Prekär waren jedoch erneute Weigerungen des 128. Polizeireviers in Charlottenburg, wo im Dezember 1935 einem jüdischen Angestellten aus rassischen Gründen der Umtausch der Versicherungskarte verwehrt wurde. Offensichtlich war das auch anderen jüdischen Versicherten dort passiert. Auf die entsprechende Beschwerde des Versicherten beim zuständigen Überwachungsbeamten hin leitete dieser eine offizielle Untersuchung ein, bei der der zuständige Reviervorsteher offen gegen den Überwachungsbeamten und dessen Eintreten für einen Juden polemisierte. ${ }^{355}$ Doch dieser verwahrte sich nicht nur gegen die herablassenden Äußerungen der Polizeibeamten über die Anordnungen der RfA, sondern auch explizit gegen die rassenpolitische Polemik. Womöglich, so vermutete er, haben die Revierbeamten zur Vertuschung bzw. Begründung ihrer offensichtlichen Pflichtverletzung erst nachträglich festgestellt, dass der Beschwerdeführer Jude war. Aus der Angestelltenversicherungskarte selbst war dies nicht ersichtlich, und die arbeitgebende Firma hatte nach Kenntnis des Überwachungsbeamten mindestens ebenso viele arische wie jüdische Angestellte. ${ }^{356}$

Unerschrockenheit und Durchhaltevermögen war von den Überwachungsbeamten auch dann gefordert, wenn es um die Überwachung und Überprüfung der Sozialversicherungsbeitragszahlungen der diversen NS-Parteistellen und ihrer Gliederungen wie SA, SS, NSV etc. ging. Im August 1938 monierte etwa der zuständige Überwachungsbeamte nach einem Besuch bei der Münchner NSDAP-Kreisleitung fehlende Beitragszahlungen, ebenso wie sein Nürnberger Kollege bei der dortigen

352 DAF-Schreiben vom 17.9.1937, in: RfA-Archiv Fach 69, Nr. 7.

353 Vgl. dazu auch die Abteilungsverfügung vom 26.10.1939, in: ebd.

354 Vgl. Bericht des Überwachungsbeamten vom 29.1.1934, in: RfA-Archiv Fach 5, Nr. 5.

355 Vgl. den Bericht vom 18.12.1935, in: RfA-Archiv Fach 5, Nr. 6.

356 Bericht des Überwachungsbeamten vom 8.2.1936, in: ebd. 
Gauleitung. ${ }^{357}$ Beide leiteten die umgehende Nachzahlung in die Wege. Ärger gab es jedoch vor allem mit den SA-Dienststellen. Schon 1934 hatten eine ganze Reihe von Überwachungsbeamten hier über Probleme mit der Beitragsentrichtung berichtet, die sich nur langsam besserten. ${ }^{358}$ Mit der SA-Brigade 84 in Rosenheim, wo der zuständige Überwachungsbeamte im September 1936 für einen hauptamtlichen Brigadeführer nicht abgeführte Beiträge zur AV in Höhe von 132,12 bzw. 275 RM festgestellt hatte, stritt sich die RfA bis Juni 1942, ehe sich die SA, nachdem sie von der RfA offiziell verklagt und es zu einem Verfahren vor dem Versicherungsamt München gekommen war, bereit erklärte, die inzwischen auf 875 RM angewachsenen Rückstände nachzuzahlen. ${ }^{359}$ Auch das Heereswaffenamt hatte im November 1935 Besuch des RfAÜberwachungsbeamten erhalten, dem dort jedoch die Einsicht in die gewünschten Unterlagen verweigert und der zudem aufgefordert wurde, sich künftig vor jedem Besuch bei der Obersten Heeresleitung anzumelden. ${ }^{360}$ Dagegen verwahrte sich der RfA-Beamte jedoch und erst nach längeren Verhandlungen im Reichswehrministerium willigte das Heereswaffenamt im Februar 1936 doch in die bedingungslosen Überprüfungen ein.

Die Grenze zwischen Ordnungswidrigkeiten wegen Beitragsrückständen und tatsächlichen Verstößen gegen die Reichsversicherungsordnung mit strafrechtlichen Folgen, d.h. Unterschlagungen, Manipulationen der Versichertenkarten, Betrug, Markenfälschungen und Markendiebstahl, waren dabei oft fließend. Die Kreativität der Kriminellen kannte dabei keine Grenzen, handelte es sich doch bei dem Markenbeitragsverfahren um einen Bereich, in dem monatlich Riesensummen bewegt wurden. Immer wieder kam es etwa vor, dass sich Unbefugte bei einzelnen Kleinbetrieben als Überwachungsbeamte ausgaben und durchaus mit Erfolg die sofortige Zahlung von angeblichen Beitragsrückständen forderten. ${ }^{361}$ Die komplexe „Versicherungskarten- und Beitragsmarken-Bürokratie“ mit Ausgabe-, Umtausch- und Kontrollstellen und der Vielzahl der dabei involvierten Instanzen - Bürgermeister, Kreishandwerkerschaft, Ortspolizei, DAF-Rechtsberatung und später auch Krankenkassen - bot ein Einfallstor für zahlreiche beabsichtigte, aber auch unbeabsichtigte Manipulationen und Fehler.

Ein erheblicher Teil der Probleme, mit denen die Überwachungsbeamten schon seit 1933/34 konfrontiert waren, bestand aus Unterschlagungen von Versicherungsbeiträgen infolge der Weltwirtschaftskrise. Mit einiger zeitlicher Verzögerung kamen

357 Vgl. Berichte der Überwachungsbeamten vom 4.8.1938 bzw. vom 30.6.1938, in: RfA-Archiv Fach 1, Nr. 1.

358 Vgl. dazu den Bericht auf der Dienstbesprechung der in Pommern und Ostpreussen tätigen Überwachungsbeamte am 3.4.1936, in: RfA-Archiv Fach 68, Nr. 1.

359 Der umfangreiche Vorgang in: RfA-Archiv Fach 22, Nr. 2. Dort auch ein ähnlich gelagerter Fall mit der SA-Brigade 85 in München.

360 Vgl. Bericht des Überwachungsbeamten vom 29.11.1935, in: RfA-Archiv Fach 13, Nr. 6.

361 Vgl. dazu den Bericht des Überwachungsbeamten Berlin-Halensee vom 1.12.1934, in: RfA-Archiv Fach 13, Nr. 6. Zu Markenfälschungen vgl. auch RfA-Archiv Fach 45, Nr. 3. 

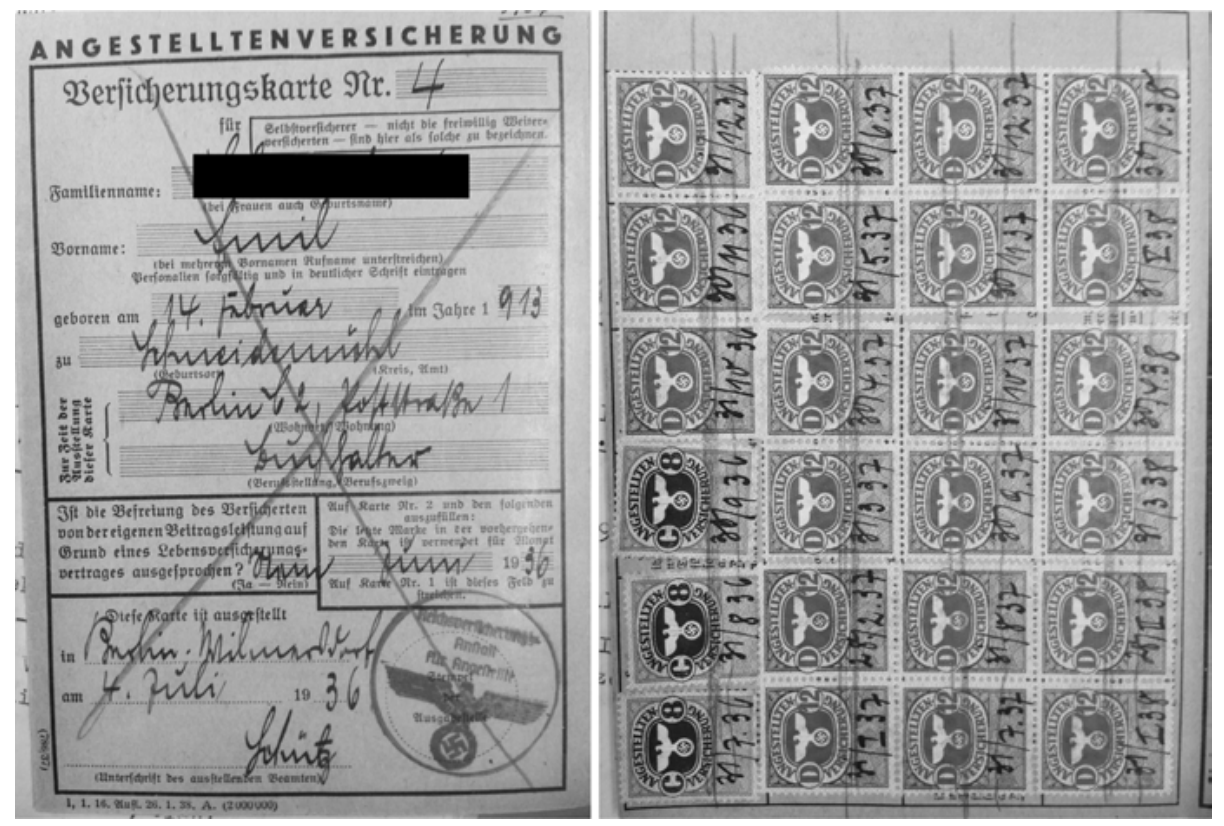

Abb. 21: Versicherungskarte mit geklebten Beitragsmarken

nun vermehrt jene Fälle ans Tageslicht, in denen Firmen wegen der damaligen schlechten finanziellen Lage oder aufgrund von Zusammenbrüchen und Insolvenzen zum Teil über viele Jahre hinweg die Rentenversicherungsbeiträge für ihre Arbeiter und Angestellten unterschlagen hatten. Damit waren aber auch, wie die betroffenen Belegschaftsmitglieder nun erst erfuhren, auch deren Anrechte auf Invaliden- oder Angestelltenversicherung erloschen.

Über die Frage, inwieweit die Arbeitgeber für die entgangene Rente gegenüber den Versicherten schadensersatzpflichtig waren, stritten sich die Experten, und die ergangenen Urteile bei den Arbeitsgerichten waren keineswegs einhellig. ${ }^{362}$ In vielen Fällen waren jedoch Zwangsbeitreibungen längst erfolglos und die Versicherten, die prinzipiell die Möglichkeit hatten, die in der damaligen Zeit unterschlagenen Beiträge aus eigenen Mitteln nachzuzahlen, waren mit den sich daraus ergebenden hohen Summen völlig überfordert. ${ }^{363}$ In diesen Fällen ging die Verwaltungsübung der RfA

362 Insbesondere auch in den Fällen, in denen zwar Marken geklebt worden waren, aber entweder in der falschen Versicherung, d.h. in der IV statt der AV, oder in einer zu niedrigen Beitragsklasse. Vgl. „Schadensersatzpflicht des Arbeitgebers bei Verstößen gegen die Beitragspflicht in der Sozialversicherung“, in: „Der deutsche Unternehmer“ 13 (1934), 3.6.1934, S. 41, in: RfA-Archiv Fach 11. Dort auch weitere Zeitungsartikel zu dem Themenkomplex aus den Jahren 1934 und 1935. Vgl. auch die entsprechende Anfrage einer Rechtsberatungsstelle der DAF an die RfA vom 18.10.1935.

363 Vgl. das Schreiben des Zentralbüros der DAF an das RAM vom 6.12.1934, in: RfA-Archiv Fach 9, Nr. 3. 
dahin, die Zeiten, in denen wegen Verschuldens des Arbeitgebers keine Beiträge geleistet wurden, den versicherten Angestellten unter gewissen Voraussetzungen anzurechnen, d.h. die dadurch unverschuldet entstandenen Nachteile von den Versicherten abzuwenden. Dennoch wurde daran festgehalten, dass von den Versicherten die fehlenden Beiträge selbst nachentrichtet werden musste mit der einzigen Konzession, dass dies in einer niedrigeren als der ursprünglich erforderlichen Gehaltsklasse erfolgen konnte. ${ }^{364}$ Einen generellen Anspruch auf einen Ausgleich der ausgefallenen Beiträge durch die RfA, wie das Sozialamt der DAF forderte, gab es jedoch nicht. Die RfA-Beamten entschieden vielmehr nach Lage des einzelnen Falles.

Im Übrigen hatte das NS-Regime im Zuge der Machtergreifung und Ausschaltung aller sogenannter staatsfeindlichen Organisationen selbst dafür gesorgt, dass eine Reihe von Angestellten Lücken in ihren Beitragszahlungen durch die damaligen Arbeitgeber aufwiesen. Im Mai 1937 erstellte die RfA eine Liste von Beitragsrückständen früherer staatsfeindlicher Organisationen, darunter diverse Druckereien und Verlage von KPD und SPD, deren Rückstände sich auf die eher geringe Summe von insgesamt 3702 RM beliefen. ${ }^{365}$ Schon im Januar 1933 hatte sich eine ehemalige Angestellte der Bezirksleitung Düsseldorf der KPD an die RfA mit dem Hinweis auf fehlende Beitragszahlungen des vormaligen Arbeitgebers gewandt. Es fehlten ganze 56 RM, aber wegen der Grundsätzlichkeit des Falles sollte es bis September 1938 dauern, bis die RfA den Betrag vom Regierungspräsidenten von Düsseldorf erstattet bekam. Im Interesse der geschädigten Versicherten forderte die RfA nun das Finanzministerium dazu auf, die Beitragsrückstände aus dem eingezogenen Vermögen zu begleichen. ${ }^{36}$ Dort sah man jedoch die nötigen Voraussetzungen als nicht erfüllt an, womit die Forderungen von Rechts wegen abgelehnt wurden. ${ }^{367}$ Immerhin enthielt das Ausbaugesetz eine Bestimmung, dass die vom Arbeitgeber nicht abgeführten Rentenversicherungsbeiträge als entrichtet galten, wenn die Beitreibung ergebnislos geblieben war und der Versicherte selbst glaubhaft machen konnte, dass ihm gleichzeitig aber seine Beitragsanteile abgezogen worden waren. Um es erst gar nicht zu den Unterschlagungen kommen zu lassen, bestand seit jeher schon die Möglichkeit, diejenigen Arbeitgeber mit Ordnungsstrafen von bis zu 1000 RM zu belegen, die es unterlassen hatten, rechtzeitig die richtigen Marken zu verwenden oder die Marken verspätet geklebt worden waren.

Unabhängig von der Strafe und der Nachholung der Rückstände konnte dem Bestraften die Zahlung des Ein- bis Zweifachen dieser Rückstände inklusive ange-

364 Schreiben der RfA an das Sozialamt der DAF vom 21.3.1935, in: ebd. sowie dazu auch schon das ausführliche Schreiben der RfA an das RAM vom 26.5.1934, in: RfA-Archiv Fach 10, Nr. 4.

365 Schreiben der RfA an das RVA mit der Liste im Anhang vom 8.5.1937, in: BArch R 89/3390.

366 Vgl. dazu auch die Abteilungsverfügung vom 6.1.1938 zur Geltendmachung entsprechender Beitragsansprüche durch die RfA, in: ebd.

367 Schreiben des Finanzministeriums an die RfA vom 30.7.1937, in: RfA-Archiv Fach 1, Nr. 1. 
fallener Zinsen auferlegt werden. ${ }^{368}$ Seit jeher war es dabei auch Verwaltungspraxis der RfA gewesen, die „schwarzen Schafe“, die wegen Vergehen nach §338 AVG rechtskräftig verurteilt worden waren, an die Arbeitgeberverbände zu melden. Nach 1933 schaltete sich nun die DAF in dieses Verfahren ein. In der Regel war das Procedere so, dass der jeweilige Betriebsinhaber nach Feststellung der Beitragsrückstände eine offizielle Vorladung in die Geschäftsstelle des zuständigen Überwachungsbeamten erhielt, um dort die ordnungsgemäßen Versicherungskarten vorzulegen, verbunden mit der oben erwähnten Strafandrohung. Die nachträgliche Rückforderungsmöglichkeit bestand allerdings nur zwei Jahre; danach war der Fall verjährt. Der DAF erschien dies als ein zu langwieriges, mit unnötigen Verwaltungskosten verbundenes Verfahren und sie drängte daher auf eine Verschärfung der Kontroll- und Sanktionsmöglichkeiten, unter anderem über die Einführung eines (letztlich vermutlich nicht minder bürokratischen) Markenkaufzettels. ${ }^{369}$ Das praktizierte Verfahren der Beitreibung von Markenrückständen bei Firmen war tatsächlich langwierig, denn in den meisten Fällen legten die Betroffenen Beschwerde gegen die Strafbescheide der RfA ein, und der Fall musste dann schließlich vor den Oberversicherungsämtern entschieden werden. In den meisten Fällen ging es dabei zudem um relativ geringe Summen von unter 1000 RM. ${ }^{370}$ Dass aber dabei nicht gleiches Recht für alle gelten sollte, zeigt ein Rundschreiben des RAM vom Oktober 1939, in dem die Versicherungsträger angewiesen wurden, denjenigen Unternehmern, „die nachweislich infolge ihres Eintretens für die nationalsozialistische Erhebung in wirtschaftliche Notlage geraten sind, weitgehend Zahlungserleichterungen für rückständige Sozialversicherungsbeiträge zu gewähren“. 371

In den Unterlagen der RfA (ca. 60 Akten) finden sich allerdings auch eine Reihe von Unterschlagungsfällen mit deutlich höheren Rückstands- bzw. Schadenssummen. Bei der Kölner Niederlassung der Berlin-Anhaltinischen Maschinenbau AG hatte der Überwachungsbeamte im März 1936 Beitragsrückstände von 16.186 RM festgestellt, zudem waren in erheblichem Maße zu niedrige Beiträge entrichtet und ein Teil von einem dortigen kaufmännischen Angestellten offensichtlich unterschlagen worden. ${ }^{372}$ Opfer von innerbetrieblichen Betrügereien wurde auch die Vereinigte Oberschlesische Hüttenwerke AG, bei der im Oktober 1933 schon fehlende Marken von über 10.544 RM festgestellt wurden. Eine Anzahl von Marken wurde zudem bei der Entwertung ge-

368 Von der Erhebung der Zinsen wurde jedoch von der RfA wegen des damit verbundenen erheblichen Verwaltungsaufwandes nur in Ausnahmenfällen Gebrauch gemacht. Vgl. Schreiben der RfA an das RVA vom 18.4.1935, in: RfA-Archiv Fach 115, Nr. 12.

369 Vgl. Schreiben des Zentralbüros der DAF an das RVA vom 17.12.1936 sowie die ablehnende Stellungnahme der RfA dazu vom 20.3.1937, in: RfA-Archiv Fach 40, Nr. 10.

370 Vgl. dazu etwa exemplarisch das Streitverfahren mit einem westfälischen Autohändler, das 1925 eingeleitet worden war und erst im September 1933 entschieden wurde, in: BArch R 89/22701.

371 Das Rundschreiben vom 7.11.1939, in: RfA-Archiv Fach 74, Nr. 1.

372 Bericht der Überwachungsstelle Nr. 91 vom 14.3.1936, in: RfA-Archiv Fach 107, Nr. 1. 
ändert, indem die früheren Entwertungsvermerke ausradiert wurden. ${ }^{373}$ Bemerkenswert war auch der Fall der Braunkohle-Benzin AG (Brabag), bei der im Dezember 1939 infolge von Unterschlagung Rückstände in Höhe von 5452 RM festgestellt worden waren, die sich später noch auf fast 15.300 RM erhöhten. Dem zuständigen Überwachungsbeamten war aufgefallen, dass sehr viele Marken Abänderungen in den Entwertungsdaten aufwiesen; teils waren die Marken umgeklebt, überschrieben oder überstempelt worden. Zudem war auch eine Reihe von Versicherungskarten verschwunden. Aufgabe des Überwachungsbeamten war es dann, das Markenbild zur Wahrung der Ansprüche der geschädigten Versicherten in aufwändiger Rekonstruktion wiederherzustellen. ${ }^{374}$ In seinem Bericht hatte der Überwachungsbeamte Hitlers Finanzberater Wilhelm Keppler, der zugleich in der Führung der Brabag saß, als für die Bestrafung in Betracht kommend genannt. Tatsächlich endete das Verfahren jedoch im April 1940 mit der Verurteilung von zwei Unternehmensangestellten zu zwei Jahren Haft.

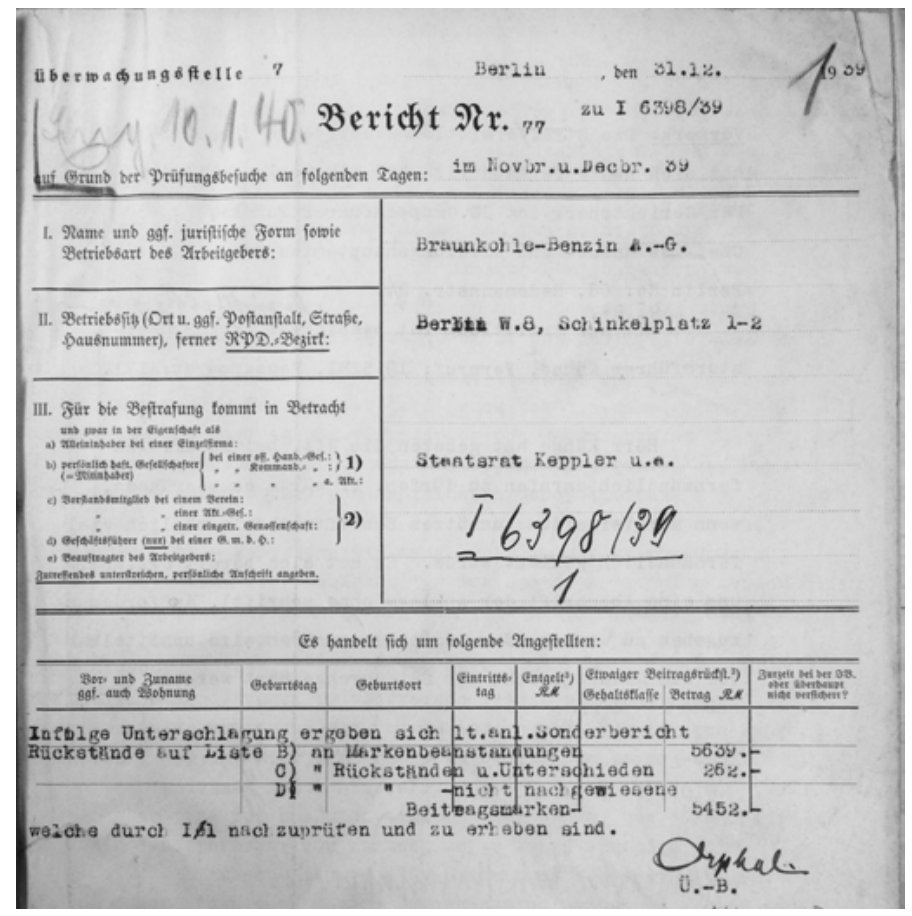

Abb. 22: Bericht eines Berliner Überwachungsbeamten vom 31. Dezember 1939

373 Vgl. Vermerk zu diesem Fall vom 11.10.1933, in: RfA-Archiv Fach 104, Nr. 9.

374 Bericht des Überwachungsbeamten über die Sonderprüfung vom 9.1.1940, in: ebd. 
Geradezu ein Sumpf krimineller Verstöße gegen die Versicherungsordnung war die AOK Berlin. Im April 1935 waren dort durch den Überwachungsbeamten fehlende Beitragszahlungen für die ca. 1800 Angestellten festgestellt worden, die sich zu einem Gesamtbetrag von 45.000 bis 50.000 RM summierten. ${ }^{375}$ Der Fall drang zwar nicht an die Öffentlichkeit, schlug aber verwaltungsintern hohe Wellen; es folgten Gespräche zwischen der RfA, dem RAM und dem für die AOK zuständigen Reichskommissar. ${ }^{376}$ Waren hier allgemeine verwaltungstechnische Probleme als Ursache der Rückstände vorgeschoben worden, so standen hinter den im November 1937 und Oktober 1940 bei der Berliner AOK erneut festgestellten Beitragsrückständen Unterschlagungen einzelner Verwaltungsangestellter. ${ }^{377}$ Das Ausmaß der Kriminalität auf dem Gebiet der Rentenversicherung war aber bei der RfA nicht so groß, dass man, wie bei einer Reihe von Landesversicherungsanstalten, eigene Fahndungsabteilungen zur Bekämpfung der spezifischen Kriminalität im Sozialversicherungsbereich eingerichtet hätte. ${ }^{378}$

Manchmal verhinderte der bürokratische Rigorismus der Überwachungsbeamten auch rasseideologische Diskriminierungsmaßnahmen. Die Versicherungskarte galt rechtlich als Urkunde und damit waren handschriftliche oder andere nachträgliche Eintragungen verboten und strafbar. Aus den Karten war daher auch nicht ersichtlich, welche Religionszugehörigkeit die Versicherten besaßen. Im August 1938 wurde nun ein Berliner Überwachungsbeamter mit der Tatsache konfrontiert, dass die Polizeibehörden künftig sämtliche Vorgänge, die jüdische Personen betrafen, mit einem roten Zeichen versehen sollten. Dementsprechend sollten von den Ausgabestellen auch die jüdischen Namen auf den Versichertenkarten rot unterstrichen werden. Der Überwachungsbeamte wandte sich daher folgendermaßen an die zuständige Dienststelle in der Ruhrstraße:

Kann diese Anordnung anerkannt werden? Eine derartige Bestimmung ist mir nicht bekannt und auch in den bisher erlassenen Judengesetzen nicht enthalten. Meines Erachtens kommen für die Versichertenkarten die Bestimmungen der $\S \S 180$ und 334 in Frage, nach denen besondere Merkmale auf den Versichertenkarten unzulässig sind. ${ }^{379}$

Es waren diese alltäglichen Diskriminierungsmaßnahmen, die die spätere gesellschaftliche Exklusion bis hin zur persönlichen Verfolgung und Ermordung der Juden erst möglich machten bzw. halfen, diese in Gang zu setzen. RfA-intern war die Sache durchaus strittig. In einem ersten Vermerk sah der zuständige Sachbearbeiter keine Probleme. Juden hätten, so das Argument, aufgrund der inzwischen erlassenen Ge-

375 Vgl. Bericht Nr. 26 des Überwachungsbeamten vom 3.4.1935, in: RfA-Archiv Fach 103, Nr. 2.

376 Vgl. dazu den Bericht des Überwachungsbeamten über diverse Verhandlungen und Untererdungen vom 4.7.1935, in: ebd.

377 Vgl. das Urteil vom 25.3.1939 zu den Vorfällen im November 1937 sowie das Schreiben der RfA zu den Verhandlungen des Überwachungsbeamten mit der AOK vom August 1940, in: ebd.

378 Vgl. dazu auch W. Heess, S. Fetscher: Die Kriminalität auf dem Gebiete der Invalidenversicherung und ihre Bekämpfung. Archiv für Kriminologie 102 (1938), S. 1-38.

379 Bericht des Überwachungsbeamten vom 30.8.1938, in: RfA-Archiv Fach 73, Nr. 1. 
setze eigene Kennkarten zu beantragen und unaufgefordert auf ihre Eigenschaft als Jude hinzuweisen. Zudem müssten diese ab Januar 1939 zusätzlich den Vornamen Israel bzw. Sara führen. „Gegenüber diesen Vorschriften und im Hinblick auf die Tendenz der gesamten anderen Gesetzgebung über die Juden kommt wohl der bloßen roten Unterstreichung der Namen auf den Versichertenkarten keine besondere Bedeutung zu. “380 Doch Direktor Granzow, dem die Angelegenheit Anfang September zur Entscheidung vorgelegt wurde, beharrte auf dem alten Rechtsstandpunkt der Unzulässigkeit von Kenntlichmachung auf den Versichertenkarten. Grießmeyer intervenierte und Ende September 1938 teilte der Berliner Polizeipräsident tatsächlich mit, dass aufgrund der Haltung der RfA die Anordnung zur Kenntlichmachung jüdischer Versicherter auf ihren Karten durch die Polizeistellen wieder aufgehoben worden war. ${ }^{381}$ Für die NS-Stellen war es im Übrigen ein willkommener Anlass, wenn bei der Verfolgung von Straftaten Juden unter den Tätern identifiziert worden waren. Im Juli 1939 war etwa ein bereits vorbestrafter Vertreter gefasst worden, der jahrelang eine systematische Hehlerei mit bereits verwendeten Marken der Invaliden- wie Angestelltenversicherung betrieben hatte. Der dabei entstandene Schaden wurde auf hunderttausende RM geschätzt. Im August wurde er dafür zu zwei Jahren Haft verurteilt. Der Fall wurde groß in der Presse ausgeschlachtet. Dabei hatte man aus Sicht der RfA-Beamten bedauerlicherweise versäumt hatte, den Kundenkreis des Beschuldigten zu ermitteln, um die gefälschten Marken aus dem Verkehr ziehen und damit die Folgeschäden der Markenhehlerei beheben zu können, mit denen die RfA daher weiterhin konfrontiert war. ${ }^{382}$

Die Überwachungsbeamten sahen sich im Übrigen immer wieder auch Instrumentalisierungsversuchen diverser NS-Stellen ausgesetzt. Im März 1937 wurden etwa die im Bezirk Brandenburg tätigen Beamten durch ein Rundschreiben aus der Ruhrstraße dazu angehalten, unter dem Deckmantel der Amtshilfe für den dortigen Treuhänder der Arbeit im Zuge ihrer Beitragsprüfungen in den Betrieben auch auf Verstöße gegen die Tarifordnung $\mathrm{zu}$ achten. ${ }^{383}$ Sofern sie diese feststellten oder vermuteten, sollten sie vom Betriebsführer entsprechend Auskünfte und Rechenschaft verlangen. Tatsächlich erhielten die Überwachungsbeamten ebenso tiefen wie detaillierten Einblick in die Gehalts- und Tarifrealität vor Ort, da für die Berechnung der Versicherungsbeiträge nicht das tarifmäßig vereinbarte, sondern das faktisch gezahlte Gehalt zugrunde gelegt wurde. Das RAM informierte im Juli 1937 alle Versicherungsträger darüber, dass nach Angaben der DAF einzelne, insbesondere jedoch in Berlin einzelne Fälle aufgetreten seien, in denen Inhaber jüdischer Betriebe unter Zurücklassung erheblicher Schulden an Sozialversicherungsbeiträgen ins Ausland geflüchtet seien. Deshalb wurde empfohlen, die Entrichtung der Sozialversicherungsbeiträge durch

380 Vermerk vom 6.9.1938, in: ebd.

381 Schreiben vom 30.9.1938, in: ebd.

382 Vgl. dazu den Vorgang sowie die Pressemeldung aus dem Berliner Anzeiger vom 3. 8.1939, in: RfAArchiv Fach 75, Nr. 8.

383 Vgl. das Rundschreiben vom 10.3.1937, in: RfA-Archiv Fach 68, Nr. 1. 
jüdische Betriebe „besonders zu überwachen und bei Verstößen und Unregelmäßigkeiten gegen die Verantwortlichen vorzugehen“. ${ }^{384}$ Es ist nicht klar, inwieweit diese Anordnung von den Überwachungsbeamten der RfA tatsächlich umgesetzt wurde, aber in den Akten findet sich kein einziger Fall, der die übertriebene und vermutlich frei erfundene Darstellung der DAF bestätigt hätte. Doch die NS-Machthaber ließen nicht locker. Im Februar 1939 wurde in Berlin eine Zentralstelle für jüdische Auswanderer eingerichtet: Neben Passstelle, Finanzamt, Devisenstelle, Landesarbeitsamt und Gestapo war auch die RfA zur Abordnung eines kundigen Beamten aufgefordert worden. ${ }^{385}$ Das RAM rechnete damit, dass dort künftig täglich ca. 100 Juden „abgefertigt“" werden würden, und der RfA-Beamte sollte vermeiden helfen, dass Juden auswanderten, ehe sie ihre Beiträge zur Sozialversicherung bezahlt hatten. Damit verbunden war, dass künftig sämtliche Auswanderungsanzeigen auch den Überwachungsbeamten zur Nachprüfung zugestellt wurden und diese in vordringlich zu behandelnden Sonderaufträgen entsprechende Kontrollbesuche vorzunehmen hatten. Als im Laufe des Mai die entsprechenden Berichte der Überwachungsbeamten in der Ruhrstraße eingingen, zeigte sich, dass in keinem der insgesamt etwa 150 Sonderkontrollen Beitragsrückstände festgestellt worden waren. ${ }^{386}$ Dass bei der mit erheblichem Aufwand durchgeführten Aktion keine Verfehlungen aufgedeckt werden konnten, hing, so betonte die RfA in ihrem Schreiben an das RVA, vermutlich auch damit zusammen, „dass die Juden mit den Beitragsentrichtungen sehr pünktlich sind, um jede Reibungsfläche mit den Behörden zu vermeiden““. ${ }^{387}$ Auf Bitten der RfA wurde daher von weiteren Sonderprüfungen abgesehen und das Verfahren eingestellt. Die Überwachungsbeamten, eigentlich über die politischen Brüche hinweg ein Kernelement der Unabhängigkeit und Selbstverwaltungskompetenzen der RfA, waren somit dennoch wie die gesamte Behörde in den Strudel politischer Instrumentalisierungsversuche durch den NS-Staat geraten.

\section{Das Ruhen der Renten wegen staatsfeindlicher Tätigkeit und die vielen Facetten der Verwaltungsmaßnahmen gegen jüdische Versicherte}

Die spezifischen Erfassungs-, Kontroll- und Überwachungsmaßnahmen gegen Juden waren nur ein Teil des insgesamt durchaus komplexen und sich über Jahre hinziehenden Prozesses der Exklusion aus der Versichertengemeinschaft. Wer unter den versicherten Beitragszahlern und Rentnern „Nichtarier“ war und wie groß der Anteil der Juden an den versicherungspflichtig bei der RfA gemeldeten Angestellten und Selbständigen war, wusste man in der Ruhrstraße nicht und konnte es auch gar nicht wissen, denn die Angaben auf den Versichertenkarten beschränkten sich auf den

384 Das Rundschreiben vom 31.7.1937, in: BArch R 89/3390.

385 Vgl. Schreiben des RAM an die RfA vom 23.2.1939, in: RfA-Archiv Fach 13, Nr. 6.

386 Vgl. dazu die Berichte vom 5.5.1939 und 2.5.1939, in: ebd.

387 Schreiben vom 12.5.1939, in: ebd. 
Namen und das Geburtsdatum. Selbst eine Sortierung nach Wohnort war nicht möglich, was viele NSDAP-Stellen und ihre Mitgliedsorganisationen nicht glauben mochten, wenn sie sich mit ihren häufigen Anfragen nach einer Liste sämtlicher in ihren jeweiligen Städten oder Bezirken lebenden Angestelltenrentnern an die RfA wandten. Und selbst wenn man über die Konfession der Versicherten und Rentner Bescheid gewusst hätte, so fehlte gegen Juden mit deutscher Staatsangehörigkeit jegliche gesetzliche Handhabe, die Bestimmungen der RVO und der AV nicht anzuwenden und etwaige Einschränkungen bei den Leistungsansprüchen vornehmen zu können. Solange die Juden als anonyme Beitragszahler im Millionenheer der RfAVersicherten regelmäßig ihre Versicherungsmarken erwarben und klebten, waren sie für die Behörde wie die NS-Stellen gleichsam unsichtbar. Je prekärer jedoch im Zuge von Diskriminierung und „Arisierung“ ihre Beschäftigungsverhältnisse wurden, je mehr sie von erzwungenen Betriebsschließungen und „Arisierungsmaßnahmen“ in der Belegschaft der Konzerne wie Verwaltungsbehörden betroffen waren, desto unmittelbarer waren die rentenversicherungsrechtlichen Rückwirkungen. Damit wurden sie für die Versicherungsträger gleichsam nach und nach sichtbar.

So konzentrierten sich die Diskriminierungsmaßnahmen in der Rentenversicherung zunächst auf die ausreisewilligen bzw. bereits im Ausland lebenden Juden. Schon im Oktober 1933 hatte die RfA von der Reichsstelle für das Auswanderungswesen eine Anfrage zu den häufig vorgebrachten Wünschen Ausreisewilliger erhalten, die nach der Möglichkeit fragten, vor der Auswanderung die zur Angestelltenversicherung eingezahlten Summen ganz oder teilweise zurückzuerhalten, da diese ja andernfalls verloren seien. ${ }^{388}$ Mit Verweis auf die gesetzliche Lage und auch verbunden mit grundsätzlichen Hinweisen auf den Sinn und Zweck des Versicherungsprinzips wurde das von der RfA verneint, und den Auswanderern im Gegenteil empfohlen, die erworbenen Ansprüche durch freiwillige Weiterversicherung aus dem Ausland zu erhalten. ${ }^{389}$ So antwortete die RfA auch auf ähnliche Anfragen, die seit 1936 verstärkt in der Ruhrstraße eingingen, wie etwa des Wohlfahrsamts der Synagogen-Gemeinde Köln. „Die Auszahlung reichsgesetzlicher Leistungen nach dem Ausland unterliegt zur Zeit keinen Beschränkungen durch die deutsche Devisengesetzgebung. Sonderbestimmungen für nichtarische Versicherte sind bisher nicht ergangen“, hieß es nun ergänzend. ${ }^{390}$ Das sollte sich allerdings, zumindest in Bezug auf das Devisenrecht, bald ändern. Prinzipiell galt, dass Deutsche ihre Rente auch im Ausland erhielten. Nur wenn sich ein Ausländer, der bereits Rentenbezieher war, freiwillig und nicht nur vorübergehend im Ausland aufhielt, dann ruhte die Rente für diese Zeit. Erwarb z. B. ein deutscher Auswanderer eine ausländische Staatsangehörigkeit, so konnte er trotzdem seine freiwillige Weiterversicherung fortsetzen. Kehrten er oder seine rentenberechtigten Angehörigen später nach Deutschland zurück, so hatten sie Anspruch

388 Das Schreiben vom 23.10.1933, in: RfA-Archiv Fach 111, Nr. 9.

389 Vgl. das Antwortschreiben vom 15.11.1933, in: ebd.

390 Anfrage an die RfA vom 9.4.1936 sowie Antwortschreiben vom 26.4.1936, in: RfA-Archiv Fach 37, Nr. 1. 
auf Rente, auch wenn sie die deutsche Staatsangehörigkeit nicht mehr besaßen oder nicht wieder erwarben. ${ }^{391}$ Gegenüber jüdischen Rentenbeziehern im Ausland ergab sich dadurch eigentlich keine Handhabe, die Rentenzahlung zu verweigern bzw. ruhen zu lassen, denn von einem freiwilligem Aufenthalt konnte bei den jüdischen Emigranten, die auch schon lange vor der Reichspogromnacht von 1938 bei einer Rückkehr zunehmend mit Sanktionen zu rechnen hatten, keine Rede sein. Genau das aber wurde von den deutschen Behörden und auch von der RfA bestritten. Ihre Übersiedelung ins Ausland galt als freiwillig und keineswegs erzwungen, und somit ergab sich die Handhabe, die Rentenzahlungen ruhen zu lassen.

Die strittige Frage hatte schon im März 1934 die RfA und den Revisionssenat des RVA beschäftigt. Ein 68-jähriger staatenloser Angehöriger der israelitischen Gemeinde in Dresden war im Mai 1933 zusammen mit seiner Frau nach Palästina ausgewandert. Seit Oktober 1932 bezog er ein Altersruhegeld der RfA von monatlich 83,60 RM. Der Betroffene hatte nun an die RfA den Antrag gestellt, die fälligen Beträge entweder an seine in Dresden verbliebene Tochter zu zahlen oder ihm nach Tel Aviv zu überweisen. ${ }^{392}$ Von der RfA war jedoch mit Verweis auf die Freiwilligkeit des Aufenthalts im Ausland das Ruhen der Rente veranlasst worden. Beim Ruhen der Rente bestand zwar der Anspruch auf die Rente prinzipiell weiter, aber es ruhte das Recht auf die Auszahlung. Dagegen hatte die Tochter im Namen ihres Vaters geklagt und, nachdem das Oberversicherungsamt Dresden die Position der RfA gestützt hatte, Revision beim RVA eingelegt. Die Argumentation des Klägers versuchte dabei die bestehende Gesetzeslage und auch die antisemitische Politik des NS-Regimes, die die „Judenfrage“ noch durch massenhafte Auswanderung „lösen“ wollte, zu nutzen. Der Betroffene verwies auf einen Runderlass des Reichswirtschaftsministeriums vom August 1933, in dem die Auswanderung von „Nichtariern“ ausdrücklich als im deutschen Interesse liegend bezeichnet wurde, und er beteuerte auch den ernsthaften Willen, nach Deutschland zurückzukehren, was aber aufgrund des Gesundheitszustands nicht möglich war. „Der Kläger bekommt“, so wurde zudem weiter argumentiert, ,als Staatenloser keinesfalls eine Wiedereinreiseerlaubnis von den deutschen Behörden, da das Deutsche Reich aus rassenpolitischen Gründen sich gegen den Zuzug von Nichtariern ab-

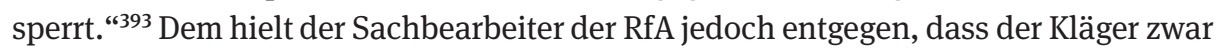

von seinem Standpunkt aus triftige Gründe politischer Art zur Auswanderung gehabt haben mag, dass indessen der Entschluss ins Ausland zu gehen seiner freien Willensbestimmung entsprungen ist. Letzteres ergibt sich allein schon daraus, dass die Mehrzahl seiner in Deutschland lebenden Rassegenossen sich bis heute zu diesem Entschluss noch nicht durchzuringen vermocht haben. ${ }^{394}$

391 Vgl. dazu auch die entsprechende Notiz in: Mitteilungen der RfA Heft 4, 1933, S. 56.

392 Vgl. Bericht und Gutachten zur Streitsache Gustav W. vom 9.11.1934, in: BArch R 89/23085.

393 Schreiben der Tochter an das RVA vom 19.3.1934, in: ebd.

394 Vermerk und Gutachten vom 9.11.1934, in: ebd. 
Die Revision wurde daher als unbegründet zurückgewiesen und die Rentenzahlung weiter ausgesetzt.

Ähnlich zynisch war die Begründung der Ablehnung einer Klage einer ebenfalls nach Tel Aviv ausgewanderten Witwe, deren Rente von der RfA zum Ruhen gebracht worden war. Eine Ausweisung sei nicht erfolgt und die Nachreise zu ihrem bereits in Palästina lebenden Sohn freiwillig. Aus der Begründung, dass die Witwenrente allein nicht ausreiche, den Lebensunterhalt $\mathrm{zu}$ bestreiten, ergebe sich kein Zwang, Deutschland $\mathrm{zu}$ verlassen, sondern es bestehe die Möglichkeit, sich an das Wohlfahrsamt zu wenden. ${ }^{395}$ Es gab eine Reihe weiterer Fälle, in denen ausgewanderte Juden gegen das ungerechtfertigte Ruhen ihrer Alters- und Witwenrenten klagten. Für Ruhegeldempfänger, denen die Rente wegen Arbeitslosigkeit bewilligt worden war, galt schon vorher grundsätzlich, dass die Rente bei Verlegung des Wohnsitzes ins Ausland entzogen wurde, weil der Auslandsaufenthalt rechtlich als Unterbrechung der Arbeitslosigkeit anzusehen war. Inzwischen hatten die Behörden mit der zwangsweisen Ausbürgerung und vor allem mit der Aberkennung der deutschen Staatsbürgerschaft einen weiteren formalrechtlichen Hebel entwickelt, durch den tausende deutsche Juden wie auch andere als Staatsfeinde geltende politische Gegner von Inländern zu Ausländern gemacht wurden - mit entsprechenden rentenversicherungsrechtlichen Rückwirkungen. In einem Bescheid der RfA, den diese am 22. November 1938 an einen Rentenempfänger ins piemontesische Verbania schickte, heißt es:

Durch Bekanntgabe vom 22. September 1938 ist Ihnen die deutsche Staatsangehörigkeit aberkannt worden. Sie sind hierdurch Ausländer (staatenlos) geworden [und] damit ruht Ihre Rente vom 1. Oktober 1938 an. Die Ihnen für Oktober und November noch gezahlten Bezüge von 2x 69,10 RM sind überzahlt und müssen zurückerstattet werden. ${ }^{396}$

Der Betroffene legte mit Hinweis auf die erzwungene Ausbürgerung Berufung ein, doch im März 1939 entschied das Reichsinnenministerium im Einvernehmen mit dem RAM, dass dem Kläger als Juden und zugleich ehemaligem SPD-Funktionär die Rente nun auch wegen staatsfeindlicher Hetze zum Ruhen gebracht, sprich entzogen wurde. ${ }^{397}$ Die RfA konnte sich dabei auch auf ein Grundsatzurteil des RVA vom 28. März 1938 stützen. Darin wurde in diesen und anderen Fällen entschieden, dass nach wie vor die Rente zu ruhen hätte, wenn sich der Betroffene freiwillig gewöhnlich im Ausland aufhalte. Dabei kam es nicht darauf an, auf welche Weise der Aufenthalt begründet worden war, es sei lediglich zu prüfen, ob der Aufenthalt im Ausland in der

395 Vgl. Schreiben der RfA vom 29.9.1934 sowie Vorentscheidung in der Witwenrentensache Ernestine S., in: BArch R 89/23085. Vgl. auch das Schreiben der RfA zur Frage des freiwilligen oder unfreiwilligen Auslandsaufenthalts vom 4.4.1935 aus Anlass der Beantwortung einer um Klärung bittenden Anfrage der italienischen Botschaft in Berlin, in: BArch R 89/3469.

396 Bescheid vom 22.11.1938, in: RfA-Archiv Fach 65, Nr. 6.

397 Entscheidung vom 15.3.1939, in: ebd. 
Zeit, für die das Ruhen der Rente verfügt werden soll, dem Willen des Berechtigten entsprach. Die Nichterteilung einer Einreiseerlaubnis mache zwar den Auslandsaufenthalt tatsächlich zu einem unfreiwilligen, Voraussetzung dafür sei aber weiterhin, dass der in Frage kommende Ausländer den ernsten Willen gehabt habe und noch besitze, tatsächlich nach Deutschland überzusiedeln. „Die Sachlage, wie sie in Deutschland für einen ausgebürgerten Nichtarier besteht, muss diesen Willen aber von vornherein praktisch als aussichtslos und unmaßgeblich erscheinen lassen. “398 Entsprechende Revisionen seien daher nach der Sach- und Rechtslage unbegründet und zurückzuweisen.

Im Verfahren der Auslandsüberweisungen von Renten gab es aber noch zwei weitere bürokratische Hürden, die von den NS-Stellen ausgiebig für Diskriminierungsmaßnahmen genutzt wurden: Zum einen war für eine Rentenüberweisung ins Ausland die regelmäßige, sprich monatliche Vorlage einer Lebensbescheinigung erforderlich, die nur das jeweilige deutsche Konsulat ausstellen konnte. Zum anderen gab es zum Teil schon seit 1934 im Zuge der Devisenbewirtschaftung umfangreiche devisenrechtliche Restriktionen, die anstelle der bislang erfolgten Zusendung der Rente per Wertbrief nur noch komplizierte Transfers und Auszahlungen über verschiedene Banken wie etwa die Banco Germanico de la America del Sud in Sao Paolo zuließ. ${ }^{399}$ Das letzte Wort über die Genehmigung einer Rentenauszahlung ins Ausland hatte seit Jahresbeginn 1937 nicht die RfA, sondern die zuständige Devisenstelle. Rentenempfänger, die nach dem Februar 1937 ihren Wohnsitz ins Ausland verlegen wollten, mussten erst durch eine behördliche Bescheinigung nachweisen, dass die Voraussetzungen für die Genehmigung der Zahlung ins Ausland erfüllt waren. ${ }^{400}$ In dieses Verfahren versuchte sich auch die DAF einzuschalten. In einem Schreiben an Präsident Grießmeyer schlug das Sozialamt der DAF vor, seitens der RfA künftig auch die Lebensbescheinigungen anzuerkennen, die von der Parteidienststelle oder von der Ortsgruppenwaltung der DAF ausgestellt wurden. ${ }^{401}$ Wie Grießmeyer darauf antwortete, ist aus den Akten nicht ersichtlich, aber zweifellos reichte der lange Arm der NSDAP-Auslandsorganisation auch bis in den Bereich der Sozialversicherung hinein. Im Juni 1937 erhielten etwa die Rechtsberatungsstellen der DAF auch die Erlaubnis zur Vertretung von Versicherten ausländischer Staatsangehörigkeit gegenüber Versicherungsträgern und Versicherungsbehörden.

Durch Erlass vom Dezember 1936 wurde dann auch das Verfahren zur Zahlung freiwilliger Beiträge und für die Selbstversicherung beim Aufenthalt im Ausland neu

398 Entscheidung des RVA vom 28.3.1938, in: RfA-Archiv Nr. 109.

399 Vgl. dazu einen entsprechenden Bescheid der RfA an eine in Brasilien wohnende Rentenbezieherin vom 8.5.1934, in: RFA-Archiv, Fach 113, Nr. 4.

400 Auskunftschreiben der RfA vom 20.7.1937 an das Schweizer Generalkonsulat in Köln, in: RfAArchiv Nr. 91 c. Nur in den Fällen, in denen die Erstattungen auf einem zwischenstaatlichen Abkommen beruhten, wurde die Genehmigung der Devisenstelle noch von Amts wegen durch die RfA eingeholt. Vgl. auch Abteilungsverfügung der Abt. I Leistung 11/37 vom 29.1.1937, in: RfA-Archiv, Regal 5. 401 Schreiben der DAF vom 6.1.1937, in: RfA-Archiv Nr. 86. 
geregelt. Die Verwendung von durch eine beauftragte Person im Inland erworbenen Beitragsmarken war nicht mehr zulässig, sondern nur noch die direkte Überweisung an die RfA in ausländischer Währung. Vor allem aber musste der Versicherte detaillierte Angaben zu seiner Person und seinem ausländischen Einkommen machen. ${ }^{402}$ Für Pflichtbeiträge galten diese Bestimmungen nicht, was darauf hinweist, dass es bei all diese Maßnahmen nicht nur um die notorische Devisenknappheit des Reichs ging, sondern vor allem auch darum, emigrierten Juden die Aufrechterhaltung von Versicherungsansprüchen erheblich zu erschweren oder gar unmöglich zu machen. Auch bei den Rentenauszahlungen schaltete sich die Reichsstelle für Devisenbewirtschaftung mit ein. Sie erklärte es im Januar 1936 für nicht mehr zulässig, dass Rentenberechtigte, die in ausländischen Grenzbezirken wohnten, ihre Renten in deutschen Postämtern in Empfang nehmen konnten.

Wie hoch die monatlichen Beitragseinnahmen der RfA aus dem Ausland waren, lässt sich nicht mehr rekonstruieren. Genaue Angaben gibt es jedoch für die ins Ausland überwiesenen Rentenzahlungen. Sie betrugen im Jahr 1936 insgesamt 1,507 Mio. RM. ${ }^{403}$ Das war im Vergleich $\mathrm{zu}$ den insgesamt transferierten Ruhegeld- und Witwenrentenzahlungen der RfA nur ein verschwindend geringer Bruchteil, deren Abwicklung aber infolge der zunehmend rigideren Devisenbewirtschaftung hochkompliziert und mit einem erheblichen Verwaltungsaufwand verbunden war. Die Summe verteilte sich letztendlich auf ca. 1800 Rentenempfänger. ${ }^{404} 48$ Länder standen auf der Auslandszahlungsliste der RfA, und die größten Beträge gingen an die unmittelbaren Nachbarländer, allen voran die Tschechoslowakei (210.000 RM), Österreich (160.000 RM) und Dänemark (156.000 RM). Größere Beträge gingen auch an Rentenberechtigte in der Schweiz (136.000 RM), Polen (100.000 RM) und Holland (ebenfalls 100.000 RM), aber auch in den Freistaat Danzig (92.000 RM) und ins Memelgebiet (61.000 RM) sowie Frankreich (66.000 RM). Unter den Überseeländern ragten Argentinien (104.000 RM) und die USA (80.000 RM) hervor, nach Palästina gingen im Jahr 1936 knapp 50.000 RM an RfA-Renten. ${ }^{405}$ Bis 1938 sollte hier die Auszahlungssumme auf 56.000 RM leicht steigen, was angesichts der in der Zwischenzeit drastisch gestiegenen Auswanderungswelle weniger darauf hinweist, dass es jüdischen Auswanderern offensichtlich gelang, weiter ihre Rentenzahlungen aus Deutschland zu erhalten, als vielmehr auf die immer wirksameren Restriktionen. In Relation zu der Zahl ausgewanderter jüdischer RfA-Rentner hätte der Anstieg der Auslandszahlungen nach Palästina weit höher sein müssen. Immerhin liefen auch im Frühjahr 1939 noch regelmäßige Auszahlungen von Angestelltenrenten an die in Pa-

402 Vgl. dazu Mitteilungen der RfA vom 1.2.1937, S. 1f. sowie auch „Die Beitragsnachweise der Angestelltenversicherung“. Teil 1: Ein Überblick über die Beitragsentrichtung zur Angestelltenversicherung und die Kontenführung bei der RfA/BfA (Schriftenreihe der Bundesversicherungsanstalt für Angestellte Bd. 16), Berlin 1964, S. 11.

403 Vgl. dazu die Aufstellung vom 27.6. und 29.12.1936 in: RfA-Archiv Nr. 214.

404 So die Angaben für die Überweisungen im Monat März 1938, in: RfA-Archiv Nr. 125.

405 Vgl. die Aufstellung vom 27.6. und 29.12.1936 in: RfA-Archiv Nr. 214. 
lästina wohnenden Rentenberechtigten, obwohl es zunehmend auch technische Probleme gab. So bekam die RfA im Januar 1939 die ursprünglich angewiesenen Renten von der ägyptischen Postverwaltung mit der Bemerkung zurück, dass der Postanweisungsverkehr nach Palästina „zur Zeit eingestellt“ sei. ${ }^{406}$ Welche absurden bürokratischen Blüten dabei in Einzelfällen entstehen konnten, zeigt sich am Fall eines bereits nach Tel Aviv emigrierten ehemaligen Amtsgerichtsrates, der im August 1938 zunächst erfolgreich beim Oberversicherungsamt Berlin gegen einen RfA-Bescheid zur Aberkennung der Berufsunfähigkeit und des damit verbundenen Ruhegelds geklagt hatte. Zur Bekräftigung seines Ruhegeldantrags hatte sich der Betroffene ein ärztliches Gutachten eines Jerusalemer Spezialisten erstellen lassen und an die RfA geschickt. Doch die RfA hatte Widerspruch gegen die Entscheidung des Oberversicherungsamtes eingelegt und Revision vor dem Senat des RVA beantragt. Der Fall wurde im März 1939 verhandelt und zugunsten der RfA entschieden, d.h. die Berufsunfähigkeitsrente wurde aberkannt. Zur Begründung wurde auch seitens der RfA angeführt, dass der Antragsteller nachweislich nur aufgrund der klimatischen Bedingungen in Tel Aviv berufsunfähig und laut Gutachten auch nur zu 35 Prozent in seiner Erwerbsfähigkeit gemindert sei. Nach Lage der Dinge wäre der Kläger mithin in Orten mit gemäßigterem Klima berufsfähig und ihm sei auch zuzumuten, seinen Wohnsitz an einen entsprechenden Ort zu verlegen. „Denn gegen das Risiko, dass der Kläger infolge der Auswanderung an einen Ort mit für ihn ungünstigen klimatischen Verhältnissen berufsunfähig wird, ist er durch das Angestelltenversicherungsgesetz nicht versichert. “407

Das Problem der Auslandsrenten war aber für die RfA-Beamten auch ohne rassenpolitische Vorzeichen schon kompliziert genug. Aufgrund von entsprechenden Gegenseitigkeitsabkommen zur Sozialversicherung, die das Deutsche Reich zwischen 1931 und 1935 mit der Tschechoslowakei, Dänemark, den Benelux-Ländern sowie Polen und Frankreich geschlossen hatte, war der Rentenzahlungsverkehr prinzipiell gesetzlich geregelt. Laufend ergaben sich aber etwa Probleme mit den Währungsrelationen. Im Frühjahr 1935 etwa hatte sich die DAF beim RAM über erhebliche Kursverluste durch Umrechnung polnischer Renten beklagt. ${ }^{408}$ Auch im Zahlungsverkehr mit Dänemark gab es Probleme. Wenn der Umrechnungskurs der deutsche-dänischen Vereinbarung vom Dezember 1928 dem im Juni 1939 amtlichen Devisenkurs (1 RM = 1,92 Kronen) angepasst würde, so hieß es in einem Schreiben der RfA an das RVA und den Reichsarbeitsminister,

406 Schreiben der RfA an die Reichspost vom 26.1.1939 sowie Vermerk dazu für das RAM vom 21.2. 1939, in: RfA-Archiv Nr. 126.

407 Das Urteil vom 10.3.1939 mit ausführlicher Urteilsbegründung in: RfA-Archiv Fach 101, Nr. 5.

408 Schreiben vom 10.4.1935, in: BArch R 89/3413. Die Renten wurden zum Kurs von 100 Zloty = 46,90 RM umgerechnet, tatsächlich jedoch ergab sich aufgrund der starken Unterbewertung der RM im Ausland ein Kurs von 100 Zloty = 54 RM. Für die deutschen Rentner, die aus Polen Ruhegelder bekamen, ergaben sich dadurch Verluste von 13 Prozent. 
so hätte das zur Folge, dass die Rentenempfänger mehr als das Doppelte von dem ausgezahlt erhalten würden, was sie nach dem Kurs von 1 RM gleich 89 Oere erhalten, dass andererseits aber auch die Versicherten als Beiträge mehr als das Doppelte von dem bezahlen müssten, was sie heute bezahlen. Die Tatsache, dass die Versicherten in Nordschleswig tatsächlich weniger als die Hälfte für die Beiträge bezahlen und dass der Unterschied gedeckt wird aus der Ersparnis bei der Auszahlung der Renten, ist unseres Erachtens auf die Dauer nicht zu verantworten. ${ }^{409}$

Seit 1937 häuften sich im Zuge der wachsenden Auswanderungswelle jüdischer Versicherter die Anfragen an die RfA über die Aufrechterhaltung von Anwartschaften und die Weitergewährung von Renten beim Umzug ins europäische Ausland oder nach Übersee. Die Beamten in der Ruhrstraße wurden geradezu mit einer Flut von entsprechenden Briefen überhäuft, die die Behörde mit einem Standardschreiben beantwortete, in dem die wichtigsten Bestimmungen aufgeführt waren. ${ }^{410}$ „Ob der Auslandsaufenthalt des Rentenberechtigten freiwillig ist“, so ließ man verlauten, „lässt sich nur nach Lage des einzelnen Falles entscheiden. “411 Wenn ein Rentenempfänger der AV auswandert, stehe ihm die Rente auch beim Aufenthalt im Ausland weiter zu, solange er die deutsche Reichsangehörigkeit besaß. Die Rente dürfe aber nur mit Genehmigung der zuständigen Devisenstelle ins Ausland gezahlt werden. Von den Devisenstellen würde eine Überweisung angemessener Beträge aus Versicherungsrenten allerdings nur erteilt, wenn dem Empfänger eine Rückkehr nach Deutschland aus gesundheitlichen oder anderen persönlichen Gründen nicht zugemutet werden könne und er auf die Bezüge für seinen Lebensunterhalt dringend angewiesen sei. Erteile die Devisenstelle keine Genehmigung, so könne der Rentenempfänger beantragen, dass die Rente auf ein bei einer inländischen Devisenbank zu errichtendes „Sonderkonto für Inlandszahlungen“ überwiesen werde. Die Rente werde dann jeweils nach Eingang einer Lebensbescheinigung an die Bank gezahlt. ${ }^{412}$ Für die Betroffenen waren die Renten damit faktisch genauso unerreichbar, wie im Fall des erzwungenen Ruhens. Im Fall der Palästina-Renten gab es ein noch komplizierteres Transferverfahren. ${ }^{413}$ Immer öfter konnte man daher bei der RfA die letzte Ver-

409 Schreiben der RfA vom 10.6.1939, in: BArch R 89/3413.

410 Vgl. dazu die Schreiben bzw. Schriftwechsel in: RfA-Archiv Nr. 91.

411 Bescheid vom 21.7.1938 sowie weitere wortwörtlich deckungsgleiche Bescheide als Antwort auf ähnliche Fragen, in: RfA-Archiv Nr. 91 b.

412 Vgl. ebd.

413 Es sah vor, dass sich der Antragsteller mit der Palästina-Treuhand-Stelle der Juden in Deutschland $\mathrm{GmbH}$ in Berlin in Verbindung setzen musste. Die RfA überwies dann, vorausgesetzt die Devisenstelle hatte ihre Zustimmung erteilt, das Ruhegeld jeweils nach Eingang der Lebensbescheinigung auf das beim Bankhaus A.E. Wassermann in Berlin geführte Sonderkonto I der Bank der Tempelgesellschaft in Jaffa.Vgl. Auskunftschreiben der RfA vom 18.11.1938, in: RfA-Archiv Nr. 92. „Gegen die Transferierung von Renten aus der Angestelltenversicherung durch die Palästina Treuhand-Stelle bzw. Haavara Ltd. bestehen keine Bedenken“, so antwortete man etwa im November 1937 der Darmstädter Zweigstelle des Palästina-Amtes Berlin, „wenn die zuständige Devisenstelle die Genehmigung dazu erteilt.“ Schreiben vom 23.11. bzw. 30.11.1937, in: ebd. Vgl. dazu auch Petra Kirchberger, Die Stellung der Juden in der 
antwortung für Rentenüberweisungen unabhängig von der versicherungsrechtlichen Lage auf die Devisenstellen schieben.

Innerhalb der RfA gab es durchaus Bestrebungen, sich gegen die zunehmenden Einmischungen der Devisenbehörden in das Rentenverfahren zu wehren, und im Herbst 1938 riskierte man diesbezüglich sogar einen offenen Konflikt mit den Stellen. Mitte Juni 1938 hatten die Sachbearbeiter der Leistungsabteilung einen Anruf der Devisenstelle Berlin mit der Aufforderung erhalten, künftig bei Anfragen zur Auszahlungsgenehmigung auch anzugeben, ob der Rentenberechtigte Arier oder Jude sei, ergänzt durch das Auswanderungsdatum. Mit der Erklärung des RfA-Beamten, dass die Fragebögen und Vordrucke der RfA keine Fragen nach der Rasse- und Religionszugehörigkeit enthielten und damit die Behörde die gewünschten Angaben nicht machen könne, gab man sich bei der Devisenstelle jedoch nicht zufrieden. Für die Bearbeitung des entsprechenden Antrags seien gerade diese Angaben entscheidend, „weil nach einem vertraulichen Erlass Juden keine Genehmigung mehr erteilt werden soll“. ${ }^{414}$ Von einem derartigen vertraulichen Erlass des Reichsfinanzministers hatte niemand in der RfA Kenntnis, aber auf ihn berief sich die Devisenstelle auch in einem konkreten Auslandsruhegeldfall im Juli 1938 beim Oberfinanzpräsidenten in Leipzig. Im September richtete daher die RfA dazu eine entsprechende Anfrage an das Reichswirtschaftsministerium, und verteidigte darin auch die bisher gehandhabte Verwaltungspraxis, Ruhegelder wie Hinterbliebenenrenten an Berechtigte mit Wohnsitz in Gegenseitigkeitsabkommens-Ländern wie Frankreich und Dänemark, aber auch überhaupt in all denen Fällen, in denen der Umzug ins Ausland vor dem 31. Januar 1937 erfolgt war, auch ohne vorherige Information und Genehmigung der Devisenstelle zu überweisen. ${ }^{415}$ Interne Recherchen der RfA-Beamten hatten zudem ergeben, dass sich der bemühte Erlass tatsächlich nur auf Bezüge aus öffentlichen Kassen bezog und Rentenleistungen der deutschen Sozialversicherungsträger nicht berührte. Die Sache blieb dennoch zwischen den Devisenstellen und der RfA strittig, und Anfang Januar 1939 kamen Vertreter beider Behörden zu einer Besprechung über die Auslegung des vertraulichen Erlasses zusammen. ${ }^{416}$ Anfang Februar 1939 erging schließlich ein Rundschreiben des Reichswirtschaftsministers, das die Position der RfA bestätigte und die Genehmigungskompetenzen der Devisenstellen bei Rentenzahlungen in 13 angrenzende Länder, mit denen inzwischen sozialversicherungsrechtliche Vereinbarungen getroffen worden waren, verneinte. ${ }^{417}$

deutschen Rentenversicherung, in: Sozialpolitik und Judenvernichtung. Gibt es eine Ökonomie der Endlösung?, Berlin 1987, S. 117.

414 Vermerk und Vorlage an den Abteilungsleiter vom 17.6.1938, in: RfA-Archiv Nr. 126.

415 Schreiben der RfA an das RWM vom 28.9.1938, in: ebd.

416 Vgl. dazu das Besprechungsprotokoll vom 3.1.1939, in: ebd.

417 Vgl. Erlass vom 5.2.1939, in: ebd. Es handelte sich um folgende Länder: Belgien, Dänemark, Danzig, Finnland, Frankreich, Italien, Jugoslawien, Luxemburg, Memelgebiet, Niederlande, Polen, Tschechoslowakei und Ungarn. 
Tatsächlich hatte sich neben den Devisenstellen spätestens seit Ende 1937 auch die Gestapo für die rentenversicherungsrechtliche Situation der Auswanderer interessiert. Regelmäßig bekam nun die RfA eine Liste der dort erfassten Emigranten mit der Bitte um Nachprüfung, wer davon noch Renten oder sogenannte Versorgungsgebührnisse erhielt. ${ }^{418}$ In einer Reihe von Fällen machte sich die Behörde zur Komplizin, wohlerworbene Rechte ihrer jüdischen Rentenversicherten willkürlich zu verbescheiden. Exemplarisch dafür, wenn auch als Fall nicht typisch, ist die Rentensache des früheren Vorstandsmitglieds der Krankenkasse des Gewerkschaftsbunds der Angestellten (DAK), Jakob M. Dieser war im Dezember 1933 im Zuge der Machtergreifung und Gleichschaltung entlassen worden, und bezog seit Januar 1934 das ihm zustehende Ruhegehalt von monatlich 501,67 RM. Bis Frühjahr 1939 war dies unbeanstandet ausgezahlt worden, aber als der Betroffene nun einen Ausreiseantrag nach Palästina stellte sowie bei der RfA um den Transfer des Ruhegeldes ersuchte, schrillten in der Präsidialabteilung der RfA, die inzwischen auch für die Rentensachen der Ersatzkassen zuständig war, die Alarmglocken. Ein Dorn im Auge war nicht nur das vergleichsweise hohe Ruhegehalt, sondern auch noch weitere Lebensversicherungsprämien, die M. zustanden. Grießmeyer verhielt sich dennoch zunächst neutral und legte den Antrag dem RVA bzw. RAM zur Entscheidung vor. ${ }^{419}$ Das RAM ging zunächst den üblichen Weg und ließ über die RfA bei der Gestapo, der Staatsanwaltschaft und dem zuständigen Finanzamt überprüfen, ob in politischer, straf- oder steuerlicher Hinsicht Bedenken gegen die Fortzahlung der Versorgungsbezüge bestanden. Im Juli 1939 konnte Grießmeyer jedoch nur entsprechende Unbedenklichkeitsbescheinigungen weiterleiten, so dass dem RAM nichts anderes übrig blieb, als der Wohnsitzverlegung zunächst für die Dauer von zwei Jahren und mit der Maßgabe zuzustimmen, dass die Versorgungsbezüge in voller Höhe auf ein bei einer Devisenbank einzurichtendes „Sonderkonto“ eingezahlt würden. ${ }^{420}$ Der Bescheid wurde dem Betroffenen durch die RfA jedoch „im Hinblick auf den bestehenden Kriegszustand“ nie ausgehändigt, und stattdessen meldete sich Grießmeyer Ende September 1939 mit einem neuen Schreiben zum Ruhegeldfall M. beim RVA bzw. RAM. ${ }^{421}$ Darin griff er die ihm gegenüber vom damaligen Leiter der zuständigen ruhegeldpflichtigen Ersatzkasse geäußerte Idee auf, die inzwischen erfolgte antisemitische Rechtsprechung des Reichsarbeitsgerichts heranzuziehen. Demnach wurde es für rechtmäßig erklärt, dass „das verstärkte Hervortreten des Rassegedankens, besonders seit Herbst 1938, Veranlassung sein kann, frühere Ruhegehaltsvereinbarungen dahingehend zu überprüfen, ob und inwieweit sie noch mit dem nationalsozialistischen Volks- und Rechts-

418 Schreiben der Gestapo Leipzig vom 29.12.1937, in: RfA-Archiv Nr. 91.

419 Vgl. Schreiben der RfA an das RAM über das RVA vom 4.4.1939, in: BArch R 89/3505. Der Fall und dazugehörender weiterer Schriftwechsel auch in: BArch R 89/3506 und 3507.

420 Vgl. Bescheid des RAM vom 11.8.1939, in: BArch R 89/3505.

421 Schreiben Grießmeyers an das RVA bzw. RAM vom 30.9.1939 und vom 25.6.1940, in: BArch R 89/ 3506. 
empfinden vereinbar sind““.222 Damit war es scheinbar auf dem Rechtswege möglich, das Ruhegehalt des Juden M. wenn schon nicht ganz zu verweigern, so doch deutlich herabzusetzen. Nachdem über die rentenversicherungsrechtlichen Bestimmungen keine Handhabe bestand, wurden nun neben den devisenrechtlichen Bestimmungen auch die arbeitsgerichtliche Rechtsprechung als Hebel zur Verweigerung eigentlich rechtlich zustehender Versicherungsleistungen benutzt, und Grießmeyer hatte offenbar keine Probleme damit, auf diese Option nicht nur hinzuweisen, sondern diese auch verwaltungspraktisch umzusetzen. Vorgeschlagen wurde eine willkürliche Herabsetzung der Ruhegeldbezüge auf 200 bis 250 RM, d.h. knapp die Hälfte; das RAM schreckte dann aber doch vor einem derartigen Präzedenzfall zurück. Ende Juni 1940 beschied es in einem Schreiben an Grießmeyer, dass man „im Hinblick auf die beabsichtigte gesetzliche Regelung der Frage [der Weiterzahlung von Ruhegehalt an Juden] Maßnahmen in Einzelfällen zur Zeit nicht für angebracht [halte]““423

Der Umgang mit der sogenannten „Judensache“ - so die verwaltungsinterne Bezeichnung der entsprechenden Vorgänge in der RfA - radikalisierte sich 1938, und das schlug sich auch im Schriftwechsel der Reichsanstalt nieder. Im April 1939 erhielt Grießmeyer ein Schreiben des Polizeipräsidenten von Breslau, in dem über Probleme bei der Anwendung der Ausländerpolizeiverordnung geklagt wurde.

Bei der Durchführung dieser Maßnahmen wurde in mehreren Fällen festgestellt, dass ausländische und staatenlose Juden, deren Anwesenheit im Reichsgebiet unerwünscht ist, zur Zeit noch nicht ausgewiesen werden können, weil sie Rentenempfänger sind und auf die Zahlung der Rente einen gesetzlichen Anspruch haben. Da es keinesfalls angängig sein dürfte, den Aufenthalt dieser Juden im Reichsgebiet lediglich aus dem Grunde weiterhin zu dulden, weil sie Rentenempfänger sind, bitte ich um baldige Mitteilung, ob die Möglichkeit besteht, die Rente durch einmalige Auszahlung abzulösen oder, wenn das nicht zulässig ist, evtl. durch Überweisung in das Ausland zu zahlen, andernfalls sich die sonderbare Lage ergeben würde, dass diese oft noch sehr rüstigen Personen, soweit sie [sich] nicht staatsfeindlich betätigt haben oder bestraft wurden, aus dem Reichsgebiet nicht entfernt werden können. ${ }^{424}$

Die RfA leitete das Schreiben zur Beantwortung an das RVA weiter, verbunden allerdings mit dem Hinweis auf die rechtliche Unmöglichkeit der Vorschläge. Das Ganze war auch deshalb bedeutsam, weil es vergegenwärtigte, dass den deutschen Behörden und NS-Stellen auch deshalb vielfach die Hände gebunden waren, da die Regelung des freiwilligen und gewöhnlichen Aufenthalts für Ausländer dann nicht galt, wenn es sich um Danziger, jugoslawische, polnische oder tschechische Staatsangehörige handelte, die aufgrund der existierenden Gegenseitigkeitsabkommen versicherungsrechtlich den deutschen Inländern gleichgestellt waren. Im August 1939 war es dann das Reichsarbeitsministerium, das den Breslauer Polizeipräsidenten darauf hinwies,

422 Schreiben des Leiters der Ersatzkasse an Grießmeyer vom 4.6.1940, in: ebd.

423 Schreiben des RAM an die RfA vom 24.6.1940, in: BArch R 89/3507.

424 Schreiben des Polizeipräsidenten an den leiter der RfA vom 17.4.1939, in: RfA-Archiv Nr. 92. Der Vorgang auch in: BArch R 89/3413. 
dass die Zahl der Fälle, in denen Ausweisung lediglich wegen des Bezugs von Rente nicht verfügt werden konnte, vermutlich verschwindend gering sein dürfte. Im Übrigen werde „gegenwärtig geprüft, inwieweit die Rentenzahlung an Juden im Ausland weiter eingeschränkt werden kann“. ${ }^{425}$

Inzwischen musste man sich in der RfA mit den Folgen der in großem Stil angelaufenen und restriktiv gehandhabten Ausbürgerungspolitik des NS-Regimes befassen. In zahlreichen Fällen war im Ausland lebenden Juden die deutsche Staatsbürgerschaft aberkannt und damit auch - vielfach lange Zeit rückwirkend - eventuell bisher gewährtes Altersruhegeld „auf Lebenszeit“ zum Ruhen gebracht, d. h. entzogen worden. Von Seiten der RfA waren diesen Betroffenen, wie etwa im Fall einer nach Florenz emigrierten Nürnberger Jüdin, noch über Monate hinaus Renten gezahlt worden, so dass sich zum Teil erhebliche Rückforderungen von mehreren hundert RM ergaben, die bei den Betroffenen selbst, zumal auch oft schon die Auswandersperrkonten vom Reich beschlagnahmt worden waren, nicht mehr zurückzuholen waren. ${ }^{426}$ Gemäß einer Abteilungsverfügung vom Mai 1939 wurde dann geregelt, dass sich die zuständigen RfA-Sachbearbeiter mit ihren Forderungen an die Devisenabteilung der Reichshauptbank, Abteilung Ablieferungskontrolle, wenden konnten. ${ }^{427}$ Wie hoch diese Forderungen insgesamt waren und vor allem auch, wieviel davon tatsächlich durch die Devisenstelle zurückgezahlt wurde, lässt sich aus den Akten nicht rekonstruieren. Prinzipiell galt allerdings schon seit Februar 1939 aufgrund eines Erlasses des Reichsfinanzministeriums, dass die Finanzämter den Sozialversicherungsträgern zur Begleichung etwaiger Rückstände Einblick in die jüdischen Vermögen bzw. Auskunft über die jüdischen Vermögensverzeichnisse zu gewähren hatten. ${ }^{428}$ Involviert wurde die RfA zudem auch in die sich nun häufenden Fälle, in denen Rentenempfänger der Angestelltenversicherung ihre Ruhegelder an die Reichsvereinigung der Juden in Deutschland, Abteilung Wanderung, verpfändeten bzw. abtraten und dafür von dieser ein Darlehen für die Auswanderung erhielten. ${ }^{429}$ Zur wirksamen Abtretung der Rentenansprüche bedurfte es der Zustimmung des Versicherungsträgers, allerdings genügte ein entsprechender Bescheid des örtlichen Versicherungsamtes und erforderte keine zusätzliche Einschaltung der RfA. In den verschiedenen Behörden herrschte dennoch inzwischen allenthalben Unklarheit und Unübersichtlichkeit über die rentenrechtliche Situation der Juden und die verwaltungspraktische Handhabung unterhalb der formalen Gesetzeslage. „Gelten irgendwelche abweichenden Vorschriften über die Auszahlung der Renten im Inland und ins Ausland an Bezugsberechtigte nichtarischer Herkunft?“, heißt es daher unter anderem Anfang Juli 1939 in einer Anfrage der Allgemeinen Pensionsanstalt in Prag an die RfA. ${ }^{430}$ Von dort kam die

425 Schreiben des RAM vom 21.8.1939, in: ebd.

426 Vgl. Schreiben der RfA an die Berliner Devisenstelle vom 12.4.1939, in: RfA-Archiv Nr. 24.

427 Vgl. Abteilungsverfügung vom 9.5.1939, in: ebd.

428 Vgl. dazu die Notiz in Deutsche Rentenversicherung Nr. 4 (1939), S. 77.

429 Schreiben der RfA an das RVA vom 26.7.1939, in: BArch R 89/3413.

430 Schreiben vom 3.7.1939, in: RfA-Archiv Nr. 126. 
knappe Antwort: „Für die Rentenberechtigten nichtarischer Herkunft gelten für die Rentenauszahlung im Inlande und ins Ausland dieselben Bestimmungen wie für die übrigen Rentenberechtigten. Abweichende Vorschriften sind bisher nicht getroffen worden. “431 Das war tatsächlich die geltende Rechtslage, aber angesichts der vielen Restriktionen, die entweder außerhalb des formalen Rentenrechts devisenrechtlich kaschiert oder in den versicherungsrechtlichen Ausführungsbestimmungen und $\mathrm{Zu}$ satzverordnungen versteckt waren, nicht nur beschönigend, sondern letzlich schlichtweg unwahr. Seit 1933/34 hatten sich die Bedingungen eines Rentenbezugs im Ausland ebenso wie für die Aufrechterhaltung der Anwartschaft vor allem für Juden massiv verschlechtert, und die Chancen, als Emigrant in den Genuss laufender oder künftiger Rentenbezüge zu kommen, waren verschwindend gering geworden.

Die zunehmend restriktiven Bestimmungen zur Überweisung von Renten ins Ausland sowie vice versa zur Regelung von Beitragszahlungen zur Aufrechterhaltung der Anwartschaft betraf nicht nur Juden, sondern auch alle anderen aus politischen Gründen ins Exil geflohenen Deutschen, aber auch die zahlreichen für deutsche Firmen im Ausland arbeitenden Angestellten. Einer der Betroffenen war etwa Friedrich Wilhelm Sollmann, SPD-Mitglied und 1923 für vier Monate Innenminister in der Weimarer Republik, der als aktiver Widerstandskämpfer 1935 nach Luxemburg geflüchtet war. Von dort schickte er im September 1936 seine Versicherungskarte mit freiwilligen Beitragsmarken an die RfA. Da Sollmann glaubhaft versichert hatte, dass er die Beitragsmarken durch seine Ehefrau in Trier rechtmäßig mit Devisen erworben hatte, war an der Rechtswirksamkeit der eingereichten Beiträge nicht zu zweifeln, unabhängig davon, dass dem Betroffenen im Dezember 1936 rückwirkend die deutsche Staatsangehörigkeit entzogen und sein Vermögen beschlagnahmt worden war. ${ }^{432}$ Die Annahme weiterer Beitragszahlungen von Sollmann, die dieser auch zur Aufrechterhaltung seiner Ruhegeldansprüche angekündigt hatte, unterlagen zwar den neuen, verschärften devisenrechtlichen Bestimmungen, waren aber nach wie vor möglich und rechtlich zulässig. Unklar war jedoch, ob diese noch versicherungsrechtlich relevant waren, d.h. inwieweit die weiteren Beitragszahlungen bereits der Beschlagnahme unterlagen oder erst die spätere Leistung aus diesen. Nach der bestehenden Rechtslage durfte die RfA die weiteren Beiträge nicht auf das Versichertenkonto buchen, sondern musste sie wegen der Beschlagnahme einstweilen sicherstellen und abwarten, bis dieser Betrag und eine sich daraus aufgrund eines inzwischen eingetretenen Versicherungsfalls ergebende Rente infolge des Ausbürgerungsgesetzes endgültig als dem Reich verfallen erklärt werden würde. Innerhalb der RfA jedenfalls suchte man den Fall Sollmann zunächst intern und ohne Einschaltung des RVA zu regeln. Der Vermerk des zuständigen Beamten lautet:

431 Antwortschreiben vom 22.7.1939, in: ebd.

432 Vgl. den ausführlichen Aktenvermerk zum Fall Sollmann vom 10.2.1937, in: RfA-Archiv Fach 65, Nr. 6. 
Ich schlage vor, dass wir im Hinblick auf die Beschlagnahme seines Vermögens eingehende Zahlungen abliefern müssen und dass deshalb diese nicht als Beiträge verbucht werden können. Diese Zurückweisung der Beiträge halte ich für nötig, da die Annahme als Anerkennung des Beitrags gelten würde. ${ }^{433}$

RfA-Vizepräsident Schaefer erhob gegen eine entsprechende Mitteilung an Sollmann, dass seine etwaigen weiter an die RfA gezahlten Beiträge letztlich unwirksam und damit umsonst sein würden, Einspruch und plädierte dafür, „derartige Einsendungen“ erst einmal abzuwarten. ${ }^{434}$ Die Behörde vereinnahmte mithin weiterhin regelmäßige Beitragszahlungen des Betroffenen, wohl wissend, dass diese über kurz oder lang für unwirksam und verfallen erklärt werden würden.

Auf der anderen Seite versuchte die NSDAP-Auslandsorganisation jedoch für in ihren Augen genehme und regimeloyale Auslandsdeutsche bei der RfA eine Ausnahmegenehmigung zu erhalten. Im Juni 1935 hatte bereits ihr Rechtsamt bei der RfA moniert, dass gerade in den USA eine ganze Reihe von Volksgenossen gezwungen seien, ihre Reichsangehörigkeit aufzugeben, um ihren Arbeitsplatz zu behaupten. Falls sie nicht ins Reich zurückkehrten, müsste ihr Aufenthalt als unfreiwillig gelten, wodurch sie nicht in den Genuss der entsprechenden versicherungsrechtlichen Bestimmungen kämen. ${ }^{435}$ Mit den komplizierten devisenrechtlichen Bestimmungen für die Beitragszahlungen zur AV für im Ausland lebende Versicherte hatten nicht zuletzt auch die großen, international agierenden Konzerne wie die IG Farben zu kämpfen. Im Oktober 1937 verhandelten etwa Vertreter der IG-Farben-Zentralfinanzverwaltung mit der RfA darüber, das für das Unternehmen komplizierte und umständliche technische Verfahren zur Entrichtung freiwilliger Beiträge beim Aufenthalt im Ausland einfacher zu gestalten. Tatsächlich konnten die IG-Farben-Vertreter eine Sondergenehmigung des Reichswirtschaftsministeriums vorlegen, nach denen es künftig erlaubt war, die Beiträge für bzw. durch die betreffenden Gefolgschaftsmitglieder nicht mehr in Devisen, sondern in RM und in Form von Beitragsmarken an die RfA zu leisten. ${ }^{436}$ Durch Erlasse, Sondergenehmigungen und einzelne Bestimmungen übergeordneter Behörden waren in der Verwaltungspraxis der RfA damit zunehmend Optionen für eine gewisse Willkürlichkeit eröffnet worden, die unter unterschiedlichen Vorzeichen praktiziert werden konnte.

Die Diskriminierungsmaßnahmen gegen Juden waren alles in allem zunächst auf die auswanderungswilligen oder sich bereits im Ausland befindlichen konzentriert. $\mathrm{Zu}$ diesem Zeitpunkt gab es noch keine formellen Sonderbestimmungen für inländische Juden in der Rentenversicherung und bei der RfA wusste man auch nicht, ob ein

433 Vermerk Kochs vom 9.2.1937, in: ebd.

434 Vermerk Schaefers vom 9.2.1937 und die entsprechende Entscheidung vom 10.2.1937, in: ebd. 435 Schreiben an die RfA betr. Versicherungsansprüche Deutschstämmiger fremder Staatsangehörigkeit vom 5.6.1935, in: RfA-Archiv Fach 113, Nr. 14.

436 Vgl. Schreiben der IG Farben an die RfA vom 15.3.1937 sowie auch vom 1.10.1937 und dazu den Vermerk von Direktor Koch vom 25.10.1937, in: RfA-Archiv Nr. 88. 
einzelner Versicherter oder Rentner Jude war oder nicht und wie groß der Kreis der „Nichtarier“ unter den inzwischen fast fünf Mio. bei der RfA Versicherten überhaupt war. Eingriffe in das materielle Recht der Sozialversicherung - beim Beitragssystem wie bei den Versicherungsleistungen - zum Nachteil jüdischer Versicherter und Leistungsbezieher, die innerhalb des Deutschen Reichs lebten, unterblieben, wohl nicht zuletzt auch deshalb, weil noch nicht klar war, wie man dies in versicherungsrechtliche Bestimmungen hätte gießen sollen. ${ }^{437}$ Nach wie vor kamen so auch Juden in den Genuss von Rentenzahlungen und Gesundheitsvorsorgemaßnahmen; sie konnten auf ihr Recht der gesetzlich garantierten Leistungsansprüche pochen und profitierten von den kleinen Verbesserungen, die etwa das Ausbaugesetz mit sich gebracht hatte. Auch jüdische Eltern kamen daher etwa in den Genuss der Kinderzuschläge, die im Ausbaugesetz vorgesehen waren, denn die im Zuge der Nürnberger Gesetze von 1935 erfolgte Aberkennung der „Reichsbürgerschaft“ für Juden war im Rentenrecht bedeutungslos. ${ }^{438}$

Das Ausbaugesetz markiert dennoch einen versicherungsrechtlichen Wendepunkt, denn quasi durch die Hintertür wurden dort erste diskriminierende Maßnahmen gegen die noch in Deutschland lebenden und die deutsche Staatsangehörigkeit besitzenden Juden in Gang gesetzt. So wurde in einer der Durchführungsverordnungen zum Gesetz vom Dezember 1937 geregelt, dass bestimmte Leistungsverbesserungen auf gleichzeitige Fürsorgeleistungen nicht angerechnet wurden. Der Erlass nahm aber ausdrücklich Juden vom begünstigten Personenkreis aus, d. h. bei ihnen hatte die Verbesserung von Rentenleistungen eine Kürzung der evtl. zusätzlich gezahlten Fürsorgeunterstützung zur Folge. ${ }^{439}$ Doch auch hier war die RfA aus eigener Initiative mit antisemitischen Regelungen schon früher vorgeprescht. Bereits im Februar 1936 informierte man das RVA über eine Änderung der bereits erwähnten RfA-Satzung, nach der ausbildungsbezogene Mehrleistungen bei Kinderzuschuss und Waisenrente bis zum 18. Lebensjahr möglich waren. Als Begründung wurde angeführt:

Es mehren sich die Fälle, in denen jüdische Rentenempfänger deutscher Staatsangehörigkeit oder staatsfeindlich gesinnte Rentenempfänger ins Ausland auswandern und nun Mehrleistungen in der Angestelltenversicherung auch dann erhalten müssen, wenn die deutsche Erziehung des Kindes nicht gewährleistet ist. ${ }^{440}$

Mit Rücksicht auf diese Tatsache erfolge eine Satzungsänderung dahingehend, dass die Mehrleistung zu versagen sei, solange das Kind im Ausland lebt und seine deut-

437 Vgl. dazu auch Klimo, Arbeitseinsatz, S. 307 ff.

438 Vgl. Petra Kirchberger, Die Stellung der Juden in der deutschen Rentenversicherung, in: Sozialpolitik und Judenvernichtung. Gibt es eine Ökonomie der Endlösung?, Berlin 1987, S. 114.

439 Vgl. dazu Hans-Jörg Bonz, Geplant, aber nicht in Kraft gesetzt: Das Sonderrecht für Juden und Zigeuner in der Sozialversicherung des nationalsozialistischen Deutschland, in: Zeitschrift für Sozialreform 38 (1992), H. 3, S. 150. Vgl. auch ders., Die Stellung der Juden in der Deutschen Rentenversicherung, in: Zeitschrift für Sozialreform 34 (1988), H. 7, S. 425-427

440 Schreiben vom 3.2.1936, in: BArch R 89/3469. 
sche Erziehung nicht gewährleistet ist. Es war mithin die RfA, die mit der unverhohlenen rentenrechtlichen Diskriminierung der Juden eine neue Phase des rentenpolitischen Antisemitismus einleitete.

Antisemitische und rassenpolitische Stigmatisierungen und Diskriminierungen hatte es zudem auch früher schon vor allem im Bereich der Heilfürsorge gegeben. Als Kann-Leistung innerhalb der versicherungsrechtlichen Bestimmungen und Gesetze gab es hier am ehesten ein Einfallstor für entsprechende Maßnahmen. Indizien dafür, dass jüdischen Versicherten explizit Heilverfahrensanträge abgelehnt wurden, gibt es, allein schon aufgrund der fehlenden Quellen, nicht. Dennoch war die RfA an Maßnahmen gegen Juden aktiv beteiligt. In Bad Soden im Taunus gab es etwa eine „Kuranstalt für arme Israeliten“, in die auch die RfA versicherte Tuberkulosekranke zu Heilaufenthalten schickte. Anfang März 1936 beschwerte sich das Hauptamt für Volkswohlfahrt der NSDAP beim RAM darüber und bat, „die Reichsversicherungsanstalt veranlassen $\mathrm{zu}$ wollen, dass im Wege eines Tauschgeschäfts der ZentralWohlfahrtsstelle der deutschen Juden eine andere Anstalt zur Verfügung gestellt wird, um Bad Soden vor wirtschaftlichen Schäden zu bewahren“. ${ }^{441}$ Doch Grießmeyer konnte daraufhin melden, dass die RfA von sich aus schon seit Ende November 1935 die Einweisung von (jüdischen) Versicherten in die dortige Kuranstalt eingestellt hatte und an eine Übernahme ganz in den Besitz der RfA nicht zu denken sei, weil für sie ein Bedarf an den dort vorhandenen Betten nicht bestehe. ${ }^{442}$ Vor allem jüdische Ärzte wurden von der Heilverfahrensabteilung der RfA systematisch diskriminiert. Im Oktober 1935 berichtete etwa ein Versicherter in einem Beschwerdebrief an das Oberversicherungsamt Magdeburg, dass ihm die RfA per Bescheid einen finanziellen Zuschuss zu einem Heilverfahren gegen krankhafte Luftansammlungen im Brustkorb (Pneumothorax) bewilligt hatte. Die RfA weigerte sich dann jedoch, den Zuschuss zu den eingereichten Rechnungen des Lungenfacharztes zu bezahlen mit der alleinigen Begründung, dass dieser Jude sei. Die Behörde berief sich auf eine Passage des Bewilligungsbescheids, in der stand: „Wir erwarten dabei von unseren deutschstämmigen Versicherten, dass sie die Behandlung von einem deutschstämmigen Arzt durchführen lassen. “ ${ }^{443}$ Von der Unrechtmäßigkeit des Vorgehens der RfA überzeugt, legte der Betroffene offiziell Beschwerde beim zuständigen Oberversicherungsamt ein mit dem Ziel, dass ihm nicht nur die bereits verabreichten Behandlungen, sondern auch die weiteren künftigen Heilmaßnahmen bei dem jüdischen Facharzt bezahlt würden. Auch der betroffene Arzt selbst wandte sich in einem Beschwerdebrief an das Oberversicherungsamt und bat,

auch grundsätzlich die RfA anzuweisen, im Rahmen der Heilbehandlung jüdische Kassenärzte arischen gleichzustellen [...]. Die RfA darf nur darauf sehen, wie die drohende Arbeitsunfähigkeit

441 Schreiben vom 2.3.1936, in: BArch R 89/3427.

442 Schreiben der RfA an das RVA vom 27.3. und auch noch einmal vom 25.4.1936, in: ebd.

443 Abschrift des Bescheids vom 20.5.1935 sowie der Beschwerdebrief vom 12.10.1935, in: BArch R 89/ 3427. 
möglichst sicher verhütet wird, damit sie nämlich tunlichst keine vorzeitigen Renten zu zahlen braucht, und wie sich das möglichst wirtschaftlich erreichen lässt. Sie darf aber nicht andere Ziele dabei verfolgen, auch nicht rassepolitische im Sinne einer Absonderung der jüdischen Kassenärzte. $^{444}$

Die Reaktion der RfA auf entsprechende Nachfrage durch das RVA sah im Dezember 1935 so aus, dass man nach wie vor keinen Anlass sah, die Zuschüsse auszuzahlen. Zur Absicherung gegen etwaige weitere Beschwerden wurde der Zusatz zur „richtigen“ Arztwahl nicht mehr als Erwartung an die Versicherten, sondern als Voraussetzung des Bewilligungsbescheids umformuliert. ${ }^{445}$

Tatsächlich hatte das RAM auch von anderen jüdischen Kassenärzten ähnliche Beschwerden über das Verhalten der RfA erhalten. Aber die RfA hielt, dabei gestützt vom RVA, an ihrer Bewilligungspraxis fest. ${ }^{446}$ Formal war die RfA allerdings, wie Vizepräsident Schaefer bedauernd auf entsprechende Vorhaltungen in einer Beiratssitzung im November 1936 mitteilte, noch an das geltende Minderheitenabkommen gebunden und damit nicht dazu befugt, jüdische Ärzte aus der Liste der Vertrauensärzte zu streichen. ${ }^{447}$ So konnte es denn auch nach wie vor passieren, dass Versicherte von der RfA aufgefordert wurden, sich vor einer Ruhegeld- oder Heilfürsorgeentscheidung von einem jüdischen Arzt vertrauensärztlich untersuchen zu lassen. Tatsächlich erhielt die RfA von ,arischen“ Versicherten immer wieder antisemitische Hetzschreiben, Denunziationen und Beschwerden, vor allem wenn es um die Unterbringung in Heilanstalten mit jüdischen Besitzern oder zusammen mit jüdischen Versicherten bei Heilverfahrensaufenthalten ging. Dass sich Juden auf Kosten der RfA bei Kuren erholten, erschien als empörend. ${ }^{448}$ In einem anonymen Schreiben von Anfang August 1938 heißt es:

Ist es im Sinne unseres geliebten Führers, dass jüdische Frauen, welche arische Männer haben, nach deren Tode in den Genuss der Reichsversicherungsrente gelangen? Hier ist doch die bequeme ,Rebekka' der Nutznießer, den ganzen Tag sich pflegen, vor Speck und Fett nicht atmen können und den Staat für sich sorgen lassen. ${ }^{449}$

Die Ortsgruppe des Reichsbundes der deutschen Beamten bzw. der NSDAP im sächsischen Oberlungwitz richteten zudem im Oktober 1935 an die RfA-Führung die dringende Anregung, seitens der RfA ,allen Rentenempfängern der AV die Anweisung zu geben, nicht in jüdischen Geschäften einzukaufen“, wogegen Grießmeyer, nicht aus

444 Schreiben an das Oberversicherungsamt vom 13.10.1935, in: ebd.

445 Schreiben Grießmeyers an das RVA vom 3.12.1935, in: ebd.

446 Vgl. dazu auch die ausführliche Begründung vom 17.3.1936 gegenüber einem der beschwerdeführenden Ärzte, in: ebd.

447 Vgl. Protokoll der Beiratssitzung vom 30.11.1936, S. 5, in: BArch R 89/3469.

448 Vgl. etwa das Schreiben eines Essener NSDAP-Funktionärs an das RVA vom 21.8.1935 sowie auch Schreiben vom 24.9.1935, in: BArch R 89/3388.

449 Das Schreiben vom 8.8.1938, in: RfA-Archiv Fach 112, Nr. 8. 
moralischen, sondern aus formalgesetzlichen Gründen Bedenken erhob. ${ }^{450}$ Keine Bedenken hatte der RfA-Präsident aber im Juni 1939 gegen die Weiterverbreitung eines RAM-Erlasses in Form einer Präsidialverfügung, in der zur Meldung von freistehenden oder freiwerdenden jüdischen Mietwohnungen aufgerufen wurde. ${ }^{451}$ Schon vorher war zudem in einer Abteilungsverfügung der Leistungsabteilung das Anlegen einer gesonderten Schriftwechselkartei angeordnet und geregelt worden. Für alle Personen, die aufgrund des Gesetzes über den Widerruf von Einbürgerungen und die Aberkennung der deutschen Staatsangehörigkeit dieser verlustig erklärt wurden, wurde eine eigene Kartei mit entsprechendem rotem Aufdruck angelegt und von der Kontenverwaltung mit roten Karteireitern versehen. ${ }^{452}$ Auf den Karten wurde auch zusätzlich vermerkt, wenn das Vermögen beschlagnahmt worden war. Langsam, aber sicher siebte man daher bei der Behörde Juden und andere „Staatsfeinde“ aus dem anonymen Millionenheer der Versicherten und Rentner heraus.

Manche jüdische Versicherte, wie andere Versicherte auch, hatten aber auch den Mut oder die Unbeirrbarkeit, gegen die Bescheide der RfA zu klagen und ihre Rechte einzufordern, ungeachtet der Tatsache, dass sie damit als „Nichtarier“ identifizierbar wurden. Ob die Identität bei der Urteilsfindung eine Rolle spielte, ist nicht nachweisbar. Die wenigen vorgefundenen Fällen, in denen es wie bei den übrigen Streitfälle entweder um die Ablehnung der Berufsunfähigkeit oder um strittige Ruhensvorschriften ging, geben keine eindeutige Antwort. Im Fall des Angestellten Wilhelm G. aus Oberschlesien entschied der Revisionssenats des RVA im Juli 1939 zugunsten des Klägers und wies die Sache zur erneuten Prüfung an das zuständige Oberversicherungsamt zurück. Dagegen gab das RVA im Fall der Witwe Mathilde F. aus Frankfurt Ende April 1939 der RfA als Beklagte Recht. ${ }^{453}$ Bemerkenswert sind aber weniger die Urteile selbst als vielmehr die Tatsache, dass jüdische Versicherte und Rentner noch 1939 die Möglichkeiten der Sozialversicherungsrechtsprechung in Anspruch nahmen und ihren erworbenen Rechtsanspruch auf Leistungen einzuklagen versuchten. Ihr Recht forderten die jüdischen Versicherten auch im Zusammenhang mit den Arisierungsmaßnahmen ein. Wie bei der Reichspogromnacht die entstandenen Schäden für die Machthaber und vor allem die betroffenen Versicherungskonzerne zu entschädigungspflichtigen Versicherungsschadensfällen geworden waren, so sah sich die RfA 1937 mit einer wachsenden Anzahl von Rentenanträgen wegen Arbeitslosigkeit von versicherten jüdischen Angestellten konfrontiert, die entweder wegen der erzwungenen Geschäftsaufgabe oder infolge der Arisierung der Belegschaft in den Großunternehmen nach einjähriger Stellungslosigkeit ihre entsprechenden

450 Schreiben RfA an das RVA vom 23.10.1935, in: BArch R 89/3388.

451 Vgl. Präsidialverfügung vom 27.6.1939, in: RfA-Archiv Nr. 3.

452 Abteilungsverfügung vom 27.5.1938, in: RfA-Archiv Nr. 223.

453 Beide Fälle mit den Urteilen und knappen Begründungen vom 12.7.1939 und vom 26.4.1939, in: RfA-Archiv Fach 101, Nr. 5. 


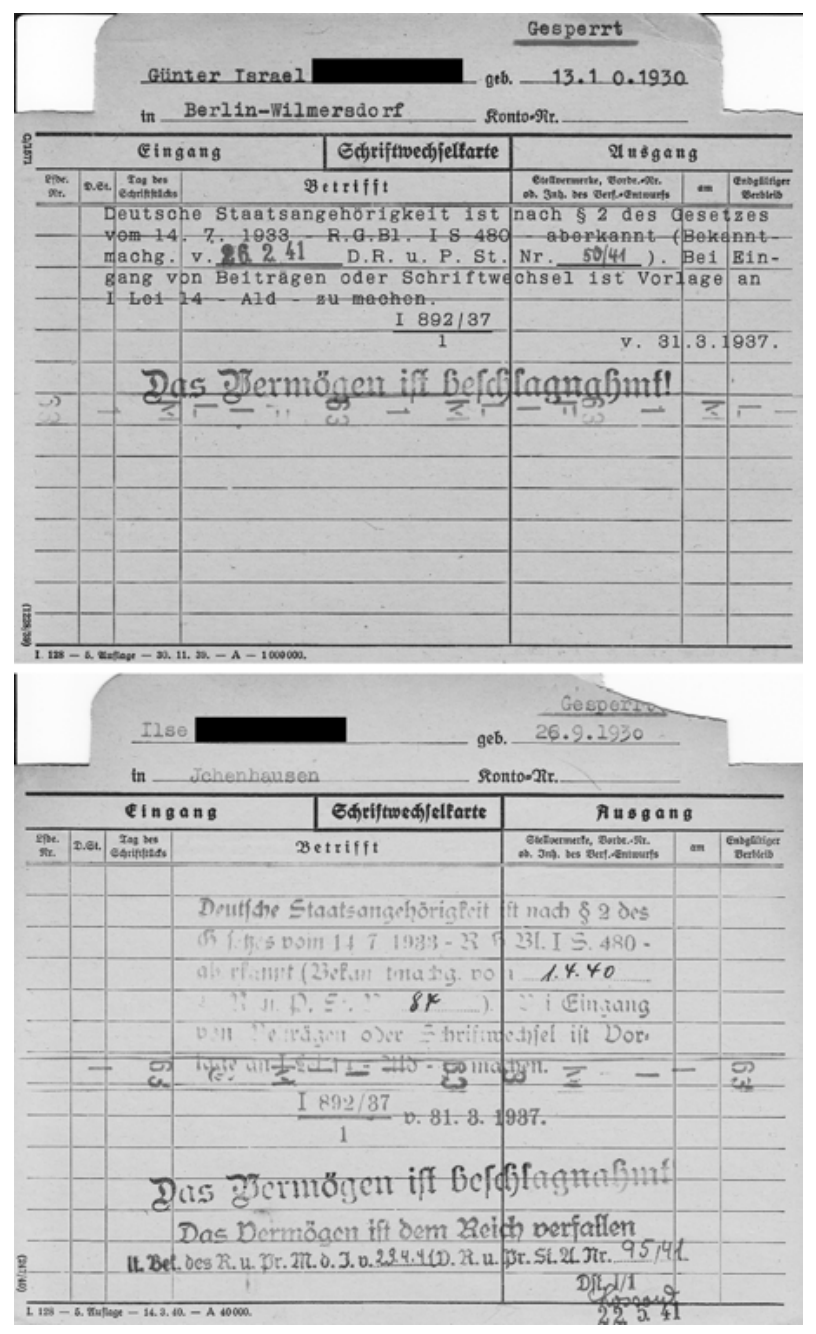

Abb. 23: Schriftwechselkarte zu jüdischen Versicherten (1937)

Ruhegelder bei der RfA beantragten. ${ }^{454}$ Die rechtliche Bewertung war durchaus heikel und keineswegs eindeutig, denn für die Bewilligung einer Rente nach § 397 AVG war Voraussetzung, dass der Versicherte dem Arbeitsmarkt zur Verfügung stand, was aber auf jüdische Versicherte, die praktisch nicht mehr in den Arbeitsprozess eingegliedert wurden, formal nicht zutraf. Die RfA-Beamten erkundigten sich daher nach der Handhabung der Arbeitslosenunterstützung für Juden durch die Arbeitsämter und

454 Vgl. dazu etwa die Anfrage an die RfA vom 25.10.1938, in: RfA-Archiv Fach 17 sowie den Bericht des Freiburger Überwachungsbeamten vom 28.2.1939, in: RfA-Archiv Nr. 113. 
man entschied nach einem entsprechenden vertraulichen Erlass des RAM im März 1939:

\begin{abstract}
Arbeitslosigkeit im Sinne des § 397 AVG kann im Einzelfall nicht deshalb verneint werden, weil die Bemühungen, eine Arbeitsstelle zu erlangen, daran scheitert, dass eine Einstellung an bestimmten, in der Person des Arbeitslosen liegenden Gründen abgelehnt wird. Daher wird auch Juden allein wegen der Schwierigkeit, die sich bei ihrer Eingliederung in den Arbeitsprozess wegen ihrer rassischen Herkunft ergaben, das Ruhegeld nach § 397 AVG nicht versagt werden dürfen, wenn die sonstigen Voraussetzungen erfüllt, insbesondere der Nachweis erbracht wird, dass sie mindestens 1 Jahr lang als Arbeitssuchender dem Arbeitsmarkt zur Verfügung gestanden haben. Ich ersuche, Anfragen von jüdischen Versicherten in diesem Sinne zu erledigen, ihnen jedoch aufzugeben, den Nachweis für ihre vergeblichen Arbeitsbemühungen durch Vorlage einer Bescheinigung des zuständigen Arbeitsamtes zu erbringen. Diese Verfügung ist nur für den Dienstgebrauch und nicht zur öffentlichen Bekanntgabe bestimmt. ${ }^{455}$
\end{abstract}

Wieviele jüdische Angestellte daraufhin tatsächlich in den Genuss eines Ruhegeldes wegen Arbeitslosigkeit gelangten, ist aus den Akten leider nicht ersichtlich. Viele dürften es aufgrund der Unkenntnis der Bestimmungen und vor allem auch wegen der Bedingung der Arbeitsamtsbescheinigung nicht gewesen sein. Ungeachtet dessen wurden inzwischen auch die Restriktionen der Finanzämter und Devisenstellen mehr und mehr auch gegen Juden innerhalb des Reichs eingesetzt. Im September 1939 wandte sich etwa das Postamt 1 in Dresden an die RfA mit der Mitteilung, dass die Auszahlung der Renten an drei jüdische Berechtigte nicht erfolgen konnte, da diese sich aufgrund eines Fragebogens gegenüber der Devisenstelle hatten verpflichten müssen, keine Gelder aus Reichs- und Staatskassen anzunehmen. Erst auf Intervention der RfA beim zuständigen Oberfinanzpräsidium erhielten sie die Erlaubnis, die ihnen von der RfA zustehende monatliche Rente unmittelbar in Empfang zu nehmen. ${ }^{456}$ Mit Kriegsbeginn und vor allem seit 1941 sollte aber eine noch weit stärkere Radikalisierung und massive Verschärfung der Maßnahmen zum Ausschluss auch der inländischen Juden aus der deutschen Versichertengemeinschaft erfolgen.

Parallel dazu und vielfach mit indirekten Bezügen zu den antisemitischen Maßnahmen trug nun auch die Initiative der RfA zur Instrumentalisierung der Ruhensvorschriften gegen Staatsfeinde von 1934 Früchte. Schon vorher hatte, wie bereits erwähnt, gegolten, dass nach $\S 128$ RVO die Rente ruhte, solange der Berechtigte eine Freiheitsstrafe von mehr als einem Monat verbüßte oder in Sicherheitsverwahrung genommen worden war. Ende Juli 1936 hatte das RAM nun seinerseits einen Gesetzentwurf „über einige Änderungen in der Sozialversicherung“ vorgelegt, der diese Regelung erweiterte und unter anderem auch explizite Ruhensbestimmungen wegen

455 Vermerk und Antwort an den Freiburger Überwachungsbeamten durch die Präsidialabteilung vom 15.3.1939, in: ebd.

456 Vgl. das Schreiben des Postamts an die RfA vom 29.9.1939 sowie Bescheid des Oberfinanzpräsidiums vom 25.10.1939, in: RfA-Archiv Nr. 92 b. 
staatsfeindlicher Betätigung enthielt. ${ }^{457}$ Im Falle dass die Versicherungsträger nicht selbst Kenntnis von staatsfeindlichen Betätigungen ihrer Rentenempfänger erhielten, konnten sie an Hand der ihnen über das RAM zugeleiteten Listen der Gestapo feststellen, ob die dort verzeichneten Staatsfeinde zu den Rentenempfängern gehörten. ${ }^{458}$ Aber nicht die RfA durfte im Zweifelsfall entscheiden, sondern die Feststellung des staatsfeindlichen Verhaltens traf das Reichsinnenministerium; über die Anordnung des Ruhens sowie Höhe und Zeitraum der ruhenden Rente entschied das RAM. Die Verordnung trat am 23. Dezember 1936 in Kraft. ${ }^{459}$ Sie ersetzte eine frühere, bereits im Juli 1934 vom RAM erlassene Regelung zum Ruhen der Renten bei staatsfeindlicher Betätigung. Wie einfach und unbürokratisch schon vorher der Entzug der durch Beitragszahlungen wohlerworbenen Rentenansprüche für erklärte Gegner des NS-Regimes ging, zeigt der Fall der Ruhegeldempfängerin Dr. Helene St., die seit Juni 1932 Empfängerin einer RfA-Rente über 64,90 RM im Monat war. Im Oktober 1935 teilte die Berliner Gestapo der RfA ohne weitere Begründung mit, dass der Anspruch der Betroffenen gegenüber der RfA auf Zahlung von Ruhegeld zugunsten des Preußischen Staates aberkannt wurde und künftig das Ruhegeld an die Polizeihauptkasse in Berlin-Schöneberg zu überweisen war, was auch schon ab 1 . November geschah. ${ }^{460}$ Schon 1933 war es im Übrigen RfA wie RAM ein Dorn im Auge gewesen, dass ausländische Rentenempfänger wegen staatsfeindlicher Betätigung aus dem Deutschen Reich ausgewiesen wurden, diesen jedoch, insbesondere wenn mit den Herkunftsstaaten sozialversicherungsrechtliche Gegenseitigkeitsabkommen bestanden, die Renten weiter ausbezahlt werden mussten. Als einfache Lösung dieses Problems wurde daher die möglichst umgehende Beschlagnahme des inländischen Vermögens vorgeschlagen, von der der Rentenanspruch als Vermögensbestandteil betroffen war. ${ }^{461}$ In der Praxis war das jedoch keineswegs so einfach, wie man sich das im RAM vorstellte. Die RfA-Beamten in die Bredouille brachten etwa die „Saarflüchtigen“. Versicherte wie der seit 1923 als Gewerkschaftsangestellter des Arbeitnehmerverbandes tätige Heinrich H. oder Leonhard B., der bis 1934 Angestellter beim Deutschen Baugewerksbund, dann selbständiger Bauunternehmer gewesen war, waren nach der Eingliederung des Saarlandes in das Reich ins benachbarte Frankreich geflüchtet und hatten von dort Anträge auf Ruhegeld an die RfA geschickt. ${ }^{462}$ Rein rechtlich konnte gegen die Anträge

457 Vgl. Schreiben des RAM an das RVA vom 19.12. 1936, in: BArch R 89/3409 und dazu nach wie vor grundlegend Hans-Jörg Bonz, Für Staatsfeinde keine Rente. Das Ruhen der Renten bei staatsfeindlicher Betätigung im nationalsozialistischen Deutschland, in: Zeitschrift für Sozialreform, 37 (1991), H.9., S. 517-531 sowie auch Eckart Reidegeld, Staatliche Sozialpolitik in Deutschland, Bd. II: Sozialpolitik in Demokratie und Diktatur 1919-1945, Wiesbaden 2006, insbesondere S. 441-561.

458 Vgl. ebd. und Bonz, MS S. 531.

459 Vgl. Mitteilungen der RfA Nr. 12, 1937, S. 40 f. sowie Rundschreiben des RAM vom 10.4.1937, in: BArch R 89/3409. Siehe auch Bonz, S. $521 \mathrm{ff}$. und Schlegel-Voß, S. 79f. zu den Gesetzesberatungen. 460 Schreiben der RfA an das RVA vom 15.11.1935, in: BArch R 89/3388.

461 Vgl. Erlass des RAM vom 17.7.1934, in: BArch R 89/3409.

462 Zu beiden Fällen vgl. Schreiben der RfA an das RVA vom 7.5.1937 bzw. 24. 2.1937, in: BArch R 89/ 3167. 
und die damit verbundenen Ansprüche auf Rentenzahlungen nichts unternommen werden, da beide unter die Bestimmungen des erst im Februar 1935 geschlossenen deutsch-französischen Abkommens über die Sozialversicherung im Saarland fielen, wonach das Ruhegeld „ohne jede Einschränkung“ zu zahlen war. ${ }^{463}$ Auch die Anwendung der nun möglichen Ruhensbestimmungen wegen staatsfeindlicher Tätigkeit war ein zweischneidiges Schwert, denn die Zahl der Renten, die von Frankreich in das Saarland und das übrige Deutschland gezahlt wurden, war wesentlicher größer als umgekehrt. „Es wäre zu befürchten, dass ein Ruhen der Renten aufgrund der neuen Ruhensbestimmungen Frankreich zu Gegenmaßnahmen Veranlassung gäbe, durch die viele unserer Volksgenossen geschädigt werden würden“, gab denn auch der Leiter der LVA Saarland gegenüber dem RVA zu Bedenken. ${ }^{464}$ Wohl oder übel mussten daher die Rentenzahlungen an die „Staatsfeinde“ ausbezahlt werden.

Bereits im Januar 1937 schickte die RfA aufgrund des neuen Gesetzes zu den Ruhensbestimmungen über das RVA an das RAM eine erste Liste mit Rentenberechtigten, deren Renten wegen staatsfeindlicher Betätigung möglicherweise ruhen sollten, mit der Bitte um rasche Entscheidung. ${ }^{465}$ Eine Gewähr dafür, dass das Verzeichnis vollständig war, mochte man nicht gegeben, weil die RfA über eine staatsfeindliche Betätigung ihrer Versicherten keine Mitteilung erhielt und es sich daher eher um bei der Bearbeitung der Leistungsanträge zufällig bekannt gewordene Fälle handelte. Tatsächlich hatte es die Gestapo in mehreren Fällen abgelehnt, den Versicherungsträgern die Informationen über die Unterbringung von Schutzhäftlingen als Grundlage für die Beurteilung als eventueller Ruhensfall wegen staatsfeindlicher Betätigung zu überlassen. Dennoch ergibt sich aus den Unterlagen der Eindruck, dass die RfABeamten wie schon 1933/34 auch weiterhin durchaus eifrig bei der Identifikation entsprechender Ruhensfälle waren. Schon die Durchsicht der zur voraussichtlichen Anwendung der Ruhensbestimmungen gemeldeten Rentenempfänger vom Januar 1937 zeigte, dass bei einigen von ihnen die Rentenzahlung bereits seit einigen Monaten aufgrund von anderen Bestimmungen ruhte, so dass es sich hier nur noch quasi um die nachträgliche Verbescheidung und Begründung des Rentenentzugs entsprechend den neuen formalrechtlichen Bestimmungen handelte.

463 Zwischen Heinrich H. und der RfA war dabei auch der Zeitpunkt des Beginns der Ruhegeldauszahlung strittig und die RfA hatte sich, um die zur Klärung ihrer Meinung nach erforderliche ärztliche Untersuchung durchführen zu können, absurderweise beim Polizeipräsidenten von Saarbrücken für die Zusicherung eines freien Geleits eingesetzt.

464 Schreiben der LVA Saarland an das RVA vom 18.1.1937, in: BArch R 89/3167. Im Dezember 1938 kam es dann zu einer Abteilungsverfügung der Abt. I Leistung, nach der auf Anordnung des RAM unverzüglich zu prüfen war, ob sich unter den ausgebürgerten Personen Rentenempfänger der RfA befanden. Vgl. Abteilungsverfügung vom 21.12.1938, in: RfA-Archiv Nr. 2. Doch die schon kurz darauf erstattete Rückmeldung nach Überprüfung unter anderem auch von Thomas Mann, enthielt keine Fälle. Vgl. dazu der Vermerk in: RfA-Archiv Nr. 95.

465 Schreiben der RfA an das RVA vom 14.1.1937 mit dem Verzeichnis, in: RfA-Archiv Nr. 22, auch in: BArch R 89/3167. 
Die angenommenen Formen der staatsfeindlichen Betätigung variierten dabei zudem beträchtlich. Die wenigsten Betroffenen saßen bereits rechtskräftig wegen Hochverrat verurteilt im Gefängnis. Gegen eine Versicherte lief erst noch das Verfahren wegen Vorbereitung zum Hochverrat, zwei andere Versicherte waren nach Frankreich bzw. in die Tschechoslowakei übergesiedelt. Einem anderen Versicherten war das Ruhegehalt entzogen worden, nachdem man festgestellt hatte, dass er von 1902 bis 1932 SPD-Mitglied gewesen war: Nachdem aufgrund der gesetzlichen Bestimmungen wieder eine volle Auszahlung erforderlich wurde, sollte auf diesem Wege aus dem vorübergehenden ein dauernder Rentenentzug möglich gemacht werden. Ähnliches galt für einen anderen Versicherten, dessen Ruhegeld aus der AV durch die Geheime Staatspolizei wegen angeblicher Agententätigkeit zunächst beschlagnahmt worden war; später aber musste die Sperre wieder aufgehoben werden und nun drohte ein neuer Entzug. Einer Empfängerin von Witwenrente sollte schließlich die Rente deshalb zum Ruhen gebracht werden, weil sie „in politischer Beziehung als ausgesprochen litauisch eingestellt anzusehen sein soll“. ${ }^{466}$ Die RfA hatte sich in diesem Fall sogar die Mühe gemacht und das Deutsche Generalkonsulat für das Memelgebiet um Auskunft und ein politisches Gutachten gebeten. ${ }^{467}$ Die von dort erhaltene Antwort war für die vorauseilend gehorsamen RfA-Sachbearbeiter allerdings peinlich, denn dort ruderte man nun bezüglich der negativen politischen Einschätzung wieder zurück und bat, die Zahlung der Versorgungsbezüge für die Betroffene wieder aufzunehmen.

Noch im Lauf des Jahres 1937 meldete die RfA an das RVA dutzende weitere Fälle von potenziellen Ruhensanwendungen wegen staatsfeindlicher Betätigung. ${ }^{468}$ In nicht wenigen Fällen kamen aber die Versichertenakten zusammen mit dem Bescheid des Reichsführers SS und Chefs der Deutschen Polizei zurück, dass es keinen Nachweis für staatsfeindliche Tätigkeit gebe und daher die Voraussetzungen für die Anwendung der Ruhensvorschriften fehlten. ${ }^{469}$ Die RfA-Beamten besaßen bei ihren Anträgen zur Anwendung der Ruhensbestimmungen aus politischen Gründen durchaus die Möglichkeit, auf die Dauer des Rentenentzugs Einfluss zu nehmen, ebenso wie darauf, ob und in welcher Höhe die Ruhegelder an die Ehefrau und andere Familienangehörige weitergezahlt würden. Doch in keinem der Fälle lässt sich eine entsprechende Intervention zugunsten der Rentenempfänger feststellen. Im Gegenteil: Im Juni 1936 hatte sich ein RfA-Sachbearbeiter mit einem Vermerk an den zuständigen Unterabteilungsleiter gegen die im Allgemeinen praktizierte Verwaltungsübung gewandt, dass das Ruhegeld während der Dauer der Strafverbüßung meist in voller Höhe, zum Teil aber auch nur zu zwei Dritteln an die Ehefrauen weitergezahlt wur-

466 Ebd.

467 Vgl. Schreiben der Abt. I Leistung vom 4.2.1937 sowie vom 26.2.1937, in: ebd.

468 Vgl. die Fallakten in: BArch R 89/23304-23307 sowie zum Folgenden BArch R 89/3167.

469 Vgl. Schreiben des RAM an die RfA mit Abschrift der Bescheide der Sicherheitsbehörden vom 21.8. 1937, vom 9.9.1937 und vom 11.1.1938, in: ebd. 
de. ${ }^{470}$ Und geradezu perfide war der Vorstoß eines RfA-Beamten im November 1937, einem Ruhegeldempfänger, der seit Oktober 1937 im Monat 62,40 RM erhielt, rückwirkend und nachträglich für den Zeitraum von Oktober 1935 bis September 1936 das Ruhegeld wegen staatsfeindlicher Betätigung entziehen zu lassen. Das RAM schickte daher die Akten ohne entsprechenden Bescheid zurück. ${ }^{471}$ In einigen wenigen Fällen hatten die Betroffenen auch den Mut, gegen die entsprechenden Ruhensbescheide zu klagen, allerdings mit wenig Aussicht auf Erfolg. Ein Fall, der im November 1938 vor die Spruchkammer des Berliner Oberversicherungsamtes gelangte und erst im März 1940 dann vom Revisionssenat des RVA endgültig entschieden wurde, betraf einen Ruhegeldempfänger, der vom 21. Februar 1938 bis 25 . Mai 1939 eine Gefängnisstrafe verbüßte. ${ }^{472}$ Die RfA hatte daraufhin seine Rente zum Ruhen gebracht und auch die Überweisung an die vom Unterhalt des Mannes abhängige Ehefrau verweigert, da man festgestellt hatte, dass auch diese vom 6. November 1937 bis zum 6. Juni 1938 eine Freiheitsstrafe verbüßt hatte. Das Ruhegeld des Ehemannes wurde daher vom 1. März bis zum 6. Juni 1938 nicht ausbezahlt, wogegen beide Betroffene beim Oberversicherungsamt Berufung eingelegt hatten. Letztlich wurde die Berufung jedoch als unbegründet zurückgewiesen.

Aus Sicht der betroffenen Rentner war es dabei wenig beruhigend, dass anders als bei den anderen Ruhensbestimmungen der jeweilige Versicherungsträger eigentlich nicht berechtigt war, die Rente schon bei dem bloßen Verdacht einer staatsfeindlichen Tätigkeit vorsorglich einzubehalten. ${ }^{473}$ Das war jedoch offensichtlich bei einer Reihe von Versicherungsträgern und auch bei der RfA ungeachtet der bestehenden Vorschriften vorgekommen, denn im April 1937 sah sich das RAM noch einmal zu einem expliziten Hinweis auf seine letzte Entscheidungskompetenz veranlasst. ${ }^{474}$ Soweit in der Vergangenheit Versicherungsträger Rentenzahlungen wegen staatsfeindlicher Betätigung bereits eingestellt hatten, könne es hierbei jedoch sein Bewenden haben. ${ }^{475}$ Erst nach der Entscheidung des RAM konnte die Zahlung eingestellt werden, dann allerdings auch rückwirkend, was entsprechende Rückforderungen an die Betroffenen nach sich zog. Im Februar 1939 kippte dann das RAM diesen Vorbehalt. Für bereits laufende Rentenzahlungen ins Ausland galt zwar die alte Regelung, aber bei erstmalig aufgenommenen Verfahren bezüglich Rentenzahlung ins Ausland konnte der jeweilige Versicherungsträger nun schon im Voraus die Zahlungen einfach ein-

470 Vgl. Vermerk vom 17.6.1936, in: RfA-Archiv Nr. 115. Wie über das weitere Procedere entschieden wurde, ist unklar, allerdings zeigen die Einzelfälle, dass an den Rentenzahlungen an die Familienangehörigen festgehalten wurde.

471 Schreiben der RfA an das RVA vom 28.10.1937 sowie Brief des RAM vom 17.2.1938, in: ebd.

472 Vgl. dazu das Urteil mit ausführlicher Begründung vom 20.3.1940, in: BArch R 89/23088.

473 Vgl. Schreiben des RVA an das RAM vom 16.3.1937, in: BArch R 89/3409.

474 Auch wenn Grießmeyer Ende Mai 1937 dem RVA gegenüber versicherte, dass bei der RfA von sich aus keine Rentenzahlungen wegen staatsfeindlicher Betätigung zum Ruhen gebracht worden seien. Vgl. Schreiben Grießmeyers an das RVA vom 28.5.1937, in: ebd.

475 Schreiben des RAM an das RVA vom 23.4.1937, in: ebd. 
behalten. „Bei der gegenwärtigen Devisenknappheit“, so heißt es in dem Erlass, „halte ich es nicht für vertretbar, dass Renten nach dem Ausland überwiesen werden, die aller Wahrscheinlichkeit nach wegen der staatsfeindlichen Betätigung des Berechtigten mit rückwirkender Kraft zum Ruhen gebracht werden.““476

Dennoch gibt es eine Reihe von Fällen, bei denen sich die RfA nachweislich nicht an die zeitliche Unterscheidung des RAM bei der Entscheidung bezüglich des Ruhens der Rente hielt. In einem Fall hatte der jüdische Versicherte Erich S. seit Januar 1934 ein monatliches Ruhegeld von 34,40 RM erhalten. Gegen S. war im Frühjahr 1938 ein Verfahren wegen des Verdachts auf „Rassenschande“ eingeleitet worden, und von der RfA war daraufhin, obschon das Verfahren erst im August 1939 beendet werden sollte und ohne dass ein entsprechender Beschluss des Reichsinnenministeriums bzw. RAM vorlag, seit März 1938 das Ruhegeld wegen staatsfeindlichen Verhaltens einbehalten worden. In einem anderen Fall ging es um die jüdische Witwe Emmy O., die seit 1926 bereits Witwen- und für ihren Sohn auch Waisenrente erhielt. Beide waren im September 1938 nach Paris emigriert und allein diese Tatsache genügte den RfA-Beamten offensichtlich, die laufende Hinterbliebenenrente wegen möglicher staatsfeindlicher Betätigung ab November 1938 ruhen zu lassen. ${ }^{477}$ In beiden Fällen war mithin das Ruhen bzw. der Entzug der Rente unter Verletzung der gesetzlichen Bestimmungen, sprich offenem Rechtsbruch, erfolgt und erst durch die späteren Entscheidungen des RAM, in dem einen Fall im September 1940, im anderen Fall sogar erst im März 1941, nachträglich sanktioniert worden. ${ }^{478}$ Soweit aus den Quellen ersichtlich, prüfte die RfA zwischen 1937 und 1943 in über 700 Fällen das Ruhen der Rente wegen staatsfeindlicher Betätigung; in ca. 250 Fällen gingen dann nach entsprechenden Vorermittlungen die entsprechenden Sanktionsempfehlungen an das RAM. ${ }^{479}$ Bei wie vielen Betroffenen dies dann auch umgesetzt wurde, ist nicht klar, aber sämtliche verdächtige Versicherte bzw. Rentenberechtigte mussten erst diskriminierende Nachforschungen über sich ergehen lassen. Und letztlich war der Vorgang nicht wegen seines quantitativen Umfangs von Bedeutung, sondern weit mehr wegen der damit sichtbaren Entwicklung der RfA zu einem Teil des nationalsozialistischen Repressionssystems.

Die Schutzhaft in einem KZ löste allerdings noch kein Ruhen oder den Entzug der Rente aus. In der Fachliteratur hatte es dazu 1933/34 eine absurd anmutende kontroverse Debatte gegeben, ehe in einem Grundsatzurteil das RVA im September 1933 bzw. im Juni 1934 entschied, dass Schutzhaft nicht der Verhängung einer Freiheitsstrafe oder einer Sicherungsverwahrung gleichzustellen sei und daher die Rente

476 Rundschreiben des RVA zum Erlass des RAM vom 15.2.1939, in: RfA-Archiv Nr. 223.

477 Vgl. dazu Schreiben der RfA vom 26.4.1939 an das RVA in Sachen S. und vom 9.2.1939 in Sachen O., in: BArch R 89/3408.

478 Vgl. weitere Fälle, in denen die RfA sich ähnlich verhielt, bei Bonz, Staatsfeinde, S. 528.

479 Vgl. Bonz-MS, S. 533 und ders., Staatsfeinde, S. 529. 
weitergezahlt werden müsse. ${ }^{480}$ Noch wichtiger war die ergänzende Bestimmung zur Regelung der Anwartschaftsansprüche der Inhaftierten. Da deren Erhaltung im staatlichen Interesse liege, so heißt es dazu in einem Erlass des Chefs der Gestapo vom März 1934, „bin ich damit einverstanden, dass bei den Schutzhaftgefangenen, die länger als 9 Monate in Schutzhaft und mittellos sind, diejenigen Beiträge zur Sozialversicherung, die zur Erhaltung der Anwartschaft erforderlich sind, aus staatlichen Mitteln geleistet werden. “481 Tatsächlich musste sich auch die RfA etwa im Herbst 1935 mit mehreren Anfragen von Ortsbürgermeistern auseinandersetzen, in deren Zuständigkeitsbereich sich Angehörige von noch in Haft befindlichen oder bereits entlassenen KZ-Strafgefangenen befanden, die als Wohlfahrtserwerbslose nur durch öffentliche Fürsorgeleistungen dauerhaft unterstützt wurden. ${ }^{482}$ „Es dürfte sich empfehlen“, so die lapidare Antwort der RfA, „die für den Versicherten aus der Zeit seines Aufenthaltes im Konzentrationslager zur Erhaltung der Anwartschaft fehlenden freiwilligen Beiträge aus Wohlfahrtsmitteln nachzuentrichten. “483 Nonkonformes und regimekritisches Verhalten konnte mithin zunehmend auch rentenrechtliche Konsequenzen haben, und die Fallbeispiele zeigen, dass damit vielfach die Existenz nicht nur der Betroffenen, sondern auch der Familienangehörigen bedroht wurde. Das galt noch weit mehr für die aus rassischen Gründen diskriminierten jüdischen Versicherten und Rentner. Unter dem Strich bleibt der bedrückende Befund, dass sich die RfA unter Grießmeyer eifrig an allen gegen jüdische Bürger gerichteten Maßnahmen in ihrem Bereich beteiligte und diese umsetzte, sei es bei der Ausschaltung jüdischer Ärzte, der Diskriminierung jüdischer Beitragszahler und Rentenbezieher, bei der Ausschaltung jüdischer Rechtsanwälte als Behördenvertreter in strittigen Rentenverfahren vor Gericht oder bei der Dienstentfernung ,jüdisch versippter“ RfA-Angestellter. Die RfA war, wie die anderen Versicherungsträger auch, längst Teil des NS-Unterdrückungsapparates geworden. ${ }^{484}$ Die Angestelltenversicherung ist mithin nachgerade exemplarisch für die virtuose Bedienung der Klaviatur bürokratischer Maßnahmen, die mit oft nur kleinen und fast unsichtbaren Änderungen in den Verwaltungspraktiken höchst wirkungsvolle Rückwirkungen im Sinne des NS-Regimes erreichten. So kompliziert aber schon die Exklusion unerwünschter Bevölkerungsgruppierungen aus dem Rentenversicherungssystem war, desto mehr gestaltete sich

480 Vgl. dazu Mitteilungen der RfA Nr. 11, 1935, S. 53 sowie Soziale Praxis 44 (1935), S. 20. Zur Debatte mit Literaturhinweisen vgl. Reidegeld, S. 460, Anm. 649.

481 Abschrift des Erlasses vom 19.3.1934 sowie ein weiterer Erlass von Gestapo-Chef Best dazu vom 14.6.1935, in: RfA-Archiv Fach 1, Nr. 1.

482 Vgl. dazu den Schriftwechsel vom November 1935, in: RfA-Archiv Fach 94, Nr. 5. Dort auch der weitere Schriftwechsel der RfA mit verschiedenen Zuchthäusern in den Jahren 1937 und 1938 zur Frage der Art und Weise der Selbstversicherung und evtl. der Verpflichtungen der Strafanstalten zur Nachentrichtung von Versicherungsbeiträgen.

483 Schreiben der RfA vom 6.1.1936, in: ebd. Vgl. auch die dann im April 1938 erlassene Verordnung des Reichsjustizministeriums über die Sozialversicherung für Gefangene, in: Mitteilungen der RfA Nr. 7, 1938, S. $24 \mathrm{f}$.

484 So auch die etwas vorsichtiger formulierte Schlussfolgerung von Bonz, Staatsfeinde, S. 531. 
die gleichzeitig stattfindende Inklusion hunderttausender neuer Versicherter wie Rentner im Zuge der konzeptionellen wie geographischen Expansion der Angestelltenversicherung als Herausforderung für die RfA. 